\title{
Analysen zum subzellulären Lokalisationsverhalten der atypischen Myrosinase PEN2 in Arabidopsis-Mikroben-Interaktionen
}

\author{
Dissertation \\ zur Erlangung des mathematisch-naturwissenschaftlichen Doktorgrades \\ "Doctor rerum naturalium" \\ der Georg-August-Universität Göttingen
}

vorgelegt von

Rene Fuchs

aus Heinsberg

Göttingen 2011 
Ich versichere hiermit, dass ich die vorliegende Dissertationsarbeit mit dem Titel „Analysen zum subzellulären Lokalisationsverhalten der atypischen Myrosinase PEN2 in ArabidopsisMikroben-Interaktionen“ selbstständig verfasst und keine anderen als die angegebenen Hilfsmittel und Quellen verwendet habe. Ebenfalls erkläre ich hiermit, dass ich mich an keiner anderen Universität um einen Doktorgrad beworben habe.

Rene Fuchs

Göttingen, den 12.09.11

Mitglieder des Betreuungsausschusses:

Referent: $\quad$ Prof. Dr. Volker Lipka

Koreferentin: $\quad$ Prof. Dr. Christiane Gatz

Tag der mündlichen Prüfung: $\quad$ 13.10.11 


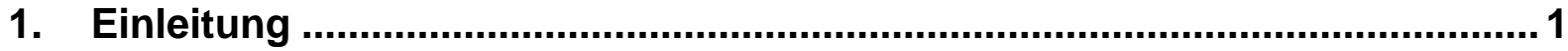

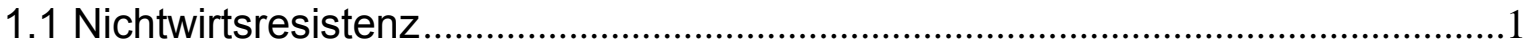

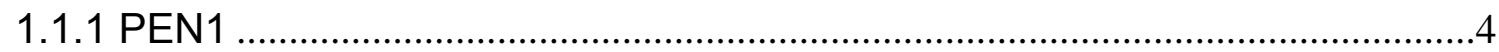

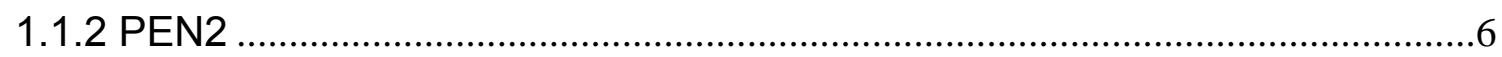

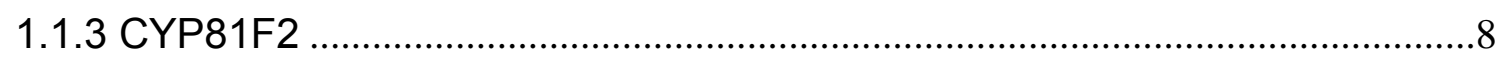

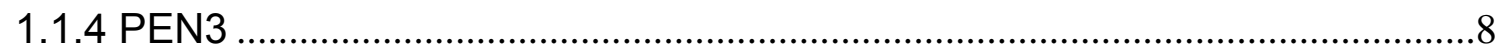

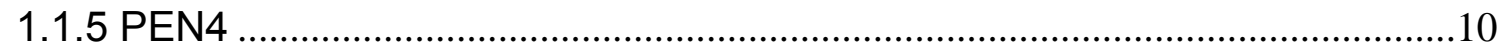

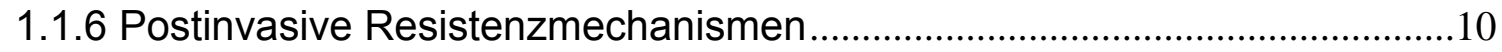

1.2 Basale und Rassenspezifische Resistenzmechanismen ....................................11

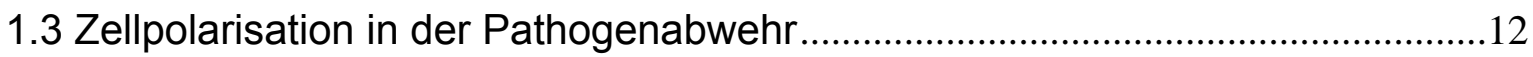

1.4 Funktion von Peroxisomen in der Pathogenabwehr ...........................................15

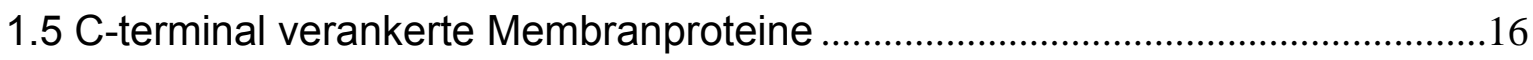

1.6 Beteiligung von PYK10 an Multienzymkomplexen ............................................18

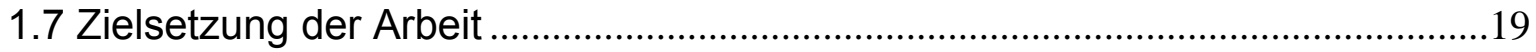

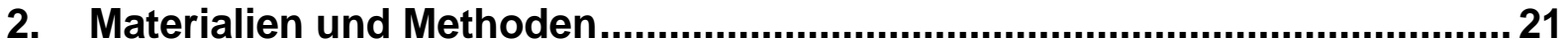

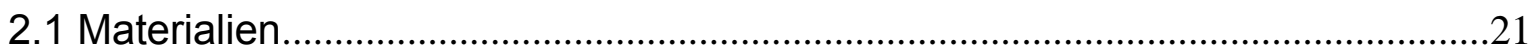

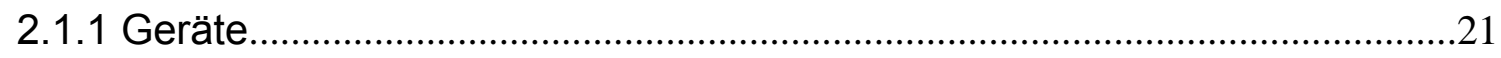

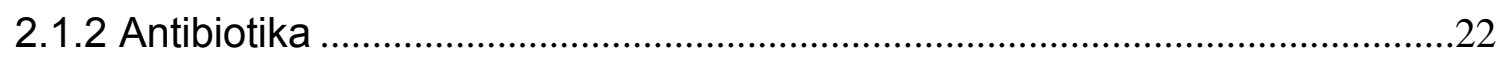

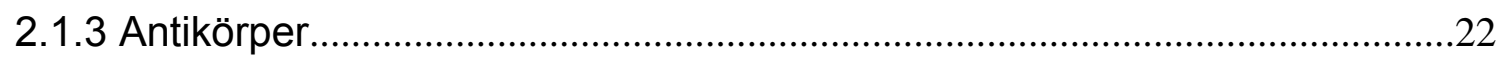

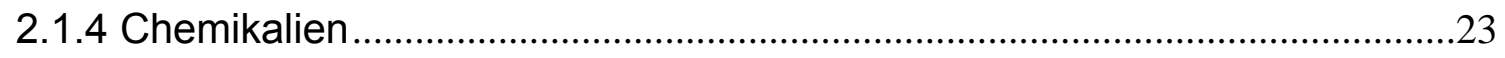

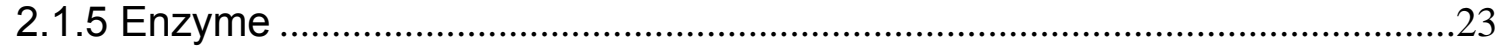

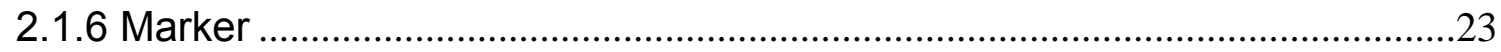

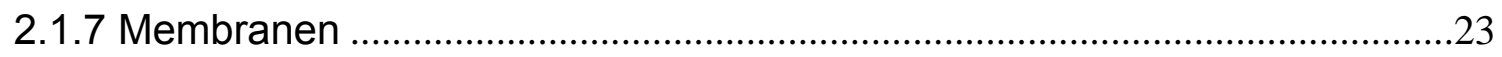

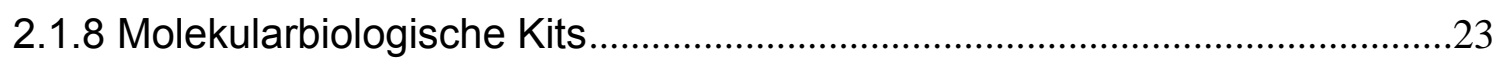

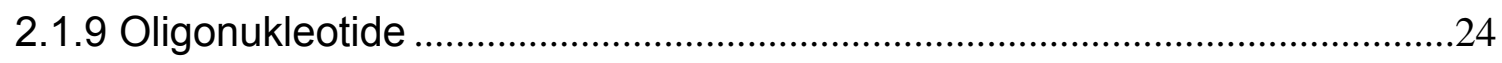

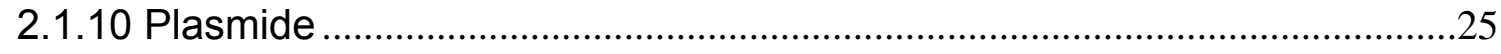

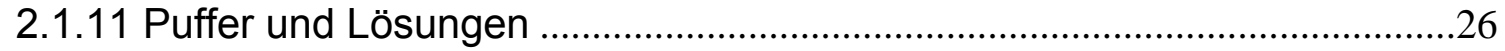

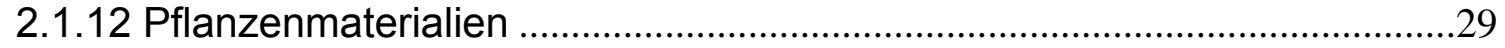

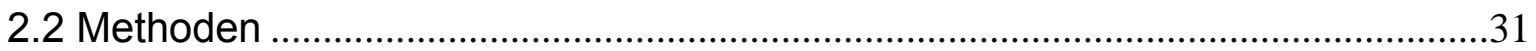

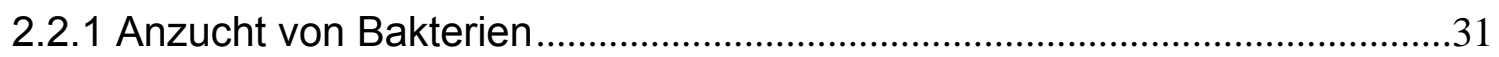

2.2.2 Herstellung und Transformation kompetenter E. coli-Zellen ........................31

2.2.3 Herstellung und Transformation kompetenter Agrobakterien ......................32

2.2.4 Extraktion genomischer DNA aus Pflanzen ................................................33

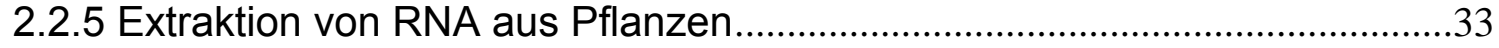


2.2.6 Reverse Transkription zur Herstellung von cDNA.......................................34

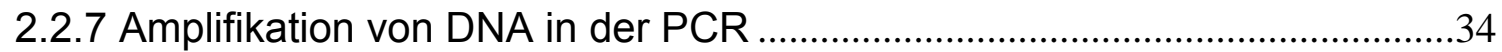

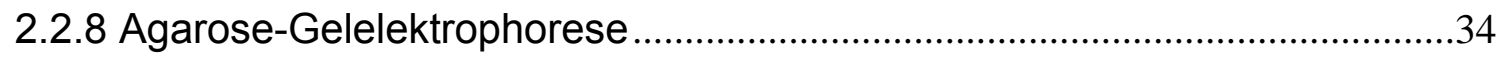

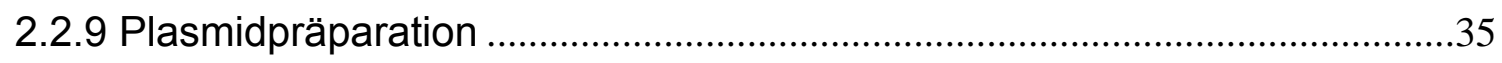

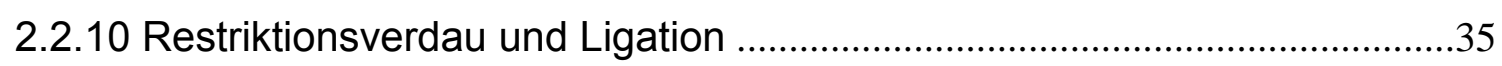

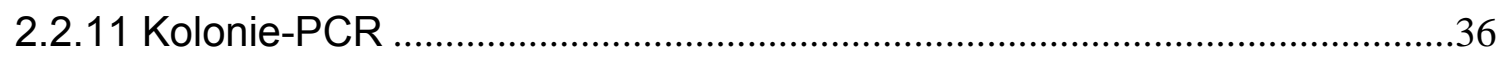

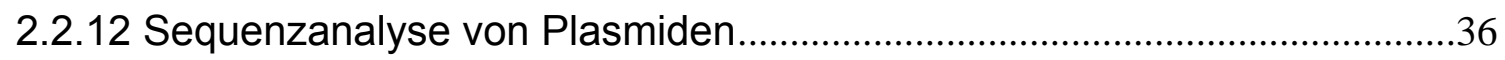

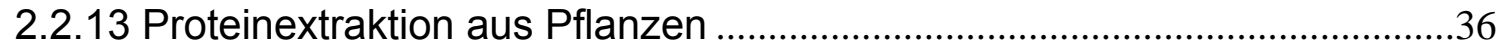

2.2.14 Quantitative Bestimmung von Proteinen .....................................................37

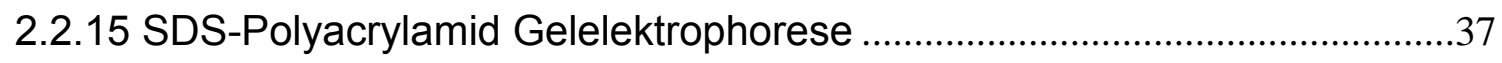

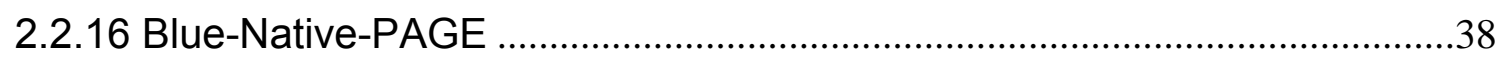

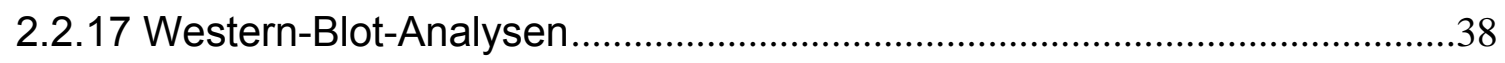

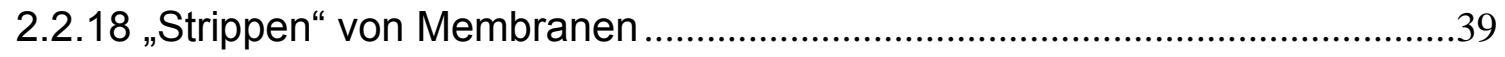

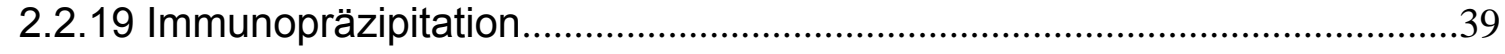

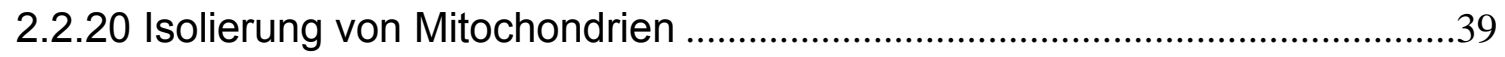

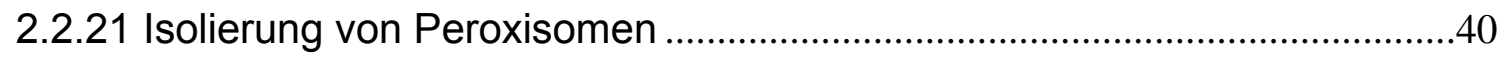

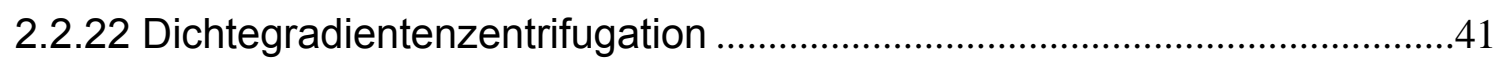

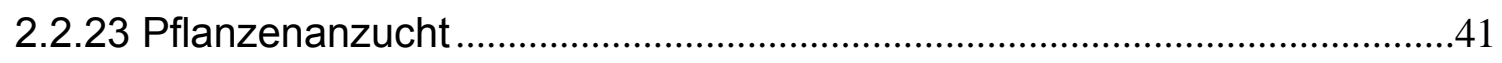

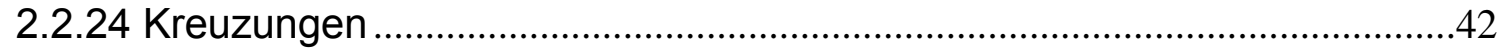

2.2.25 Stabile Transformation von Arabidopsis...................................................42

2.2.26 Transiente Expression in Tabak .................................................................43

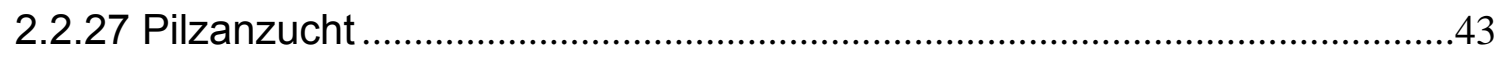

2.2.28 Inokulation von Arabidopsis mit Pilzsporen .................................................44

2.2.29 Analyse der Invasions- und Zelltodraten ....................................................44

2.2.30 Konfokalmikroskopische Analysen ........................................................45

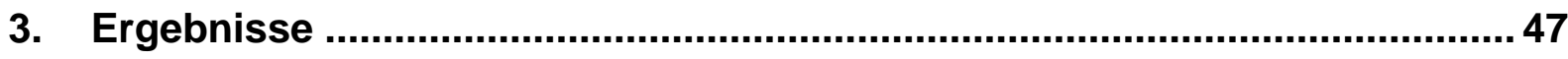

3.1 Untersuchungen zur subzellulären Lokalisation von PEN2 ..............................47

3.1.1 Fluoreszenzmikroskopische Analysen zur PEN2-Aggregation...................47

3.1.2 Bestimmung der PEN2-Proteinabundanz in der Pathogenabwehr ..............55

3.1.3 In-vivo-Experimente zur Homomerisierung von PEN2 ................................56

3.1.4 Funktionsanalyse der C-terminalen Extension von PEN2 ...........................61

3.1.5 Fluoreszenzmikroskopische Untersuchungen zum Assoziationsverhalten von PEN2 mit Membrankompartimenten................................................................73

3.1.6 Biochemische Analyse der subzellulären PEN2-Lokalisation ......................80 
3.1.7 Lokalisationsbestimmung chimärer PEN2-GFP-Proteine. 86

3.2 Untersuchungen zur pathogen-induzierten Akkumulation von Mitochondrien und Peroxisomen

3.3 Analysen zur subzellulären Lokalisation weiterer Komponenten des PEN2vermittelten Abwehrmechanismus.

3.3.1 Bestimmung der PEN2-Aggregation in Abhängigkeit von PEN3 .98

3.3.2 Untersuchungen zur PEN4-Lokalisation nach Pathogenbehandlung........100

3.3.3 Mikroskopische und molekularbiologische Analysen von CYP81F2 102

4. Diskussion.

4.1 Akkumulation von PEN2 an der Pathogen-Interaktionsstelle 108

4.2 Pathogen-induzierte Oligomerisation von PEN2

4.3 Abhängigkeit der subzellulären PEN2-Lokalisation von der C-terminalen

Extension 115

4.4 Assoziation der PEN2-Aggregate mit Mitochondrien

4.5 Beteiligung von PEN4 an PEN2-Aggregaten

4.6 ER-Lokalisierung des pathogen-induzierten CYP81F2-Genprodukts.

5. Zusammenfassung

6. Literaturangaben 131

7. Anhang 141

7.1 Abkürzungs- und Symbolverzeichnis 141

7.2 Verzeichnis der Abbildungen

7.3 Verzeichnis der Tabellen 146

8. Danksagung 


\section{Einleitung}

Pflanzen sind in ihrer Umwelt einer Vielzahl unterschiedlicher potentiell pathogener Mikroorganismen ausgesetzt. Dennoch kommt es in der Regel nicht zu einer kompatiblen Pflanzen-Pathogen-Interaktion, in deren Verlauf sich das Pathogen vermehrt und die Pflanze Krankheitssymptome ausbildet. Die meisten dieser Interaktionen verlaufen inkompatibel, d. h. die Pflanze ist resistent gegenüber einem entsprechenden Pathogen und kann dem entsprechend nicht von diesem besiedelt werden. Dabei können mehrere Resistenzmechanismen unterschieden werden, die an der Pathogenabwehr beteiligt sind. Neben der Basalen und Rassenspezifischen Resistenz konnten in den letzten Jahren mehrere Komponenten der Nichtwirtsresistenz identifiziert werden, die in der vorliegenden Arbeit näher betrachtet werden soll (zusammengefasst in Jones und Dangl, 2006; Chisholm et al., 2006).

\subsection{Nichtwirtsresistenz}

Der Begriff Nichtwirtsresistenz bezeichnet die am meisten robuste und dauerhafteste Form der pflanzlichen Krankheitsresistenz in der Natur (Heath, 2000; Thordal-Christensen, 2003). Er beschreibt das Phänomen, dass eine komplette Pflanzenspezies resistent gegenüber allen genetischen Varianten eines bestimmten Pathogens ist (Heath, 2000; ThordalChristensen, 2003). Somit bildet diese Immunitätsform die Grundlage für die Resistenz der meisten Pflanzen gegenüber einer Vielzahl potentieller pflanzenschädigender Mikroorganismen. Auch wenn die molekularen Mechanismen der Nichtwirtsresistentz noch nicht vollständig erforscht sind, wird jedoch angenommen, dass ein Zusammenspiel verschiedenster Abwehrkomponenten an dieser Form der Resistenz beteiligt ist.

Zur Untersuchung dieser Mechanismen wurde unter anderem das Pathosystem Arabidopsis-Gerstenmehltau verwendet, das auch die Grundlage für die Analysen der vorliegenden Arbeit bildet.

Die Ackerschmalwand Arabidopsis thaliana ist eine dikotyledone Pflanze, während der eigentliche Wirt des Gerstenmehltaupilzes Blumeria graminis f. sp. hordei (Bgh), die monokotyledone Gerste (Hordeum vulgare) ist. In Abbildung 1.1 ist der asexuelle Entwicklungszyklus des biothrophen Ascomyceten Bgh auf Gerste dargestellt. Nachdem die Konidiospore auf der Blattoberfläche gelandet ist, bildet diese kurze Zeit später den primären Keimschlauch aus. Die Funktion des primären Keimschlauchs ist bisher nicht geklärt, es wird allerdings vermutet, dass dieser der Anheftung der Spore an der 
Blattoberfläche dient. Wenige Stunden später bildet die Konidiospore den sekundären Keimschlauch aus, an dessen Ende sich das so genannte Appressorium formiert. Mit Hilfe des Appressoriums und des in ihm gebildeten Penetrationskeils durchstößt der Pilz die pflanzliche Zellwand. Nach der erfolgreichen Penetration wird die Plasmamembran des Wirts bei der Entwicklung des pilzlichen Haustoriums eingestülpt, jedoch nicht zerstört. Durch die Bildung des Haustoriums kann der Pilz nun Nährstoffe und Wasser für seinen Stoffwechsel aus der Pflanzenzelle gewinnen und dadurch weitere Pilzhypen ausbilden, die dann zur Entstehung von Mikrokolonien führen. Der Entwicklungszyklus ist nach ca. 5 Tagen durch die Produktion neuer Sporen an den Konidiophoren abgeschlossen (zusammengefasst in Both et al., 2005).

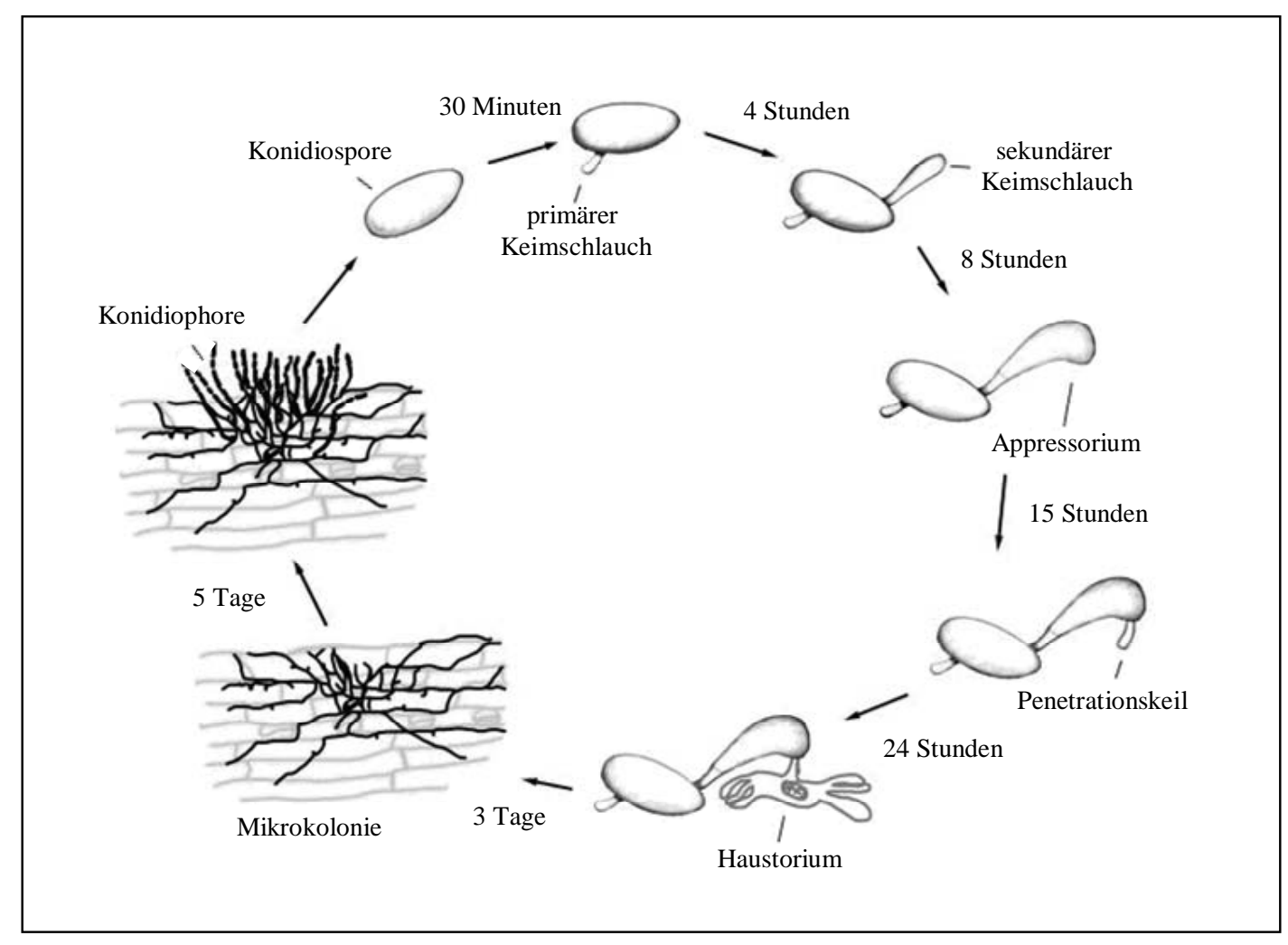

Abb. 1.1: Asexueller Entwicklungszyklus von Blumeria graminis f. sp. hordei (Bgh) auf Gerste (aus Both et al., 2005).

Im Gegensatz zur vorgestellten kompatiblen Interaktion kann der Gerstenmehltaupilz seinen Entwicklungszyklus auf Arabidopsis nicht vollenden. Die versuchte Penetration des nichtadaptierten Pilzes wird entweder durch prä- oder postinvasive Abwehrmechanismen gestoppt (Lipka et al., 2005). Präinvasive Abwehrreaktionen bestehen zum Einen aus konstitutiven und zum Anderen aus induzierbaren Mechanismen (Heath, 2000; ThordalChristensen, 2003). Die pflanzliche Zellwand stellt ein konstitutives mechanisches Hindernis dar, welches die Invasion der meisten „Möchtegern“-Pathogene verhindert. Zusätzlich zur 
mechanischen Festigkeit der Zellwand, die der Pathogeninvasion entgegenwirkt, beinhaltet diese toxische Sekundärmetabolite, sowie antimikrobielle Enzyme wie Chitinasen oder Glucanasen (Thordal-Christensen, 2003).

Im Unterschied zu den konstitutiven Abwehrmechanismen werden die induzierbaren Komponenten erst nach der Erkennung des mikrobiellen Pflanzenschädlings aktiviert (Nürnberger und Lipka, 2005). Die Erkennung hängt dabei von der Perzeption sogenannter PAMPs („pathogen-associated molecular patterns“) ab. PAMPs sind entweder Fragmente von Mikroorganismen selbst wie Chitin und Flagellin, oder Abbauprodukte der pflanzlichen Zellwand, die auch als DAMPs („damage-associated molecular patterns“) bezeichnet und durch die Aktivität des Pathogens freigesetzt werden (Nürnberger und Lipka, 2005; Boller und Felix, 2009). Die Perzeption der PAMPs erfolgt hierbei durch spezifische Rezeptoren („PRRs - pattern recognition receptors“), die in der Plasmamembran lokalisiert sind und das Signal auf eine nachgeschaltete Kaskade übertragen. Diese Signaltransduktion bewirkt wiederum eine transkriptionelle Induktion von Genen, die an der Pathogenabwehr beteiligt sind (Felix et al., 1999; Asai et al., 2002; Thordal-Christensen, 2003; Petutschnig et al., 2010). Den gesamten Vorgang der PAMP-Perzeption, Signaltransduktion und Genaktivierung bezeichnet man auch als PAMP-induzierte Immunisierung („PAMP-triggered immunity - PTI“; Jones und Dangl, 2006; Chisholm et al., 2006). Das Ergebnis der PTI kann unter anderem die Zellpolarisation sein, die zu einer zielgerichteten Verstärkung der Zellwand und fokalen Akkumulation von reaktiven Sauerstoffspezies oder Phytoalexinen führt (Nürnberger und Lipka, 2005). Diese Verstärkung der Zellwand, auch Papille genannt, kann in der Interaktion von Pflanzen mit phytopathogenen Pilzen unterhalb des Appressoriums fluoreszenzmikroskopisch nachgewiesen werden. Hierzu wird die in der Papille vorhandene Callose mit dem Fluoreszenzfarbstoff Anilinblau eingefärbt (siehe Abb. 1.2; Stone et al., 1984). Callose ist ein Biopolymer aus Glucose-Einheiten, die über eine $\beta$ 1,3-glycosidische Bindung miteinander verknüpft sind (Aspinall und Kessler 1957). Es wird davon ausgegangen, dass Callose als Gerüst zur Einlagerung von reaktiven Sauerstoffspezies, toxischen Sekundärmetaboliten und weiteren Polysacchariden dient, aber vermutlich nicht zur Verstärkung der Papille beiträgt (Smart et al., 1986; Bolwell, 1993; Bestwick et al., 1997; Thordal-Christensen et al., 1997; Heath, 2002; Jacobs et al., 2003).

Mit Hilfe genetischer Screens konnten in den letzten Jahren zusätzlich weitere molekulare Komponenten identifiziert werden, die Bestandteil der PTI sind. Zu diesen Komponenten gehören die PEN (Penetration) -Proteine PEN1 bis PEN4 und die Cytochrom-P450Monooxygenase CYP81F2. All diese unterschiedlichen Enzyme sind an der Nichtwirtsresistenz von Arabidopsis beteiligt (Collins et al., 2003; Lipka et al., 2005; Stein et al., 2006; Melisa Lim, persönliche Kommunikation; Bednarek et al., 2009). Eine Mutation der einzelnen Proteine führt zu einer erhöhten Penetrations- und Zelltodrate nach Inokulation mit 
nicht-adaptierten Mehltauspezies, jedoch nicht zum Verlust der Resistenz. Erst ein Verlust von mehreren Komponenten der Prä- und Post-Invasionskontrolle führt zum Bruch der Nichtwirtsresistenz von Arabidopsis gegenüber dem Gerstenmehltaupilz (Lipka et al., 2005). Im Folgenden werden nun die einzelnen Komponenten der präinvasiven Nichtwirtsresistenz genauer vorgestellt.

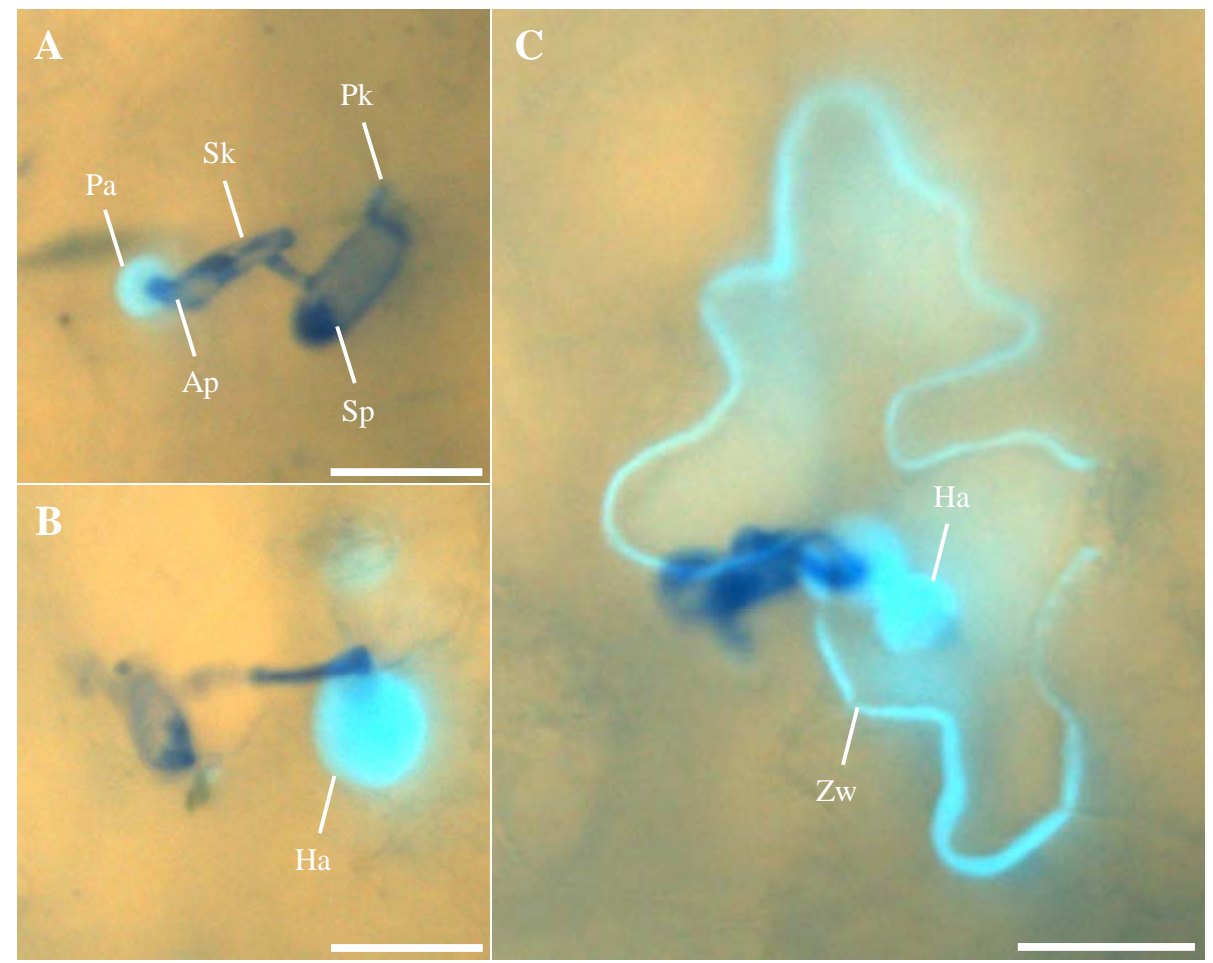

Abb. 1.2: Prä- und postinvasive Abwehreaktionen tragen zur Nichtwirtsresistenz von Arabidopsis gegenüber inkompatiblen Mehltaupilzen bei.

(A) Präinvasive Abwehrmechanismen, wie z. B. die Bildung von Papillen, verhindern eine erfolgreiche Penetration der Pflanzenzelle. Durch postinvasive Abwehrmechanismen kommt es entweder (B) zur Einkapselung des Haustoriums oder (C) zur Zelltodreaktion, welche die weitere Entwicklung des Pilzes endgültig stoppt. Die pilzliche Struktur ist mit Coomassie-Brilliant-Blau (dunkelblau) und die pflanzliche Callose mit Anilinblau (hellblau) angefärbt. Die fluoreszenzmikroskopischen Aufnahmen wurden 72 Stunden nach Inokulation von pen2-1-Mutanten Pflanzen mit Bgh gemacht. Ap, Appressorium; Ha, Haustorium; Pa, Papille; Pk primärer Keimschlauch, Sk, sekundärer Keimschlauch; Sp, Spore; Zw, Zellwand. Maßstabsbalken = $25 \mu \mathrm{m}$.

\subsubsection{PEN1}

Das PEN1-Gen, ebenso bekannt als SYP121 („syntaxin of plants 121“), codiert für ein plasmamembran-lokalisiertes SNARE-Protein (,soluble N-ethylmaleimide-sensitive factor attachment protein receptor“; Collins et al., 2003). SNARE-Proteine sind in Membranfusionen von Vesikeln und sekretorischen Prozessen, sowie in Exo- und Endocytose involviert (zusammengefasst in Lipka et al., 2007).

Durch die funktionale Fusion des PEN1-Proteins mit GFP („green fluorescent protein“) konnte in fluoreszenzmikroskopischen Analysen eine fokale Akkumulation des Reporterproteins in Subdomänen der Plasmamembran unterhalb des pilzlichen 
Appressoriums nachgewiesen werden (Abb. 1.3A; Collins et al., 2003). Weiterführende Studien von Meyer et al. (2009) konnten zusätzlich einen Einschluss von GFP-PEN1 in Papillen und eingekapselten Haustorien demonstrieren, der vermutlich durch die Bildung und Freisetzung von Exosomen bedingt ist.

Als weitere Komponenten des PEN1-vermittelten Abwehrmechanismus konnten die Proteine SNAP33 („synaptosome-associated protein 33“) und VAMP721 bzw. VAMP722 („vesicleassociated membrane protein 722") identifiziert werden (Kwon et al., 2008a). Während das Adapterprotein SNAP33 ebenfalls mit der Plasmamembran assoziiert, ist das VAMP722Protein in der Peripherie eines bis jetzt noch nicht identifizierten Endomembrankompartiments lokalisiert (Heese et al., 2001; Kwon et al., 2008a). Wie die Analysen von Kwon et al. (2008a) weiter gezeigt haben, bilden PEN1, SNAP33 und VAMP721/722 einen pathogen-induzierten, detergenz-resistenten ternären Komplex aus. Diese Komplexformation führt wiederum zur Fusion des VAMP721/722-assoziierten Endomembrankompartiments mit der Plasmamembran und bewirkt dadurch die Sekretion der transportierten Substanzen in den Apoplasten unterhalb der Pathogen-Interaktionsstelle (Kwon et al., 2008a). Es wird angenommen, dass es sich bei den sekretierten Substanzen um Stoffe handelt, die entweder zur Verstärkung der Zellwand beitragen und/oder antimikrobielle Eigenschaften haben (Collins et al., 2003). Eine Beteiligung von PEN1 an der Callosedeposition in Papillen und eingekapselten Haustorien konnte nach Meyer et al. (2009) jedoch ausgeschlossen werden. Allerdings konnten Assaad et al. (2004) demonstrieren, dass in pen1-1-Mutanten die Papillenbildung um ca. 2 Stunden verzögert ist. Somit scheint das SNARE-Protein notwendig für eine möglichst frühzeitige Formation der Papille zu sein. Weiterhin vermuteten sie, dass ein Verlust des PEN1-Proteins durch funktionsredundante Syntaxine kompensiert wird.

Interessanterweise zeigen pen1-Mutanten keine erhöhte Suszeptibilität gegenüber adaptierten Mehltauspezies wie Golovinomyces cichoracearum (Stein et al., 2006). Im Kontrast dazu, zeigen pen2-Mutanten eine deutlich erhöhte Anfälligkeit gegenüber adaptierten Mehltauspezies (Lipka et al., 2005; Stein et al., 2006). Durch Kreuzung der beiden Mutantenlinien konnte zusätzlich gezeigt werden, dass die Penetrationsrate in der Nichtwirtsresistenz gegenüber Bgh im Unterschied zu den Einzelmutanten deutlich erhöht ist. Aufgrund dieser Ergebnisse wurde geschlussfolgert, dass PEN1 und PEN2 unabhängig voneinander in unterschiedlichen präinvasiven Abwehrmechanismen agieren. Im Gegensatz dazu konnte ein kooperatives Zusammenwirken von PEN2 mit den Komponenten PEN3, PEN4 und CYP81F2 nachgewiesen werden (Stein et al., 2006; Melisa Lim, persönliche Kommunikation; Bednarek et al., 2009). 

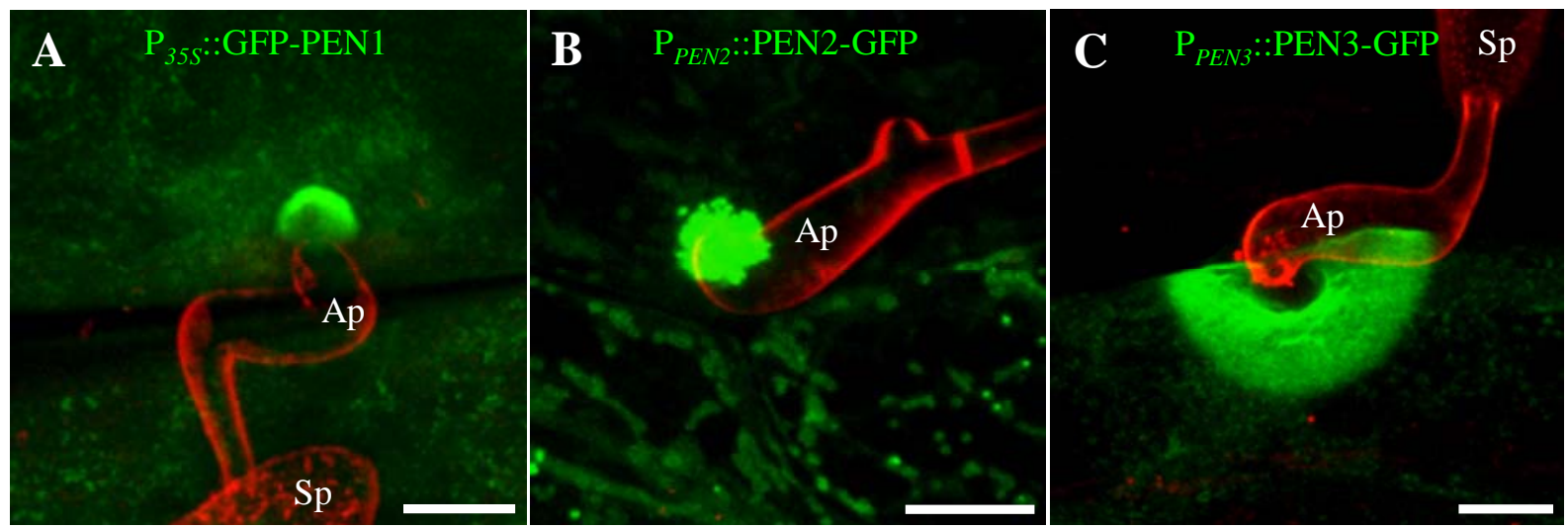

Abb. 1.3: PEN-Genprodukte unterliegen der pathogen-induzierten Zellpolarisation.

(A) Das GFP-markierte SNARE-Protein PEN1 akkumuliert in Subdomänen der Plasmamembran am Ort der versuchten Invasion 24 Stunden nach Inokulation mit Bgh. (B) PEN2-GFP-assoziierte Membrankompartimente konzentrieren sich fokal an der Invasionsstelle 18 Stunden nach Inokulation (Bgh). (C) Der Plasmamembran lokalisierte ABC-Transporter PEN3-GFP akkumuliert ebenfalls an der Penetrationsstelle 19 Stunden nach Inokulation mit Bgh. Die pilzliche Struktur ist mit dem organischen Farbstoff FM 4-64 gefärbt. Ap, Appressorium; Sp, Spore. Maßstabsbalken $=10 \mu \mathrm{m}$.

\subsubsection{PEN2}

Das PEN2-Gen codiert für eine von 48 vorhergesagten Familie1-Glycosidhydrolasen (F1GH) in Arabidopsis (Lipka et al., 2005). F1GHs hydrolysieren die O- bzw. S-glycosidische Bindung zwischen einer Glycosid- und einer Nicht-Kohlenhydrat-Komponente, die auch Aglycon genannt wird. Aglycons stellen die aktive Form des Substrats dar und sind an einer Reihe unterschiedlicher pflanzlicher Prozesse, wie Entwicklungsprozesse, Zellwandmodifikationen und Abwehrreaktionen gegenüber Pathogenen beteiligt ( $\mathrm{Xu}$ et al., 2004).

Unter den Mitgliedern der F1GHs stellt das PEN2-Gen eine evolutive Neuerrungenschaft des Arabidopsis-Genoms dar (Consonni et al., 2006). Außerdem zeichnet sich das PEN2Protein durch seine einzigartige C-terminale Extension im Vergleich zu den anderen Mitgliedern der Familie1-Glycosidhydrolasen aus (Lipka et al., 2005). Diese Extension besteht aus einer 15 Aminosäuren langen Region geringer Komplexität, gefolgt von einer 28 Aminosäuren großen helikalen Struktur. Aufgrund von bioinformatischen Analysen wird angenommen, dass es sich bei der helikalen Struktur um eine Transmembrandomäne handelt, die möglicherweise der Integration des Proteins in Membranen dient (Arai et al., 2004). Die Bedeutung dieser Region für die Funktionalität des PEN2-Proteins konnte durch die Expression eines Deletionskonstrukts $\left(\mathrm{PEN2}_{\triangle 28}\right)$ im pen2-Mutantenhintergrund demonstriert werden (Lipka et al., 2005). Obwohl die Proteinstabilität des PEN2 ${ }_{\triangle 28}$-Proteins nicht beeinträchtigt war, konnte das Deletionsprotein dennoch nicht den pen2-Phänotyp komplementieren. Inwiefern diese Deletion die enzymatische Aktivität und/oder die subzelluläre Lokalisation des Proteins beeinflusst, wurde bisher nicht gezeigt. 
Um die subzelluläre Lokalisation von PEN2 in der pflanzlichen Zelle zu bestimmen, generierte Lipka et al. (2005) ein GFP-Fusionsprotein. Dazu wurde das GFP-Molekül zwischen dem vorhergesagten globulären Teil und der C-terminalen Extension von PEN2 integriert. Im Gegensatz zu direkten N- oder C-terminalen GFP-Fusionen, konnte ausschließlich das Reporterprotein mit dem integrierten GFP den pen2Penetrationsphänotyp komplementieren (Lipka et al., 2005). Die Expression des PEN2-GFPFusionskonstrukts erfolgte dabei unter der Kontrolle des nativen PEN2-Promotors im Mutantenhintergrund. Mit Hilfe von konfokaler Fluoreszenzmikroskopie konnte die subzelluläre Lokalisation des Fusionsproteins genauer bestimmt werden. Entsprechend diesen Analysen ist das PEN2-GFP-Protein vornehmlich in Epidermiszellen exprimiert. Es weist eine Lokalisation im Cytoplasma auf und ist zusätzlich mit der Peripherie eines mobilen Membrankompartiments assoziiert, welches eine sphärische bis stäbchenförmige Struktur von ca. $1 \mu \mathrm{m}$ Größe besitzt (Lipka et al., 2005). Weiterhin konnte gezeigt werden, dass das PEN2-GFP-assoziierte Kompartiment 14 bis 16 Stunden nach Inokulation mit Bgh an Orten der versuchten Invasion fokal akkumuliert (Abb. 1.3B; Lipka et al., 2005). Mit Hilfe der transienten Expression eines RFP-markierten peroxisomalen Matrix-Proteins wurde eine Lokalisation von PEN2-GFP in der Peripherie von Peroxisomen postuliert. Allerdings konnte nicht gezeigt werden, ob das PEN2-Protein mit sämtlichen Peroxisomen assoziiert ist, oder vielleicht nur mit einer Subpopulation.

Durch die Arbeiten von Bednarek et al. (2009) konnte das Indolderivat 4-Methoxyindol-3ylmethylglucosinolat (4MI3G) als Substrat der PEN2-Glycosidhydrolase identifiziert werden (Abb. 1.4). Interessanterweise ist das Indolderivat über eine S-glycosidische Bindung mit Glucose verknüpft. Diese Bindungen werden normalerweise durch eine spezielle Gruppe der Glycosidhydrolasen gespalten, die als Thioglucosidasen oder auch Myrosinasen bezeichnet werden (Burmeister et al., 1997; Xu et al., 2004). Während die klassischen Myrosinasen Glutamin in ihrem katalytischen Zentrum beinhalten, besitzt das PEN2-Protein Glutaminsäure. Durch die gezielte Mutation der Glutaminsäure $\left(\mathrm{Glu}^{183} \rightarrow \mathrm{Asp}^{183}\right)$ im aktiven Zentrum des Enzyms konnte nachgewiesen werden, dass die katalytische Funktion von PEN2 essentiell für die Nichtwirtsresistenz ist (Lipka et al., 2005). Somit kann PEN2 aufgrund seiner enzymatischen Aktivität als atypische Myrosinase bezeichnet werden.

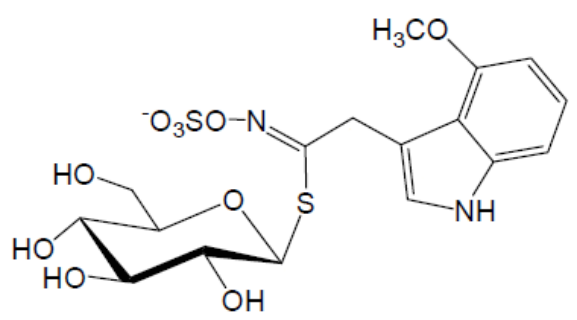

Abb. 1.4: Das PEN2-Substrat 4-Methoxyindol-3-ylmethylglucosinolat (4MI3G). 


\subsubsection{CYP81F2}

Wie zuvor erwähnt, konnte das Glucosinolat 4MI3G als Substrat der Myrosinase PEN2 identifiziert werden (Abb. 1.4). An der Glucosinolat-Biosynthese ist unter anderem die Cytochrom-P450-Monooxygenase CYP81F2 beteiligt (Bednarek et al., 2009). CytochromP450-Monooxygenasen sind Mitglieder der Familie der Hämproteine, welche eine Vielzahl unterschiedlicher Substrate oxidieren (zusammengefasst in Hamdane et al., 2008). Das CYP81F2-Protein gehört zu einer aus vier Enzymen bestehenden Subfamilie, die größtenteils redundante Funktionen aufweisen (Pfalz et al., 2011). Neben CYP81F2 konnten in früheren Arbeiten weitere Monooxygenasen identifiziert werden, die ebenfalls an der Synthese von aromatischen Glucosinolaten in Arabidopsis beteiligt sind. So konnte gezeigt werden, dass CYP79B2 und CYP79B3 nicht nur für die Synthese des Phytoalexins Camalexin und des Phytohormons Auxin essentiell, sondern auch für die Herstellung von 4MI3G notwendig sind (Hull et al., 2000; Glawischnig et al., 2004; Bednarek et al., 2009). Die subzelluläre Lokalisation der Monooxygenasen, die an der Synthese von 4MI3G beteiligt sind, ist bisher nicht bekannt. Allerdings konnte mit Hilfe von GFP-Fusionen die Lokalisation der beiden Monooxygenasen CYP79F1 und CYP79F2 bestimmt werden, welche an der Synthese von aliphatischen Glucosinolaten beteiligt sind. Beide Reporterproteine weisen eine Assoziation mit dem Endoplasmatischen Retikulum (ER) auf (Reintanz et al., 2001). Es wird angenommen, dass Cytochrom-P450-Monooxygenasen möglicherweise Bestandteile von Multienzymkomplexen darstellen, die an der cytoplasmatischen Seite des ERs lokalisiert sind (zusammengefasst in Grubb und Abel, 2006).

Inwieweit CYP81F2 ebenfalls Teil eines ER-lokalisierten Multienzymkomplexes ist, ist noch nicht bekannt. Außerdem konnte bis jetzt nicht geklärt werden, ob das freigesetzte Aglycon nach der Hydrolyse des Glucosinolats durch PEN2 eventuell noch weiter modifiziert wird, bevor es zu seinem Bestimmungsort gelangt. Allerdings konnte durch die Identifikation von PEN3 ein ABC-Transporter ermittelt werden, der möglicherweise verantwortlich für den Transport des Aglycons aus dem Cytoplasma in den Apoplasten ist (Stein et al., 2006).

\subsubsection{PEN3}

Das PEN3-Gen codiert für den ABC- („ATP binding cassette“) Transporter PDR8 („pleiotropic drug resistance 8“; Stein et al., 2006). ABC-Transporter sind in der Pflanzenzelle unter anderem für den Transport von Vorstufen des Chlorophylls, Pigmenten, Lipiden und Auxin verantwortlich. Diese Transporterproteine sind in den Membranen von 
unterschiedlichen Organellen wie Chloroplasten, Mitochondrien und Peroxisomen, aber auch im Tonoplast und in der Plasmamembran lokalisiert (zusammengefasst in Martinoia et al., 2002).

Durch die Fusion mit GFP konnte gezeigt werden, dass PEN3-GFP in der Plasmamembran lokalisiert ist und wie PEN1 ebenfalls an der Pathogen-Interaktionsstelle in Subdomänen der Plasmamembran fokal akkumuliert (Abb. 1.3C; Stein et al., 2006).

Neben der erhöhten Invasionsrate von nicht-adaptierten Mehltausspezies sind pen3Mutanten im Unterschied zu pen1- und pen2-Mutanten resistenter gegenüber adaptierten Mehltaupilzen. Diese reduzierte Anfälligkeit konnte auf eine Hyperaktivierung des Salicylsäure-abhängigen Signalwegs nach Pathogenbehandlung zurückgeführt werden, wodurch die Basale Resistenz in der pen3-Mutante deutlich erhöht wird (Stein et al., 2006). Durch die zusätzliche Mutation von PEN2 in der pen3-Mutante konnte dieses Phänomen teilweise wieder aufgehoben werden. pen2 pen3-Doppelmutanten sind in der kompatiblen Interaktion weniger suszeptibel als Wildtypflanzen, aber immer noch deutlich anfälliger als die pen3-Einzelmutante. Stein et al. (2006) haben aus diesen Ergebnissen geschlossen, dass PEN3 vermutlich für die Translokation des durch die PEN2-Aktivität freigesetzten Aglycons verantwortlich ist. Demnach kommt es in pen3-Mutanten nach Pathogenbehandlung zur Akkumulation des Aglycons im Cytoplasma, was wiederum zu einer Aktivierung der Salicylsäure-abhängigen Zelltodreaktion führt (Stein et al., 2006). Ein aktiver Transportprozess des Indolderivats durch den ABC-Transporter PEN3 konnte zwar nicht nachgewiesen werden, dafür konnten Strader und Bartel (2009) demonstrieren, dass PEN3 für den Efflux der Auxin-Vorstufe Indol-3-buttersäure in Wurzelepidermiszellen verantwortlich ist. Indol-3-buttersäure ist wie das PEN2-Substrat ebenfalls ein Indolderivat. Aufgrund der strukturellen Übereinstimmung der beiden Moleküle wird die Hypothese, dass das PEN3-Transporterprotein für die Translokation des PEN2-aktivierten Aglycons aus dem Cytoplasma in den Apoplasten verantwortlich ist, zusätzlich bestärkt.

Neben der Funktion des ABC-Tansporters in der Resistenz gegenüber Pathogenen, konnte zusätzlich eine Beteiligung in der Toleranz gegenüber Schwermetallen festgestellt werden (Kim et al., 2007). Demnach zeigen pen3-Mutanten ein deutlich reduziertes Wachstum auf cadmium- bzw. bleihaltigem Nährmedium als Wildtyppflanzen. Inwiefern die Funktion von PEN3 in der Schwermetalltoleranz mit der Funktion in der Pflanzenabwehr korreliert oder ob es sich dabei um vollkommen unterschiedliche Mechanismen handelt, ist nicht bekannt. 


\subsubsection{PEN4}

Erst kürzlich konnte mit dem PEN4-Protein eine weitere Komponente der PEN2-vermittelten Nichtwirtsresistenz identifiziert werden, die ebenfalls in der Schwermetalltoleranz involviert ist. Das PEN4-Gen codiert für die Phytochelatin-Synthase 1 (PCS1; Melisa Lim, persönliche Kommunikation). Das im Cytoplasma lokalisierte PCS1-Protein katalysiert den letzten Schritt in der Synthese des Schwermetall-bindenden Polypeptides Phytochelatin und ist somit involviert in der Stresstoleranz gegenüber Schwermetallen (Grill et al., 1989; Clemens et al., 1999; Blum et al., 2010). Neben der Funktion des PCS1-Proteins in der Schwermetalltoleranz konnten Clay et al. (2009) eine mögliche zusätzliche Funktion in der PTI nachweisen. So konnte gezeigt werden, dass pcs1-Mutanten, wie pen2-Mutanten auch, eine erhöhte Akkumulation von 4IM3G nach Flg22-Behandlung (Flagellin 22) aufweisen. Das 22 Aminosäuren lange synthetische Polypeptid Flg22, welches dem konservierten Nterminalen Teil des bakteriellen Flagellins entspricht, wird generell zur Untersuchung der PAMP-induzierten Immunantwort in der Pflanzenzelle verwendet (Gomez-Gomez und Boller, 2000). Clay et al. (2009) haben aus ihren Ergebnissen geschlossen, dass PCS1 essentiell für die Spaltung des PEN2-Substrats ist.

Durch die Arbeiten von Melisa Lim und Kian Hématy konnte ein kooperatives Zusammenwirken der beiden Proteine PEN2 und PCS1 zusätzlich bestätigt werden (persönliche Kommunikation). So wurde in vergleichenden Analysen der Penetrationsraten nach Inokulation mit Bgh kein Unterschied in der Invasionshäufigkeit zwischen beiden Einzelmutanten und der pen2 pen4-Doppelmutante festgestellt. Daher ist anzunehmen, dass PEN2 und PEN4 im gleichen Abwehrmechanismus zusammenarbeiten.

\subsubsection{Postinvasive Resistenzmechanismen}

Im Falle einer erfolgreichen Überwindung der präinvasiven Resistenzebene, wie sie in den pen-Mutanten vermehrt auftritt, führt die nachgeschaltete postinvasive Ebene zum endgültigen Entwicklungsstopp des nicht-adaptierten Mehltaupilzes. Diese Resistenzebene ist entweder durch die Einkapselung des haustoriellen Komplexes oder durch eine programmierte Zelltodreaktion gekennzeichnet. Eine Ablagerung von Callose kann in beiden Prozessen beobachtet und durch Anilinblau-Färbung fluoreszenzmikroskopisch visualisiert werden (Abb. 1.2).

Als molekulare Komponenten der Post-Invasionsresistenz konnten die partiell funktionsredundanten lipase-ähnlichen Proteine EDS1 („enhanced disease susceptibility 1“), PAD4 („phytoalexin deficient 4“) und SAG101 („senescence associated gene 101“) 
identifiziert werden (Lipka et al., 2005; Stein et al., 2006). Diese Proteine sind neben ihrer Funktion in der Nichtwirtsresistenz auch in der Basalen und Rassenspezifischen Resistenz involviert (Hammond-Kosack und Parker, 2003; Wiermer et al., 2005). Im Unterschied zu den pen-Mutanten zeigen Mutanten von eds1, pad4 und sag101 keine erhöhte Invasionsrate. Allerdings konnte vereinzelt ein epiphytisches Wachstum von Bgh auf diesen Mutanten beobachtet werden (Lipka et al., 2005). Dieses Wachstum war deutlich auf den Doppelmutanten pen2 eds1, pen2 sag101, sowie pen2 pad4 verstärkt, aber auch auf diesen Mutanten wurde das weitere Wachstum des Pilzes durch eine Zelltodreaktion gestoppt. Erst in der Dreifachmutante pen2 pad4 sag101 konnte gelegentlich eine Bildung von Konidiophoren beobachtet werden, was ein Indiz für den Bruch der Nichtwirtsresistenz gegenüber dem nicht-adaptierten Gerstenmehltaupilz darstellt (Lipka et al., 2005). Interessanterweise wurde in der Interaktion mit dem ebenfalls nicht-adaptierten Erbsenmehltaupilz (Erysiphe pisi) ein Bruch der Nichtwirtsresistenz schon in pen2 eds1- und pen2 pad4-Mutanten festgestellt. Darüber hinaus konnte ein makroskopisch sichtbares Pilzwachstum von E. pisi auf pen2 pad4 sag101-Dreifachmutanten beobachtet werden, das vergleichbar mit dem des adaptierten Mehltaupilzes Golovinomyces orontii auf ArabidopsisWildtyppflanzen war (Lipka et al., 2005). Möglicherweise ist der Grund für die erhöhte Virulenz des Erbsenmehltaupilzes auf die nähere Verwandtschaft der beiden dikotyledonen Pflanzen Arabidopsis und Erbse zurückzuführen. Zusätzlich weist E. pisi eine nähere Verwandtschaft zu Erysiphe cruciferarum auf, der wie G. orontii ebenfalls ArabidopsisWildtyppflanzen besiedeln kann (zusammengefasst in Lipka et al., 2010). Diese Ergebnisse verdeutlichen zum Einen, dass die beiden nicht-adaptierten Mehltaupilze Bgh und E. pisi nach Überwindung der Abwehrmechanismen generell dazu befähigt sind, eine biotrophe Interaktion mit Arabidopsis zu etablieren und zum Anderen, dass die Stabilität der Nichtwirtsresistenz vermutlich von der koevolutiven Entwicklung zwischen der Pflanze und dem potentiellen Pathogen abhängig ist.

\subsection{Basale und Rassenspezifische Resistenzmechanismen}

Wie bereits zu Anfang erwähnt, besteht die Immunität von Pflanzen je nach Art der PflanzePathogen-Interaktion (kompatibel/inkompatibel) nicht ausschließlich aus der Nichtwirtsresistenz, sondern zusätzlich aus der Basalen und Rassenspezifischen Resistenz (zusammengefasst in Jones und Dangl, 2006; Chisholm et al., 2006).

Rassenspezifische Resistenz, oder auch Effektor-induzierte Resistenz („effector-triggered immunity, ETI“) genannt, basiert auf der direkten oder indirekten Perzeption von mikrobiellen 
Effektoren, welche die PAMP-induzierte Immunisierung inhibieren sollen. Diese Form der pflanzlichen Abwehr ist im Laufe der Koevolution zwischen Pflanzen und Pathogenen entstanden, in deren Vorfeld zunächst eine Überwindung der PTI durch den mikrobiellen Organismus stattgefunden hat. Diese Überwindung der pflanzlichen Abwehr, die auch als Effektor-induzierte Suszeptibilität („effector-triggered susceptibility, ETS“) bezeichnet wird, führte demnach zunächst zu einer kompatiblen Interaktion der beiden Organismen und erst im weiteren Verlauf der Evolution zur Entwicklung der ETI durch die Pflanze (zusammengefasst in Jones und Dangl, 2006; Chisholm et al., 2006). Die Effektor-induzierte Resistenz beruht teilweise auf den gleichen molekularen Komponenten, wie die der postinvasiven Nichtwirtsresistenz und führt ebenfalls zur hypersensitiven Zelltodreaktion der Pflanzenzelle (Hammond-Kosack und Parker, 2003; Lipka et al., 2005; Wiermer et al., 2005). Im Kontrast zur Nichtwirtsresistenz, die multifaktoriell ist und aus zwei Abwehrebenen besteht, beruht die Rassenspezifische Resistenz meist nur auf der Erkennung eines Effektors durch ein Resistenzprotein und kann daher schneller durch evolutive Prozesse gebrochen werden.

Nach Jones und Dangl (2006) ist die Basale Resistenz als der Teil der pflanzlichen Resistenz definiert, der nach Abzug der ETS von der PTI und einer unzureichenden ETI noch übrig bleibt. In der Regel ist diese Form der Resistenz nicht ausreichend für eine erfolgreiche Pathogenabwehr, sondern entscheidet vielmehr über den Grad der Suszeptibilität. Als Beispiel um diesen Sacherverhalt zu verdeutlichen, kann auf die Funktion der Myrosinase PEN2 in der Interaktion mit adaptierten Mehltaupilzen hingewiesen werden. Wie zuvor schon beschrieben, ist PEN2 Bestandteil der induzierbaren präinvasiven Nichtwirtsresistenz in der inkompatiblen Interaktion mit dem Gerstenmehltaupilz, wohingegen in der kompatiblen Interaktion mit G. orontii die Myrosinase als ein Teil der Basalen Resistenz zu verstehen ist, der von der PAMP-induzierten Immunisierung nach Suppression durch die pilzlichen Effektoren übrig geblieben ist. Ein Verlust von PEN2 in kompatiblen Interaktionen führt daher zur Reduktion der Basalen Resistenz und ist anhand des vermehrten Pilzwachstums von G. orontii auf pen2-Mutanten deutlich zu erkennen (Lipka et al., 2005).

\subsection{Zellpolarisation in der Pathogenabwehr}

Neben der fokalen Akkumulation der PEN-Proteine an der Pathogen-Invasionsstelle konnten eine Reihe weiterer subzellulärer Prozesse identifiziert werden, die dem Phänomen der Zellpolarisation unterliegen. 
So konnte gezeigt werden, dass es zu einer frühen Cytoplasma-Aggregation an der versuchten Penetrationsstelle sowohl in kompatiblen, als auch in inkompatiblen PathogenInteraktionen kommt (Takemoto et al., 2003; Koh et al., 2005). Zusätzlich konnten GusMayer et al. (1998) und Hardham et al. (2008) nachweisen, dass die Translokation des Cytoplasmas ebenfalls durch rein mechanische Stimulation ausgelöst werden kann, welche durch Berührung der Zelle mit einer Nadelspitze verursacht wurde. Darüber hinaus führt die mechanische Stimulation wie auch die Pathogenbehandlung zur fokalen Akkumulation von $\mathrm{H}_{2} \mathrm{O}_{2}$, zum Transport des Zellkerns und Peroxisomen, sowie zur Reorganisation des ERs und Cytoskeletts (Gus-Mayer et al., 1998; Koh et al., 2005; Hardham et al., 2008).

Die Akkumulation von $\mathrm{H}_{2} \mathrm{O}_{2}$ zieht Quervernetzungsreaktionen in der Papille nach sich, was wiederum zu einer Verstärkung dieser Struktur führt. Außerdem besitzt Wasserstoffperoxid antimikrobielle Eigenschaften und induziert Gene in der pflanzlichen Zelle, die an der Pathogenabwehr beteiligt sind (Levine et al., 1994; Mellersh et al., 2002).

Im Kontrast zur Funktion von $\mathrm{H}_{2} \mathrm{O}_{2}$ in der Pathogenabwehr, ist die Bedeutung der Translokation des Zellkerns hin zur Penetrationsstelle nicht bekannt. Zusätzlich zur Migration kann auch eine Vergrößerung des Nucleus in attackierten Zellen beobachtet werden, was auf eine erhöhte Transkription zurückgeführt wird (Baluska et al., 1995; Heath und Skalamera, 1997; Koh et al., 2005). So konnte nachgewiesen werden, dass bis zu $20 \%$ des Genoms nach Pathogenbehandlung unterschiedlich stark exprimiert werden (Maleck et al., 2000; Tao et al., 2003).

Neben dem Zellkern werden Peroxisomen ebenfalls zum Stimulus hin transportiert (Koh et al., 2005; Hardham et al., 2008). Auf ihre Funktion in der Pathogenabwehr wird im folgenden Kapitel näher eingegangen.

Warum es zur Reorganisation des ERs an Pathogen-Interaktionstellen bzw. an mechanisch stimulierten Regionen kommt, und welche Funktion dadurch ausgeübt wird, muss noch im Detail untersucht werden (Abb. 1.5). Es steht allerdings fest, dass das ER eine wichtige Funktion in der Qualitätskontrolle von PAMP-Rezeptoren besitzt und der Speicherung von $\mathrm{Ca}^{2+}$-Ionen dient, die als sekundäre Botenstoffe in der Pathogenabwehr dienen können (zusammengefasst in Padmanabhan und Dinesh-Kumar, 2010). Leckie et al. (1995) postulierten zusätzlich eine Beteiligung des ERs an Exocytoseprozessen, die neues Membranmaterial liefern, welches für die Bildung des haustoriellen Komplexes benötigt wird. Neben der Reorganisation des ERs konnte auch eine pathogen-induzierte bzw. Druckinduzierte Neuordnung des Cytoskeletts beobachtet werden (Kobayashi et al., 1997; GusMayer et al., 1998; Takemoto et al., 2003; Hardham et al., 2008). Durch die Verwendung spezifischer Inhibitoren, welche entweder die Polymerisation bzw. Depolymerisation von Actinfilamenten oder die von Mikrotubulis verhindern, konnte die Bedeutung des Cytoskeletts in der Pathogenabwehr näher untersucht werden. Hierbei wurde festgestellt, 
dass eine Inhibierung der Actinfilamente die Aggregation des Cytoplasmas verhindert und zu einer erhöhten Penetration der Zelle in unterschiedlichen kompatiblen und inkompatiblen Interaktionen führt (Tomiyama et al., 1982; Hazen und Bushnell, 1983; Kobayashi et al., 1997; Yun et al., 2003; Jarosch et al., 2005). Durch die Applikation eines Actin Polymerisations-Inhibitors konnten Yun et al. (2003) eindeutig nachweisen, dass Actinfilamente eine essentielle Rolle in der Nichtwirtsresistenz von Arabidopsis gegenüber nicht-adaptierten Mehltaupilzen spielen. So konnte durch Applikation des Inhibitors Cytochalasin E in eds1-Mutanten, die in ihrer postinvasiven Resistenz beeinträchtigt sind, die Nichtwirtsresistenz gegenüber dem normalerweise inkompatiblen Weizenmehltaupilz Blumeria graminis f. sp. tritici (Bgt) gebrochen werden. Daher ist anzunehmen, dass die Reorganisation der Actinfilamente wichtig für die präinvasive Resistenz ist. Diese Annahme wird auch durch die bis jetzt unveröffentlichten Daten von W. Underwood und S.C. Somerville unterstützt, wonach die Akkumulation von PEN3-GFP unterhalb des pilzlichen Appressoriums nach Behandlung mit Cytochalasin E aufgehoben wird (Underwood und Somerville, 2008). Interessanterweise hat diese pharmakologische Behandlung keinen Einfluss auf die fokale Akkumulation von GFP-PEN1 (Underwood und Somerville, 2008). Ob die Actin-unabhängige Translokation von PEN1 möglicherweise Mikrotubuli abhängig ist, ist nicht bekannt. Allerdings konnte gezeigt werden, dass die Mikrotubuli-Reorganisation nicht in jeder Pathogen-Interaktion statt findet und dass die Inhibierung der De- bzw. Polymerisation von Mikrotubuli einen wesentlich geringeren Effekt auf die Nichtwirtsresistenz hat (Kobayashi et al., 1997; Takemoto et al., 2003).
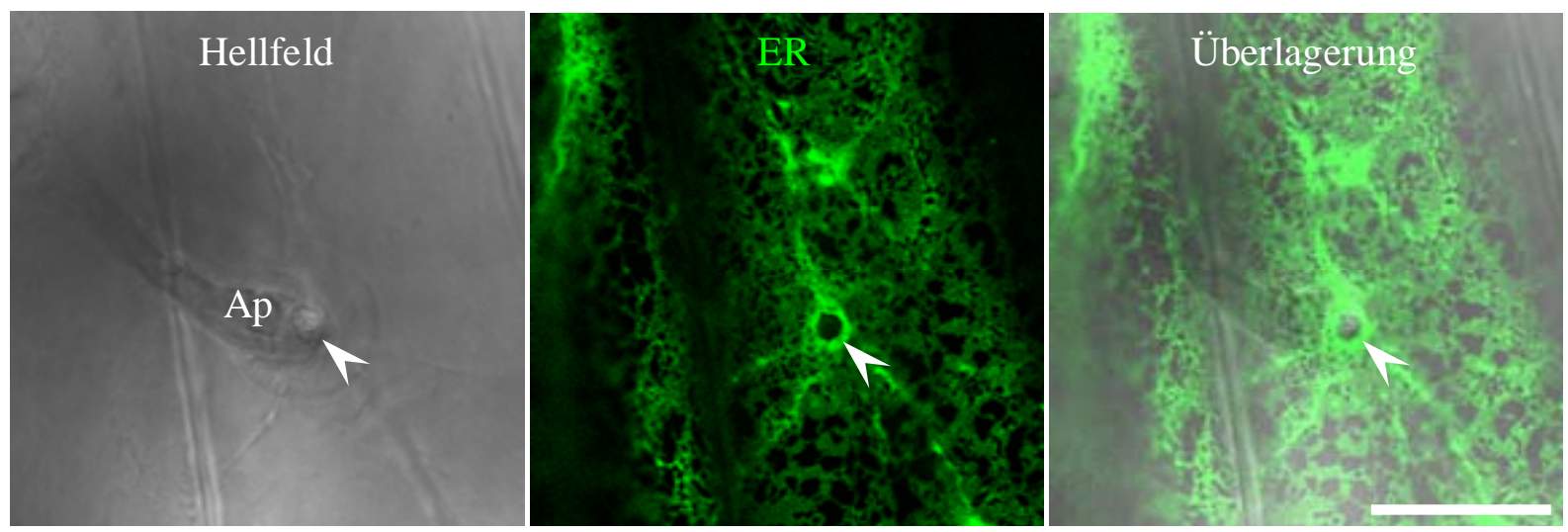

Abb. 1.5: Reorganisation des ERs an der pilzlichen Invasionsstelle.

Die fluoreszenzmikroskopische Aufnahme zeigt das GFP-markierte ER-Lumen 18 Stunden nach Inokulation mit dem kompatiblen Mehltaupilz Golovinomyces orontii. Die Pfeile weisen auf die Akkumulation des ERs an der Penetrationsstelle hin. Ap, Appressorium. Maßstabsbalken $=20 \mu \mathrm{m}$.

Welche Komponente des Cytoskeletts nun verantwortlich für die fokale Akkumulation des PEN2-GFP-assoziierten Membrankompartiments ist, muss ebenfalls noch untersucht werden, und wurde in dieser Arbeit nicht im Detail analysiert. 


\subsection{Funktion von Peroxisomen in der Pathogenabwehr}

Wie schon erwähnt, konnte mittels eines transienten Expressionsassays die Lokalisation von PEN2-GFP in der Peripherie von Peroxisomen demonstriert werden. Aufgrund dieses Befunds schlossen Lipka et al. (2005), dass die PEN2-GFP-assoziierten Membrankompartimente, welche fokal an der Pathogen-Interaktionsstelle akkumulieren, möglicherweise Peroxisomen sind. Neben der Peroxisomen-Positionierung in der Interaktion mit dem nicht-adaptierten Mehltaupilz Bgh, konnten Koh et al. (2005) ebenfalls eine Akkumulation von Peroxisomen an der Invasionsstelle eines virulenten Mehltauisolats nachweisen, was auf eine mögliche generelle Funktion dieser Organellen in der Pathogenabwehr hinweist.

Peroxisomen sind ungefähr $1 \mu \mathrm{m}$ große Zellorganellen, die nur von einer Membran umgeben und an einer Vielzahl unterschiedlicher oxidativer Prozesse beteiligt sind. So sind Peroxisomen in Pflanzen unter anderem in der Photorespiration (Liepman und Olsen, 2001 und 2003), Auxin- und Jasmonsäurebiosynthese (Bartel et al., 2001; Feussner und Wasternack, 2002; Zolman und Bartel, 2004; Schneider et al., 2005), Lipidmobilisierung (Goepfert et al., 2005), Detoxifikation und Signaltransduktion reaktiver Sauerstoffspezies involviert (del Rio et al., 2002; Foyer und Noctor, 2005). Allerdings ist die Funktion von Peroxisomen in Epidermiszellen nach Pathogenbehandlung nicht näher bekannt. Es wird jedoch angenommen, dass sie essentiell für Signaltransduktions-Prozesse und die RedoxRegulation in attackierten Zellen sind (del Rio et al., 2002; Mittler et al., 2004; Apel und Hirt, 2004; Torres und Dangl, 2005). So konnten auch Lopez-Huertas et al. (2000) demonstrieren, dass unter anderem oxidativer Stress und Pathogenbehandlung die Expression von Peroxisomenbiogenese-Genen induziert, was eine Stress-induzierte de novo-Biogenese oder Proliferation impliziert. Welche Funktion nun Peroxisomen in der Assoziation mit PEN2 ausüben, ist bisher nicht bekannt. Eine mögliche Beteiligung der Organellen an der Biosynthese des PEN2-Substrats ist durchaus denkbar. Alternativ dazu könnten Peroxisomen auch als Transportmaschinerie von PEN2 zur Invasionsstelle hin dienen.

Um dieser Fragestellung nachzugehen, wurde das Akkumulationsverhalten von Peroxisomen an der versuchten Penetrationsstelle in doppelt transgenen PEN2-GFP und RFP-markierten Peroxisomen Pflanzen in der vorliegenden Arbeit untersucht. 


\subsection{C-terminal verankerte Membranproteine}

Die Myrosinase PEN2 besitzt wie zuvor schon erwähnt, eine vorhergesagte Transmembrandomäne in der $\mathrm{C}$-terminalen Extension, die vermutlich für die Assoziation mit der Peripherie von Peroxisomen verantwortlich ist (Lipka et al., 2005). Aufgrund der putativen Transmembrandomäne am C-Terminus gehört PEN2, wie auch PEN1 und VAMP722, zur Gruppe der C-terminal verankerten Membranproteine [,tail-anchored (TA) proteins“; zusammengefasst in Pedrazzini, 2009]. Zu dieser heterogenen Gruppe zählen nicht nur Proteine, die an der Pflanzenabwehr, sondern auch an einer Vielzahl unterschiedlicher homöostatischer Prozesse wie Elektronentransport, $\mathrm{H}_{2} \mathrm{O}_{2}$-Detoxifikation, Organellenteilung und Proteintranslokation beteiligt sind (zusammengefasst in Abell und Mullen, 2011). Beispiele für diese heterogene Gruppe sind APX3 („ascorbate peroxidase 3“) und TOM20-4 („translocase of outer membrane 20-4"). APX3 ist Bestandteil der peroxisomalen $\mathrm{H}_{2} \mathrm{O}_{2}$-Detoxifikationsmaschinerie (Narendra et al., 2006), während TOM20-4 in der äußeren Mitochodrienmembran lokalisiert und für die Translokation von Proteinen verantwortlich ist (Werhahn et al., 2001).

Trotz der funktionalen Komplexität bestehen alle TA-Proteine aus einer N-terminalen cytosolischen Domäne, einer Transmembrandomäne (TMD) in der C-terminalen Region und einem hydrophilen Ende am C-Terminus selbst, welches in die Organellenmatrix hineinragt (Kutay et al., 1993). Aufgrund der Position der TMD am C-Terminus wird diese Region erst zum Ende der Translation an freien Ribosomen im Cytosol freigesetzt, weshalb TA-Proteine post-translational zu ihrem Bestimmungsort transportiert werden (Abb. 1.6). Die Translokation der C-terminal verankerten Membranproteine kann dabei direkt zu Chloroplasten, ER, Mitochondrien und Peroxisomen erfolgen oder indirekt über das sekretorische System zu allen weiteren Membrankompartimenten gelangen (zusammengefasst in Abell und Mullen, 2011). Wie TA-Proteine zu ihrem Zielort dirigiert und wie sie in die entsprechende Membran integriert werden, ist nur in wenigen Fällen bekannt. So konnte unter anderem gezeigt werden, dass molekulare Chaperone wie AKR2A („ankyrin repeat protein 2A“), HSP40/70/90 („heat shock protein 40/70/90“) oder PEX19 („peroxin 19“) eine wichtige Funktion in der Überführung von TA-Proteinen zur äußeren Membran von Chloroplasten, Mitochondrien, ER bzw. Peroxisomen besitzen (zusammengefasst in Abell und Mullen, 2011). Allerdings konnte ebenso nachgewiesen werden, dass C-terminal verankerte Membranproteine auch ohne die Hilfe von anderen Proteinen zur Selbstintegration in Doppellipidschichten befähigt sein können (Schleiff et al., 2001; Qbadou et al., 2003). 


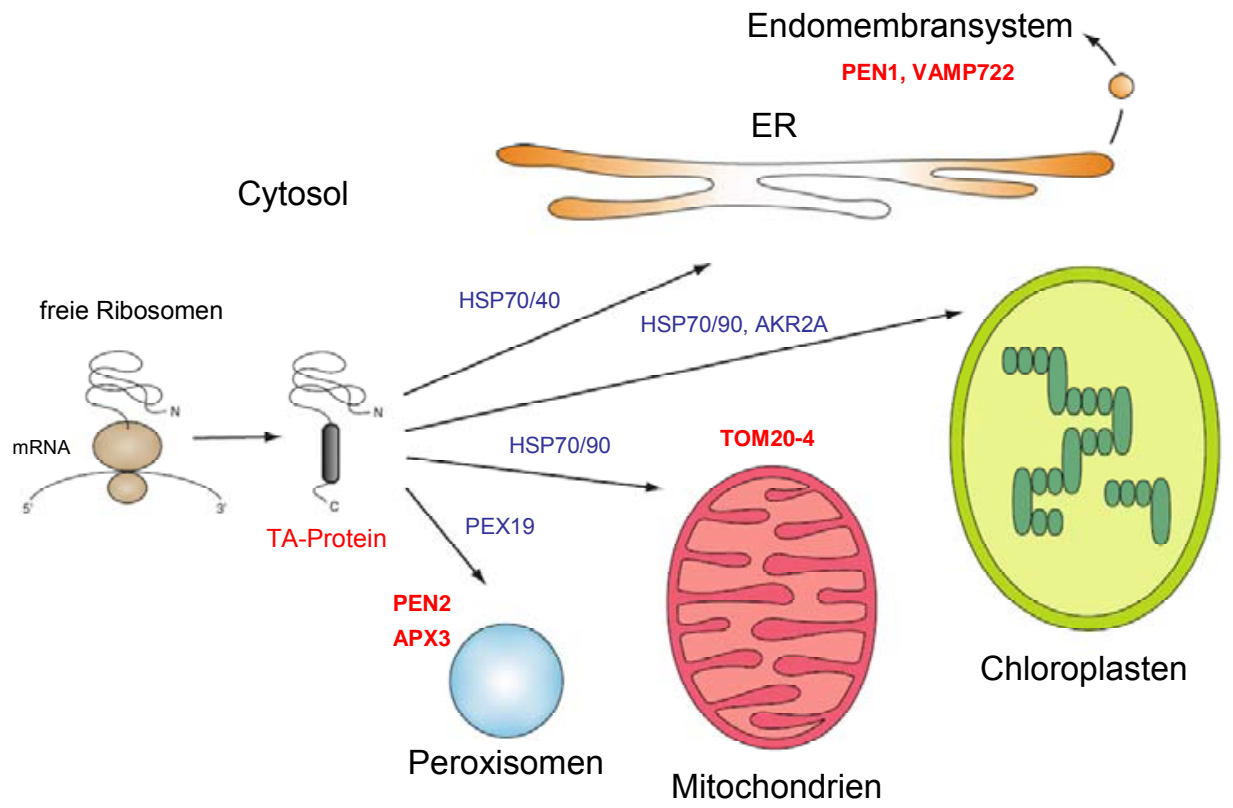

Abb. 1.6: Übersicht über den post-translationellen Transport von TA-Proteinen (modifiziert nach Abell und Mullen, 2011). Die im Text behandelten C-terminal verankerten Membranproteine sind rot, während potentielle molekulare Chaperone blau markiert sind. AKR2A (,ankyrin repeat protein 2A“); APX3 (,ascorbate peroxidase 3“); HSP40/70/90 („,heat shock protein 40/70/90“); PEX19 („peroxin 19“); TA-Proteins („tail-anchored“); TOM20-4 (,translocase of outer membrane 20-4“).

Es wird generell angenommen, dass die TMD und deren flankierende Regionen für den zielgerichteten Transport und die spezifische Integration in die Akzeptormembran verantwortlich sind. Weiterhin wird angenommen, dass die Translokation und Insertion von TA-Proteinen nicht durch ein definiertes Aminosäurenmotiv bedingt ist, sondern eher durch die physikalisch-chemischen Eigenschaften der C-terminalen Region (zusammengefasst in Borgese et al., 2003 und 2007). Neben der Länge und Hydrophobizität der TMD, sowie der Anzahl der Aminosäuren nach der Membrandomäne, scheint auch die Nettoladung der Peptidsequenz am Ende des C-Terminus zielbestimmend zu sein (Mullen und Trelease, 2000; Borgese et al., 2001; Kriechbaumer, et al., 2009). Ein Einfluss der N-terminalen Region auf die subzelluläre Lokalisation der TA-Proteine ist hingegen weniger wahrscheinlich (Mullen und Trelease, 2000; Zhang und Hu, 2008).

Inwieweit die Assoziation von PEN2 mit Peroxisomen ebenfalls abhängig von der Nettoladung oder anderen Eigenschaften der C-terminalen Region ist, ist nicht bekannt und wurde aus diesem Grund in der vorliegenden Arbeit näher untersucht. 


\subsection{Beteiligung von PYK10 an Multienzymkomplexen}

Neben PEN2 ist ein weiteres Mitglied der Arabidopsis-F1GH ebenfalls involviert in der Interaktion mit filamentösen Pilzen. Im Unterschied zur Myrosinase PEN2, ist die Glycosidhydrolase PYK10 unbeteiligt an der Nichtwirtsresistenz gegenüber nicht-adaptierten Mehltauspezies, sondern stellt eine Komponente in der Interaktion mit dem Endophyten Piriformospora indica dar. Der Basidiomycet $P$. indica besiedelt unter anderem die Wurzeln von Arabidopsis durch inter- und intrazelluläres Wachstum, was zu einer gesteigerten Aufnahme von Nährstoffen und damit zu einer Stimulierung des Wachstums sowie der Samenproduktion der Pflanze führt (Sherameti et al., 2008). pyk10-Mutanten zeigen trotz einer erhöhten Wurzelbesiedlung durch den Pilz keine Wachstumsförderung mehr, woraus Sherameti et al. (2008) geschlossen haben, dass die Glycosidhydrolase das Pilzwachstum in den Wurzeln beschränkt und somit wichtig für das Gleichgewicht der mutualistischen Interaktion der beiden Symbionten ist.

PYK10 ist ein ER-lokalisiertes Protein, welches einen Hauptbestandteil der ER-Körper darstellt (Matsushima et al., 2003). ER-Körper („ER bodies“) sind spindelförmige Strukturen von ca. $10 \mu \mathrm{m}$ Länge und $1 \mu \mathrm{m}$ Breite, die vom ER gebildet werden (Abb. 1.7; Hayashi et al., 2001). Diese Strukturen sind in jungen Keimlingen in der Epidermis von Kotyledonen, des Hypokotyls und Wurzel vorhanden, werden aber bis auf die Wurzelepidermis im Laufe der Pflanzenentwicklung zurückgebildet (Matsushima et al., 2002 und 2003). Durch Verwundung oder Applikation des Pflanzenhormons Jasmonsäure kann die Bildung der ER-Körper in Rosettenblättern jedoch induziert werden, weshalb Hara-Nishimura und Matsushima (2003) eine Funktion in der pflanzlichen Pathogenabwehr vermutet haben.

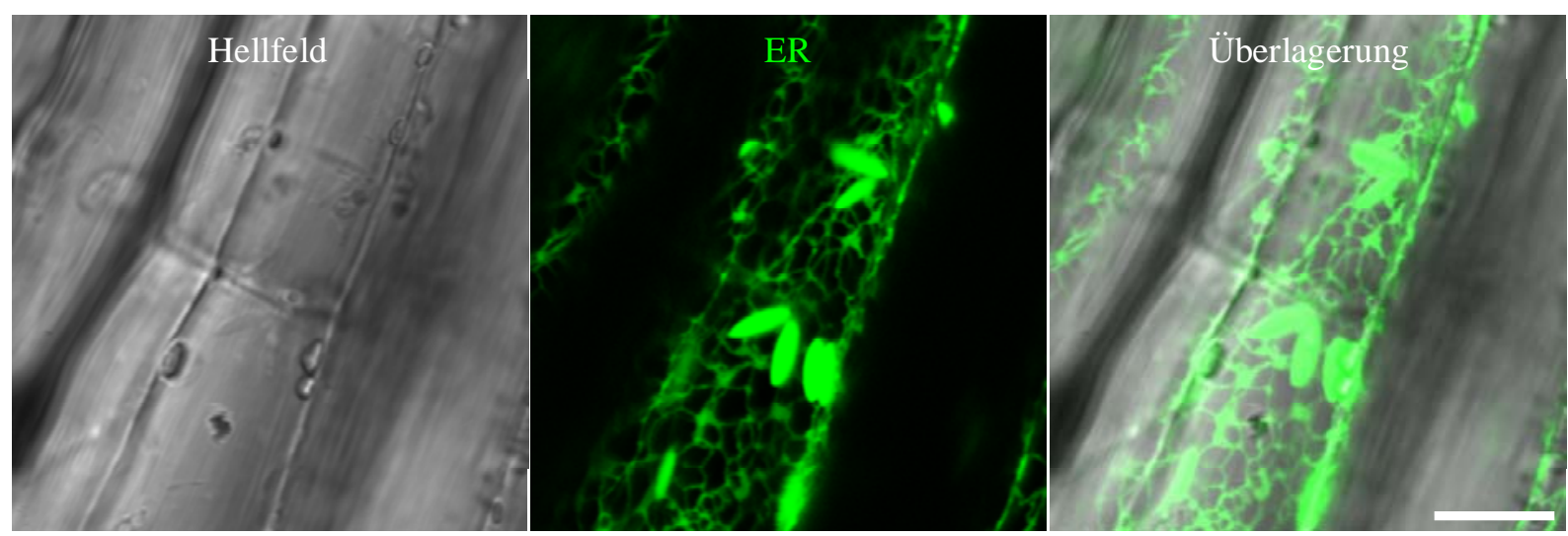

Abb. 1.7: ER-Körper in der Wurzelepidermis von transgenen Arabidopsis-Pflanzen.

Die fluoreszenzmikroskopische Aufnahme zeigt GFP-markiertes ER. Maßstabsbalken = $10 \mu \mathrm{m}$. 
Interessanterweise bildet PYK10 nach Zerstörung der subzellulären Struktur Komplexe von 0,65 bis $70 \mu \mathrm{m}$ im Durchmesser aus. Durch die Isolation der Komplexe konnten neben PYK10 noch zwei weitere Glycosidhydrolasen und mehrere JAL-Proteine (,jacalin-related lectins") als Teil des Komplexes identifiziert werden (Nagano et al., 2008). Weiterhin konnte gezeigt werden, dass die unterschiedlichen JAL-Proteine Einfluss auf die Größe des PYK10Komplexes haben. In Mais konnten ebenfalls JAL-Proteine identifiziert werden, die spezifisch mit $\beta$-Glucosidase 1 und 2 (Glu1/Glu2) interagieren, was zu einer Aggregation und Bildung von hochmolekularen unlöslichen Komplexen führt (Esen und Blanchard, 2000; Kittur et al., 2007). Neben PYK10 und Glu1/Glu2 sind noch weitere Glycosidhydrolasen in unterschiedlichen Pflanzenspezies bekannt, die ebenfalls Dimere bzw. Multimere ausbilden (Nisius, 1988; Fieldes und Gerhardt, 1994; Kim et al., 2000). Inwiefern PEN2 ebenfalls Dibzw. Multimere ausbildet, ist bisher nicht bekannt und wurde deshalb in der vorliegenden Arbeit näher untersucht.

\subsection{Zielsetzung der Arbeit}

Im Rahmen der vorliegenden Arbeit soll mittels konfokaler Fluoreszenzmikroskopie die fokale Akkumulation des PEN2-GFP-assoziierten Membrankompartiments in der Interaktion mit phytopathogenen Pilzen, im Speziellen mit dem nicht-adaptierten Gerstenmehltaupilz Blumeria graminis f. sp. hordei, näher untersucht werden. Dazu werden unter anderem Zeitreihenaufnahmen durchgeführt, die neue Details zum Akkumulationsverhalten der Myrosinase liefern können. Zusätzlich sollen anhand von Deletionskonstrukten die Bereiche der C-terminalen Extension des PEN2-Proteins identifiziert werden, die möglicherweise entscheidend für die subzelluläre Lokalisation des potentiellen TA-Proteins sind. Darüber hinaus wird durch die stabile Expression von spezifischen Organellenmarkerproteinen die Assoziation von PEN2 mit Peroxisomen, Mitochondrien, Plastiden und weiteren Membrankompartimenten in der Pathogenabwehr näher bestimmt. Somit wird beabsichtigt, die Ergebnisse der transienten Expressionsassays von Lipka et al. (2005) entweder zu bestätigen, widerlegen oder zu erweitern. Neben der fluoreszenzmikroskopischen Analyse des PEN2-GFP-Fusionsproteins erfolgt ergänzend eine Analyse mit Hilfe der Dichtegradientenzentrifugation, wodurch zusätzlich die subzelluläre Lokalisation des nativen Proteins ermittelt werden soll.

Eine weitere Fragestellung bezieht sich darauf, inwieweit die Myrosinase PEN2 ebenfalls Dibzw. Multimere ausbilden kann. Hierfür werden außer mikroskopischen auch biochemische 
Analysen durchgeführt, die Hinweise auf eine Homomerisierung von PEN2 nach Pathogenbehandlung liefern können.

Abschließend wird die subzelluläre Lokalisation weiterer Komponenten des PEN2vermittelten Abwehrmechanismus, insbesondere die der Cytochrom-P450-Monoxygenase CYP81F2, mit Hilfe von Fluoreszenzprotein-Markierung mikroskopisch untersucht und mit der Lokalisation von PEN2-GFP verglichen. Außerdem soll die Proteinabundanz sowie die Transkriptmenge der Monoxygenase mit der von PEN2 nach Pathogenbehandlung verglichen werden, um einen möglichen Unterschied in der transkriptionellen bzw. posttranslationellen Regulation der Proteine festzustellen. 


\section{Materialien und Methoden}

In diesem Kapitel sind die Materialen und Methoden beschrieben, die in der vorliegenden Arbeit verwendet wurden.

\subsection{Materialien}

\subsubsection{Geräte}

In Tabelle 2.1 sind die Geräte aufgelistet, welche für die vorliegende Arbeit benötigt wurden.

Geräte, die zur Standardlaborausrüstung gehören, wurden nicht extra aufgeführt.

Tab. 2.1: Auflistung der verwendeten Geräte

\begin{tabular}{|l|l|l|}
\hline Gerät & Typbezeichnung & Firma \\
\hline Analysenwaage & ED224 & Sartorius, Göttingen \\
\hline Blotting-Apparatur & Mini Trans-Blot Cell & Bio-Rad, Hercules (USA) \\
\hline Brutschrank & IPP 500 & Memmert, Schwabach \\
\hline Digitale Fotokamera & Cybershot DSC-H5 & Sony, Tokio (Japan) \\
\hline Elektrophorese-Apparatur & XCell SureLock Mini-Cell & Invitrogen (Carlsbad, USA) \\
\hline Elektrophorese-Apparatur & Sub-cell GT & Bio-Rad, Hercules (USA) \\
\hline Elektrophorese-Apparatur & Mini-PROTEAN Tetra & Bio-Rad, Hercules (USA) \\
\hline Elektroporator & Micro Pulser & Bio-Rad, Hercules (USA) \\
\hline Fluoreszenzmikroskop & DM5000 B & Leica, Wetzlar \\
\hline Fluoreszenzmikroskop & DM750 & Leica, Wetzlar \\
\hline Geldokumentationssystem & GenoPlex & VWR, Darmstadt \\
\hline Gradientenmixer & SG50 & Hoefer, Holliston (USA) \\
\hline Inkubationsschüttler & Certomat BS-1 & Sartorius, Göttingen \\
\hline Konfokalmikroskop & TCS SP5 & Leica, Wetzlar \\
\hline Kreisschüttler & 3005 & GFL, Burgwedel \\
\hline Kühlzentrifuge & Heraeus Mulitfuge 3SR+ & Thermo Scientific, Waltham (USA) \\
\hline Kühlzentrifuge & Heraeus Fresco 17 & Thermo Scientific, Waltham (USA) \\
\hline Netzgerät & PowerPac HC & Bio-Rad, Hercules (USA) \\
\hline Netzgerät & BluePower 500 & Serva, Heidelberg \\
\hline Peristaltikpumpe & 2120 Varioperpex II & LKB Bromma (Schweden) \\
\hline pH-Meter & inoLap pH 720 & WTW, Weilheim \\
\hline Präzisionswaage & ED6202S-CW & Sartorius, Göttingen \\
\hline Refraktometer & Convex & Medline, Oxfordshire (GB) \\
\hline Rotator & SB3 & Stuart, Staffordshire (GB) \\
\hline Rotor & SA-600 & Thermo Scientific, Waltham (USA) \\
\hline Rotor & SS-34 & Thermo Scientific, Waltham (USA) \\
\hline Rotor & AH-629 & Thermo Scientific, Waltham (USA) \\
\hline Rotor & SLA-1000 & Thermo Scientific, Waltham (USA) \\
\hline Rotor & F10-6x500y & Thermo Scientific, Waltham (USA) \\
\hline & & \\
\hline
\end{tabular}




\begin{tabular}{|l|l|l|}
\hline Fortsetzung von Tabelle 2.1 & MZ6 & Leica, Wetzlar \\
\hline Stereomikroskop & Biowave II & Biochrom WPA, Cambridge (GB) \\
\hline Spektrophotometer & compact & Eppendorf, Oldenburg \\
\hline Thermomixer & comfort & Eppendorf, Oldenburg \\
\hline Thermomixer & GT-482 & AlphaMetrix, Rödermark \\
\hline Thermocycler & MyCycler & Bio-Rad, Hercules (USA) \\
\hline Thermocycler & Heraeus Pico 17 & Thermo Scientific, Waltham (USA) \\
\hline Tischzentrifuge & $\begin{array}{l}\text { Kontron Centrikon T- } \\
1170\end{array}$ & Thermo Scientific, Waltham (USA) \\
\hline Ultrazentrifuge & AR-95L3 & Percival, Perry (USA) \\
\hline Wachstumsschrank & Trans-Blot Cell & Bio-Rad, Hercules (USA) \\
\hline $\begin{array}{l}\text { Western-Blotting } \\
\text { Apparatur }\end{array}$ & Sorvall RC-5B & Thermo Scientific, Waltham (USA) \\
\hline Zentrifuge & &
\end{tabular}

\subsubsection{Antibiotika}

Die Antibiotika wurden entweder von der Firma Duchefa (Haarlem, Niederlande) oder Roth (Karlsruhe) bezogen. Folgende Stammlösungen (1000x) wurden hergestellt und bis zum Gebrauch bei $-20^{\circ} \mathrm{C}$ gelagert:

Carbenicillin (Carb) $50 \mathrm{mg} / \mathrm{ml}$ in $\mathrm{H}_{2} \mathrm{O}$

Kanamycin (Kan) $\quad 50 \mathrm{mg} / \mathrm{ml}$ in $\mathrm{H}_{2} \mathrm{O}$

Rifampicin (Rif) $100 \mathrm{mg} / \mathrm{ml}$ in DMSO

\subsubsection{Antikörper}

Eine Liste der für die Western-Blot-Analysen verwendeten Antikörper und deren Verdünnung sind in Tabelle 2.2 angegeben.

Der PEN2 spezifische Antikörper ist gegen die C-terminale Aminosäuresequenz ${ }^{506}$ EEKKESYGKQLLHSVQ ${ }^{521}$ gerichtet (Lipka et al., 2005).

Tabelle 2.2: Auflistung der verwendeten Antikörper

\begin{tabular}{|l|l|l|l|}
\hline Antikörper & Verdünnung & Beschreibung & Firma \\
\hline$\alpha$-GFP & $1: 5000$ & Ratte, monoklonal & ChromoTek, Martinsried \\
\hline$\alpha$-PEN2 & $1: 10000$ & Hase, polyklonal & Eurogentec, Seraing (Belgien) \\
\hline$\alpha$-PEX14 & $1: 10000$ & Hase, polyklonal & Agrisera, Vännäs (Schweden) \\
\hline$\alpha$-RFP & $1: 5000$ & Ratte, monoklonal & ChromoTek, Martinsried \\
\hline$\alpha$-VDAC1 & $1: 5000$ & Hase, polyklonal & Agrisera, Vännäs (Schweden) \\
\hline Anti-Hase & $1: 10000$ & lgG (Ziege) & Sigma-Aldrich, Steinheim \\
\hline Anti-Ratte & $1: 5000$ & IgG (Ziege) & Sigma-Aldrich, Steinheim \\
\hline
\end{tabular}




\subsubsection{Chemikalien}

Die Chemikalien wurden von folgenden Firmen bezogen:

Bio-Rad (Hercules, USA), Duchefa (Haarlem, Niederlande), Fermentas (St.Leon-Rot), Invitrogen life technology ${ }^{\mathrm{TM}}$ (Carlsbad, USA), Roth (Karlsruhe), Sigma-Aldrich (Steinheim) und VWR (Darmstadt).

\subsubsection{Enzyme}

Enzyme wie DNA-Polymerasen, DNA-Ligase, Restriktionsendonukleasen etc., wurden entweder von Fermentas (St. Leon-Rot), New England Biolabs (Ipswich, GB) oder Invitrogen life technology ${ }^{\mathrm{TM}}$ (Carlsbad, USA) bezogen und den Herstellerangaben entsprechend verwendet.

\subsubsection{Marker}

Als Größenstandard für DNA-Fragmente im Agarosegel diente die DNA-Leiter GeneRuler ${ }^{\text {TM }}$ $1 \mathrm{~kb}$ DNA Ladder von Fermentas (St. Leon-Rot). Zur Bestimmung des Molekulargewichts von Proteinen im SDS-Polyacrylamidgel wurde der Proteinmarker PageRuler ${ }^{\mathrm{TM}}$ Plus Prestained Protein Ladder von Fermentas (St. Leon-Rot) und für native Polyacrylamidgele der Marker NativeMark ${ }^{\mathrm{TM}}$ von Invitrogen life technology ${ }^{\mathrm{TM}}$ (Carlsbad, USA) eingesetzt.

\subsubsection{Membranen}

Die PVDF-Membran Roti®-PVDF (Polyvinylidenfluorid) mit einer Porengröße von 0,45 $\mu \mathrm{m}$ der Firma Roth (Karlsruhe) wurde zum Transfer der Proteine im Western-Blot benutzt.

\subsubsection{Molekularbiologische Kits}

Für die Aufreinigung von DNA aus Agarosegelen wurde das NucleoSpinExtract II Kit von der Firma Macherey-Nagel (Düren) verwendet. Zur Isolation und Aufreinigung von Plasmiden aus Bakterien wurde das Plasmid Midi Kit von Qiagen (Venlo, Niederlande) angewendet. Mit Hilfe des Qiagen (Venlo, Niederlande) RNeasy Plant Mini Kits erfolgte die Aufreinigung der gesamten RNA aus Pflanzenmaterial, mittels des RevertAid ${ }^{\mathrm{TM}} \mathrm{H}$ Minus Reverse Transcriptase Kit von Fermentas (St. Leon-Rot) wurde die reverse Transkription der RNA in cDNA durchgeführt. 


\subsubsection{Oligonukleotide}

In Tabelle 2.3 sind die Primer aufgelistet, die zum Klonieren, Sequenzieren und für die semiquantitative RT-PCR verwendet wurden. Die Primer wurden von der Firma Invitrogen life technology ${ }^{\mathrm{TM}}$ (Carlsbad, USA) bezogen, mit TE-Puffer zu einer $100 \mu \mathrm{M}$ Stammlösung verdünnt und bei $-20^{\circ} \mathrm{C}$ gelagert.

Tab. 2.3: Liste der verwendeten Oligonukleotide

\begin{tabular}{|c|c|}
\hline Primer & Sequenz $\left(5^{\prime} \rightarrow 3^{\prime}\right)$ \\
\hline \multicolumn{2}{|l|}{ Klonierung } \\
\hline APX3-Notl-F & GCGGCCGCCATGGCTGCACCGATTGTTGATGCGGAG \\
\hline APX3-EcoRI-R & GAATTCGAATTTTACTTCATCCTCTTCCGGATCTC \\
\hline CYP81F2-Xhol-F & CCTCGAGATGGATTACGTTTTGATTGTTTTGC \\
\hline CYP81F2-Notl-R & CAGCGGCCGCAGCCAAGAGATTAGTCATAATGGGA \\
\hline GFP-Xhol-F & AACCTCGAGATGAGTAAAGGAGAAGAAC \\
\hline Np-APX3-Ascl-F & CAGGCGCGCCGATCCAGAAAACATAAATCACC \\
\hline Np-APX3-HindIII-R & CAAGCTTAGCTCCTACTCGTTTAGGATTTGTG \\
\hline Np-CYP81F2-Ascl-F & AAGGCGCGCCTCATATTTACCTATTTTGGTTTTGG \\
\hline Np-CYP81F2-SnaBI-R & CCGACGAATCTCGTCTTTACGTACGGAGAGGAATC \\
\hline PEN4-Notl-F & AGCGGCCGCAATGGCTATGGCGAGTTTATATC \\
\hline PEN4-EcoRI-R & AGAATTCCTAATAGGCAGGAGCAGCGAG \\
\hline RFP-HindIII-F & TCAGAAGCTTATCAACAATGGCCTCCTCCGAGGA \\
\hline RFP-EcoRI-R & TCAGAATTCTTAGGCGCCGGTGGA \\
\hline TOM20-4-Notl-F & AGCGGCCGCAATGGATATGCAGAATGAAAACG \\
\hline TOM20-4-EcoRI-R & CGAATTCTTACTGCCTTGACACCGGCG \\
\hline GFP-PEN2 ${ }_{\text {cterm }}$-F1 & AACCAAAGATGAGTAAAGGAGAAGAAC \\
\hline GFP-PEN2 cterm $^{-}$Xhol-F2 & TCTCGAGGCAACCAAAGATGAGTAAAGG \\
\hline PEN2-GFP- $\triangle$ C3-EcoRI & GGAATTCTCATCCTTTGAAGAACAGAGAAGTACC \\
\hline PEN2-GFP- $\triangle$ C4-EcoRI & GGAATTCTCATTTGAAGAACAGAGAAGTACC \\
\hline PEN2-GFP- $\Delta$ C5-EcoRI & GGAATTCTCAGAAGAACAGAGAAGTACCAAC \\
\hline PEN2-GFP- $\Delta$ Cterm-EcoRI & GGAATTCTTATTTGTATAGTTCATCC \\
\hline PEN2-GFP- $\triangle T M-R 1$ & GAAGAACAGAGAACTGTCTTTAATCGAATGAAC \\
\hline PEN2-GFP- $\triangle T M-R 2$ & ATTAGCTCCTTTGAAGAACAGAGAACTGTCTTTAATCG \\
\hline PEN2-GFP- $\Delta$ TM-EcoRI-R3 & CTGCAGGAATTCTCAATTATTAGCTCCTTTGAAGAACAG \\
\hline 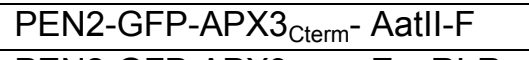 & TTCGACGTCTAAGAAACTCTCTGAGCTTGG \\
\hline PEN2-GFP-APX3 ${ }_{\text {Cterm }}$ - EcoRI-R & GAATTCGAATTTTACTTCATCCTCTTCCGGATCTC \\
\hline PEN2-GFP ${ }^{K 556 G}$-EcoRI-R & GGAATTCTCAATTATTAGCTCCTCCGAAGAACAGAG \\
\hline PEN2-GFP-TOM20 ${ }_{\text {Cterm-AatII-F }}$ & TTCGACGTCTAAAAAGACCAGTGAGTTCAAG \\
\hline PEN2-GFP-TOM20 ${ }_{\text {cterm }}$-EcoRI-R & CGAATTCTTACTGCCTTGACACCGGCG \\
\hline PEN2-RFP-AccIII-F & CAAGCCTCCGGAATGGCCTCCTCCGAGGACG \\
\hline PEN2-RFP-Kpnl-R & CTTGGGCCTCGGTACCGGCGCCGGTGGAGTGGCGGCCCTC \\
\hline RFP-HindIII-F & TCAGAAGCTTATCAACAATGGCCTCCTCCGAGGA \\
\hline RFP-Notl-F & $\begin{array}{l}\text { GCTGGAGCGGCCGCTGGCGCAGGGGCAATGGCCTCCTC } \\
\text { CGAGGACGTC }\end{array}$ \\
\hline RFP-EcoRI-R & TCAGAATTCTTAGGCGCCGGTGGA \\
\hline RFP-Notl-R & GCGGCCGCGGCGCCGGTGGAGTGGCGGCCCTCGGC \\
\hline \multicolumn{2}{|l|}{ Sequenzierung } \\
\hline 35S-Term-R & CTCTGGTCTTCTGAGACCG \\
\hline CYP81F2-F & AAGTGTTCGGACACGGCTAC \\
\hline
\end{tabular}




\begin{tabular}{|l|l|}
\hline Fortsetzung von Tabelle 2.3 & \multicolumn{1}{l|}{ TGATCCGAGTGATCCAGATGATGTC } \\
\hline F4l1-30-F2 & AACAAGAATTGGGACAACTCCAGTG \\
\hline GFP-R & ACACATAGACCATCCACC \\
\hline Np-CYP81F2-F & CTTGTCCAACTTCTTCTGAATC \\
\hline Np-PEN2-F & GACGCACAATCCCACTATCCTTCG \\
\hline P35S-F & CAAGGGTACCGAGGCCCAAGAAGACGATTCTTCGACG \\
\hline PEN2-Kpnl-F & GTTATTACGTATGGTCATTGC \\
\hline PEN2-SnaBI-F & GGAGCGCGTGATGAACTTCGAG \\
\hline RFP-F & TTGGAGCCGTACTGGAACTGAG \\
\hline RFP-R & AGACTCATACACTCTGGTGGGCCTT \\
\hline Semiquantitative RT-PCR & CGTCCTTTATGTACGTGTGTATGCA \\
\hline EP13 PR1-F & AGAGAGATTGGAGTACATTGAAGG \\
\hline EP14 PR1-R & TCAAGAACAACAACAAATCCCAAC \\
\hline EP28 PEN2-F & AATGGAGAGAGCAACACAATG \\
\hline EP29 PEN2-R & ATACTGAGCATGAGCCTTTG \\
\hline EP88 CYP81F2-F & GTCCACCCTTCATCTTGTTC \\
\hline EP89 CYP81F2-R & TCTTTCCGGTGAGAGTCTTC \\
\hline UBQ10-F &
\end{tabular}

\subsubsection{Plasmide}

Zur Herstellung der verwendeten Plasmide wurden die binären Vektoren pAMPAT-NpPEN2-GFP (Lipka et al., 2005) bzw. pAMPAT-MCS-35S und pAM-MCS-35S verwendet. Die Vektoren PAMPAT-MCS-35S und pAM-MCS-35S beinhalten beide eine „multiple cloning site" (MCS), den 35S-Promotor des Blumenkohl-Mosaik-Virus und den bakteriellen Resistenzmarker Ampicillin (Carbenicillin). Während das pAMPAT-MCS-35S Plasmid eine Herbizidresistenz (BASTA) als Selektionsmarker trägt, besitzt das Plasmid pAM-MCS-35S die Antibiotikaresistenz gegen Kanamycin.

In Tabelle 2.4 sind die Plasmide aufgelistet, die zu Versuchszwecken in der vorliegenden Arbeit hergestellt worden sind. Neben den in der Tabelle aufgeführten Vektoren wurden zusätzlich die von Nelson et al. (2007) beschriebenen Plasmide verwendet.

Tab. 2.4: Auflistung der hergestellten binären Vektoren

\begin{tabular}{|c|c|c|c|}
\hline Konstrukt & Promotor & Vektor & $\begin{array}{l}\text { Restriktions- } \\
\text { schnittstellen }\end{array}$ \\
\hline CYP81F2-RFP & CYP81F2 & pAMPAT-MCS & Xhol/BamHI \\
\hline GFP-PEN2 ${ }_{\text {Cterm }}$ & PEN2 & PAMPAT-MCS & Xhol/EcoRl \\
\hline PEN2-GFP- $\triangle$ C3 & PEN2 & pAMPAT-MCS & HindIII/EcoRI \\
\hline PEN2-GFP- $\triangle \mathrm{C} 4$ & PEN2 & pAMPAT-MCS & HindIII/EcoRI \\
\hline PEN2-GFP- $\triangle \mathrm{C} 5$ & PEN2 & pAMPAT-MCS & HindIII/EcoRI \\
\hline PEN2-GFP- $\Delta$ Cterm & PEN2 & pAMPAT-MCS & HindIII/EcoRI \\
\hline PEN2-GFP- $\triangle T M$ & PEN2 & pAMPAT-MCS & HindIII/EcoRI \\
\hline PEN2-GFP-APX3 ${ }_{\text {Cterm }}$ & PEN2 & pAMPAT-MCS & HindIII/EcoRI \\
\hline PEN2-GFP ${ }^{K 556 G}$ & PEN2 & pAMPAT-MCS & HindIII/EcoRI \\
\hline
\end{tabular}




\begin{tabular}{|l|l|l|l|}
\hline \multicolumn{5}{|l|}{ Fortsetzung von Tabelle 2.4 } & pAMPAT-MCS & HindIII/EcoRI \\
\hline PEN2-GFP-TOM20-4 Cterm & PEN2 & pAMPAT-MCS & HindIII/EcoRI \\
\hline PEN2-RFP & PEN2 & pAM-MCS & HindIII/EcoRI \\
\hline RFP & $35 S$ & pAMPAT-MCS & HindIII/EcoRI \\
\hline RFP-APX3 & APX3 & pAM-MCS & HindIII/EcoRI \\
\hline RFP-PEN4 & $35 S$ & pAM-MCS & HindIII/EcoRI \\
\hline RFP-TOM20-4 & $35 S$ & pAMPAT-MCS & HindIII/EcoRI \\
\hline RFP-TOM20-4 & $35 S$ &
\end{tabular}

\subsubsection{Puffer und Lösungen}

Neben den Puffern und Lösungen, die in molekularbiologischen Kits enthalten waren bzw. den Enzymen vom Hersteller beigefügt worden sind, wurden die in Tabelle 2.5 aufgeführten Puffer und Lösungen zusätzlich in Experimenten verwendet.

Tab. 2.5: Zusammenstellung der verwendeten Puffer und Lösungen

\begin{tabular}{|c|c|}
\hline \multicolumn{2}{|l|}{ Allgemeine Puffer und Lösungen } \\
\hline $\begin{array}{l}\text { Infiltrationspuffer (transiente Transformation von } \\
\text { N. benthamiana) }\end{array}$ & $\begin{array}{l}10 \mathrm{mM} \mathrm{MgCl}_{2} \\
10 \mathrm{mM} \mathrm{MES} \\
\mathrm{pH} 5,5 \\
150 \mu \text { Acetosyringon }\end{array}$ \\
\hline Sterilisationslösung (Samen) & \begin{tabular}{|l|}
$70 \%$ EtOH \\
$0,05 \%$ Tween20 \\
\end{tabular} \\
\hline Transformationslösung („flower dip“ Methode) & $\begin{array}{l}5 \%(w / v) \text { Sucrose } \\
0,01 \%(v / v) \text { Silwet L-77 }\end{array}$ \\
\hline \multicolumn{2}{|l|}{ Dichtegradientenzentrifugation } \\
\hline Extraktionspuffer & $\begin{array}{l}400 \mathrm{mM} \text { Sucrose } \\
100 \mathrm{mM} \mathrm{HEPES} \\
5 \mathrm{mM} \mathrm{MgCl}_{2} \\
3 \mathrm{mM} \mathrm{DTT} \\
\mathrm{pH} 7,5\end{array}$ \\
\hline HEPES-Puffer & $\begin{array}{l}25 \mathrm{mM} \text { HEPES } \\
\mathrm{pH} 7,5\end{array}$ \\
\hline $15 \%$ Sucrose-Lösung & $\begin{array}{l}15 \%(w / v) \text { Sucrose } \\
\text { HEPES-Puffer }\end{array}$ \\
\hline 55 \% Sucrose-Lösung & $\begin{array}{l}55 \%(w / v) \text { Sucrose } \\
\text { HEPES-Puffer }\end{array}$ \\
\hline \multicolumn{2}{|l|}{ Mikroskopische Analysen } \\
\hline Anilinblau-Färbelösung & $\begin{array}{l}150 \mathrm{mM} \mathrm{KH} \mathrm{PO}_{4} \\
0,01 \%(\mathrm{w} / \mathrm{v}) \text { Anilinblau } \\
\mathrm{pH} 9,5\end{array}$ \\
\hline Coomassie-Färbelösung & $\begin{array}{l}45 \%(v / v) \text { Methanol } \\
10 \%(v / v) \text { Essigsäure } \\
0,05 \%(w / v) \text { Coomassie R-250 }\end{array}$ \\
\hline Einbettungslösung & $50 \%(v / v)$ Glycerin \\
\hline FM 4-64 bzw. FM 1-43 Färbelösung (1000x) & $\begin{array}{l}2 \text { mM FM 4-64 / FM 1-43 } \\
\text { DMSO }\end{array}$ \\
\hline Propidiumiodid-Färbelösung & $\begin{array}{l}2,5 \%(\mathrm{w} / \mathrm{v}) \text { Mannitol } \\
0,5 \%(\mathrm{w} / \mathrm{v}) \text { Propidiumiodid } \\
0,01 \%(\mathrm{v} / \mathrm{v}) \text { Silwet L-77 }\end{array}$ \\
\hline
\end{tabular}




\begin{tabular}{|c|c|}
\hline \multicolumn{2}{|l|}{ Fortsetzung von Tabelle 2.5} \\
\hline \multicolumn{2}{|l|}{ Mitochondrien Isolierung } \\
\hline Mitochondrien-Extraktionspuffer & $\begin{array}{l}300 \mathrm{mM} \text { Sucrose } \\
50 \mathrm{mM} \text { Tetranatrium-pyrophosphat } \\
10 \mathrm{mM} \mathrm{KH}_{2} \mathrm{PO}_{4} \\
2 \mathrm{mM} \mathrm{EDTA} \\
1 \%(\mathrm{w} / \mathrm{v}) \mathrm{PVP}-40 \\
0,2 \%(\mathrm{w} / \mathrm{v}) \mathrm{BSA} \\
\mathrm{pH} 7,5 \\
20 \mathrm{mM} \text { Ascorbinsäure } \\
5 \mathrm{mM} \text { Cystein }\end{array}$ \\
\hline Gradientenlösung mit PVP-40 (70 ml) & $\begin{array}{l}35 \mathrm{ml} \text { Sucrose-Waschpuffer (2x) } \\
19,6 \mathrm{ml} \text { Percoll } \\
\text { 15,4 ml PVP-40 Stammlösung }\end{array}$ \\
\hline Gradientenlösung ohne PVP-40 (70 ml) & $\begin{array}{l}35 \mathrm{ml} \text { Sucrose-Waschpuffer }(2 \mathrm{x}) \\
19,6 \mathrm{ml} \text { Percoll } \\
15,4 \mathrm{ml} \text { Aqua dest. }\end{array}$ \\
\hline PVP-40 Stammlösung & $20 \%(w / v)$ \\
\hline Sucrose-Waschpuffer ohne BSA (1x) & $\begin{array}{l}300 \mathrm{mM} \text { Sucrose } \\
10 \mathrm{mM} \text { TES } \\
\mathrm{pH} 7.5\end{array}$ \\
\hline Sucrose-Waschpuffer (2x) & $\begin{array}{l}600 \mathrm{mM} \text { Sucrose } \\
20 \mathrm{mM} \text { TES } \\
0,2 \%(\mathrm{w} / \mathrm{v}) \mathrm{BSA} \\
\mathrm{pH} 7.5\end{array}$ \\
\hline \multicolumn{2}{|l|}{ Molekularbiologische Anwendungen } \\
\hline Alkalischer Lysepuffer I & $\begin{array}{l}100 \mathrm{mM} \text { Tris } \\
10 \mathrm{mM} \text { EDTA } \\
100 \mu \mathrm{g} / \mathrm{mL} \text { RNAse I } \\
\mathrm{pH} 7,5\end{array}$ \\
\hline Alkalischer Lysepuffer II & $\begin{array}{l}200 \mathrm{mM} \mathrm{NaOH} \\
1 \%(\mathrm{w} / \mathrm{v}) \mathrm{SDS}\end{array}$ \\
\hline Alkalischer Lysepuffer III & $\begin{array}{l}60 \mathrm{ml} 5 \mathrm{M} \text { Kaliumacetat } \\
11,5 \mathrm{ml} \text { Eisessig } \\
28,5 \mathrm{ml} \text { Aqua dest. }\end{array}$ \\
\hline DNA-Ladepuffer (6x) & $\begin{array}{l}30 \%(\mathrm{v} / \mathrm{v}) \text { Glycerin } \\
0,25 \%(\mathrm{w} / \mathrm{v}) \text { Orange G } \\
0,25 \%(\mathrm{w} / \mathrm{v}) \text { Xylenxyanol }\end{array}$ \\
\hline Edwards DNA Extraktionspuffer & $\begin{array}{l}250 \mathrm{mM} \mathrm{NaCl} \\
200 \mathrm{mM} \text { Tris } \\
25 \mathrm{mM} \text { EDTA } \\
0,5 \%(\mathrm{v} / \mathrm{v}) \mathrm{SDS} \\
\mathrm{pH} 7,5\end{array}$ \\
\hline TAE-Puffer (50x) & $\begin{array}{l}2 \mathrm{M} \text { Tris } \\
2 \text { M Acetat } \\
0,05 \text { M EDTA } \\
\mathrm{pH} 8,5\end{array}$ \\
\hline TE-Puffer & $\begin{array}{l}10 \mathrm{mM} \text { Tris } \\
1 \mathrm{mM} \text { EDTA } \\
\mathrm{pH} 8,0\end{array}$ \\
\hline $\begin{array}{l}\text { TFB1-Puffer } \\
\text { (Herstellung kompetenter E. coli-Zellen) }\end{array}$ & $\begin{array}{l}100 \mathrm{mM} \mathrm{RbCl} \\
50 \mathrm{mM} \mathrm{MnCl}_{2} \times 4 \mathrm{H}_{2} \mathrm{O} \\
30 \mathrm{mM} \mathrm{Kaliumacetat} \\
10 \mathrm{mM} \mathrm{CaCl}_{2} \times 2 \mathrm{H}_{2} \mathrm{O} \\
15 \%(\mathrm{v} / \mathrm{v}) \text { Glycerin }\end{array}$ \\
\hline
\end{tabular}




\begin{tabular}{|c|c|}
\hline \multicolumn{2}{|l|}{ Fortsetzung von Tabelle 2.5} \\
\hline $\begin{array}{l}\text { TFB2-Puffer } \\
\text { (Herstellung kompetenter E. coli-Zellen) }\end{array}$ & $\begin{array}{l}200 \mathrm{mM} \mathrm{MOPS} \\
75 \mathrm{mM} \mathrm{CaCl} \\
10 \mathrm{mM} \mathrm{RbCl} \\
10 \mathrm{H}_{2} \mathrm{O} \\
15 \%(\mathrm{v} / \mathrm{v}) \text { Glycerin }\end{array}$ \\
\hline \multicolumn{2}{|l|}{ Peroxisomen Isolierung } \\
\hline 15 \% Percoll-Lösung & $\begin{array}{l}15 \%(v / v) \text { Percoll } \\
85 \%(v / v) \text { Gradientenpuffer }\end{array}$ \\
\hline 38 \% Percoll-Lösung & $\begin{array}{l}38 \%(v / v) \text { Percoll } \\
62 \%(v / v) \text { Gradientenpuffer }\end{array}$ \\
\hline 36 \% Sucrose-Lösung & $\begin{array}{l}36 \%(w / v) \text { Sucrose } \\
\text { Gradientenpuffer ohne Sucrose }\end{array}$ \\
\hline Gradientenpuffer mit Sucrose & $\begin{array}{l}750 \mathrm{mM} \text { Sucrose } \\
20 \mathrm{mM} \text { Tricin } \\
1 \mathrm{mM} \text { EDTA } \\
0,2 \%(\mathrm{w} / \mathrm{v}) \mathrm{BSA} \\
\mathrm{pH} 7,5\end{array}$ \\
\hline Peroxisomen-Extraktionspuffer & $\begin{array}{l}750 \mathrm{mM} \text { Sucrose } \\
170 \mathrm{mM} \text { Tricin } \\
10 \mathrm{mM} \mathrm{KCl} \\
2 \mathrm{mM} \mathrm{EDTA} \\
1 \mathrm{mM} \mathrm{MgCl} \\
1 \%(\mathrm{w} / \mathrm{v}) \mathrm{BSA} \\
\mathrm{pH} 7,5 \\
5 \mathrm{mM} \text { DTT }\end{array}$ \\
\hline \multicolumn{2}{|l|}{ Western-Blot-Analysen } \\
\hline Alkalischer Phosphatase-Puffer (AP-Puffer) & $\begin{array}{l}100 \mathrm{mM} \mathrm{NaCl} \\
100 \mathrm{mM} \mathrm{Tris} \\
50 \mathrm{mM} \mathrm{MgCl}_{2} \\
\mathrm{pH} \mathrm{9,0}\end{array}$ \\
\hline Blockierungspuffer & $\begin{array}{l}0,2 \%(w / v) \text { Magermilchpulver } \\
\text { TBST-Puffer }\end{array}$ \\
\hline Entfärbelösung (Membranen) & $\begin{array}{l}25 \% \text { Methanol } \\
7 \% \text { Eisessig }\end{array}$ \\
\hline GTEN-Puffer (Proteinextraktion) & $\begin{array}{l}150 \mathrm{mM} \mathrm{NaCl} \\
25 \mathrm{mM} \text { Tris } \\
1 \mathrm{mM} \text { EDTA } \\
\mathrm{pH} 7,5 \\
10 \% \text { Glycerin } \\
0,1 \% \text { Tween } 20 \\
\end{array}$ \\
\hline Lämmli-Ladepuffer (4x) & $\begin{array}{l}250 \mathrm{mM} \text { Tris } \\
20 \%(\mathrm{v} / \mathrm{v}) \text { Glycerin } \\
20 \%(\mathrm{v} / \mathrm{v}) \beta-\text { Mercaptoethanol } \\
8 \%(\mathrm{w} / \mathrm{v}) \text { SDS } \\
0,4 \%(\mathrm{w} / \mathrm{v}) \text { Bromphenol Blau } \\
\mathrm{pH} 6,8\end{array}$ \\
\hline Lowry-Reagenz A & $\begin{array}{l}2 \%(\mathrm{w} / \mathrm{v}) \mathrm{Na}_{2} \mathrm{CO}_{3} \\
0,4 \%(\mathrm{w} / \mathrm{v}) \mathrm{NaOH} \\
0,02 \%(\mathrm{w} / \mathrm{v}) \mathrm{Kalium}-\text { Natrium-Tartrat } \\
\end{array}$ \\
\hline Lowry-Reagenz B & $0,5 \%(\mathrm{w} / \mathrm{v}) \mathrm{CuSO}_{4} \times 5 \mathrm{H}_{2} \mathrm{O}$ \\
\hline
\end{tabular}




\begin{tabular}{|c|c|}
\hline \multicolumn{2}{|l|}{ Fortsetzung von Tabelle 2.5} \\
\hline Sammelgel (5 \%iges) & $\begin{array}{l}3,4 \mathrm{ml} \text { Aqua dest. } \\
830 \mu \mathrm{l} 30 \% \text { \% iger Acrylamid-Mix } \\
630 \mu \mathrm{l} 1 \mathrm{M} \text { Tris (pH 6,8) } \\
50 \mu \mathrm{l} 10 \%(\mathrm{w} / \mathrm{v}) \text { SDS } \\
50 \mu \mathrm{l} 10 \%(\mathrm{w} / \mathrm{v}) \text { APS } \\
5 \mu \mathrm{l} \text { Temed }\end{array}$ \\
\hline SDS-Laufpuffer (10x) & $\begin{array}{l}192 \mathrm{mM} \text { Glycin } \\
25 \mathrm{mM} \text { Tris } \\
0,1 \% \text { SDS }\end{array}$ \\
\hline „Stripping“-Puffer & 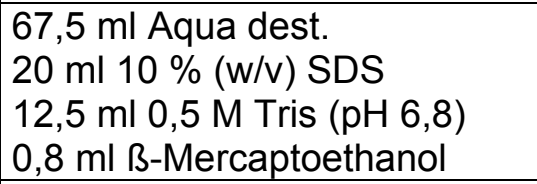 \\
\hline TBST-Puffer & $\begin{array}{l}20 \mathrm{mM} \text { Tris } \\
500 \mathrm{mM} \mathrm{NaCl} \\
0,1 \% \text { Tween } 20 \\
\mathrm{pH} 7,5\end{array}$ \\
\hline Transferpuffer Native-PAGE (20x) & $\begin{array}{l}500 \text { mM Bicin } \\
500 \text { mM Bis-Tris } \\
20,5 \text { mM EDTA } \\
\text { pH } 7,2\end{array}$ \\
\hline Transferpuffer SDS-PAGE (20x) & $\begin{array}{l}1 \mathrm{M} \text { Borsäure } \\
1 \mathrm{M} \text { Tris } \\
\mathrm{pH} 8,3\end{array}$ \\
\hline Trenngel (10 \%iges) & $\begin{array}{l}4 \mathrm{ml} \text { Aqua dest. } \\
3,3 \mathrm{ml} 30 \% \text { iger Acrylamid-Mix } \\
2,5 \mathrm{ml} 1,5 \mathrm{M} \text { Tris (pH 8,8) } \\
100 \mu \mathrm{l} 10 \%(\mathrm{w} / \mathrm{v}) \text { SDS } \\
100 \mu \mathrm{ll} 10 \%(\mathrm{w} / \mathrm{v}) \text { APS } \\
4 \mu \mathrm{l} \text { Temed }\end{array}$ \\
\hline
\end{tabular}

\subsubsection{Pflanzenmaterialien}

Neben Arabidopsis thaliana Columbia-0- (Col-0) und Col-3, gl1-Pflanzen wurden für die unterschiedlichen Experimente die in den Tabellen 2.6 bis 2.9 aufgelisteten Linien verwendet. Für die Linien, die nicht im Zuge der vorliegenden Arbeit erzeugt worden sind, wurde die entsprechende Bezugsquelle angegeben.

Tab. 2.6: Verwendete Einfach- bzw. Doppelmutanten

\begin{tabular}{|l|l|l|l|}
\hline \multicolumn{1}{|c|}{ Allele } & \multicolumn{1}{|c|}{ Ökotyp } & Bezeichnung & \multicolumn{1}{c|}{ Referenz } \\
\hline pen2-1 & Col-3, gl1 & & Lipka et al., 2005 \\
\hline pen2-2 & Col-0 & GABI-KAT 134C04 & Rosso et al., 2003 \\
\hline cyp81F2-2 & Col-0 & GABI-KAT 097D04 & Rosso et al., 2003 \\
\hline pen3-1 pen2-3 & Col-0 & & Stein et al., 2006 \\
\hline
\end{tabular}


Tab. 2.7: Verwendete einfach transgene Fluoreszenzmarkerlinien

\begin{tabular}{|c|c|c|}
\hline Linie & Genotyp & Selektionsmarker \\
\hline CYP81F2-RFP & 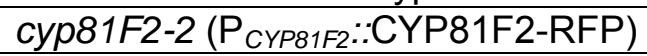 & BASTA \\
\hline GFP & Col-0 ( $\mathrm{P}_{355}::$ GFP $)$ & Kan \\
\hline GFP-APX3 ${ }^{1)}$ & $B M\left(\mathrm{P}_{355::: G F P-A P X 3)}\right.$ & Kan \\
\hline GFP-PEN2 ${ }_{\text {Cterm }}$ & 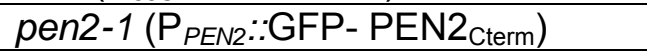 & Kan \\
\hline $\mathrm{mt}^{-\mathrm{ck}^{2}}$ & Col-0 ( $\left.\mathrm{P}_{35 s}:: \mathrm{mt}-\mathrm{ck}\right)$ & Kan \\
\hline $\mathrm{mt}^{-\mathrm{gk}^{2}}$ & Col-0 ( $\left(P_{355}:: m t-g k\right)$ & Kan \\
\hline mt-rk & Col-3, gl1 ( $P_{355}::$ mt-rk) & Kan \\
\hline mt-rk & pen2-1 ( $\left(\mathrm{P}_{355}:\right.$ :mt-rk) & Kan \\
\hline PEN2-GFP ${ }^{3)}$ & pen2-1 (P $P_{P E N 2::: P E N 2-G F P)}$ & BASTA \\
\hline PEN2-GFP- $\Delta$ C3 & 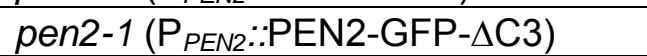 & BASTA \\
\hline PEN2-GFP- $\triangle \mathrm{C} 4$ & pen2-1 (P (PEN2::PEN2-GFP- $\triangle \mathrm{C} 4)$ & BASTA \\
\hline PEN2-GFP- $\Delta$ C5 & 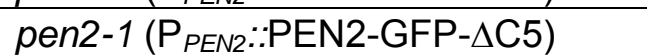 & BASTA \\
\hline PEN2-GFP- $\Delta$ Cterm & pen2-1 (P (PEN2::PEN2-GFP- $\Delta$ Cterm) & BASTA \\
\hline PEN2-GFP- $\triangle T M$ & 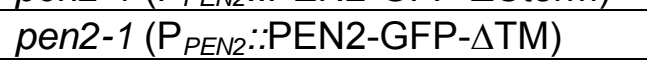 & BASTA \\
\hline PEN2-GFP-APX3 ${ }_{\text {Cterm }}$ & pen2-1 $\left(\mathrm{P}_{P E N 2}:\right.$ PEN2-GFP-APX3 $\left.{ }_{\text {cterm }}\right)$ & BASTA \\
\hline PEN2-GFP ${ }^{\mathrm{K} 556 \mathrm{G}}$ & pen2-1 ( P PEN2 $::$ PEN2-GFP $\left.^{K 5666}\right)$ & BASTA \\
\hline PEN2-RFP & 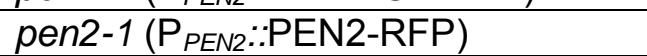 & BASTA \\
\hline PEN2-RFP & pen3-1 pen2-3 ( $\mathrm{P}_{P E N 2}::$ PEN2-RFP) & BASTA \\
\hline PEN3-GFP ${ }^{4)}$ & pen3-1 $\mathrm{P}_{P E N 3}:$ :PEN3-GFP) & Kan \\
\hline $\mathrm{px}-\mathrm{ck}^{2)}$ & Col-0 ( $\left.\mathrm{P}_{355}: .: \mathrm{px}-\mathrm{ck}\right)$ & Kan \\
\hline px-rk & Col-3, gl1 ( $\mathrm{P}_{355}::$ px-rk) & Kan \\
\hline px-rk & pen2-1 ( $\mathrm{P}_{355}:$ : px-rk) & Kan \\
\hline RFP-PEN4 & pen2-1 ( ( $_{35 s}:$ :RFP-PEN4) & Kan \\
\hline
\end{tabular}

${ }^{1)}$ Narendra et al., 2006; ${ }^{2)}$ Nelson et al., 2007; ${ }^{3)}$ Lipka et al., 2005; ${ }^{4)}$ Stein et al., 2006

Tab. 2.8: Verwendete doppeltransgene Fluoreszenzmarkerlinien

\begin{tabular}{|c|c|}
\hline Line & Genotyp \\
\hline ER-ck x CYP81F2-RFP & cyp81F2-2 ( $\mathrm{P}_{\text {CYP81F2: }: \text { CYP81F2-RFP }}$ x $\mathrm{P}_{355}::$ ER-ck $)$ \\
\hline ER-rk x PEN2-GFP & 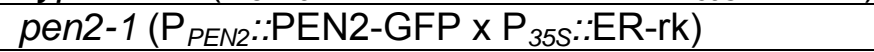 \\
\hline G-rk x PEN2-GFP & 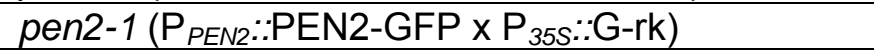 \\
\hline mt-rk x GFP-PEN2 ${ }_{\text {Cterm }}$ & pen2-1 ( $P_{P E N 2}::$ GFP- PEN2 ${ }_{\text {cterm }} \times P_{35 s:: \text { mt-rk })}$ \\
\hline mt-rk x PEN2-GFP & pen2-1 ( $\left.\mathrm{P}_{\text {PEN2 }:: \mathrm{PEN} 2-G F P} \times \mathrm{P}_{35 \mathrm{~S}}:: \mathrm{mt}-\mathrm{rk}\right)$ \\
\hline mt-rk x PEN2-GFP-APX3 $3_{\text {cterm }}$ & 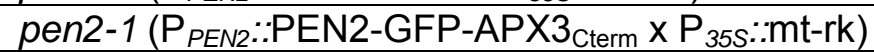 \\
\hline pm-rk x PEN2-GFP & 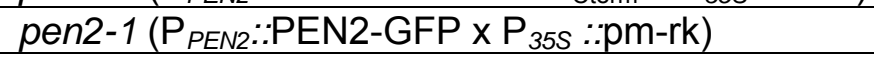 \\
\hline pt-rk x GFP-PEN2 ${ }_{\text {Cterm }}$ & pen2-1 ( P PEN2: $:$ GFP- PEN2 $_{\text {Cterm }} \times \mathrm{P}_{35 s .:: \text { pt-rk })}$ \\
\hline pt-rk x PEN2-GFP & pen2-1 ( $\mathrm{P}_{\text {PEN2 }:: \text { PEN2-GFP }}$ x $\mathrm{P}_{35 \text { s.:.pt-rk) }}$ \\
\hline px-rb x GFP-APX3 & 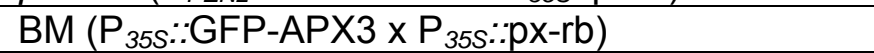 \\
\hline px-rk x GFP-PEN2 ${ }_{\text {Cterm }}$ & pen2-1 ( $P_{P E N 2}::$ GFP- PEN2cterm $\times P_{35 s .:}$ px-rk) \\
\hline px-rk x PEN2-GFP & 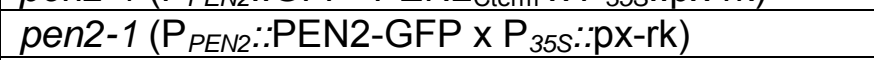 \\
\hline px-rk x PEN2-GFP-APX3 ${ }_{\text {Cterm }}$ & 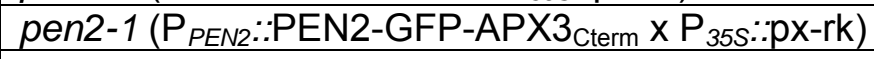 \\
\hline RFP $\times$ PEN2-GFP- $\Delta$ TM & 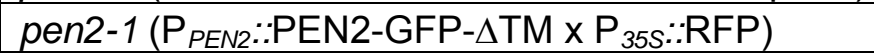 \\
\hline RFP-APX3 x mt-gk & Col-0 $\left(\mathrm{P}_{35 \mathrm{~s}}:: \mathrm{mt}-\mathrm{gk} \times \mathrm{P}_{A P X 3}::\right.$ RFP-APX3) \\
\hline RFP-APX3 x px-ck & Col-0 ( $\left.P_{35 s .:: p x-c k} \times P_{A P X 3}:: R F P-A P X 3\right)$ \\
\hline RFP-PEN4 x PEN2-GFP & 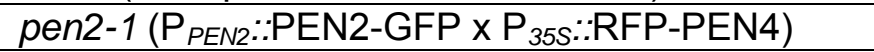 \\
\hline RFP-TOM20-4 x mt-gk & Col-0 $\left(\mathrm{P}_{35 \mathrm{~s}}:: \mathrm{mt}-\mathrm{gk} \times \mathrm{P}_{35 \mathrm{~s}}::\right.$ RFP-TOM20-4) \\
\hline RFP-TOM20-4 x PEN2-GFP & 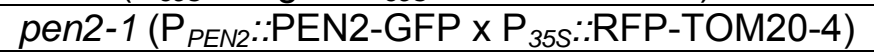 \\
\hline RFP-TOM20-4 x px-ck & 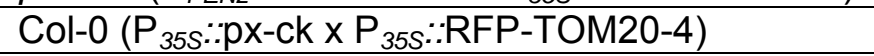 \\
\hline
\end{tabular}


Tab. 2.9: Verwendete Kreuzungen unterschiedlicher Linien

\begin{tabular}{|c|c|c|}
\hline$\hat{\sigma}$-Linie & & Q-Linie \\
\hline$B M\left(\mathrm{P}_{35 \mathrm{~s}:: \mathrm{GFP}-\mathrm{APX} 3)}\right.$ & $x$ & Col-0 ( $\mathrm{P}_{35 \mathrm{~s}:: \mathrm{mt}-\mathrm{ck})}$ \\
\hline 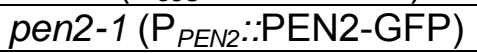 & $\mathrm{x}$ & cyp81F2-2 ( $\mathrm{P}_{\text {CYP81F2::CYP81F2-RFP) }}$ \\
\hline pen2-1 ( $\mathrm{P}_{P E N 2: .: P E N 2-R F P)}$ & $x$ & 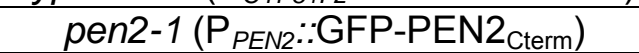 \\
\hline pen2-1 ( $\mathrm{P}_{\text {PEN2 }:: P E N 2-R F P)}$ & $\mathrm{x}$ & pen2-1 ( $\mathrm{P}_{\text {PEN2 }:: P E N 2-G F P)}$ \\
\hline pen2-1 ( $\mathrm{P}_{P E N 2:: \mathrm{PEN} 2-\mathrm{RFP})}$ & $x$ & pen2-1 (P $\mathrm{P}_{P E N 2:: \text { PEN2-GFP- } \triangle T M)}$ \\
\hline pen2-1 ( P PEN2::PEN2-RFP) & $x$ & 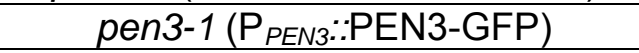 \\
\hline
\end{tabular}

\subsection{Methoden}

\subsubsection{Anzucht von Bakterien}

Zur Kultivierung von Bakterien über einen gewissen Zeitraum hinweg wurde, je nach Bakterienstamm, LB-Medium (10 g/l Trypton, $5 \mathrm{~g} / \mathrm{l}$ Hefeextrakt, $5 \mathrm{~g} / \mathrm{l} \mathrm{NaCl}, \mathrm{pH} 7$ ) und $15 \mathrm{~g} / \mathrm{l}$ Agar für Escherichia coli (E. coli) bzw. dYT-Medium (16 g/l Trypton, $10 \mathrm{~g} / \mathrm{l}$ Hefeextrakt, $10 \mathrm{~g} / \mathrm{l}$ $\mathrm{NaCl}$ ) und $15 \mathrm{~g} / \mathrm{l}$ Agar für Agrobakterien verwendet. Dazu wurde eine Kultur von Bakterien mit einer sterilen Impföse nach der Drei-Strich-Ausstrich-Methode auf Agar mit dem jeweiligen Medium und den für den Stamm spezifischen Selektionsmarkern ausplattiert. Die Inkubationstemperatur sowie die Länge der Inkubation wurde gemäß den Wuchsbedingungen des Bakterienstamms angeglichen. Für E. coli betrugen diese Parameter $37^{\circ} \mathrm{C}$ über Nacht während Agrobakterien zwei Tage bei $28{ }^{\circ} \mathrm{C}$ inkubiert wurden. Die anschließende Lagerung der Platten erfolgte bei $4{ }^{\circ} \mathrm{C}$ im Kühlschrank. Flüssigkulturen wurden bei den entsprechenden Temperaturen und $180 \mathrm{rpm}$ im Inkubationsschüttler geschüttelt. Für eine längere Lagerzeit wurden Glycerolstocks hergestellt und bei $-80{ }^{\circ} \mathrm{C}$ gelagert. Dazu wurden Vorkulturen des jeweiligen Stammes angezogen und die Bakterien bei 4500 rpm pelletiert. Nachdem der Überstand verworfen worden war, wurde das Pellet unverzüglich in sterilem $60 \%$ igem Glycerol resuspendiert und in flüssigem Stickstoff schockgefroren.

\subsubsection{Herstellung und Transformation kompetenter E. coli-Zellen}

Die in diesem Labor verwendeten Zellen wurden als chemisch kompetente E. coli-Zellen mit der Rubidiumchlorid-Methode hergestellt. Hierfür wurden zunächst $5 \mathrm{ml}$ dYT-Medium ohne weitere Selektionsmarker mit TOP10 E. coli-Zellen angeimpft und über Nacht bei $37^{\circ} \mathrm{C}$ und 180 rpm im Schüttelinkubator kultiviert. Diese Vorkultur wurde zum Animpfen von $500 \mathrm{ml}$ dYT-Medium eingesetzt und bis $z u$ einer $O D_{600}=0,5$ für ca. drei Stunden im Schüttelinkubator angezogen. Anschließend wurden die Zellen mittels Zentrifugation nach 
einer 15-minütigen Inkubation auf Eis bei $4{ }^{\circ} \mathrm{C}$ und $4000 \mathrm{rpm}$ in sterilen Behältern pelletiert. Das Pellet wurde in $80 \mathrm{ml}$ TFB1-Puffer resuspendiert und erneut nach einer weiteren 15minütigen Inkubation auf Eis abzentrifugiert $\left(4^{\circ} \mathrm{C}, 4000 \mathrm{rpm}\right)$. Die pelletierten Zellen wurden in $8 \mathrm{ml}$ TFB2-Puffer resuspendiert und für die nachfolgende Verwendung in Einheiten von 50 $\mu \mathrm{l}$ aliquotiert. Nach Schockgefrieren in flüssigem Stickstoff konnten die Zellen anschließend bei $-80{ }^{\circ} \mathrm{C}$ aufbewahrt werden.

Die chemisch kompetenten Zellen konnten nun für die Transformation von DNA mittels Hitzeschock herangezogen werden. Dazu wurden zu $50 \mu$ l kompetenter, auf Eis aufgetauter Zellen ca. 10 bis 25 ng Plasmid-DNA eines Ligationsansatzes gegeben und vorsichtig gemischt. Nach einer Inkubation auf Eis für 10 Minuten erfolgte der Hitzeschock für 60 Sekunden bei $42{ }^{\circ} \mathrm{C}$, gefolgt von einer erneuten 10-minütigen Inkubationszeit auf Eis. Nach Zugabe von $800 \mu \mathrm{l}$ sterilem dYT-Medium wurden die Zellen für eine Stunde bei $37^{\circ} \mathrm{C}$ unter leichtem Schütteln (180 rpm) angezogen. Abschließend erfolgte die Ausplattierung der transformierten Zellen auf antibiotika-haltigem Medium.

\subsubsection{Herstellung und Transformation kompetenter Agrobakterien}

Zur Herstellung elektrokompetenter Agrobakterien wurden die Zellen zunächst für 2 Tage bei $28{ }^{\circ} \mathrm{C}$ auf dYT-Agarplatten kultiviert. Mit einer Einzelkolonie wurden im Folgenden $5 \mathrm{ml}$ dYT-Medium angeimpft und für weitere 2 Tage bei $28{ }^{\circ} \mathrm{C}$ unter Schütteln (180 rpm) inkubiert. Mit dieser Vorkultur erfolgte die Animpfung der Hauptkultur (500 ml dYT-Medium), die bis zu einer $\mathrm{OD}_{600}=0,5$ wachsen gelassen und bei $4{ }^{\circ} \mathrm{C}$ und $4000 \mathrm{rpm}$ für 15 Minuten anschließend abzentrifugiert wurde. Das Pellet wurde in $100 \mathrm{ml}$ eiskaltem sterilen Aqua dest. resuspendiert und erneut bei $4{ }^{\circ} \mathrm{C}$ und $4000 \mathrm{rpm}$ zentrifugiert. Anschließend nahm man das Pellet in $50 \mathrm{ml}$ eiskaltem Wasser auf und überführte die Lösung in ein steriles FalkonGefäß. Nach wiederholter Zentrifugation mit gleichen Parametern homogenisierte man das Pellet in $800 \mu \mathrm{l}$ eiskaltem, $10 \%$ igem Glycerol. Die kompetenten Zellen konnten nun in $50 \mu \mathrm{l}-$ Einheiten aliquotiert und bei $-80^{\circ} \mathrm{C}$ eingelagert werden.

Die elektrokompetenten Agrobacterium tumefaciens-Zellen des Stammes GV3101 bzw. GV3101 pMP90RK wurden für Experimente der vorliegenden Arbeit durch Elektroporation mit Plasmid-DNA transformiert. Hierfür wurde ein auf Eis aufgetautes Aliquot kompetenter Zellen vorsichtig mit 0,5 bis $1 \mu \mathrm{g}$ DNA einer Plasmid-Präparation gemischt. Anschließend wurden die Zellen in eine vorgekühlte Elektroporations-Küvette transferiert und mittels Elektroporator transformiert $(25 \mu \mathrm{F}, 2,5 \mathrm{kV}, 400 \Omega)$. Hiernach wurden die Zellen erneut auf Eis überführt und $600 \mu \mathrm{l}$ steriles dYT-Medium zugegeben. Nach mehrmaligem Auf- und Abpippettieren wurden die Zellen aus der Küvette in ein 1,5 ml Reaktionsgefäß überführt. 
Die anschließende Inkubation der Zellen erfolgte bei $29^{\circ} \mathrm{C}$ und $180 \mathrm{rpm}$ für ca. 1 Stunde, wonach der Ausstrich auf Selektivmedium erfolgte.

\subsubsection{Extraktion genomischer DNA aus Pflanzen}

Zur Extraktion genomischer DNA wurden zwei Arabidopsis-Blättchen mit Edwards-Puffer im Reaktionsgefäß gemörsert und anschließend bei $65^{\circ} \mathrm{C}$ für 10 Minuten inkubiert. Nach einer 10-minütigen Lagerung auf Eis wurde den Proben $200 \mu \mathrm{l}$ eisgekühltes Chloroform hinzugesetzt und durch Vortexen gut gemischt. Hiernach wurden die Zellbestandteile bei 13000 rpm für 10 Minuten abzentrifugiert und die obere Phase in ein neues Reaktionsgefäß überführt. Die Fällung der DNA erfolgte mit $300 \mu$ l eiskaltem Isopropanol, wonach sich eine erneute Zentrifugation bei Raumtemperatur (10 min; $13000 \mathrm{rpm}$ ) anschloss. Das Pellet wurde mit $1 \mathrm{ml} 70$ \%igem Ethanol gewaschen und erneut abzentrifugiert. Nach vollständigem Trockenen des Pellets konnte dieses in $100 \mu \mathrm{l}$ TE-Puffer aufgenommen und gelöst werden. Die auf diese Weise isolierte DNA wurde zur Genotypisierung von transgenen Linien verwendet. Die Lagerung der genomischen DNA erfolgte bei $-20{ }^{\circ} \mathrm{C}$.

\subsubsection{Extraktion von RNA aus Pflanzen}

Das Alter der zur Extraktion von RNA herangezogenen Pflanzen betrug innerhalb der vorliegenden Arbeit höchstens 6 Wochen. Dazu wurden die Blätter nach der Ernte unverzüglich in flüssigem Stickstoff tiefgefroren und unter Zugabe desselbigen gemörsert. Hiernach aliquotierte man das Pflanzenmaterial zu jeweils $100 \mathrm{mg}$ und versetzte die Proben mit $1 \mathrm{ml}$ Qiazol (Qiagen, Venlo, Niederlande). Für ca. 10 Minuten wurden die Proben auf dem Schüttler gut gemischt und anschließend mit $200 \mu \mathrm{l}$ Chloroform versetzt. Erneut erfolgte eine 10-minütige Schüttelphase bevor das Zellmaterial schließlich bei 13000 rpm für eine Stunde bei $4{ }^{\circ} \mathrm{C}$ abzetrifugiert wurde. Die obere Phase wurde in ein neues Reaktionsgefäß überführt, mit $500 \mu \mathrm{l}$ Isopropanol versetzt und nach einer 10-minütigen Inkubationsphase erneut abzentrifugiert (13000 rpm; $15 \mathrm{~min} ; 4{ }^{\circ} \mathrm{C}$ ). Das Pellet wurde vorsichtig vom Isopropanol befreit, mit 70 \%igem Ethanol gewaschen und erneut abzentrifugiert (13000 rpm; $10 \mathrm{~min} ; 4^{\circ} \mathrm{C}$ ). Nach der Trocknung konnte das Pellet in $50 \mu \mathrm{l}$ autoklaviertem und RNase-freiem destillierten Wasser resuspendiert werden.

Um die letzten Rückstände an DNA zu entfernen, wurde ein DNase-Verdau mit Hilfe des Qiagen-Kits durchgeführt. 


\subsubsection{Reverse Transkription zur Herstellung von cDNA}

Für den Einsatz der aus Pflanzen isolierten RNA in weiteren Experimenten wie der semiquantitativen RT-PCR musste diese zunächst in cDNA umgeschrieben werden. Dies geschah in der vorliegenden Arbeit mit Hilfe des RevertAid ${ }^{\mathrm{TM}} \mathrm{H}$ Minus Reverse Transcriptase Kits von Fermentas (St. Leon-Rot), das eine reverse Transkriptase und andere für die Reaktion benötigten Komponenten beinhaltet. Dazu wurden ca. 1,5 $\mu \mathrm{g}$ RNA mit den entsprechenden Komponenten aus dem Kit versehen und für eine Stunde bei $42{ }^{\circ} \mathrm{C}$ inkubiert. Die Reaktion wurde durch Erhöhung der Temperatur auf $70{ }^{\circ} \mathrm{C}$ für 10 Minuten gestoppt und anschließend bei $-20^{\circ} \mathrm{C}$ gelagert. Für die darauf folgende semiquantitative RTPCR wurde eine 1:10 Verdünnung der gebildeten cDNA als Template verwendet.

\subsubsection{Amplifikation von DNA in der PCR}

Für die Vervielfältigung eines definierten DNA-Abschnitts in vitro dienten in der vorliegenden Arbeit die Enzyme Pfu (Pyrococcus furiosus) DNA-Polymerase und DreamTaq ${ }^{\mathrm{TM}}$ (Thermus aquaticus) DNA-Polymerase von Fermentas (St. Leon-Rot), die mit den weiteren Komponenten des Kits nach den Herstellerangaben gemischt wurden. In Tabelle 2.10 sind die Konditionen der PCR angegeben, die je nach Größe der zu amplifizierenden DNASequenz bzw. Beschaffenheit der Primer entsprechend angepasst wurden. Dieses Verfahren wurde sowohl für die Klonierung, als auch für die semiquantitative RT-PCR und Kolonie-PCR herangezogen.

Tab. 2.10: Konditionen der PCR

\begin{tabular}{|l|l|l|l|}
\hline Schritt & Temperatur & Zeit & Zyklen \\
\hline Denaturierung & $95^{\circ} \mathrm{C}$ & $2 \mathrm{~min}$ & $1 \mathrm{x}$ \\
\hline Denaturierung & $95^{\circ} \mathrm{C}$ & $30 \mathrm{sek}$ & \multirow{2}{*}{$25-35 \mathrm{x}$} \\
\hline Annealing & $50-65^{\circ} \mathrm{C}$ & $30 \mathrm{sek}$ & \\
\cline { 1 - 3 } Elongation & $72{ }^{\circ} \mathrm{C}$ & $\begin{array}{l}1 \mathrm{~min} / \mathrm{kbp}(\text { DreamTaq } \\
2 \mathrm{~min} / \mathrm{kbp}(\mathrm{Pfu})\end{array}$ & $1 \mathrm{x}$ \\
\hline Extension & $72{ }^{\circ} \mathrm{C}$ & $5-10 \mathrm{~min}$ & \\
\hline
\end{tabular}

\subsubsection{Agarose-Gelelektrophorese}

Die Auftrennung von DNA und RNA erfolgte mit Hilfe der Gelelektrophorese bei $90 \mathrm{~V}$ für ca. 45 Minuten. Dazu wurde ein entsprechendes Volumen der aufzutrennenden NukleinsäureLösung mit 6x DNA-Ladepuffer versetzt und auf ein 0,5 bis 2 \%iges Agarosegel als Träger geladen. Als Laufpuffer diente TAE-Puffer. Die Anfärbung der Nukleinsäuren im Gel erfolgte mit Ethidiumbromid (1 Tropfen Ethidiumbromid-Lösung pro $50 \mathrm{ml}$ Agarosegel, Roth, 
Karlsruhe), das zwischen den Basen der DNA interkaliert und mittels UV-Strahlung detektiert werden kann. Zu Klonierungszwecken wurden die DNA-Fragmente aus dem Gel ausgeschnitten und anschließend mit dem NucleoSpinExtract II Kit der Firma MachereyNagel (Düren) extrahiert.

\subsubsection{Plasmidpräparation}

Die Isolierung von Plasmiden aus Zellen von E. coli oder Agrobakterien erfolgte mittels alkalischer Lyse. Hierfür wurden zunächst 5 ml LB-Flüssigmedium mit dem Bakterienstamm angeimpft, die entsprechenden Antibiotika hinzugefügt und für ein bis zwei Tage im Schüttelinkubator kultiviert. Anschließend wurden die Zellen in ein $2 \mathrm{ml}$ Reaktionsgefäß überführt und bei Raumtemperatur und $6000 \mathrm{rpm}$ für 5 Minuten abzentrifugiert. Die Resuspendierung des Bakterienpellets erfolgte in $200 \mu$ L Lyse-Puffer I (siehe Tab. 2.5). Nach Zugabe von $200 \mu$ l Lyse-Puffer II schwenkte man das Gefäß vorsichtig vier- bis sechsmal um $180^{\circ}$ und fügte sofort $200 \mu \mathrm{l}$ Lyse-Puffer III hinzu. Das Gefäß wurde erneut vorsichtig über Kopf geschwenkt und bei Raumtemperatur und 13000 rpm für 10 Minuten zentrifugiert. Der entstandene Überstand wurde in ein neues Reaktionsgefäß überführt und mit $450 \mu \mathrm{l}$ eiskaltem Isopropanol versetzt, was zur Fällung der Plasmid-DNA führte. Diese wurde für 10 Minuten bei 13000 rpm pelletiert und mit 70 \% Ethanol gewaschen. Nach Lufttrocknung konnte die Plasmid-DNA in sterilem TE-Puffer aufgenommen und für weitere Zwecke verwendet werden.

\subsubsection{Restriktionsverdau und Ligation}

Der Restriktionsverdau von Plasmid-DNA oder der in der PCR amplifizierten DNA erfolgte in der Regel bei $37{ }^{\circ} \mathrm{C}$ für ein bis drei Stunden im Thermomixer. Dazu wurde die zu schneidende DNA in ein Reaktionsgefäß mit den jeweiligen Restriktionsenzymen und dem entsprechenden Puffer nach Herstellerangaben pipettiert. Nach dem Verdau erfolgte entweder die direkte Aufreinigung des Reaktionsansatzes mit Hilfe des NucleoSpinExtract II Kits der Firma Macherey-Nagel (Düren) oder eine vorgeschaltete Auftrennung der Fragmente durch die Gelelektrophorese.

Für die Ligation der Plasmid-DNA (Vektor) mit dem DNA-Fragment (Insert) wurde die T4 DNA-Ligase von Fermentas (St. Leon-Rot) verwendet und ein Verhältnis von 1:5 von Vektor zu Insert für den Reaktionsansatz gewählt. Die Ligations-Reaktion erfolgte in einem Gesamtvolumen von $10 \mu \mathrm{l}$ bei $16{ }^{\circ} \mathrm{C}$ über Nacht oder für drei Stunden bei $18{ }^{\circ} \mathrm{C} \mathrm{im}$ Thermomixer. Anschließend konnte der Ligationsansatz in kompetente E. coli-Zellen transformiert oder bei $-20^{\circ} \mathrm{C}$ gelagert werden. 


\subsubsection{Kolonie-PCR}

Nach Transformation der kompetenten E. coli-Zellen mit dem Ligationsansatz und anschließender Selektion auf antibiotika-haltigen LB-Agarplatten wurde die Integration des Inserts in den Vektor mittels Kolonie-PCR überprüft. Hierfür wurde ein Teil der Bakterienkolonie mit einer Pipettenspitze in ein Reaktionsgefäß mit $100 \mu$ Aqua dest. transferiert, gevortext und anschließend bei $95{ }^{\circ} \mathrm{C}$ für 10 Minuten inkubiert. Die so entstandene Lösung diente als Template ( 1 bis $2 \mu \mathrm{l}$ pro $50 \mu \mathrm{l} \mathrm{PCR-Reaktionsansatz)} \mathrm{für} \mathrm{die}$ PCR. Mit Hilfe bestimmter Primer-Kombinationen, die innerhalb und außerhalb des Fragments binden, konnte eine erfolgreiche Insertion des Fragments in den Vektor überprüft werden.

\subsubsection{Sequenzanalyse von Plasmiden}

Um ganz sicher zu gehen, dass das Insert im Plasmid in der korrekten Nukleotidabfolge vorlag, erfolgte eine Sequenzierung des Fragments. Hierfür wurden in einem Gesamtvolumen von $7 \mu \mathrm{l}$ ca. 600 bis $700 \mathrm{ng}$ Plasmid-DNA zusammen mit 20 pmol Primer angesetzt, zur Firma Seqlab (Göttingen) geschickt, die die Sequenzierung im Extended Hot Shot Verfahren durchführte. Die darauf folgende Analyse der Sequenzinformationen erfolgte mit Hilfe der Software Clone Manager Professional Suite Version 8 (Scientific \& Educational Software, USA).

\subsubsection{Proteinextraktion aus Pflanzen}

Für die Extraktion der Proteine wurde das Blattmaterial in flüssigem Stickstoff mit einer kleinen Spatelspitze voll Sand gemörsert und anschließend bei $-80{ }^{\circ} \mathrm{C}$ gelagert oder mit GTEN-Puffer plus Protease-Inhibitor-Cocktail von Sigma-Aldrich (Steinheim) im Verhältnis von $100 \mathrm{mg}$ Pflanzenmaterial zu $300 \mu \mathrm{l}$ GTEN-Puffer weiter verarbeitet. Um eine Degradation der Proteine zu verhindern, wurden die Proben stets auf Eis gehalten. Der entstandene Rohextrakt wurde daraufhin in ein Eppendorfreaktionsgefäß überführt und bei 13000 rpm und $4{ }^{\circ} \mathrm{C}$ für 10 Minuten abzentrifugiert. Nach der Zentrifugation erfolgte ein Transfer des Überstandes in ein neues Reaktionsgefäß. Abschließend wurde die Proteinkonzentration mit Hilfe des Bradford-Tests bestimmt und die Proben bei $-20{ }^{\circ} \mathrm{C}$ gelagert. Die so gewonnenen Proteinextrakte wurden für Western-Blot-Analysen und Immunopräzipitationsexperimente verwendet. 


\subsubsection{Quantitative Bestimmung von Proteinen}

Zur quantitativen Bestimmung von Proteinen wurde der Bradford-Test (Bradford, 1976) bzw. das von Lowry et al. (1951) entwickelte Verfahren herangezogen. Bei beiden Tests handelt es sich um eine photometrische Methode, mit deren Hilfe sich Gesamtproteingehalte verschiedener Extrakte ermitteln lassen. Zu diesem Zweck wurden $2 \mu \mathrm{l}$ der unverdünnten Proteinextrakte mit $998 \mu \mathrm{l}$ 1x Roti-Quant Bradford-Färbelösung von Roth (Karlsruhe) gemischt und die Absorption bei $595 \mathrm{~nm}$ gemessen.

Für die Proteingehaltsbestimmung nach Lowry wurden die Reagenzien $A$ und $B$ im Verhältnis 50:1 gemischt (Tab 2.5). Von dieser Lösung wurde $1 \mathrm{ml}$ zur verdünnten Proteinprobe $(100 \mu \mathrm{l})$ pipettiert, gemischt und für 10 Minuten bei Raumtemperatur inkubiert. Danach erfolgte eine Zugabe von $100 \mu$ Folin-Ciocalteu's Phenol-Reagenz, das zuvor im Verhältnis 1:1 mit Aqua dest. verdünnt wurde. Anschließend erfolgte eine weitere Inkubation der Probe bei Raumtemperatur für 30 Minuten. Die Absorption der Lösung wurde bei 750 $\mathrm{nm}$ gemessen. Um eine Trübung der Proben durch Triton X-100 zu verhindern, wurde gegebenenfalls eine $0,1 \%$ ige SDS-Lösung zum Reagenz A hinzugefügt.

Zur Erstellung der Eichkurve wurde eine BSA-Stammlösung $(1 \mathrm{mg} / \mathrm{ml})$ verwendet und nach Herstellung einer entsprechenden Verdünnungsreihe in der jeweiligen Methode eingesetzt.

\subsubsection{SDS-Polyacrylamid Gelelektrophorese}

Die Auftrennung der Proteine erfolgte aufgrund der Anlagerung des negativ geladenen SDSMoleküls nach dem Molekulargewicht. Dazu wurde der Proteinextrakt mit einer entsprechenden Menge an Lämmli-Ladepuffer versetzt. Die Größenbestimmung erfolgte mittels des Proteinmarkers PageRuler ${ }^{\mathrm{TM}}$ Plus Prestained Protein Ladder von Fermentas (St. Leon-Rot). Für die elektrophoretische Auftrennung wurde ein SDS-Polyacrylamidgel gegossen, das aus einem Sammelgelbereich und einem Trenngelbereich bestand. In Tabelle 2.5 ist die Zusammensetzung des Sammel- und des Trenngels aufgeführt. Hierzu wurde zunächst das Trenngel zusammengemischt, in die Gießkammer bis ca. $2 \mathrm{~cm}$ unter den Rand gefüllt und anschließend mit Isopropanol überschichtet. Nach 45 Minuten war die Polymerisation weitgehend abgeschlossen. Daraufhin wurde das Isopropanol entfernt, das Sammelgel in die Kammer gegossen und ein Kamm eingeführt. Die Gießkammer wurde nach 45 Minuten aus der Halterung gelöst, in die Elektrophorese-Apparatur überführt und mit SDS-Laufpuffer überschichtet. Je nach Geltaschengröße und Proteinkonzentration wurde ein Probenvolumen von 30 bis $70 \mu$ geladen. Die elektrophoretische Auftrennung der Proteine erfolgte für ca. 90 Minuten bei $120 \mathrm{~V}$. 


\subsubsection{Blue-Native-PAGE}

Zur Auftrennung der Proteine in der Blue-Native-PAGE (PAGE - PolyacrylamidGelelektrophorese) wurden die NativePAGE ${ }^{\text {TM }}$ Novex® 3-12 \% Bis-Tris Gele von Invitrogen life technology ${ }^{\mathrm{TM}}$ (Carlsbad, USA) und die dazugehörige Elektrophorese-Apparatur den Herstellerangaben entsprechend verwendet. Hierzu wurde die Proteinprobe zunächst mit NativePAGE ${ }^{\mathrm{TM}}$ Probenpuffer verdünnt und Digitonin als Detergenz in einer Endkonzentration von $1 \%$ hinzugefügt. Die Elektrophorese erfolgte zunächst bei $150 \mathrm{~V}$ für 60 Minuten und dann für weitere 60 bis 90 Minuten bei $250 \mathrm{~V}$ im Kühlraum bei $4{ }^{\circ} \mathrm{C}$. Als Kathodenpuffer diente der NativePAGE ${ }^{\text {TM }}$ Laufpuffer mit 0,002 \% Coomassie G-250 („light blue cathode buffer").

\subsubsection{Western-Blot-Analysen}

Für den Transfer der Proteine nach der SDS-PAGE bzw. Blue-Native-PAGE auf eine PVDFMembran wurde das entsprechende Gel aus der Gelhalterung entfernt und in die Transferkammer Mini Trans-Blot der Firma Bio-Rad (Hercules, USA) überführt. Das Gel wurde dazu auf drei Lagen Transfer-Puffer getränktes Whatman-Papier gelegt, darauf folgte die Membran, die zuvor für wenige Sekunden in Methanol geschwenkt wurde, und abschließend drei weitere Lagen feuchtes Whatman-Papier. Anschließend erfolge der Transfer der Proteine auf die PVDF-Membran in der Elektrophorese-Apparatur, wobei der Protein-Transfer aus der SDS-PAGE bei $100 \mathrm{~V}$ für eine Stunde und der aus der Blue-NativePAGE bei $30 \vee$ für zwei Stunden erfolgte. Zur Fixierung der aus der Blue-Native-PAGE transferierten Proteine auf der PVDF-Membran wurde diese in 8 \%iger Essigsäure für 15 Minuten geschwenkt.

Nach dem Western-Blot wurde die Membran für eine Stunde auf dem Inkubationsschüttler in Blockierungspuffer leicht geschüttelt. Die anschließende Inkubation erfolgte mit dem primären Antikörper über Nacht bei $4{ }^{\circ} \mathrm{C}$. Dazu wurde der zuvor verwendete Blockierungspuffer entfernt und durch frischen Blockierungspuffer ersetzt, welcher den Antikörper in einer Verdünnung von 1:5000 oder 1:10000 enthielt. Nach drei Waschschritten mit TBS-T für jeweils 10 Minuten erfolgte die sekundäre Antikörperinkubation (Verdünnung des Antikörpers 1:5000 bzw. 1:10000) für eine Stunde bei Raumtemperatur. Daraufhin wurde die Membran erneut unter leichtem Schütteln dreimal für 10 Minuten mit TBS-T gewaschen und abschließend für 10 Minuten in AP-Puffer inkubiert. Der gebundene Antikörper wurde durch Chemiluminiszenz nach Zugabe des Substrats Immun-Star AP von Bio-Rad (Hercules, USA) detektiert. Dazu wurde das Substrat gleichmäßig auf der Membran verteilt und für wenige Minute inkubiert. Die überschüssige Lösung wurde entfernt und die 
Membran in eine Klarsichtfolie transferiert. In der Dunkelkammer wurde ein Röntgenfilm (CEA RP New, CEA, Hamburg) auf die Membran gelegt und in einer Röntgenfilmkassette für 5 bis 45 Minuten exponiert.

Falls die verwendete Membran nicht wieder verwendet wurde, wurde sie zur Dokumentation angefärbt und eingescannt. Hierfür wurde die PVDF-Membran zunächst für eine Minute in Coomassie-Färbelösung geschwenkt und anschließend mit Entfärbelösung für ein bis zwei Minuten gewaschen.

\subsubsection{8 „Strippen“ von Membranen}

Zur erneuten Verwendung von Membranen wurden die gebundenen Antikörper mittels „Strippen“ entfernt. Dazu wurde die Membran in $50{ }^{\circ} \mathrm{C}$ warmem „Stripping“-Puffer für eine Stunde inkubiert. Eine vollständige Entfernung des im Puffer enthaltenden $\beta$-Mercaptoethanols erfolgte durch ein- bis zweistündiges Waschen der Membran mit Aqua dest. Abschließend wurde die Membran für 10 Minuten in TBS-T gewaschen und erneut für eine Stunde in Blockierungspuffer geschüttelt.

\subsubsection{Immunopräzipitation}

Für die Immunopräzipitations- bzw. Koimmunopräzipitationsexperimente wurden die mit einem GFP-Antikörper ummantelten Agarose-Beads (GFP-Trap) der Firma ChromoTek (Martinsried) den Herstellerangaben entsprechend verwendet. Hierzu erfolgte zunächst eine Waschung und Resuspendierung der Agarose-Beads in GTEN-Puffer. Zur Immunopräzipitation der Proteine wurden ca. 30 bis $50 \mu$ l GFP-Trap Agarose-Bead-Lösung pro ml Pflanzenextrakt eingesetzt. Die Inkubation erfolgte unter ständiger Rotation entweder für 90 Minuten bei Raumtemperatur oder über Nacht bei $4{ }^{\circ} \mathrm{C}$. Anschließend wurden die Agarose-Beads durch Zentrifugation bei $2700 \mathrm{~g}$ für zwei Minuten vom Überstand getrennt, drei- bis fünfmal mit eiskaltem GTEN-Puffer gewaschen und in 50 bzw. $100 \mu$ l GTEN-Puffer aufgenommen. Die gebundenen Proteine wurden durch Kochen in Lämmli-Puffer für drei Minuten eluiert und durch Zentrifugation bei $17000 \mathrm{~g}$ für fünf Minuten von den AgaroseBeads getrennt. Das so gewonnene Eluat wurde entweder sofort für Western-Blot-Analysen verwendet oder bei $-20^{\circ} \mathrm{C}$ gelagert.

\subsubsection{Isolierung von Mitochondrien}

Zur Isolierung von Mitochondrien aus Blättern von Arabidopsis wurde das von Holger Eubel (Leibniz Universität Hannover, Institut für Pflanzengenetik) vorgeschlagene Protokoll 
verwendet (persönliche Kommunikation). Dazu erfolgten alle Arbeitsschritte entweder im Kühlraum bei $4{ }^{\circ} \mathrm{C}$ oder auf Eis. Für die Isolierung der Mitochondrien wurden ca. $200 \mathrm{~g}$ Blattmaterial und $600 \mathrm{ml}$ Extraktionspuffer verwendet. Hierzu wurde das Pflanzenmaterial mit Extraktionspuffer in drei Schritten gemörsert und jedes Mal über einen achtschichtigen Mull-Filter filtriert. Dabei mörserte man das jeweils im Filter verbliebene Pflanzenmaterial erneut mit Extraktionspuffer. Anschließend vereinigte man die Homogenate und filtrierte sie erneut über eine vierschichtige Lage aus Miracloth. Nach einem Zentrifugationsschritt bei $2500 \mathrm{~g}$ für fünf Minuten bei $4{ }^{\circ} \mathrm{C}$, wurde der Überstand in ein neues Zentrifugengefäß überführt und die Prozedur bei $24000 \mathrm{~g}$ für 30 Minuten wiederholt. Daraufhin wurde das Pellet in $4 \mathrm{ml} \mathrm{BSA-beinhaltenden} \mathrm{Sucrose-Waschpuffer} \mathrm{(1x)} \mathrm{mit} \mathrm{Hilfe} \mathrm{eines} \mathrm{weichen} \mathrm{Pinsels}$ resuspendiert. Die Mitochondrien-Fraktion wurde zu gleichen Anteilen auf zwei Dichtegradienten geschichtet und für eine Stunde bei $4{ }^{\circ} \mathrm{C}$ und $40000 \mathrm{~g}$ zentrifugiert. Die Herstellung der kontinuierlichen Dichtegradienten erfolgte in einem Gradientmixer der Firma Hoefer (Holliston, USA). Dazu wurden $16 \mathrm{ml}$ der Gradientenlösung ohne PVP-40 bzw. $17 \mathrm{ml}$ der Gradientenlösung mit PVP-40 in die entsprechenden Kammern pipettiert und durch eine Peristaltikpumpe in das Zentrifugenröhrchen transferiert. Nach der Zentrifugation war die Mitochondrien-Fraktion als hellbraune Schicht im unteren Bereich des Dichtegradienten sichtbar. Die oberen Schichten des Gradienten wurden vorsichtig abgesaugt, während die Mitochondrien-Fraktionen in neues Gefäße überführt und mit Sucrose-Waschpuffer ohne BSA dreimal gewaschen wurden (10 min; 24000g; $4{ }^{\circ} \mathrm{C}$ ). Abschließend wurde das Mitochondrien-Pellet in ca. 0,3 bis $1 \mathrm{ml}$ BSA-freiem Sucrose-Waschpuffer aufgenommen und in Western-Blot-Analysen verwendet.

\subsubsection{Isolierung von Peroxisomen}

Die Anreicherung von Peroxisomen erfolgte nach einer vereinfachten Version des von Reumann et al. (2007) publizierten Protokolls. Hierfür wurden zunächst $100 \mathrm{~g}$ Blattmaterial mit $300 \mathrm{ml}$ Extraktionspuffer gemörsert und wie im vorherigen Abschnitt beschrieben filtriert. Der so gewonnene Rohextrakt wurde dann bei $5000 \mathrm{~g}$ für eine Minute bei $4{ }^{\circ} \mathrm{C}$ zentrifugiert. Je $20 \mathrm{ml}$ des Überstandes wurden auf einen diskontinuierlichen Dichtegradienten geladen. Dieser Gradient bestand aus $3 \mathrm{ml} 15 \%$ Percoll-Lösung, $9 \mathrm{ml} 38$ \% Percoll-Lösung und $3 \mathrm{ml}$ $36 \%$ Sucrose-Lösung (Tab. 2.5). Die anschließende Dichtegradientenzentrifugation erfolgte bei $13000 \mathrm{~g}$ für 12 Minuten und für weitere 20 Minuten bei $27000 \mathrm{~g}$. Nach der Zentrifugation wurden die Peroxisomen-Pellets von mehreren Gradienten vereinigt und mit 36 \% SucroseLösung gewaschen (30 min; $27000 \mathrm{~g} ; 4^{\circ} \mathrm{C}$ ). Abschließend erfolgte eine Resuspendierung des Pellets mit einem weichen Pinsel in ca. $500 \mu \mathrm{l} 36$ \% Sucrose-Lösung. 


\subsubsection{Dichtegradientenzentrifugation}

Für die Auftrennung von Organellen in einem kontinuierlichen Dichtegradienten wurde das von Lisenbee et al. (2003) publizierte Protokoll modifiziert. Dazu wurden ca. $20 \mathrm{~g}$ Blattmaterial in $40 \mathrm{ml}$ Extraktionspuffer gemörsert und mittels Lagen aus Mull und Miracloth wie bereits beschrieben filtriert. Die Zentrifugation des Rohextraktes erfolgte bei $4{ }^{\circ} \mathrm{C}$ und $2500 \mathrm{~g}$ für fünf Minuten. Ein Überstand von ca. $30 \mathrm{ml}$ wurde daraufhin auf ein Kissen von 3 $\mathrm{ml} 55 \%$ Sucrose-Lösung geschichtet und anschließend für 45 Minuten bei $100000 \mathrm{~g}$ zentrifugiert. Dieser zusätzliche Zentrifugationsschritt diente der Anreicherung von Organellen im Pellet. Das so entstandene Pellet wurde mit einem entsprechenden Volumen HEPES-Puffer auf eine Sucrose-Konzentration unterhalb von $15 \%$ verdünnt und auf einen kontinuierlichen Dichtegradienten geladen (ca. $5 \mathrm{ml}$ ). Zur Herstellung des Dichtegradienten wurden je $15 \mathrm{ml} 15 \%$ Sucrose-Lösung und $55 \%$ Sucrose-Lösung in die entsprechenden Kammern des Gradientmixers pipettiert und durch eine Peristaltikpumpe in das Zentrifugenröhrchen transferiert. Die Ultrazentrifugation erfolgte bei $4{ }^{\circ} \mathrm{C}$ und $100000 \mathrm{~g}$ für ca. 14 bis 18 Stunden in dem AH-629 Rotor der Firma Thermo Scientific (Waltham, USA). Abschließend wurde der Dichtegradient zu je 1,5 ml fraktioniert und bei $-20{ }^{\circ} \mathrm{C}$ gelagert.

Zur Bestimmung der Proteinkonzentration der einzelnen Fraktionen wurde zunächst eine Fällung der Proteine mittels TCA (Trichloressigsäure)-Fällung mit darauf folgender Konzentrationsbestimmung nach Lowry et al. (1951) durchgeführt. Dazu wurde ein entsprechendes Probenvolumen mit Aqua dest. auf $1 \mathrm{ml}$ aufgefült und mit je $100 \mu \mathrm{l}$ 0,15 \%iger DOC (Natriumdesoxycholat)-Lösung bzw. 72 \%iger TCA-Lösung gemischt. Die Fällung erfolgte für 10 Minuten bei Raumtemperatur. Zur Abtrennung der Lösung wurde die Probe für 15 Minuten bei $17000 \mathrm{~g}$ zentrifugiert und die präzipitierten Proteine anschließend bei Raumtemperatur getrocknet.

\subsubsection{Pflanzenanzucht}

Für die Aufzucht auf Erde wurden die Samen zunächst auf feuchte Fruhstorfer Erde Typ T 25 fein (Hawita, Vechta) ausgelegt, die zuvor mit Confidor WG70 (Bayer CropScience, Monheim) und Wuxal (Aglukon, Düsseldorf) gegossen wurde (3 g Confidor WG70 und $40 \mathrm{ml}$ Wuxal auf 20 I Wasser). Die weitere Anzucht der Pflanzen erfolgte bei einem Tag-NachtRhythmus von 8 Stunden Licht zu 16 Stunden Dunkelheit, einer Temperatur von 18 bis $22{ }^{\circ} \mathrm{C}$ und einer relativen Luftfeuchtigkeit von 60 bis $70 \%$. Nach ca. 7 bis 10 Tagen wurden die Keimlinge pikiert und vereinzelt (5 Pflanzen pro $9 \times 9 \mathrm{~cm}$ Topf). Zur Induktion der Blüte wurden die Pflanzen unter Langtagbedingungen angezogen (16 Stunden Licht zu 8 Stunden Dunkelheit, 18 bis $22{ }^{\circ} \mathrm{C}$ und 60 bis $70 \%$ relative Luftfeuchtigkeit). 


\subsubsection{Kreuzungen}

Für die Kreuzungen unterschiedlicher Linien von Arabidopsis wurden junge Blüten verwendet, die noch geschlossen und von außen keine weißen Kelchblätter erkennbar waren. Mit Hilfe einer besonders spitzen Pinzette wurden die Kelch- und Staubblätter zunächst entfernt, ohne dabei die Fruchtblätter zu beschädigen. Außerdem wurden die nicht für die Kreuzung verwendeten Blüten und benachbarten Seitentriebe entfernt. Zur Bestäubung der Fruchtblätter wurden die reifen Pollensäcke bereits geöffneter Blüten der Vaterlinie verwendet. Anschließend wurden die Pflanzen zur Samenreife wieder in die Langtagkammer überführt.

\subsubsection{Stabile Transformation von Arabidopsis}

Die stabile Transformation mittels Agrobakterien wurde nach dem „floral dip“-Verfahren nach Clough und Bent (1998) durchgeführt. Hierzu wurden die zu transformierenden Pflanzen zur Ausbildung von Blütenständen unter Langtagsbedingungen angezogen. Diese tauchte man für ca. eine Minute in eine Suspension aus Agrobakterien, die das zu transformierende Plasmid enthielten. Dazu wurde zuerst eine Vorkultur (5 ml dYT-Medium) des bereits transformierten Agrobakterienstammes angeimpft und für zwei Tage im Schüttelinkubator bei $28{ }^{\circ} \mathrm{C}$ und $180 \mathrm{rpm}$ mit den entsprechenden Selektionsmarkern kultiviert. Anschließend wurde die Hauptkultur (500 ml dYT-Medium), die ebenfalls die benötigten Antibiotika enthielt, mit der vollständigen Vorkultur vereinigt und ebenfalls bei $28{ }^{\circ} \mathrm{C}$ und $180 \mathrm{rpm}$ für einen Tag inkubiert. Die so entstandene Bakterienkultur wurde in $500 \mathrm{ml}$ Zentrifugenbechern bei $15{ }^{\circ} \mathrm{C}$ und $4000 \mathrm{rpm}$ für 15 Minuten abzentrifugiert. Die Resuspendierung des Pellets erfolgte in frisch angesetzter Transformationslösung. Nach dem Eintauchen der Pflanzen in die aus Agrobakteriensuspension wurden die Infloreszenzen mit Plastikhauben für ca. 24 Stunden abgedeckt, um eine möglichst hohe Luftfeuchte zu erzielen. Zur Transformation der Pflanzen wurde entweder der Agrobakterienstamm GV3101 mit den Resistenzgenen für Gentamycin und Rifampicin oder der Stamm GV3101 pMP90RK mit den Resistenzgenen für Gentamycin, Rifampicin und Kanamycin verwendet.

Die Selektion der so transformierten Pflanzen erfolgte je nach Plasmid auf kanamycinhaltigem Phytoagar oder auf Erde. Für die Selektion von Pflanzen auf Phytoagar (1/2 MSMedium: 2,2 g/l Murashige \& Skoog Salz, 0,5 g/l MES, pH 5,7 und 14 g/l Phytoagar) wurden die Samen zunächst für 10 Minuten in Sterilisationslösung inkubiert. Der Überstand wurde daraufhin durch 100 \%iges Ethanol ersetzt und die Samen unter einer Sterilbank zum Trocknen auf ein steriles Filterpapier gelegt. Daraufhin wurden die Samen auf kanamycinhaltigem Phytoagar-Platten $\left(\mathrm{Kan}^{50}\right)$ ausgelegt, mit luftdurchlässigem Micropore-Band (3M, 
Saint Paul, USA) verklebt und zur Stratifizierung bei $4{ }^{\circ} \mathrm{C}$ für 48 Stunden im Kühlraum gelagert. Die weitere Aufzucht der Pflanzen erfolgte in einem Klimaschrank bei einem TagNacht-Rhythmus von 8 Stunden Licht zu 16 Stunden Dunkelheit (Kurztag) und einer Temperatur von 18 bis $22{ }^{\circ} \mathrm{C}$. Nach ca. zwei bis drei Wochen wurden die Keimlinge auf Erde transferiert. Für die Selektion mit dem Herbizid BASTA (Bayer CropScience, Monheim; Verdünnung 1:1000) wurden die Samen zunächst dicht auf Erde ausgelegt und ebenfalls zur Stratifizierung bei $4{ }^{\circ} \mathrm{C}$ für 48 Stunden im Kühlraum gelagert. Nach ca. einer Woche erfolgte der erste Sprühvorgang mit dem Herbizid, welcher im Abstand von je drei Tagen noch zweimal wiederholt wurde. Die so selektionierten Transformanten wurden anschließend in neue Töpfe pikiert und unter Kurztagbedingungen angezogen.

\subsubsection{Transiente Expression in Tabak}

Um bestimmte Konstrukte vorübergehend in Pflanzengeweben zu exprimieren, und dadurch z.B. ihre subzelluläre Lokalisation innerhalb der Zelle mittels Fluoreszenzmikroskopie zu bestimmen, wurde eine transiente Expression der Konstrukte in Nicotiana benthamiana durchgeführt. Dazu dienten wie bereits bei der stabilen Transformation Agrobakterien, die das zu transformierende Plasmid bzw. Konstrukt enthielten. Ihre Anzucht erfolgte wiederum in $5 \mathrm{ml}$ dYT-Medium mit den für das Plasmid und den Agrobakterienstamm spezifischen Selektionsmarkern, z.B. Rif ${ }^{50}, \mathrm{Kan}^{50}$ und Carb $^{30}$ für den Stamm GV3101 pMP90RK, welcher mit pAMPAT-MCS-35S bzw. PAM-MCS-35S transformiert wurde. Durch Zentrifugation wurden die Zellen (4000 rpm; $22{ }^{\circ} \mathrm{C} ; 10 \mathrm{~min}$ ) pelletiert und in Infiltrationspuffer resuspendiert (Tab. 2.5). Die Suspension wurde in allen Infiltrationsansätzen auf eine ${ } D_{600}=0,3$ eingestellt. Mit Hilfe einer Einwegkanüle wurde die Suspension anschließend in den Interzellularraum junger Tabakpflanzen injiziert. Nach der Infiltration wurden die Pflanzen für drei Tage wieder in die Kurztagkammer überführt, bevor man sie schließlich mikroskopisch untersuchen konnte.

\subsubsection{Pilzanzucht}

Der für die Inokulationsexperimente verwendete Gerstenmehltaupilz Blumeria graminis f.sp. hordei Isolat K1 wurde auf Gerstenpflanzen (Hordeum vulgare) des Kultivars Ingrid (Linie I10) kultiviert. Hierfür wurden ca. 5 Tage alte Gerstenkeimlinge mit Sporen von Bgh inokuliert und bei 16 Stunden Licht zu 8 Stunden Dunkelheit, einer Temperatur von 18 bis $22{ }^{\circ} \mathrm{C}$ und einer relativen Luftfeuchtigkeit von 60 bis $70 \%$ angezogen. Die gleichen Anzuchtbedingungen wurden für die Kultivierung des Erbsenmehltaupilzes Erysiphe pisi auf Erbsen (Pisum sativum) der Sorte Kleine Rheinländerin verwendet. Eine Kultivierung des 
kompatiblen Mehltaupilzes Golovinomyces cichoracearum hingegen wurde unter Kurztagbedingungen bei einer Temperatur von ca. $18{ }^{\circ} \mathrm{C}$ und einer relativen Luftfeuchtigkeit von 80 \% auf Zucchinipflanzen (Cucurbita pepo) der Sorte Gold Rush durchgeführt.

\subsubsection{Inokulation von Arabidopsis mit Pilzsporen}

Zur Bestimmung der Invasions- und Zelltodraten von Wildtyppflanzen, Mutanten und transgenen Pflanzen, sowie zur fluoreszenzmikroskopischen Analyse unterschiedlicher GFP- bzw. RFP-markierter Reporterlinien, wurden unterschiedliche Arabidopsis-Linien mit Sporen kompatibler und inkompatibler Mehltaupilze inokuliert. Dazu wurden die Pflanzen in einem ca. $80 \mathrm{~cm}$ hohen Inokulationsturm platziert und gleichmäßig mit Sporen bestäubt. Dies erfolgte je nach Pathogen durch leichtes schütteln der befallen Wirtspflanzen oder durch aneinander reiben von sporentragenden Blättern, wie im Fall des Mehltaupilzes Golovinomyces cichoracearum. Je nach Experiment erfolgte die Probennahme der inokulierten Blätter zu unterschiedlichen Zeitpunkten.

\subsubsection{Analyse der Invasions- und Zelltodraten}

Für die Analyse der Invasions- und Zelltodraten mussten die Arabidopsis-Blätter zunächst entfärbt werden. Dazu wurden die mit Pilzsporen inokulierten Blättchen 72 Stunden nach Inokulation (72 hpi) geerntet, in 80 \%iges Ethanol gegeben und bei Tageslicht ca. eine Woche lang entfärbt. Bei diesem Vorgang wurde das Ethanol mehrmals gewechselt. Nach der Entfärbung konnte die pflanzliche Callose-Deposition mittels Anilinblau-Färbelösung und die pilzlichen Strukturen mit Hilfe von Coomassie-Färbelösung sichtbar gemacht werden (Tab. 2.5). Hierzu wurden die entfärbten Blätter über Nacht in Anilinblau-Färbelösung inkubiert. Um eine vorzeitige Entfärbung des Anilinblaus zu vermeiden, wurden die Proben lichtgeschützt aufbewahrt. Daraufhin erfolgte ein mehrmaliges Schwenken der Blätter in Coomassie-Färbelösung für ca. 30 Sekunden. Abschließend wurden die Blätter kurz in Aqua dest. entfärbt und in Einbettungslösung auf einem Objektträger platziert.

Die mikroskopische Analyse der Invasions- und Zelltodraten erfolgte mit Hilfe der Fluoreszenzmikroskope DM5000 B bzw. DM750 der Firma Leica (Wetzlar) unter Verwendung des Filterwürfels A4 (Exitationsfilter BP 340 - 380 nm; Suppressionsfilter BP 470/40 nm) und des Durchlichts. Für die quantitative Analyse der Invasions- und Zelltodraten wurden auf mindestens drei unterschiedlichen Blättern jeweils über 100 Interaktionsstellen ausgezählt und Zahlen von 0 bis 5 nach dem folgenden Bewertungsschema zugeordnet: 
$0=$ ungekeimte Spore oder keine Reaktion der Pflanzenzelle

1 = Bildung einer Papille

2 = Bildung eines Haustoriums

$3=$ Bildung eines Haustoriums und Zelltodreaktion

4 = Bildung eines Haustoriums und sekundäres Hyphenwachstum

5 = Bildung eines Haustoriums, sekundäres Hyphenwachstum und Zelltodreaktion

Die Berechnung des Mittelwertes und der Standardabweichung sowie die grafische Darstellung der Ergebnisse erfolgten mit Hilfe von Microsoft Office Excel 2003 von Microsoft (Redmond, USA). Zusätzlich wurden die Ergebnisse mittels des ungepaarten t-Tests statistisch ausgewertet.

\subsubsection{Konfokalmikroskopische Analysen}

Die konfokalmikroskopischen Analysen von transgenen Arabidopsis-Linien wurden mit Hilfe des TCS SP5 Konfokalmikroskops und der dazugehörigen Software LAS AF Leica Application Suite V2.2.1 der Firma Leica (Wetzlar) durchgeführt.

Zur Herstellung der Präparate wurde ein möglichst ebenes Blattstückchen von ca. drei bis fünf Wochen alten Pflanzen abgeschnitten. Diese Blattstückchen wurden mit der Blattunterseite auf einen Objektträger gelegt, in Wasser eingebettet und mit einem Deckgläschen versehen.

Für die konfokalmikroskopischen Untersuchungen der unterschiedlichen Fluoreszenzproteine und Fluoreszenzfarbstoffe wurden die in Tabelle 2.11 aufgeführten Parameter verwendet.

Tab. 2.11: Parameter zur Detektion unterschiedlicher Fluorophore

\begin{tabular}{|l|l|l|}
\hline \multicolumn{1}{|c|}{ Fluorophor } & $\begin{array}{c}\text { Anregungs- } \\
\text { wellenlänge }\end{array}$ & \multicolumn{1}{c|}{ Emissionsfilter } \\
\hline Anilinblau & $405 \mathrm{~nm}$ & $430-470 \mathrm{~nm}$ \\
\hline CFP & $458 \mathrm{~nm}$ & $465-485 \mathrm{~nm}$ \\
\hline FM 1-43 & $488 \mathrm{~nm}$ & $600-650 \mathrm{~nm}$ \\
\hline FM 4-64 & $488 \mathrm{~nm}$ & $600-650 \mathrm{~nm}$ \\
\hline GFP & $488 \mathrm{~nm}$ & $500-540 \mathrm{~nm}$ \\
\hline Propidiumiodid & $561 \mathrm{~nm}$ & $600-640 \mathrm{~nm}$ \\
\hline RFP & $561 \mathrm{~nm}$ & $580-620 \mathrm{~nm}$ \\
\hline
\end{tabular}

Zur Anfärbung der pilzlichen Strukturen wurden die zu mikroskopierenden Blattstückchen für ca. 30 Sekunden in FM 4-64- bzw. FM 1-43-Färbelösung oder Propidiumiodid-Färbelösung getaucht und anschließend kurz in Wasser gewaschen. Die Callose-Färbung erfolgte mittels einer Anilinblau-Färbelösung nach der von Meyer et al. (2009) publizierten Methode durch direkte Infiltration der Lösung, ca. eine Stunde vor Inokulation, ins Blattgewebe. 
Für die Aufnahme und Bearbeitung von Einzel- und Serienbildaufnahmen (Z-Serie bzw. Zeitreihe $\omega$ ) sowie die Erstellung von Maximalprojektionen wurde die oben aufgeführte Software verwendet. Zur Veranschaulichung ist das Prinzip der Z-Serie, nämlich die Aufnahme mehrerer Bilder in der Z-Dimension in Abbildung 2.1 dargestellt.

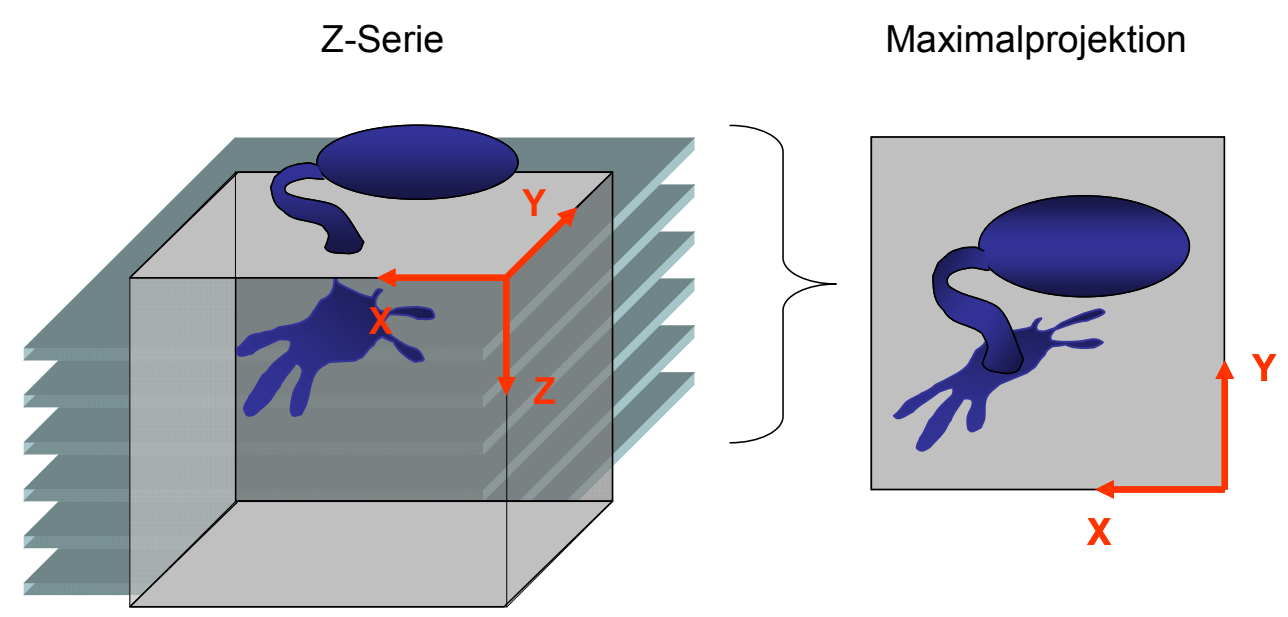

Abb. 2.1: Schematische Darstellung einer Z-Serie und der daraus gebildeten Maximalprojektion. 


\section{Ergebnisse}

\subsection{Untersuchungen zur subzellulären Lokalisation von PEN2}

Um die subzelluläre Lokalisation von PEN2 nach Pathogenbehandlung genauer zu untersuchen, wurde die von Lipka et al. (2005) generierte transgene PEN2-GFP-Linie verwendet. Hierzu wurde das Fluoreszenzprotein zwischen den vorhergesagten globulären Teil von PEN2 und der C-terminalen Extension integriert (Lipka et al., 2005). Die Expression des Fusionskonstrukts erfolgte durch den nativen Promotor von PEN2 ( $\left.\mathrm{P}_{P E N 2}\right)$ im pen2-1Mutantenhintergrund. Wie schon von Lipka et al. (2005) beschrieben, ist das PEN2-GFPFusionsprotein in der Lage, den pen2-Penetrationsphänotyp zu komplementieren. Weiterhin wurde gezeigt, dass das Fusionsprotein in der Peripherie von mobilen Membrankompartimenten lokalisiert ist, welche nach Inokulation mit Bgh an Interaktionsstellen akkumulieren (Lipka et al., 2005). Im Rahmen dieser Arbeit wurden die subzelluläre Lokalisation und das dynamische Verhalten der PEN2-GFP-assoziierten Membrankompartimente mit Hilfe konfokaler Mikroskopie im Detail analysiert.

\subsubsection{Fluoreszenzmikroskopische Analysen zur PEN2-Aggregation}

Neben der zuvor beschriebenen Akkumulation der fluoreszenz-markierten Kompartimente, konnte auch eine deutliche Fluoreszenzintensivierung der Reporterfusion am Ort der versuchten Invasion beobachtet werden (Abb. 3.1A bis 3.1E). Diese pathogen-induzierte Fluoreszenzakkumulation des PEN2-GFP-Signals tritt dabei nicht nur in der inkompatiblen Interaktion mit Bgh (Abb. 3.1A), sondern auch in weiteren Pathogen-Interaktionen auf. Wie in Abbildung $3.1 \mathrm{zu}$ erkennen ist, kann dieses Phänomen auch in der kompatiblen Interaktion mit dem Mehltaupilz Erysiphe cruciferarum beobachtet werden (Abb. 3.1B). Weitere Pilze wie z. B. der hemibiotrophe Pilz Colletotrichum higginsianum (Abb. 3.1C) oder der nekrotrophe Pilz Botrytis cinerea (Abb. 3.1D) induzieren ebenfalls die Intensivierung des PEN2-GFP-Signals an der Stelle der versuchten Invasion. Interessanterweise scheint dies nicht nur eine spezifische Reaktion der Pflanze bei pilzlichen Invasionsversuchen zu sein, da ähnliche Beobachtungen an Interaktionsstellen mit dem Oomycet Phytophthora capsici gemacht werden konnten (Abb. 3.1E). 


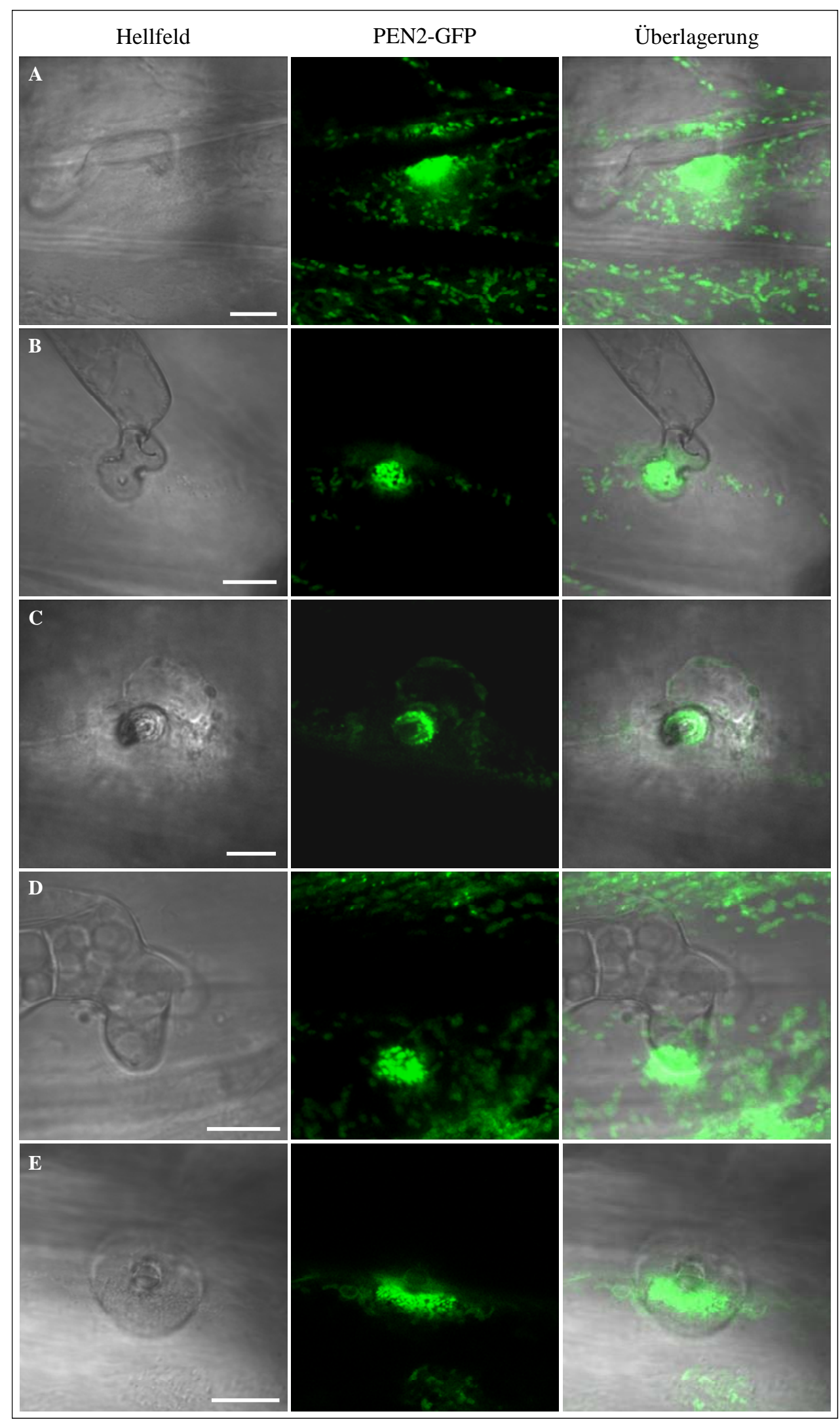

Abb. 3.1: Pathogen-induzierte PEN2-GFP-Fluoreszenzintensivierung an Orten der versuchten Penetration.

Abgebildet sind fluoreszenzmikroskopische Einzelaufnahmen von Epidermiszellen PEN2-GFP-exprimierender Pflanzen nach Inokulation mit unterschiedlichen Pathogenen: (A) Bgh (20 hpi), (B) Erysiphe cruciferarum (14 hpi), (C) Colletotrichum higginsianum (72 hpi), (D) Botrytis cinerea (48 hpi) und (E) Phytophthora capsici (18 hpi). hpi (hours post inoculation), Stunden nach Inokulation. Maßstabsbalken $=10 \mu \mathrm{m}$. 
Um die Akkumulation im Zeitverlauf genauer $\mathrm{zu}$ untersuchen, wurden Zeitverlaufsexperimente mit Hilfe von mikroskopischen Aufnahmen durchgeführt. Neben der Akkumulation der fluoreszenz-markierten Kompartimente wurde darüber hinaus auch eine deutliche zeitverlaufsabhängige Intensitätszunahme des Fluoreszenzsignals an der versuchten Invasionsstelle beobachtet (Abb. 3.2). Bei einer genaueren Betrachtung der Fluoreszenzakkumulation fällt auf, dass diese sich aus rundlichen Strukturen zusammensetzt, welche sich in ihrer Intensität von der des PEN2-GFP-assoziierten Membrankompartiments unterscheiden. Diese rundlichen Strukturen erhöhter Reporterfusion-Konzentration nehmen im Laufe der Pathogenabwehr nicht nur in ihrer Größe zu, sondern auch in ihrer Anzahl (Abb. 3.2). Zur Vereinfachung werden diese rundlichen Strukturen erhöhter PEN2-GFP-Intensität von nun an als PEN2-GFP-Aggregate bezeichnet. Wie in Abbildung 3.2 weiterhin zu erkennen ist, sind die Aggregate vornehmlich am Orten der Penetration lokalisiert und in der Regel nicht mobil (siehe Pfeil in Abb. 3.2).
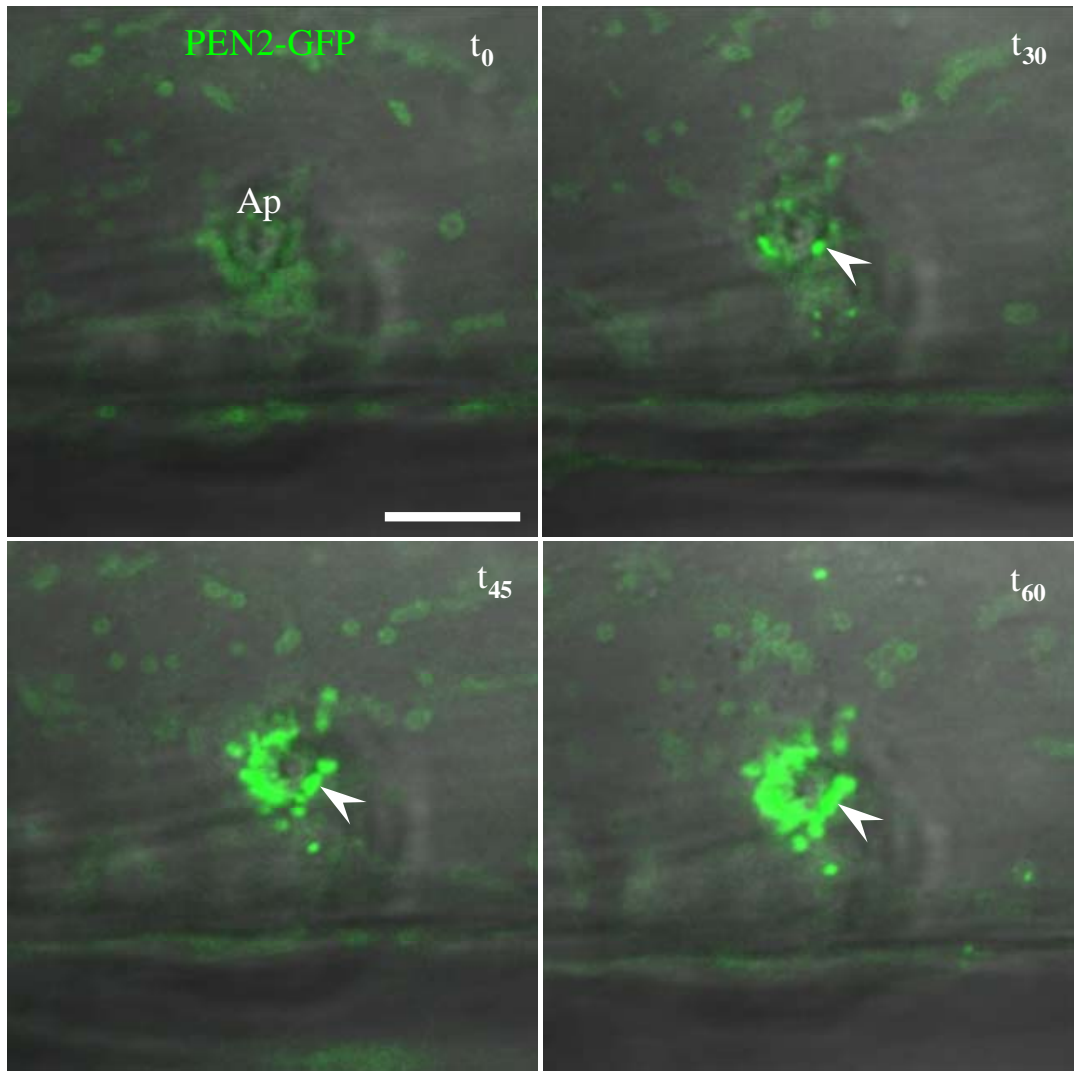

Abb. 3.2: Zeitliche Zunahme der PEN2-GFP-Fluoreszenzintensität am Ort der versuchten Penetration. Abgebildet sind fluoreszenzmikroskopische Einzelaufnahmen von Epidermiszellen PEN2-GFP-exprimierender Pflanzen. Die Pfeile weisen auf das Wachstum und die Unbeweglichkeit der rundlichen Aggregatstruktur im Zeitverlauf, 16 bis 17 Stunden nach Inokulation mit Bgh hin. Alle Einzelaufnahmen sind in derselben konfokalen Ebene aufgenommen worden. Ap, Appressorium; t, Zeit in Minuten. Maßstabsbalken = $10 \mu \mathrm{m}$. 
Die PEN2-GFP-Aggregatbildung scheint, wie in der Detailaufnahme in Abbildung $3.3 \mathrm{zu}$ erkennen ist, in distinkten peripheren Bereichen des PEN2-GFP-assoziierten Membrankompartiments zu beginnen und sich von dort an zentrifugal auszubreiten (siehe Pfeile in Abb. 3.3). Abschließend kann daher festgehalten werden, dass in der präinvasiven Abwehreaktion PEN2-GFP-Aggregate in der Peripherie eines noch nicht identifizierten Membrankompartiments am Ort der versuchten Invasion gebildet werden und akkumulieren.

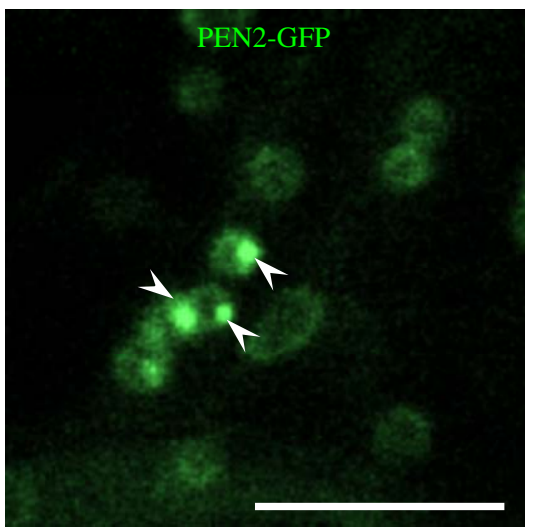

Abb. 3.3: Die PEN2-GFP-Aggregation beginnt in der Peripherie eines subzellulären Membrankompartiments.

Die fluoreszenzmikroskopische Aufnahme wurde 16 Stunden nach Inokulation mit Bgh aufgenommenn. Die Pfeile weisen auf die PEN2GFP-Aggregate in der Peripherie des PEN2-GFP-assoziierten Kompartiments hin. Maßstabsbalken $=5 \mu \mathrm{m}$.

Durch weitere Analysen sollte herausgefunden werden, ob diese Aggregate auch in der postinvasiven Abwehrreaktion der Pflanze nachgewiesen werden können. Dazu wurden in weiteren mikroskopischen Untersuchungen die pilzliche Struktur mit organischen Farbstoffen wie Propidiumiodid oder FM 1-43 bzw. FM 4-64 (Invitrogen, Carlsbad, USA)) angefärbt. Wie die Aufnahmen in Abbildung 3.4 zeigen, konnte nicht nur bestätigt werden, dass die PEN2GFP-Aggregate an Orten der versuchten Penetration (Abb. 3.4A und 3.4B), sondern auch nach erfolgter Invasion an Haustorien akkumulieren (Abb. 3.4C). In Abbildung 3.4A ist die Maximalprojektion einer Z-Serie dargestellt, die 8 Stunden nach Inokulation mit dem Erbsenmehltaupilz Erysiphe pisi aufgenommen wurde. Das pilzliche Appressorium wurde mit Propidiumiodid eingefärbt und das GFP-Signal soweit reduziert, dass nur noch die PEN2-GFP-Aggregate erkennbar sind. Durch Drehung der Z-Serie um $90^{\circ}$ und anschließender Maximalprojektion ist der vom Appressorium ausgebildete Penetrationskeil zu erkennen (siehe Pfeile in Abb. 3.4B). Da während der Penetration der pflanzlichen Zelle die Plasmamembran nicht penetriert wird, kommt es zur Invagination der Membran. Wie in Abbildung 3.4B deutlich zu sehen ist, lagern sich die Aggregate um die Einstülpung herum an. Im Fall einer erfolgreichen Invasion wird die Plasmamembran weiter eingestülpt und es kommt zur Ausbildung eines Haustoriums. In Abbildung 3.4C ist ein sich entwickelndes Haustorium des Gerstenmehltaupilzes zu erkennen, welches mit dem Farbstoff FM 1-43 angefärbt wurde. Es handelt sich bei dieser repräsentativen Abbildung wiederum um die Maximalprojektion einer Z-Serie. Durch die Überlagerung des PEN2-GFP-Signals mit dem Signal des Farbstoffes FM 1-43 kann eine Akkumulation von PEN2-GFP-Aggregaten an der 
ursprünglichen Penetrationsstelle, aber auch an der Spitze des Haustoriums nachgewiesen werden (siehe Pfeile in Abb. 3.4C). Diese duale Lokalisation der PEN2-GFP-Aggregate könnte vermutlich durch die Einstülpung und Neusynthese der Plasmamembran entstanden sein. Während ein Teil der Aggregate an der Invasionsstelle zurück geblieben ist, wurde der andere Teil durch die Entwicklung des Haustoriums weiter ins Innere der Zelle verschoben. Allerdings wäre hierfür eine stabile Interaktion der PEN2-GFP-Aggregate mit der Plasmamembran notwendig.

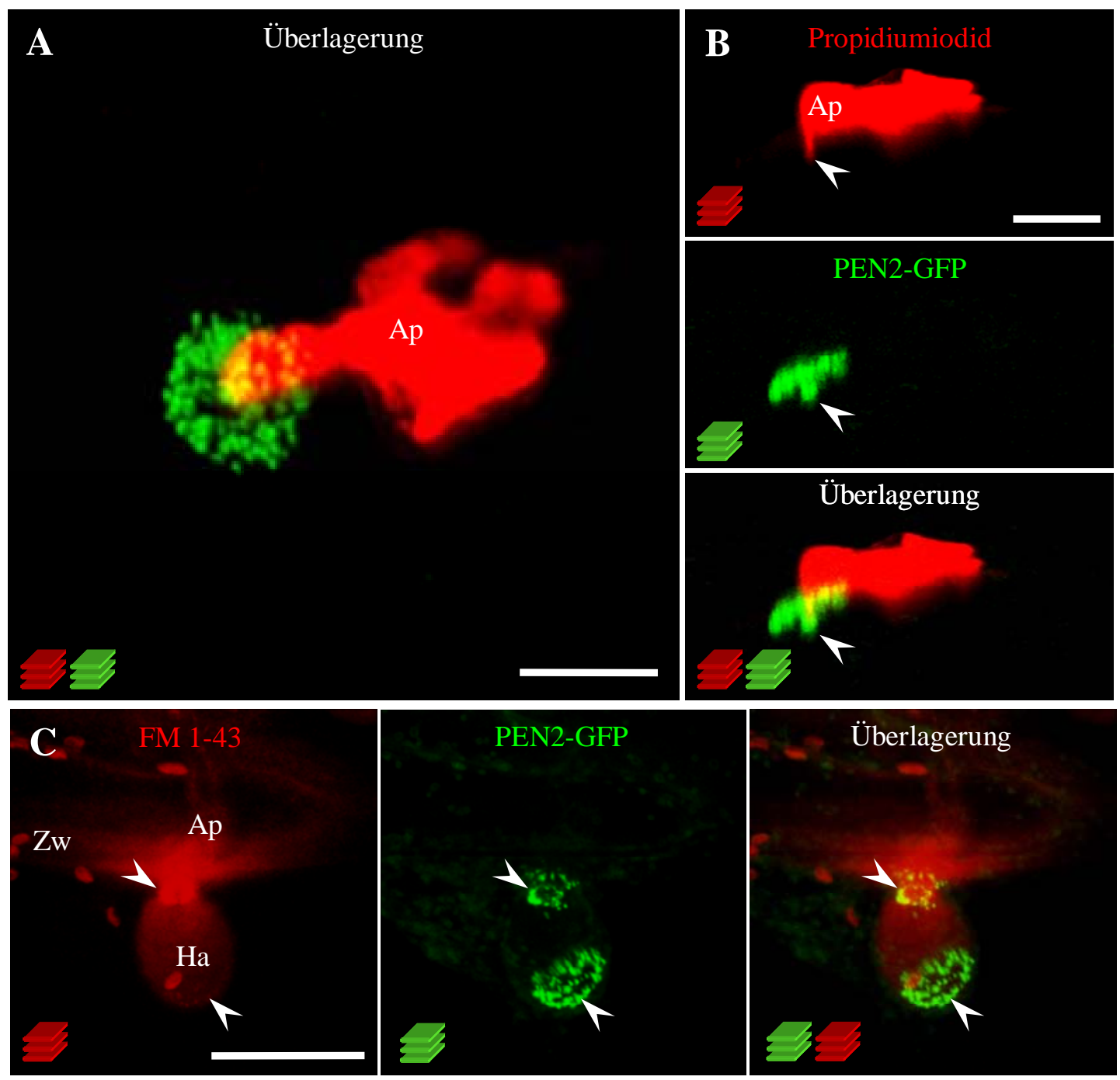

Abb. 3.4: Die PEN2-GFP-Aggregate akkumulieren unterhalb von Appressorien und an sich entwickelnden Haustorien.

(A) Abgebildet ist die Maximalprojektion einer Z-Serie, die neben dem PEN2-GFP-Signal auch das Signal des Propidiumiodid gefärbten Appressoriums 8 Stunden nach Inokulation mit $E$. pisi zeigt.

(B) Durch Drehung der gleichen Z-Serie um $90^{\circ}$, anschließender Maximalprojektion und der getrennten Darstellung der beiden Fluoreszenzsignale kann der Ort der versuchten Penetration genau lokalisiert werden (siehe Pfeile).

(C) Mit Hilfe der Maximalprojektion des FM 1-43 gefärbten Haustoriums und des PEN2-GFP-Signals kann eine Lokalisation der Aggregate sowohl am ursprünglichen Ort der Penetration, als auch an der Spitze des Haustoriums gezeigt werden (siehe Pfeile). Die Z-Serie wurde 22 Stunden nach Inokulation mit Bgh aufgenommen. Ap, Appressorium; Zw, Zellwand; Ha, Haustorium. Maßstabsbalken $=15 \mu \mathrm{m}$. 
Um eine mögliche stabile Interaktion der PEN2-GFP-Aggregate mit der Plasmamembran nachzuweisen, wurden Plasmolyseexperimente durchgeführt. Dazu wurde Blattmaterial, welches 18 Stunden zuvor mit Bgh inokuliert wurde, für 15 bis 30 Minuten in einer $1 \mathrm{M}$ Natriumchlorid-Lösung inkubiert. Wie in Abbildung 3.5A zu sehen ist, zieht sich der Protoplast von der Zellwand bis auf den Bereich unterhalb des Appressoriums zurück. Dieser Bereich ist auch der Ort der fokalen Akkumulation der Aggregate. Es kommt somit nicht zur Ablösung der PEN2-GFP-Aggregate von der Plasmamembran nach Plasmolyse. Noch deutlicher konnte die Assoziation der PEN2-GFP-Aggregate mit der Plasmamembran in der doppelt transgenen Linie gezeigt werden, welche neben dem Fusionsprotein noch ein RFP-markiertes Plasmamembranprotein exprimiert (Nelson et al., 2007). In Abbildung 3.5B ist zu erkennen, dass Teile der Plasmamembran an der Penetrationsstelle zurückgeblieben sind, während sich der Rest der Membran weiter mit dem Protoplast zurückgezogen hat. Dieser abgetrennte Bereich der Plasmamembran ist gleichzeitig auch der Bereich der PEN2-GFP-Aggregation (Abb. 3.5B). Es ist daher davon auszugehen, dass eine stabile Interaktion der Aggregate mit der Plasmamembran an der Invasionsstelle vorliegen muss, da sich sonst die Aggregate mit dem schrumpfenden Protoplasten von der Penetrationsstelle abgelöst hätten.

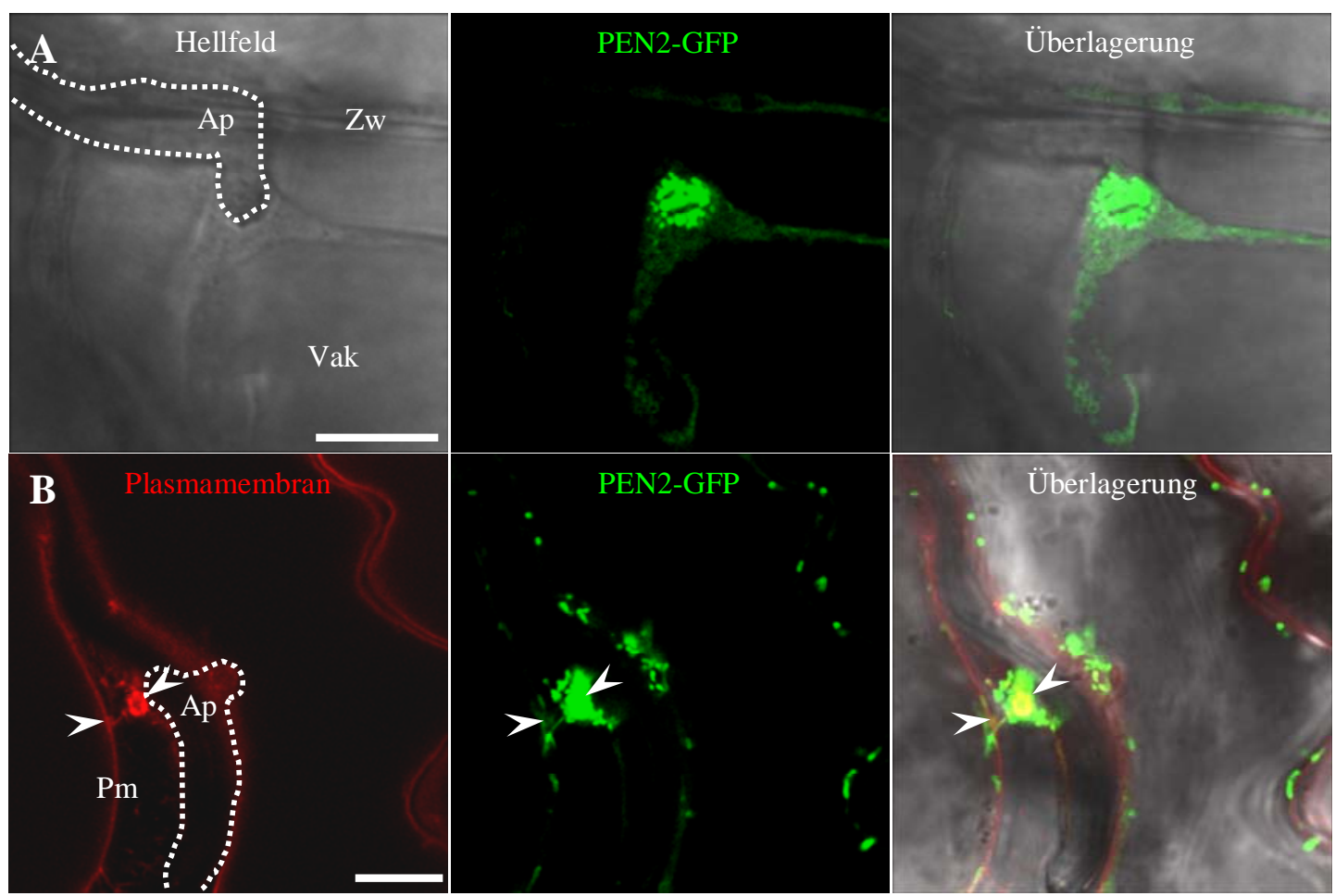

Abb. 3.5: Die PEN2-GFP-Aggregate weisen eine stabile Interaktion mit der Plasmamembran an Orten der versuchten Pathogeninvasion auf.

(A) Die mikroskopische Aufnahme zeigt die Ablösung des Protoplasten von der Zellwand 30 Minuten nach induzierter Plasmolyse mit $1 \mathrm{M}$ Natriumchlorid-Lösung und 18 Stunden nach Inokulation mit Bgh. (B) Eine Abtrennung des Protoplasten ist auch 15 Minuten nach Behandlung mit $1 \mathrm{M}$ Natriumchlorid-Lösung und 18 Stunden nach Inokulation mit Bgh in den Aufnahmen der doppelt transgenen Linie erkennbar (siehe Pfeile). Ap, Appressorium; Pm, Plasmamembran; Zw, Zellwand. Maßstabsbalken $=10 \mu \mathrm{m}$. 
Inwieweit die PEN2-GFP-Aggregate oder das PEN2-GFP-assoziierte Membrankompartiment mit der Plasmamembran interagieren, muss noch durch weitere Experimente untersucht werden.

Neben der beschriebenen Aggregatbildung an Orten der versuchten Penetration, konnte darüber hinaus wiederholt eine Bildung von PEN2-GFP-Aggregaten in benachbarten Zellen beobachtet werden. Wie in der repräsentativen Abbildung 3.6 zu erkennen ist, akkumulieren die PEN2-GFP-Aggregate unterhalb des pilzlichen Appressoriums in Zelle I. Eine zielgerichtete Akkumulation weiterer Aggregate hin zur Penetrationsstelle ist auch in den Nachbarzellen II und III zu beobachten. Demnach scheint eine direkte Penetration nicht unbedingt notwendig zu sein, um eine Zellpolarisation in den Nachbarzellen zu induzieren, die anschließend zu einer zielgerichteten Aggregatbildung führt. Man könnte an diese Stelle spekulieren, dass ein diffusibles Signal für die PEN2-GFP-Aggregation in den angrenzenden Zellen verantwortlich sein könnte.
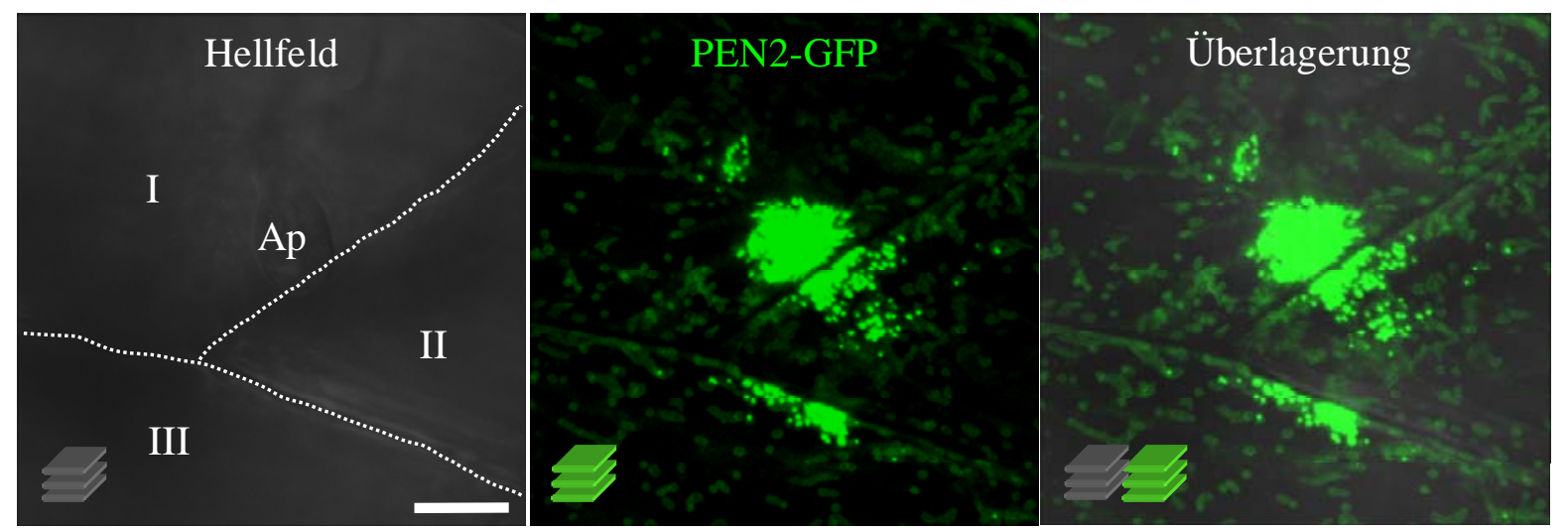

Abb. 3.6: Induzierte PEN2-GFP-Aggregation in angrenzenden Zellen zur Penetrationsstelle.

Die Abbildung zeigt die Maximalprojektion einer Z-Serie, die 20 Stunden nach Inokulation mit Bgh aufgenommen wurde. Die unterschiedlichen Zellen sind mit I-III nummeriert. Ap, Appressorium. Maßstabsbalken $=10 \mu \mathrm{m}$.

Zusätzlich konnte beobachtet werden, dass die PEN2-GFP-Aggregation zeitgleich in zwei unterschiedlichen Zellen stattfinden kann. So zeigt z.B. die Abbildung 3.7 eine synchrone Aggregation von PEN2-GFP unter dem primären und sekundären Keimschlauch einer BghSpore, welche auf zwei benachbarten Epidermiszellen ausgebildet wurden (20 Stunden nach Inokulation). Im Laufe der nächsten 20 Minuten nahm die Anzahl und Größe der PEN2-GFP-Aggregate an beiden Orten deutlich zu, wohingegen weitere 40 Minuten später an beiden Keimschläuchen keine Aggregate mehr vorhanden waren (siehe Pfeile in Abb. 3.7). Somit kann interessanterweise nicht nur die Akkumulationen der Aggregate am primären und sekundären Keimschlauch synchron stattfinden, sondern auch ihr Abbau. Eine Auflösung der Aggregate konnte in einzelnen Zellen wiederholt beobachtet werden (Daten nicht gezeigt), allerdings stellt der zeitgleiche Aggregatabbau in zwei benachbarten Zellen 
einen bis jetzt einmaligen Befund dar. Aufgrund dieses synchronen Abbaus kann angenommen werden, dass ein weiteres diffusibles Signal für die Auflösung der PEN2-GFPAggregate nach erfolgreicher Pathogenabwehr verantwortlich sein könnte. Eine Degradation der Aggregate aufgrund von Photobleichung ist hingegen eher unwahrscheinlich, da dieser Effekt direkt eintreten, sich bei jeder Aufnahme noch verstärken, und daher nicht erst nach mehreren Minuten stattfinden würde. Allerdings muss durch weitere Analysen noch geklärt werden, unter welchen Bedingungen ein Abbau der PEN2-GFP-Aggregate in attackierten Zellen abläuft.

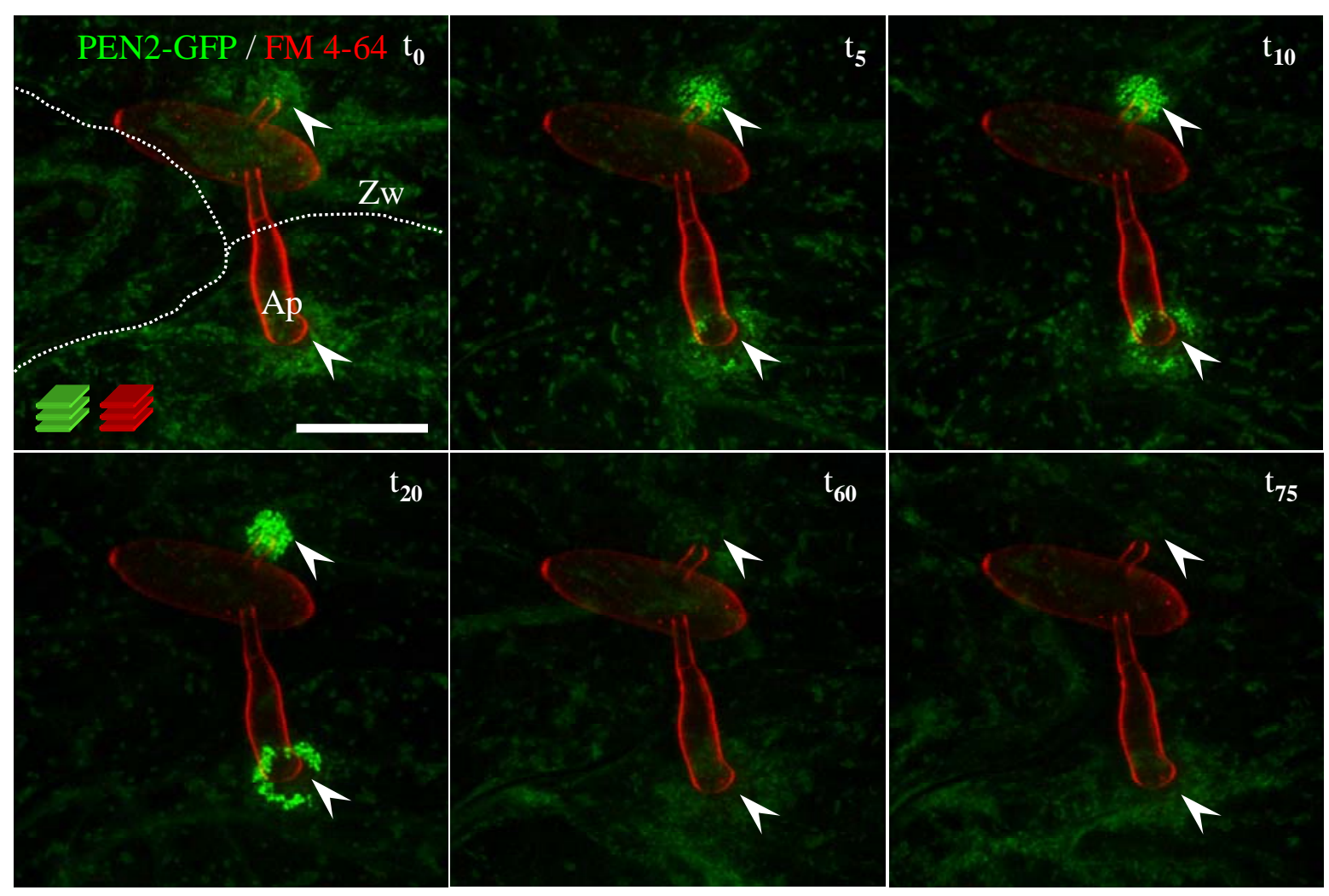

Abb. 3.7: Synchroner Auf- und Abbau der PEN2-GFP-Aggregate in zwei unterschiedlichen Zellen im Laufe der pflanzlichen Abwehrreaktion.

Abgebildet sind Maximalprojektionen von Z-Serien die an derselben Position, aber zu unterschiedlichen Zeitpunkten aufgenommen worden sind (20 bis 21 Stunden nach Inokulation mit Bgh). Mit Hilfe des Farbstoffs FM 4-64 wurde die pilzliche Struktur angefärbt. Die Pfeile weisen auf den Ort der Aggregatbildung und deren Abbau hin. Ap, Appressorium; t, Zeit in Minuten nach Beginn der Aufnahmen; Zw, Zellwand (weiße Linie). Maßstabsbalken $=25 \mu \mathrm{m}$.

Abschließend kann festgehalten werden, dass es zu einer pathogen-induzierten Aggregation des PEN2-GFP-Proteins an Orten der versuchten Invasion kommt, und dass diese Strukturen in der Peripherie eines Membrankompartiments gebildet werden. Zusätzlich konnte eine Aggregatbildung in Nachbarzellen der attackierten Zellen wiederholt beobachtet werden. In weiteren Analysen wurde zudem gezeigt, dass die PEN2-GFP-Aggregation und der Abbau der Aggregate synchron in benachbarten Zellen ablaufen können. 


\subsubsection{Bestimmung der PEN2-Proteinabundanz in der Pathogenabwehr}

Im vorherigen Abschnitt wurde gezeigt, dass PEN2-GFP-Aggregate an Orten der versuchten Invasion gebildet und wieder abgebaut werden können. Inwieweit dieses Phänomen durch Neusynthese bzw. Degradation des Fusionsproteins entsteht, sollte mit Hilfe von WesternBlot-Analysen näher untersucht werden. Alternativ könnte der Auf- und Abbau der Aggregate auch durch eine Relokalisation des Reporterproteins bedingt und damit unabhängig von der Abundanz in der Zelle verlaufen. Wie schon Lipka et al. (2005) gezeigt hat, existiert ein cytoplasmatischer und ein membran-gebundener Pool von PEN2. Es ist daher durchaus denkbar, dass ein Teil des cytoplasmatischen PEN2-GFP-Pools durch Pathogenbehandlung in den membran-assoziierten Pool rekrutiert wird, was letztendlich zur Aggregation des Fusionsproteins in der Membran führen könnte. In diesem Fall wäre keine Änderung der PEN2-Gesamtproteinmenge im Immunoblot nachweisbar. Um nachzuweisen, dass die Gesamtproteinmenge des Reporterproteins und PEN2-Proteins in der Pathogenabwehr konstant bleibt, wurde in Zeitverlaufsexperimenten die PEN2-Abundanz mit Hilfe eines PEN2-spezifischen Antikörpers in Western-Blot-Analysen bestimmt. Hierfür wurde das gesamte Blattmaterial von ca. vier Wochen alten Pflanzen zu unterschiedlichen Zeitpunkten nach Inokulation mit Bgh geerntet. Interessanterweise konnte keine Änderung des PEN2-GFP-Proteingehalts in transgenen Pflanzen oder in Col-3, gl1-Wildtyppflanzen nach Pathogenbehandlung festgestellt werden (Abb. 3.8). Wie der Immunoblot in Abbildung 3.8 zeigt, bleibt die PEN2-GFP- und PEN2-Bandenintensität im Zeitverlauf konstant. Darüber hinaus konnten keine Degradationsprodukte nachgewiesen werden. Aufgrund dieser Ergebnisse ist anzunehmen, dass eine Neusynthese des Fusionsproteins bzw. dessen Degradation nicht für die Bildung oder den Abbau der PEN2-GFP-Aggregate verantwortlich sein kann. Viel wahrscheinlicher ist daher die pathogen-induzierte Relokalisation des PEN2-GFP-Proteins aus dem cytoplasmatischen, hin zum membrangebundenen Pool. Eine Anreicherung des Reporterproteins in der Peripherie des Membrankompartiments könnte somit zur Aggregation führen. Aufgrund dieser Annahme würden nach einer erfolgreichen Pathogenabwehr oben genannte Aggregate wieder disassemblieren. In vorläufigen Experimenten konnte mittels differenzieller Zentrifugation bisher jedoch keine Erhöhung der Proteinabundanz im membran-assoziierten PEN2-Pool nach Inokulation festgestellt werden (Daten nicht gezeigt). 


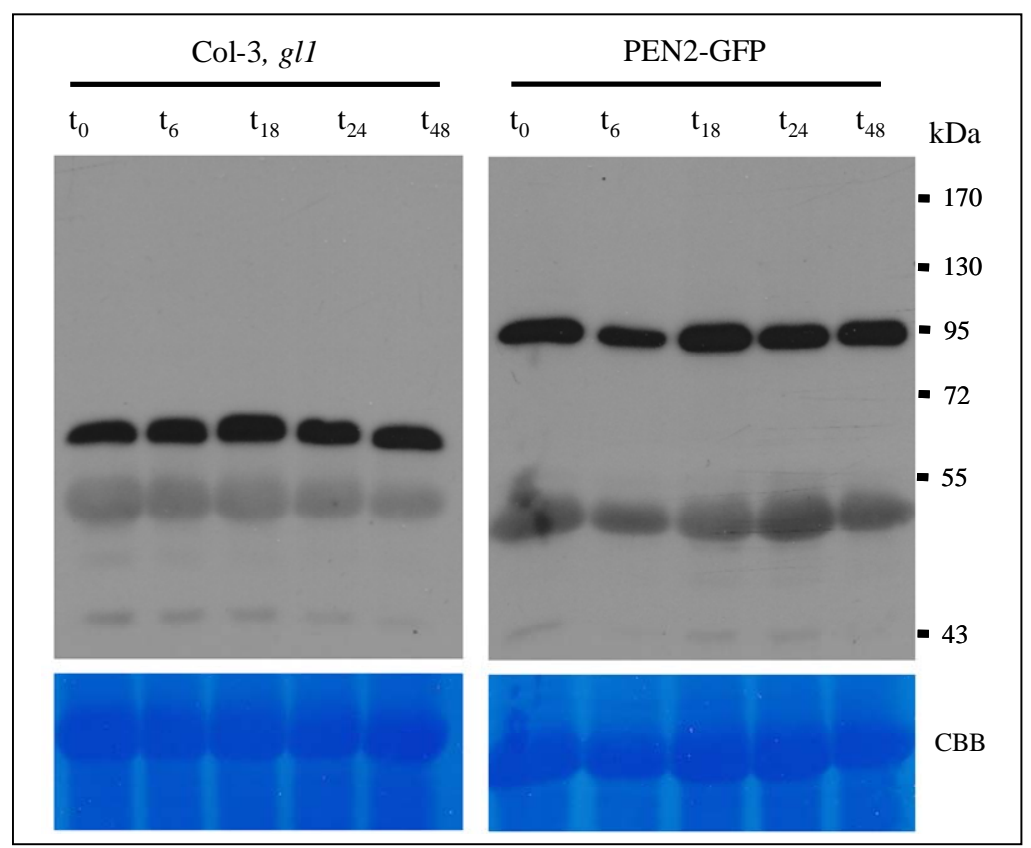

Abb. 3.8: Die PEN2- und PEN2-GFP-Proteinmenge bleibt im Laufe der Pathogenabwehr konstant. Jeweils $30 \mu \mathrm{g}$ Proteinisolat wurden in einem $10 \%$ igen SDS-Polyacryamidgel aufgetrennt und mittels Elektroblot auf eine PVDF-Membran übertragen. Der immunologische Nachweis erfolgte mit Hilfe eines PEN2-spezifischen Antikörpers (1:10000 verdünnt). Am rechten Rand ist die molekulare Masse der Markerproteine angegeben. Im unteren Teil ist die Coomassiefärbung des Gesamtproteins dargestellt. Das Experiment wurde dreimal wiederholt. CBB, Coomassie-Brilliant-Blau; t, Zeit in Stunden nach Inokulation mit Bgh.

\subsubsection{In-vivo-Experimente zur Homomerisierung von PEN2}

Inwieweit die zuvor beschriebenen Aggregate aus PEN2-GFP-Di- bzw. Oligomeren aufgebaut sind, sollte mit Hilfe von Koimmunopräzipitationsexperimenten analysiert werden. Um die Homomerisierung von PEN2 in Western-Blot-Analysen nachweisen zu können, wurde eine doppelt transgene Linie mit zwei unterschiedlich markierten PEN2-Proteinen generiert. Neben der bereits beschriebenen PEN2-GFP-Linie wurde zudem eine PEN2-RFP exprimierende Linie erzeugt und anschließend mit der PEN2-GFP-Linie gekreuzt. Zur Herstellung des PEN2-RFP-Konstrukts wurde das RFP-Protein ebenfalls zwischen den vorhergesagten globulären Teil von PEN2 und der C-terminalen Extension integriert. Die Expression des PEN2-RFP-Konstrukts erfolgte durch den nativen Promotor von PEN2 im pen2-1-Mutantenhintergrund. Zur Überprüfung der Funktionalität dieses Fusionsproteins wurden vergleichende Analysen der Invasions- und Zelltodraten Bgh-inokulierter Wildtyppflanzen, pen2-Mutanten und transgener PEN2-Fusionslinien durchgeführt. Wie in Abbildung $3.9 \mathrm{zu}$ erkennen ist, komplementiert auch das PEN2-RFP-Protein den pen2Penetrationsphänotyp. Während pen2-1-Mutnaten 72 Stunden nach Inokulation mit dem inkompatiblen Mehltaupilz eine Penetrationsrate von über $25 \%$ zeigten, lag die Penetrationsrate bei Wildtyppflanzen und transgenen PEN2-GFP Pflanzen unter $5 \%$. Mit einer Invasionshäufigkeit von $\sim 7 \%$ entspricht das Ergebnis der transgenen PEN2-RFP- 
Linien dem des Wildtyps (Abb. 3.9A). Neben der erhöhten Rate von Invasionsereignissen weist die pen2-1-Mutante außerdem eine erhöhte Zelltodreaktion auf. Die Zelltodrate ist mit $19 \%$ in der Mutante wesentlich höher als in Wildtyppflanzen ( 1 \% Zelltodrate), PEN2-GFPPflanzen ( 2 \% Zelltodrate) oder PEN2-RFP-Pflanzen ( $\sim \%$ Zelltodrate). Mit Hilfe von Western-Blot-Analysen unter Verwendung des PEN2-spezifischen Antikörpers konnte zudem demonstriert werden, dass die PEN2-Proteinabundanz in den Linien PEN2-GFP \#622 und PEN2-RFP \#1-5-9 der des Wildtyp-Proteins entspricht und in der Linie PEN2-RFP \#1-5-7 erhöht ist (Abb. 3.9B). Aufgrund der höheren Proteinmenge wurde die Linie PEN2-RFP \#1-5-7 mit der Linie PEN2-GFP \#62-2 gekreuzt und für weitere Untersuchungen verwendet.

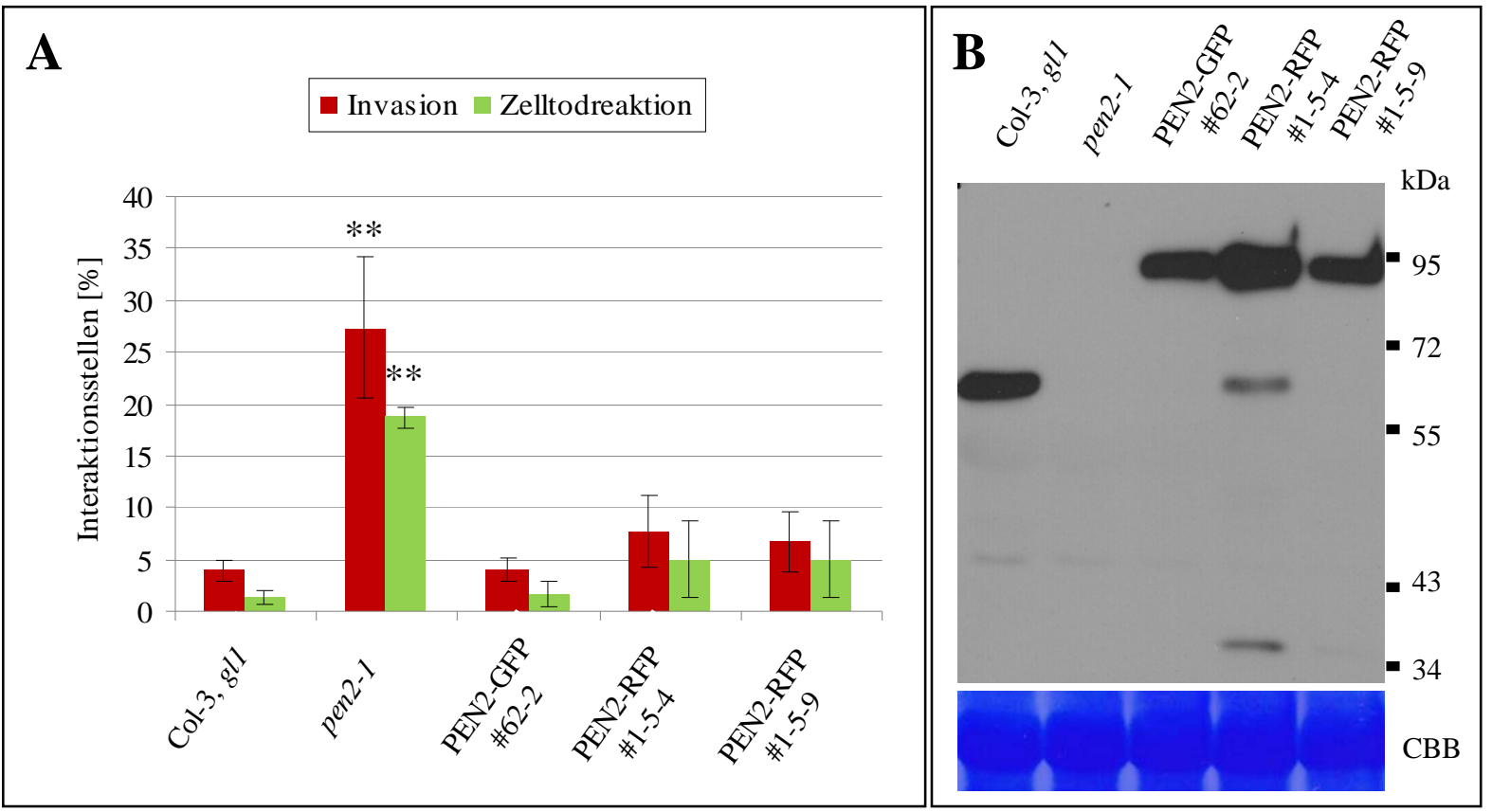

Abb. 3.9: Das PEN2-RFP-Fusionsprotein komplementiert den pen2-Phänotyp.

(A) Abgebildet ist die vergleichende Analyse der Invasions- und Zelltodraten Bgh-inokulierter Wildtyppflanzen, pen2-Mutanten und transgener FP-Fusionslinien (72 Stunden nach Inokulation). Pro Linie wurden drei Blätter mit je 100 Interaktionsstellen ausgezählt und in drei unabhängigen Experimenten wiederholt. Die Sterne geben den signifikanten Unterschied der Invasions- und Zelltodraten zu Wildtyppflanzen an $\left({ }^{*} P \leq 0,05 ;{ }^{*} P \leq 0,005\right)$.

(B) Jeweils $30 \mu \mathrm{g}$ Proteinisolat wurden in einem $10 \%$ igen SDS-Polyacryamidgel aufgetrennt und mittels Elektroblot auf eine PVDF-Membran übertragen. Der immunologische Nachweis erfolgte mit Hilfe eines PEN2spezifischen Antikörpers (1:10000 verdünnt). Am rechten Rand ist die molekulare Masse der Markerproteine angegeben. Im unteren Teil ist die Coomassiefärbung des Gesamtproteins dargestellt. Das Experiment wurde dreimal wiederholt. CBB, Coomassie-Brilliant-Blau.

Eine anschließende fluoreszenzmikroskopische Analyse der doppelt transgenen Linie konnte zudem nachweisen, dass PEN2-RFP und PEN2-GFP im gleichen Membrankompartiment lokalisiert sind und in den Aggregaten kolokalisieren (Abb. 3.10B und Abb. 3.10C). Somit besitzt das PEN2-RFP-Protein nicht nur die gleiche Funktionalität wie das GFP-Fusionsprotein, sondern auch die erwartete gleiche subzelluläre Lokalisation. 
Mit Hilfe der doppelt transgenen Linie und der beiden einfach transgenen Linien für PEN2-GFP bzw. PEN2-RFP sollte durch Koimmunopräzipitationexperimente die Homomerisierung von PEN2 nachgewiesen werden. Dazu wurde der Pflanzenextrakt der drei unterschiedlichen Linien, welcher aus nicht pathogen-behandelten Pflanzen gewonnen wurde, jeweils mit GFP-Trap Agarose-Beads (ChromoTek, Martinsried) versetzt und für 90 Minuten bei Raumtemperatur oder über Nacht bei $4{ }^{\circ} \mathrm{C}$ unter ständiger Rotation inkubiert. Die hierfür verwendeten GFP-Trap Agarose-Beads sind mit einem GFP-Antikörper ummantelt, welcher spezifisch GFP und YFP bindet, aber keine weiteren Fluoreszenzproteine wie CFP oder RFP (Rothbauer et al., 2006). Nach der Inkubation wurden die Agarose-Beads vom Überstand getrennt, mehrfach gewaschen und das gebundene Protein durch Kochen in Lämmli-Puffer eluiert. Wie die Western-Blot-Analysen mit Hilfe des GFP- und RFP-spezifischen Antikörpers zeigen, konnte PEN2-RFP durch PEN2-GFP koimmunopräzipitiert werden. Eine Immunopräzipitation des RFPFusionsproteins durch GFP-Trap Agarose-Beads konnte wie erwartet nicht nachgewiesen werden. Daher kann das RFP-Signal im Eluat der doppelt transgenen Linie nur durch eine Interaktion von PEN2-GFP mit PEN2-RFP erklärt werden. Zusätzlich konnten Experimente mit Hilfe des Split-Ubiquitin-Systems zeigen, dass das native PEN2-Protein ebenfalls homodimerisieren kann (Christine Klapprodt, eigene Arbeitsgruppe, persönliche Kommunikation). Diese Ergebnisse demonstrieren eindeutig die Fähigkeit von PEN2 in vivo in heterologen und homologen System zu homodimerisieren. Inwieweit die PEN2-GFP Aggregate aus Homodimeren oder Homooligomeren aufgebaut sind, wurde in weiteren Experimenten untersucht. 

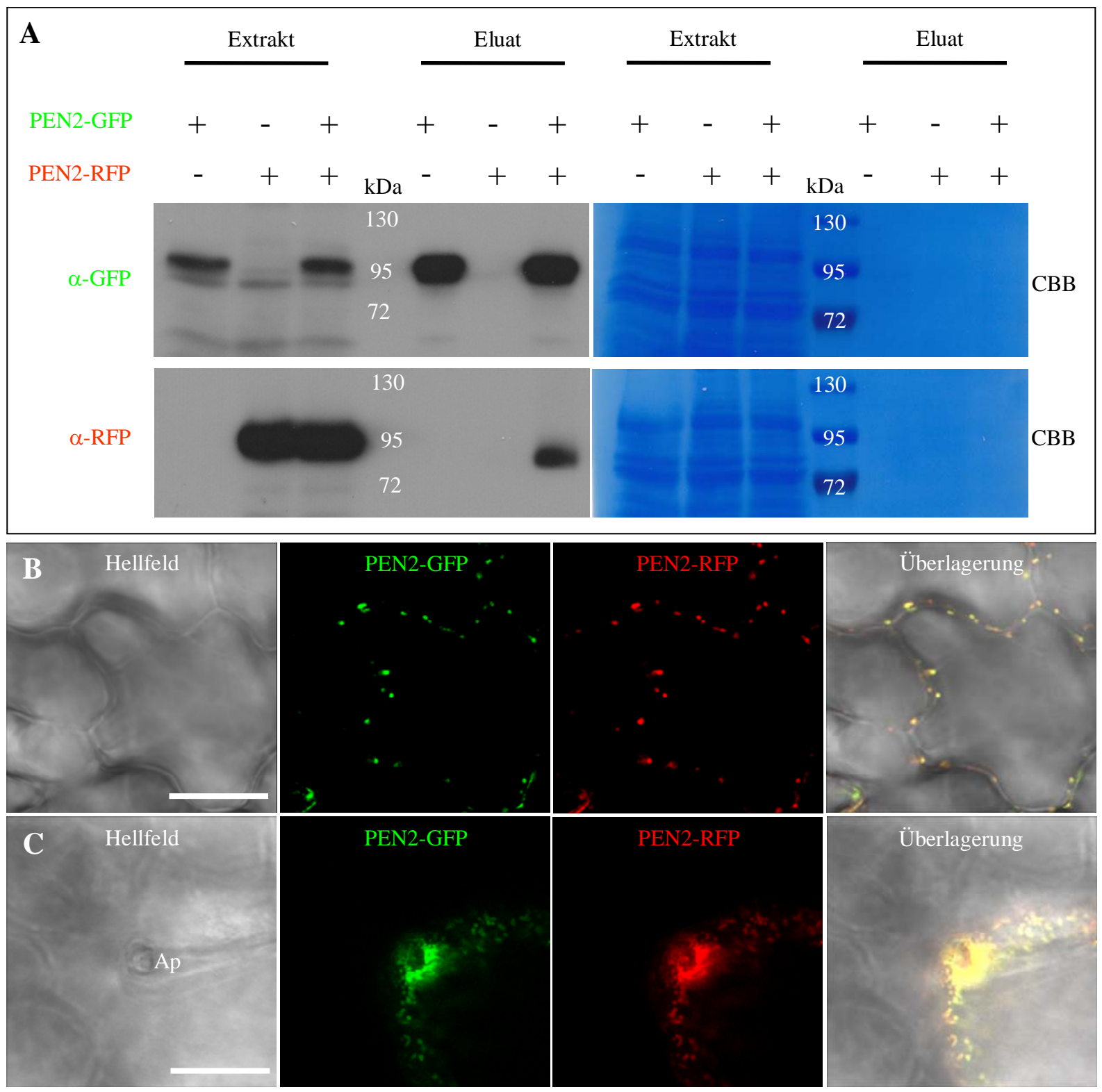

Abb. 3.10: PEN2-PEN2-Interaktion in vivo.

Abgebildet sind die die Ergebnisse der Western-Blot-Analyse der Koimmunopräzipitation, sowie die fluoreszenzmikroskopischen Aufnahmen der der doppelt transgenen Linie PEN2-GFP und PEN2-RFP.

(A) Jeweils $30 \mu \mathrm{g}$ Proteinisolat bzw. $35 \mu \mathrm{l}$ Proteineluat wurden in einem $10 \%$ igen SDS-Polyacryamidgel aufgetrennt und mittels Elektroblot auf eine PVDF-Membran übertragen. Der immunologische Nachweis erfolgte mit Hilfe eines GFP-spezifischen (1:5000 verdünnt) und RFP-spezifischen Antikörpers (1:10000 verdünnt). Im rechten Teil der Abbildung ist die Coomassiefärbung des Gesamtproteins dargestellt. Die molekulare Masse der Markerproteine ist in der Mitte des Immunoblots und in der Mitte der angefärbten Membran jeweils angegeben. Das Experiment wurde zweimal wiederholt. CBB, Coomassie-Brilliant-Blau.

Die mikroskopischen Aufnahmen zeigen die subzelluläre Lokalisation von PEN2-GFP und PEN2-RFP in (B) unbehandelten Epidermiszellen und in (C) Epidermiszellen 22 Stunden nach Inokulation mit Bgh. Ap, Appressorium. Maßstabsbalken $=20 \mu \mathrm{m}$.

Um die pathogen-induzierte Homooligomerisierung zu untersuchen, wurde unbehandeltes und mit Bgh inokuliertes Pflanzenmaterial (24 hpi) von PEN2-GFP-exprimierenden Pflanzen und Wildtyppflanzen geerntet. Der Extrakt der jeweiligen Proben wurde aufbereitet und auf eine Blue-Native-PAGE der Firma Invitrogen geladen. Eine pathogen-induzierte Homooligomerisierung konnte allerdings in der Western-Blot-Analyse nicht eindeutig 
nachgewiesen werden (Abb. 3.11). Mit Hilfe des PEN2-spezifischen Antikörpers konnten im Immunoblot lediglich PEN2- bzw. PEN2-GFP-Monomere, und nur geringe Mengen von PEN2- und PEN2-GFP-Dimeren detektiert werden. Dies könnte zum einen an einer geringen Stabilität der Oligomere, oder aber an einer geringen Abundanz der Aggregate in den pathogen-behandelten Proben liegen. So ist zu bedenken, dass die gezeigten Aggregate nur in wenigen Epidermiszellen pathogen-spezifisch induziert werden, der Großteil der PEN2-produzierenden Blattzellen jedoch nicht einer Pathogenattacke unterliegt. Eine Anreicherung der PEN2-GFP-Aggregate mittels Immunopräzipitation unter Verwendung der zuvor beschriebenen GFP-Trap Agarose-Beads wurde für die Blue-Native-PAGE Gelelektrophorese noch nicht durchgeführt, da ein schonendes Verfahren zur Elution der Aggregate von den Agarose-Beads noch nicht zur Verfügung stand.

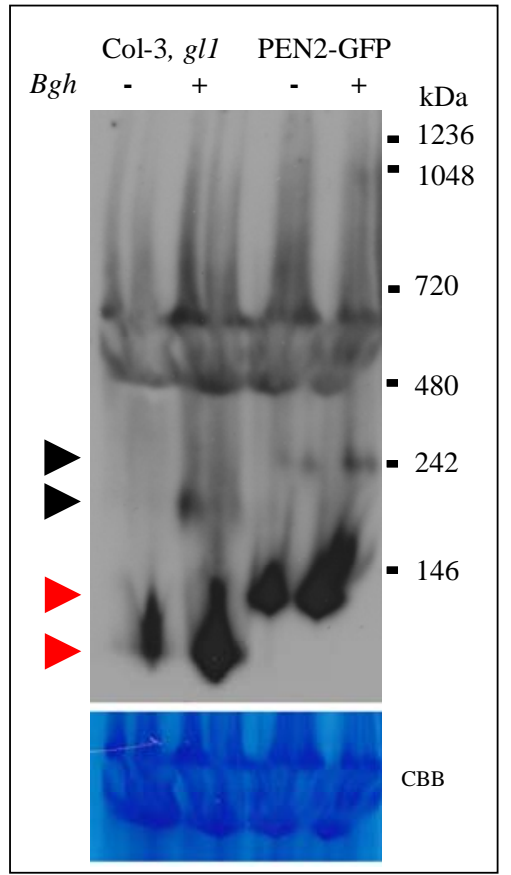

Abb. 3.11: Eine pathogen-induzierte Oliogomerisation von PEN2 und PEN2-GFP ist im nativen Gel nur unzureichend nachweisbar.

Jeweils $30 \mu \mathrm{g}$ Proteinisolat wurden in einem 4-12 \%igen nativen Polyacrylamidgel aufgetrennt und mittels Elektroblot auf eine PVDFMembran übertragen. Der immunologische Nachweis erfolgte mit Hilfe eines PEN2-spezifischen Antikörpers (1:10000 verdünnt). Am rechten Rand ist die molekulare Masse der Markerproteine angegeben. Die roten Pfeile markieren das jeweilige Monomer und die schwarzen Pfeile das entsprechende Dimer. Im unteren Teil ist die Coomassiefärbung des Gesamtproteins dargestellt. Das Experiment wurde zweimal wiederholt. CBB, Coomassie-Brilliant-Blau.

Hingegen konnte mehrfach eine Immunopräzipitaion zur Anreichung von Aggregaten, die anschließend in denaturierenden Gelen analysiert wurden, erfolgreich durchgeführt werden. Wie das Ergebnis der Western-Blot-Analyse in Abbildung 3.12 zeigt, können höher molekulare Banden in der Probe von pathogen-behandelten PEN2-GFP-Pflanzen mit Hilfe des PEN2-spezifischen Antiköpers eindeutig nachgewiesen werden. Diese Banden laufen in der SDS-PAGE höher als die eigentliche Größe des Fusionsproteins ( 92 kDa) und fehlen in der unbehandelten Probe vollkommen. Bei diesen Banden handelt es sich vermutlich um PEN2-GFP-Oligomere. Dieses Ergebnis ist insofern interessant, da eine SDSGelelektrophorese normalerweise zur Auflösung von Proteinkomplexen führt. Allerdings konnte bereits Kwon et al. (2008a) zeigen, dass detergenz-resistente Komplexe von PEN1, 
SNAP33 und VAMP721/722 nach Pathogenbehandlung entstehen. Somit scheint auch die pathogen-induzierte Homomerisierung von PEN2-GFP zu detergenz-resistenten Oligomeren denkbar. Eine genaue Aussage über den Oligomerisierungsgrad von PEN2-GFP kann jedoch nur durch eine Analyse in der Blue-Native-PAGE gemacht werden, da hier ein denaturierender Effekt vollständig ausgeschlossen werden kann. Durch die Analyse im nativen Gel könnte zudem das Molekulargewicht der PEN2-GFP-Aggregate möglicherweise näher bestimmt werden.

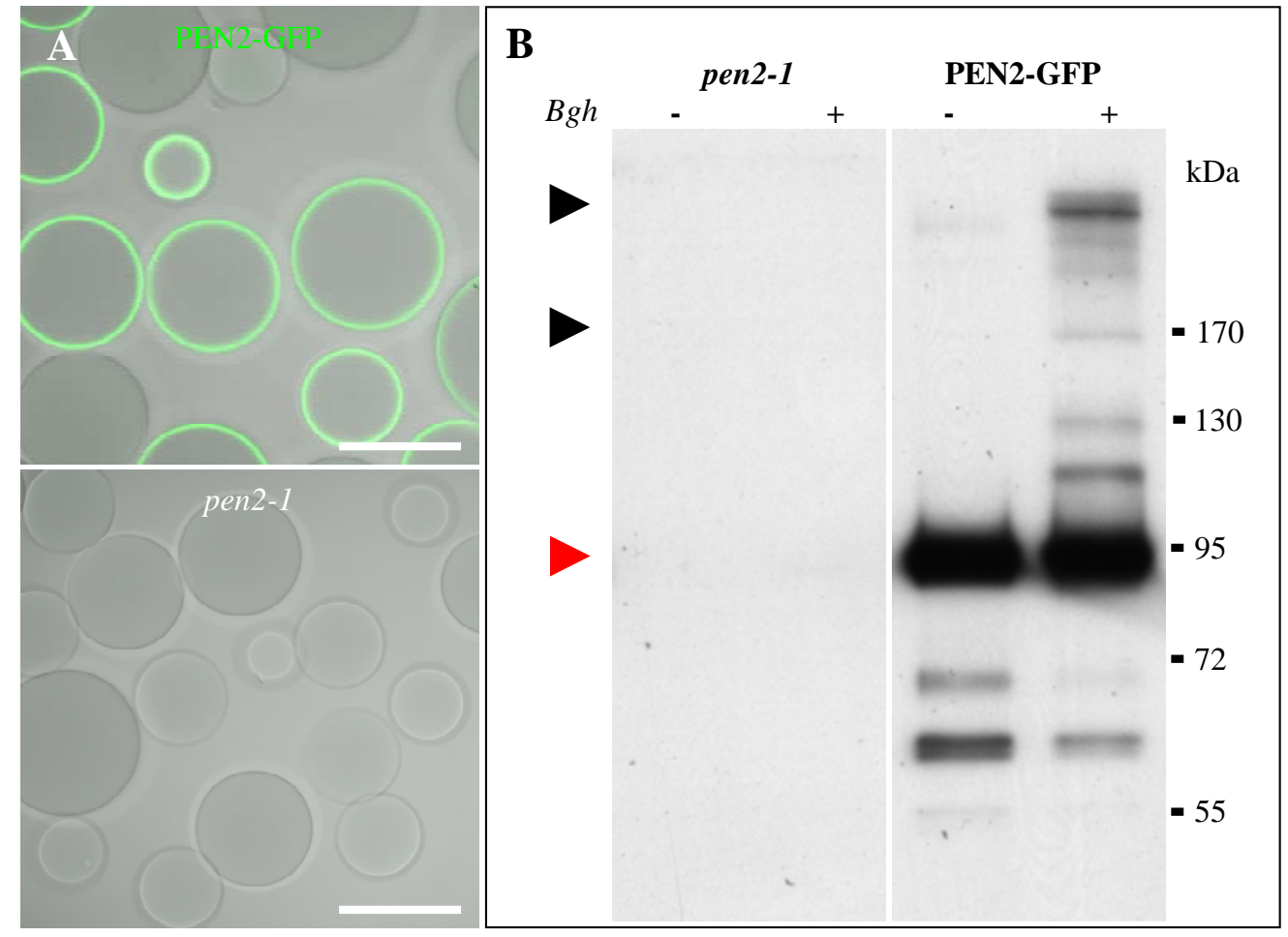

Abb. 3.12: Es entstehen detergenz-resistente PEN2-GFP-Oligomere nach Pathogenbehandlung.

Die fluoreszenzmikroskopischen Aufnahmen in (A) zeigen GFP-Trap Agarose-Beads nach Inkubation mit Pflanzenextrakt von PEN2-GFP-exprimierenden Pflanzen und pen2-1-Mutanten. (B) Jeweils $40 \mu$ l Proteineluat wurden in einem 10 \%igen SDS-Polyacryamidgel aufgetrennt und mittels Elektroblot auf eine PVDF-Membran übertragen. Der immunologische Nachweis erfolgte mit Hilfe eines PEN2-spezifischen Antikörpers (1:10000 verdünnt). Am rechten Rand ist die molekulare Masse der Markerproteine angegeben. Der rote Pfeil markiert das PEN2-GFP-Monomer, die schwarzen Pfeile mögliche Oligomere. Das Experiment wurde dreimal wiederholt. Maßstabsbalken $=100 \mu \mathrm{m}$.

\subsubsection{Funktionsanalyse der C-terminalen Extension von PEN2}

Wie anfangs schon beschrieben, wurde das GFP-Protein zwischen dem globulären Teil von PEN2 und der C-terminalen Extension integriert. Um die Bedeutung der C-terminalen Extension für die subzelluläre Lokalisation des PEN2-Proteins zu analysieren, wurde der globuläre Teil des PEN2-Proteins im PEN2-GFP-Konstrukt deletiert (siehe Abb. 3.13). Die Expression des Deletionskonstrukts GFP-PEN2 ${ }_{\text {cterm }}$ erfolgte unter der Kontrolle des nativen Promotors im pen2-1-Mutantenhintergrund. 


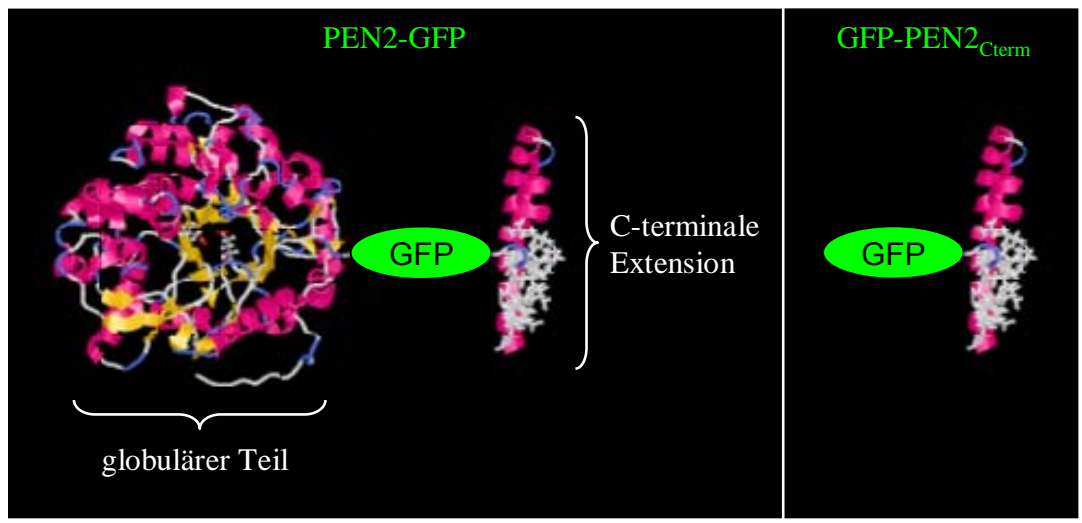

Abb. 3.13: Schematische Darstellung des PEN2-GFP-und des GFP-PEN2cterm-Konstrukts (nach Lipka et al., 2005).

Die fluoreszenzmikroskopischen Aufnahmen in Abb. 3.14 lassen darauf schließen, dass das GFP-PEN2 ${ }_{\text {Cterm}}$-Protein in der Peripherie eines Membrankompartiments lokalisiert. Dieses Kompartiment akkumuliert ebenfalls an Orten der versuchten Pathogeninvasion (Abb. 3.14B). Aufgrund dieser Ergebnisse ist davon auszugehen, dass die C-terminale Extension die subzelluläre Lokalisation von PEN2 bestimmt und unabhängig vom globulären Teil ist. Allerdings konnte keine Fluoreszenzintensivierung unterhalb von Appressorien beobachtet werden, wie es im Fall der PEN2-GFP-Aggregate nachgewiesen werden konnte (siehe Abb. 3.1 zum Vergleich). Dieser Befund belegt, dass eine unspezifische GFP-GFP-Interaktion nicht ursächlich für die beobachtete und oben detailliert beschriebene PEN2-GFPHomomerisierung sein kann. Demnach scheint die Homomerisierung, welche zur Bildung von Aggregaten notwendig ist, vom globulären Teil des PEN2-Proteins abhängig zu sein. Außerdem findet eine Akkumulation des Membrankompartiments auch unabhängig von der Aggregatbildung an der Penetrationsstelle statt. 


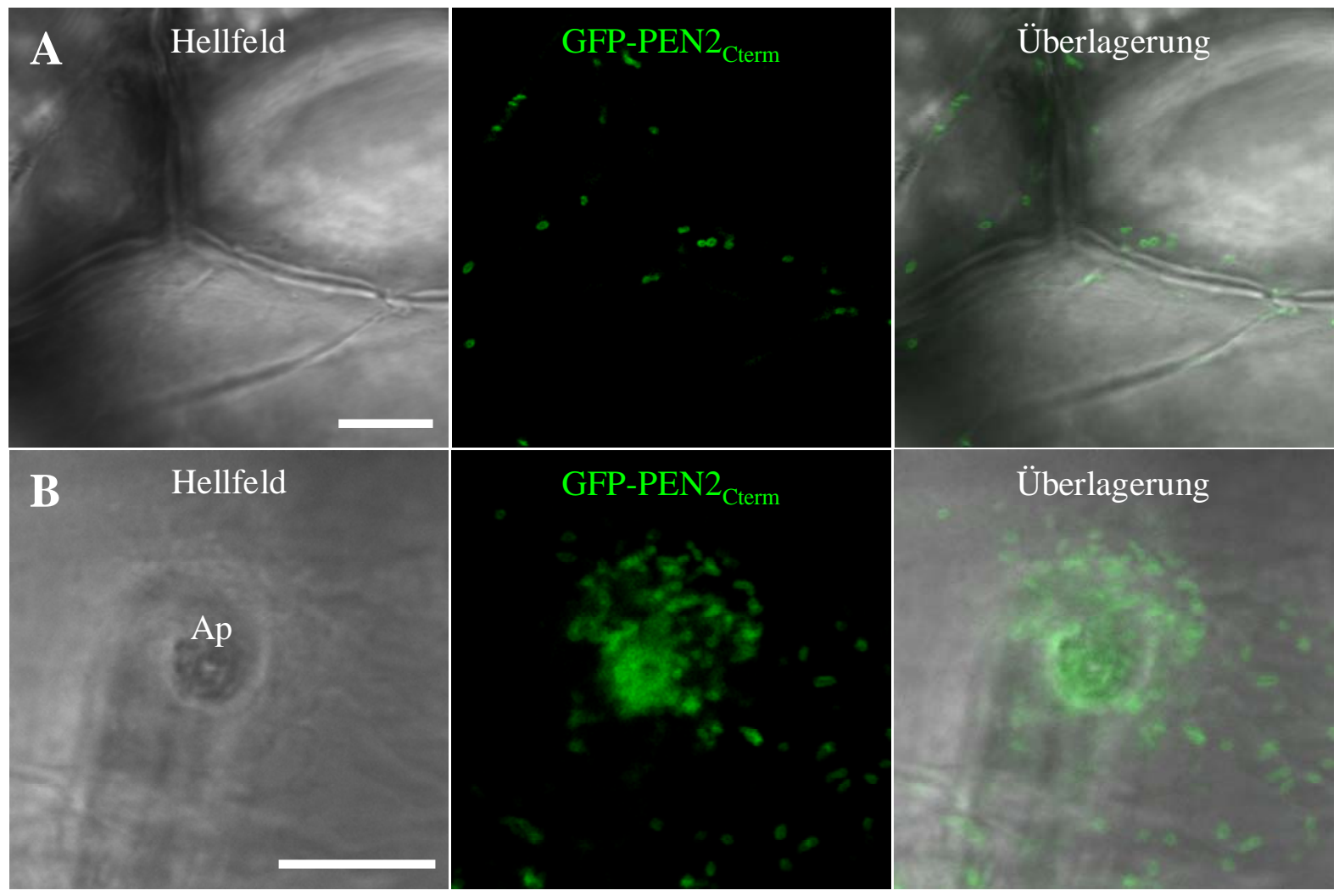

Abb. 3.14: Der C-Terminus von PEN2 bestimmt die subzelluläre Lokalisation.

Die mikroskopischen Einzelaufnahmen zeigen die subzelluläre Lokalisation des GFP-PEN2 Cterm-Proteins in unbehandelten Epidermiszellen $(A)$ und in Epidermiszellen 16 Stunden nach Inokulation mit Bgh (B). Ap, Appressorium. Maßstabsbalken $=10 \mu \mathrm{m}$.

Um sicher zu gehen, dass das GFP-PEN2 ${ }_{\text {Cterm }}$-Protein im gleichen Membrankompartiment lokalisiert ist wie das PEN2-GFP-Protein, wurden doppelt transgene Linien erzeugt. Diese Linien exprimieren das Deletionskonstrukt GFP-PEN2 ${ }_{\text {Cterm }}$ zusammen mit dem PEN2-RFPKonstrukt. Fluoreszenzmikroskopische Aufnahmen dieser Linien zeigen eine Kolokalisation der beiden Fusionsproteine in der Peripherie desselben Membrankompartiments (Abb. 3.15). Allerdings konnte keine Kolokalisation des GFP-PEN2 ${ }_{\mathrm{Cterm}}$-Deletionsproteins mit den PEN2-RFP-Aggregaten beobachtet werden (siehe Pfeil in Abb. 3.15). Diese Ergebnisse demonstrieren zum einen, dass die subzelluläre Lokalisation von PEN2 vom C-Terminus abhängig ist und zum anderen, dass der globuläre Teil notwendig für die Ausbildung von Aggregaten ist. Zusätzlich wird diese Hypothese noch durch Ergebnisse aus Split-UbiquitinExperimenten gestützt, wonach keine Interaktion zwischen dem C-terminalen Teil von PEN2 und dem vollständigen Protein nachgewiesen werden konnte (Christine Klapprodt, eigene Arbeitsgruppe, persönliche Kommunikation). 


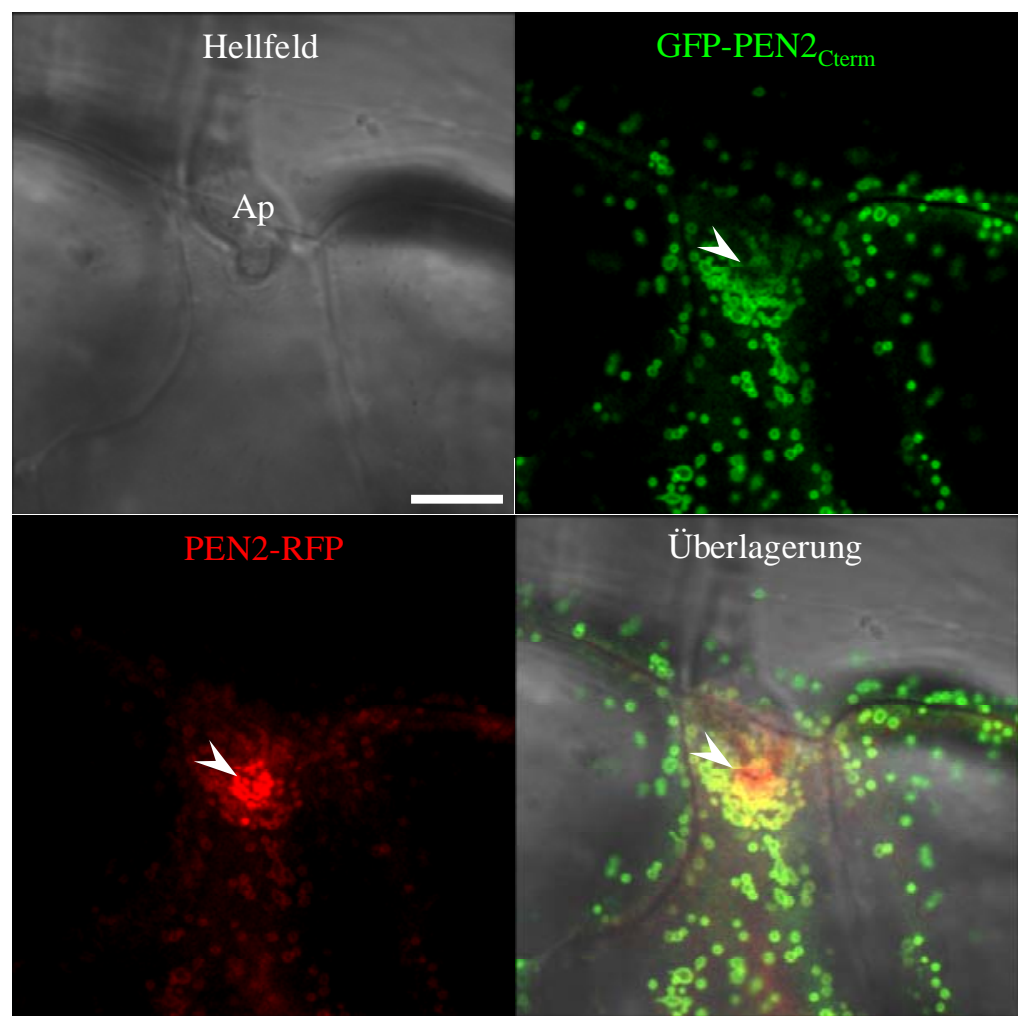

Abb. 3.15: GFP-PEN2cterm und PEN2-RFP kolokalisieren im gleichen Kompartiment, allerdings ist das Deletionskonstrukt nicht Teil der Aggregate.

Abgebildet ist eine fluoreszenzmikroskopische Einzelaufnahme der doppelt transgenen Linie GFP-PEN2Cterm und PEN2-RFP (22 hpi Bgh). Die Pfeile weisen auf das Fehlen des GFP-PEN2Cterm-Signals in den PEN2-RFPAggregaten hin. Ap, Appressorium. Maßstabsbalken $=10 \mu \mathrm{m}$.

Angesichts der Bedeutung des C-Terminus für die subzelluläre Lokalisation wurden weitere Deletionskonstrukte generiert. Eine Übersicht über die verwendeten PEN2-GFPDeletionskonstrukte ist in Abb. 3.16 aufgeführt. Diese Konstrukte sollten Aufschluss darüber geben, welche Elemente innerhalb der C-terminalen Extension für die subzelluläre Lokalisation von PEN2 verantwortlich sind.

\begin{tabular}{|ll|}
\hline [PEN2][GFP]QEDDSSTSKKEEKKESYGKQLLHSVQDSQFVHSIKDSGALPAVLGSLFVVSATVGTSLFFKGANN & PEN2-GFP \\
[PEN2][GFP]QEDDSSTSKKEEKKESYGKQLLHSVQDSQFVHSIKDSGALPAVLGSLFVVSATVGTSLFFKG & PEN2-GFP- $\Delta$ C3 \\
[PEN2][GFP]QEDDSSTSKKEEKKESYGKQLLHSVQDSQFVHSIKDSGALPAVLGSLFVVSATVGTSLFFK & PEN2-GFP- $\Delta$ C4 \\
[PEN2][GFP]QEDDSSTSKKEEKKESYGKQLLHSVQDSQFVHSIKDSGALPAVLGSLFVVSATVGTSLFF & PEN2-GFP- $\Delta$ C5 \\
[PEN2][GFP]QEDDSSTSKKEEKKESYGKQLLHSVQDSQFVHSIKDSFFKGANN & PEN2-GFP- $\Delta$ TM \\
[PEN2][GFP] & PEN2-GFP $-\Delta$ Cterm \\
[PEN2][GFP]QEDDSSTSKKEEKKESYGKQLLHSVQDSQFVHSIKDSGALPAVLGSLFVVSATVGTSLFFGGANN & PEN2-GFP-K ${ }^{556} G$ \\
\hline
\end{tabular}

Abb. 3.16: Auflistung der generierten C-terminalen Deletionskonstrukte von PEN2-GFP.

Abgebildet sind die Aminosäuresequenzen der C-terminalen Extension von PEN2-GFP und die der Deletionskonstrukte. Die positive geladene Aminosäure Lysin $\left(\mathrm{K}^{556}\right)$ ist rot markiert. Der unterstrichene Bereich entspricht der vorhergesagten Transmembrandomäne (Arai et al., 2004). 
Wie in Abbildung 3.17A zu erkennen ist, führt die Deletion der letzten drei Aminosäuren am Ende des C-Terminus nicht zu einer Veränderung der subzellulären Lokalisation. Dieses Konstrukt ist ebenfalls in der Peripherie eines Membrankompartiments lokalisiert und bildet Aggregate an der versuchten Penetrationsstelle aus. Die Deletion einer weiteren Aminosäure beeinflusst die Bildung von Aggregaten ebenfalls nicht, allerdings werden erste Effekte auf die subzelluläre Lokalisation sichtbar (Abb. 3.17B). Hierbei scheint die Signalintensität des PEN2-GFP- $\triangle$ C4-Proteins in der Peripherie des Membrankompartiments reduziert zu sein, wohingegen die Intensität im Cytoplasma zunimmt. Vermutlich ist eine verringerte Affinität des Deletionsproteins zur Membran des Kompartiments für die erhöhte Abundanz im Cytoplasma verantwortlich. Die Deletion von insgesamt fünf Aminosäuren führt zu einer rein cytoplasmatischen Lokalisation des Proteins. Demnach ist das PEN2-GFP$\Delta$ C5-Protein nicht mehr in der Peripherie eines Membrankompartiments assoziiert (Abb. 3.17C). Interessanterweise kommt es dennoch zur Akkumulation unterhalb des Appressoriums. Im Gegensatz zur Fluoreszenzintensivierung des PEN2-GFP-Proteins ist die Fluoreszenz in diesem Fall flächig an der Penetrationsstelle verteilt und bildet keine rundlichen Aggregatstrukturen mehr aus. Der gleiche Effekt tritt ebenfalls bei den Deletionsproteinen PEN2-GFP- $\triangle T$ TM und PEN2-GFP- $\triangle$ Cterm auf (Abb. 3.17D und 3.17E). Beide Fusionsproteine sind ausschließlich im Cytoplasma lokalisiert und zeigen eine flächig verteilte Akkumulation an Orten der versuchten Invasion auf. Wie in Abbildung $3.16 \mathrm{zu}$ erkennen ist, wurde im PEN2-GFP- $\triangle T$ TM-Konstrukt die vorhergesagte Transmembrandomäne entfernt (Arai et al., 2004), wohingegen im Konstrukt PEN2-GFP- $\triangle$ Cterm die komplette C-terminale Extension deletiert wurde. Anhand dieser Ergebnisse wird deutlich, dass die vorhergesagte Transmembrandomäne für die subzelluläre Lokalisation essenziell ist, und dass die C-terminale Extension nicht verantwortlich für die Fluoreszenzintensivierung an Orten der versuchten Penetration ist. Allerdings scheint die Assoziation zum Membrankompartiment ausschlaggebend zu sein für die Ausbildung der rundlichen PEN2-GFP-Aggregate.

In einem weiteren Deletionskonstrukt wurde die positiv geladene Aminosäure Lysin, welche sich in Position 556 der Aminosäuresequenz des nativen PEN2-Proteins befindet, durch die ungeladene Aminosäure Glycin ersetzt (Abb. 3.16). Mullen und Trelease (2000) konnten bereits nachweisen, dass positiv geladene Aminosäuren in der C-terminalen Region der peroxisomalen Ascorbat Peroxidase von Gossypium hirsutum für die subzelluläre Lokalisation des Proteins notwendig sind. Aus diesem Grund wurde auch die Bedeutung der Aminosäure Lysin für die subzelluläre Lokalisation des PEN2-GFP-Reporterproteins untersucht. Wie in Abbildung 3.17F zu erkennen ist, unterscheidet sich die subzelluläre Lokalisation des PEN2-GFP ${ }^{\mathrm{K} 556}$-Proteins deutlich von der des Reporterproteins und denen der zuvor beschriebenen Proteine PEN2-GFP- $\Delta$ TM und PEN2-GFP- $\Delta$ Cterm. Im Gegensatz 
zum PEN2-GFP-Fusionsprotein, weist das Deletionsprotein keine Assoziation mehr zu einem rundlichen Membrankompartimenten auf, sondern bildet netzwerkartige Strukturen aus. Diese netzwerkartigen Strukturen erinnern an fluoreszenzmikroskopische Aufnahmen des GFP-markiertem Endoplasmatischen Retikulums (ER). Interessanterweise bildet das PEN2-GFP ${ }^{\mathrm{K} 556 \mathrm{G}}$-Protein ebenfalls Aggregate an Orten der versuchten Pathogeninvasion aus. Aufgrund dieser Ergebnisse kann geschlussfolgert werden, dass die positiv geladene Aminosäure Lysin ausschlaggebend für die subzelluläre Lokalisation, aber nicht essentiell für die Aggregatbildung ist.
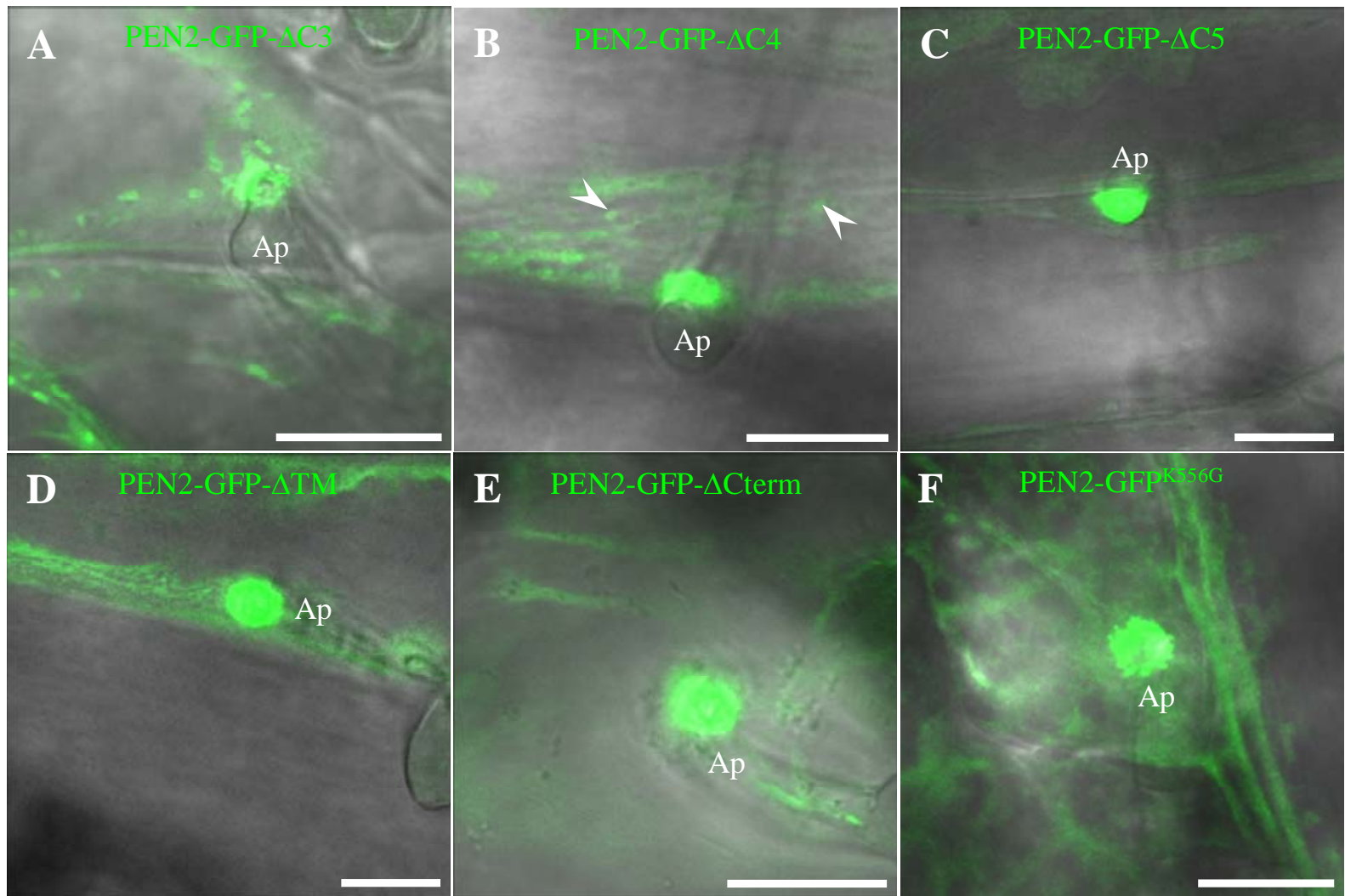

Abb. 3.17: PEN2-GFP-Deletionsproteine zeigen unterschiedliche subzelluläre Lokalisationen.

Die fluoreszenzmikroskopischen Einzelaufnahmen zeigen die subzelluläre Lokalisation der Deletionsproteine PEN2-GFP- $\triangle$ C3 (A), PEN2-GFP- $\triangle$ C4 (B), PEN2-GFP- $\Delta$ C5 (C), PEN2-GFP- $\Delta$ TM (D), PEN2-GFP- $\Delta$ Cterm (E) und PEN2-GFP ${ }^{\mathrm{K} 556 \mathrm{G}}$ (F) 18 Stunden nach Inokulation mit Bgh. Die Pfeile weisen auf die Assoziation des PEN2-GFP- $\triangle$ C4 Proteins mit einem Membrankompartiment hin. Ap, Appressorium. Maßstabsbalken = $15 \mu \mathrm{m}$.

Inwieweit die beschriebenen Deletionskonstrukte den pen2-Phänotyp komplementieren können, wurde in vergleichenden Analysen der Invasions- und Zelltodraten von Bghinokulierten Wildtyppflanzen, pen2-Mutanten und Linien der unterschiedlichen Deletionsproteine untersucht. Die Ergebnisse der Analysen sind in Abbildung 3.18A dargestellt. Zusätzlich wurde die Proteinkonzentration der jeweiligen Linien mittels Western-Blot-Analyse bestimmt (3.18B), um einen proteinkonzentrationsabhängigen Effekt auf die Penetrationsrate zu überprüfen. Wie die Ergebnisse in Abbildung 3.18A erkennen 
lassen, ist die Penetrationsrate in den PEN2-GFP- $\triangle$ C3-Linien nur leicht erhöht im Vergleich zur Reporterlinie PEN2-GFP bzw. zum Wildtyp. Trotz leichter Unterschiede in der Proteinkonzentration der beiden Linien PEN2-GFP- $\Delta$ C3 \#1-3-1-4 und \#3-1-4-1 zur PEN2-GFP-Referenzlinie, wurde keine signifikante Änderung in der Penetrationshäufigkeit nachgewiesen. Im Gegensatz dazu kann für das PEN2-GFP- $\triangle$ C4-Protein eine Abhängigkeit der Invasionsrate von der Proteinmenge beobachtet werden. Die Proteinabundanz der Linie PEN2-GFP- $\triangle C$ 4 \#1-6 ist geringer als die der Linie \#1-4 und weist eine erhöhte Penetrationsrate auf. Wie in Abbildung 3.17B gezeigt wurde, ist die Affinität des PEN2-GFP- $\triangle$ C4-Proteins zum Membrankompartiments reduziert. Diese Reduktion in Kombination mit der verringerten Konzentration des Deletionsproteins könnte der Grund für die erhöhte Anfälligkeit der Linie \#1-6 gegenüber Bgh sein. Welchen Einfluss die Assoziation des Proteins mit dem Membrankompartiment auf die Komplementation des Penetrationsphänotyps hat, wird anhand der Ergebnisse der Deletionsproteine PEN2-GFP- $\triangle \mathrm{C} 5$ und im Besonderen für PEN2-GFP- $\triangle T M$ deutlich. Beide Proteine sind ausschließlich im Cytoplasma lokalisiert und zeigen an der Invasionsstelle ein verändertes Akkumulationsverhalten verglichen mit dem PEN2-GFP-Protein (Abb. 3.17C und 3.17D). Trotz der beschriebenen Proteinakkumulation kann eine deutlich erhöhte Penetrationsrate in beiden Deletionslinien nachgewiesen werden (Abb. 3.18A). Im Vergleich zum PEN2-GFPFusionsprotein zeigen beide Linien des PEN2-GFP- $\Delta$ C5-Proteins reduzierte Proteinmengen, was einen zusätzlichen Effekt auf die Häufigkeit der Invasion haben könnte. Dagegen ist die Abundanz des PEN2-GFP- $\triangle$ TM-Deletionsproteins im Gegensatz zur PEN2-GFPReporterlinie leicht erhöht. Aus den Ergebnissen kann deshalb geschlossen werden, dass eine Assoziation des PEN2-GFP-Proteins zum Membrankompartiment wichtig für die Funktionalität des Proteins ist. Diese These wird ebenfalls durch die Ergebnisse des PEN2-GFP ${ }^{\mathrm{K} 556 \mathrm{G}}$-Proteins gestützt. Die PEN2-GFP ${ }^{\mathrm{K} 556 \mathrm{G}}$-Linie besitzt eine der PEN2-GFP- Linie entsprechend hohe Proteinkonzentration und weist trotzdem eine erhöhte Penetrationsrate im Vergleich zum Wildtyp auf und kann demnach den pen2-Mutantenphänotyp nicht komplemetieren (Abb. 3.18). Zwar bildet das PEN2-GFP ${ }^{\mathrm{K} 556 \mathrm{G}}$-Protein Aggregate an der Penetrationsstelle aus, ist aber im Unterschied zum PEN2-GFP nicht mehr mit einem rundlichen Membrankompartiment, sondern möglicherweise mit dem ER assoziiert (Abb. 3.17F). Demnach scheint die Lokalisation zum Membrankompartiment für die Funktionalität des Proteins wichtiger zu sein, als die Fähigkeit Aggregate ausbilden zu können. Wie die Abbildungen 3.14 und 3.15 veranschaulicht haben, ist das Deletionsprotein GFP-PEN2 ${ }_{\text {Cterm }}$ in der Peripherie eines Membrankompartiments lokalisiert, bildet aber keine Aggregate mehr aus. Da dieses Protein die katalytische Domäne nicht länger beinhaltet, entspricht die Invasionshäufigkeit zwangsläufig der der pen2-1-Mutante (Abb. 3.18A). 


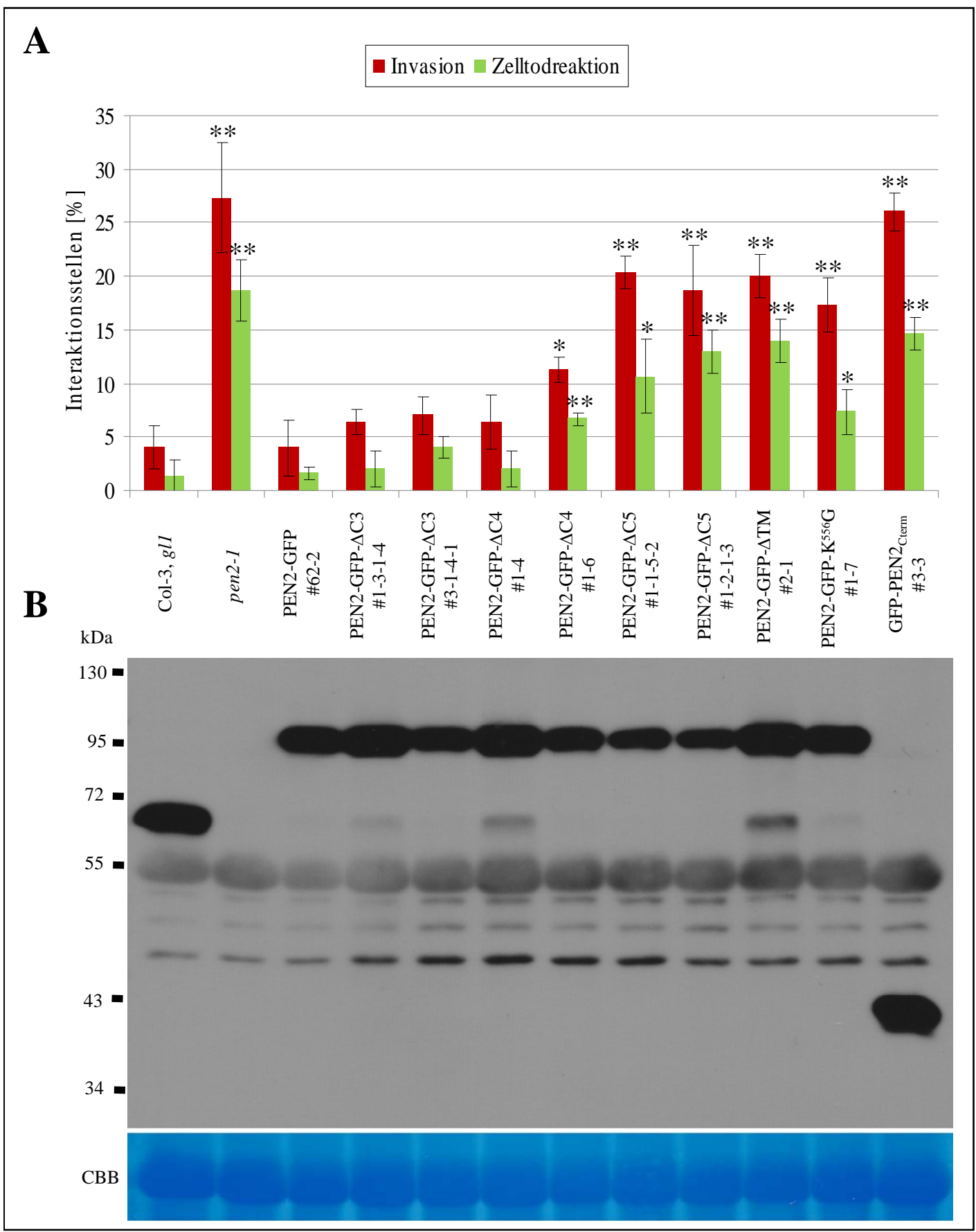

Abb. 3.18: Die Deletionsproteine PEN2-GFP- $\Delta$ C5I- $\Delta T M l^{\mathrm{K} 556 \mathrm{G}}$ und GFP-PEN2 ${ }_{C t e r m}$ komplementieren den pen2-Phänotyp nicht.

(A) Abgebildet ist die vergleichende Analyse der Invasions- und Zelltodraten Bgh-inokulierter Wildtyppflanzen, pen2-Mutanten und transgener Deletionskonstrukt-Linien (72 Stunden nach Inokulation). Pro Linie wurden drei Blätter mit je 100 Interaktionsstellen ausgezählt und in zwei unabhängigen Experimenten wiederholt. Die Sterne geben den signifikanten Unterschied der Invasions- und Zelltodraten zu Wildtyppflanzen an $\left({ }^{*} P \leq 0,05\right.$; ${ }^{* *} P \leq$ 0,005).

(B) Jeweils $30 \mu \mathrm{g}$ Proteinisolat wurden in einem $10 \%$ igen SDS-Polyacryamidgel aufgetrennt und mittels Elektroblot auf eine PVDF-Membran übertragen. Der immunologische Nachweis erfolgte mit Hilfe eines PEN2spezifischen Antikörpers (1:10000 verdünnt). Am rechten Rand ist die molekulare Masse der Markerproteine angegeben. Im unteren Teil ist die Coomassiefärbung des Gesamtproteins dargestellt. Das Experiment wurde dreimal wiederholt. CBB, Coomassie-Brilliant-Blau. 
Abschließend sind die wichtigsten Ergebnisse dieses Abschnitts noch einmal in Tabelle 3.1 zusammengefasst.

Tab. 3.1: Zusammenfassung der Ergebnisse der subzellulären Lokalisation, der Aggregatstruktur und des Penetrationsphänotyps der PEN2-GFP-Deletionsproteine

\begin{tabular}{|c|c|c|c|}
\hline Konstrukt & $\begin{array}{c}\text { Subzelluläre } \\
\text { Lokalisation }\end{array}$ & $\begin{array}{c}\text { Aggregat- } \\
\text { struktur }\end{array}$ & Penetrationsphänotyp \\
\hline PEN2-GFP & Membrankompartiment & rundlich & Wildtyp \\
\hline PEN2-GFP- $\Delta C 3$ & Membrankompartiment & rundlich & Wildtyp \\
\hline PEN2-GFP- $\Delta$ C4 & $\begin{array}{c}\text { Membrankompartiment/ } \\
\text { Cytoplasma }\end{array}$ & rundlich & Wildtyp \\
\hline PEN2-GFP- $\Delta C 5$ & Cytoplasma & flächig & pen2 \\
\hline PEN2-GFP- $\Delta$ TM & Cytoplasma & flächig & pen2 \\
\hline PEN2-GFP $5556 \mathrm{G}$ & ER & rundlich & pen2 \\
\hline GFP-PEN2 & Membrankompartiment & - & \\
\hline
\end{tabular}

Wie die Ergebnisse zeigen, sind die letzten vier Aminosäuren des C-Terminus von PEN2 nicht essentiell für die subzelluläre Lokalisation, Aggregatbildung und Komplementation des pen2-Phänotyps. Die Deletion einer weiteren Aminosäure bzw. die Deletion der putativen Transmembrandomäne ändert hingegen die Lokalisation und das Aggregationsverhaltens der Proteine, was wiederum zu einer deutlich gesteigerten Invasionsrate führt. Die Penetrationsrate ist ebenfalls signifikant erhöht für das Substitutionsprotein PEN2-GFP ${ }^{\mathrm{K} 556 \mathrm{G}}$, welches zwar PEN2-GFP typische Aggregate ausbildet, diese aber nicht länger mit einem rundlichen Membrankompartiment assoziiert sind. Somit ist nicht alleine die Ausbildung der rundlichen Aggregate essentiell für die Funktionalität, sondern auch die Assoziation zu einem bestimmten Membrankompartiment von Bedeutung. Im Gegensatz zum PEN2-GFP ${ }^{\mathrm{K} 556}$-Protein weist das Deletionsprotein GFP-PEN2 ${ }_{\text {Cterm }}$ eine Lokalisation in der Peripherie des gleichen Membrankompartiments wie das PEN2-GFP-Reporterprotein auf, bildet allerdings keine Aggregate mehr aus und komplementiert den pen2-Phänotyp nicht. An dieser Stelle soll noch einmal ausdrücklich darauf hingewiesen werden, dass die Aggregatbildung somit abhängig ist vom globulären Teil des PEN2-GFP-Proteins und nicht bedingt ist durch eine artifizielle Eigenschaft des GFP-Proteins. Es kann demnach festgehalten werden, dass nur Deletionsproteine den pen2-Phänotyp komplementieren, die eine Assoziation mit einem bestimmten Membrankompartiment aufweisen und rundliche Aggregatstrukturen ausbilden. 
Aufgrund der unterschiedlichen Lokalisation und Aggregatbildung der Deletionsproteine PEN2-GFP- $\triangle$ C5, PEN2-GFP- $\triangle T M$ und PEN2-GFP- $\triangle$ Cterm im Vergleich zum PEN2-GFPProtein, wurden weitere Experimente zur Untersuchung des Phänomens durchgeführt. Dazu wurden doppelt transgene Linien erzeugt, die neben dem PEN2-GFP- $\Delta$ TM auch freies RFP unter der Kontrolle des 35S-Promotors $\left(\mathrm{P}_{355}\right)$ exprimieren. Das freie RFP dient hierbei als cytoplasmatischer Marker. Wie in Abbildung 3.19A zu erkennen ist, kolokalisieren beide Proteine im Cytoplasma. Nach Pathogenbehandlung akkumuliert das PEN2-GFP- $\triangle T M$ wie zuvor beschrieben unterhalb des pilzlichen Appressoriums (Abb. 3.19B). Interessanterweise findet im Gegensatz zum Deletionsprotein keine Fluoreszenzintensivierung des RFPProteins an dieser Stelle statt, sondern ist sogar deutlich reduziert (siehe Pfeile in Abb. 3.19B). Insofern scheint die Akkumulation des PEN2-GFP- $\Delta$ TM-Fusionsproteins nicht innerhalb des Cytoplasmas statt $\mathrm{zu}$ finden. Dieser Befund wird zusätzlich durch Untersuchungen mit Hilfe von Anilinblau-gefärbter Callose in lebenden Zellen bestätigt (Meyer et al., 2009). In Abbildung 3.19C ist zu erkennen, dass der Bereich der flächigen Aggregation des PEN2-GFP- $\triangle T$ TM-Proteins mit dem der Anilinblau-gefärbten Callose unterhalb der Penetrationsstelle überlappt, und sich somit außerhalb der Plasmamembran befindet. Dass es sich bei der Fluoreszenzintensivierung des Deletionsproteins nicht um einen GFP-abhängigen Effekt handelt, demonstrieren die fluoreszenzmikroskopischen Aufnahmen von GFP-exprimierenden Pflanzen nach Pathogenbehandlung und Anilinblaufärbung (Abb. 3.19D). Anhand der Abbildung 3.19D wird deutlich, dass freies GFP nicht mit den Bereichen der Anilinblau-gefärbten Callose kolokalisiert. Demnach ist die flächige Akkumulation der PEN2-GFP-Deletionsproteine PEN2-GFP- $\triangle$ C5, PEN2-GFP- $\triangle T M$ und PEN2-GFP- $\triangle$ Cterm, wie sie in Abbildung 3.17 zu sehen ist, vom globulären Teil des PEN2-Proteins abhängig, und scheint demnach nicht eine artifizielle Eigenschaft des GFPProteins zu sein. Außerdem konnte somit gezeigt werden, dass die flächige Aggregation der Deletionsproteine sich nicht nur in ihrer Struktur von denen der rundlichen Aggregate des PEN2-GFP-Proteins unterscheiden, sondern auch in ihrer subzellulären Lokalisation. 


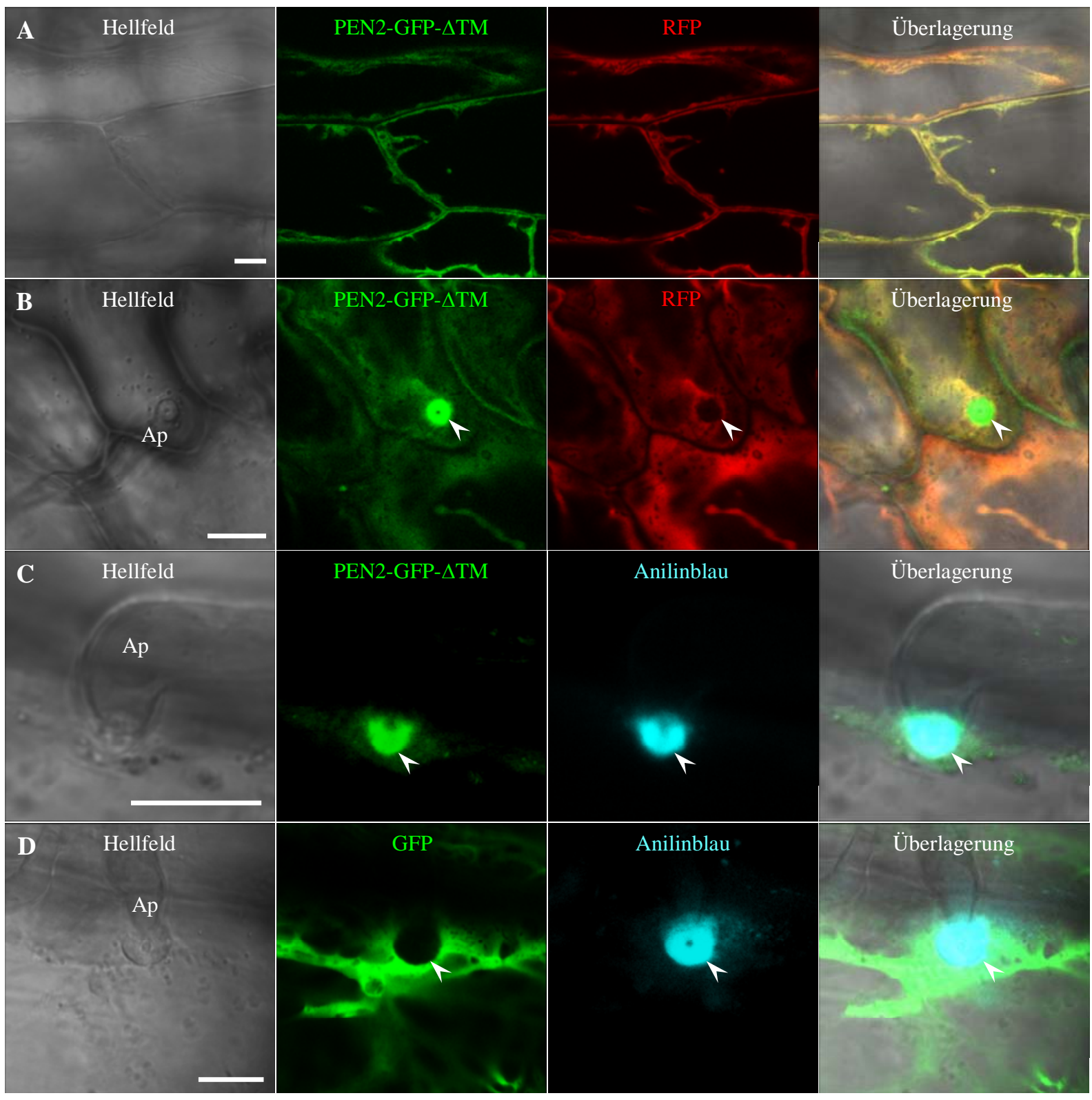

Abb. 3.19: Das Deletionsprotein PEN2-GFP- $\triangle T$ M kolokalisiert mit Anilinblau-gefärbter Callose am Ort der versuchten Pathogeninvasion.

(A, B) Abgebildet sind fluoreszenzmikroskopische Einzelaufnahmen der doppelt transgenen Linie PEN2-GFP$\triangle T M$ und RFP. (B) Die Pfeile weisen auf das fehlende RFP-Signal am Ort der versuchten Pathogeninvasion hin (20 hpi mit Bgh).

(C) Die dargestellten mikroskopischen Aufnahmen sind Einzelaufnahmen der transgenen Linie PEN2-GFP- $\Delta$ TM. Die Pfeile weisen auf die Kolokalisation des PEN2-GFP- $\triangle$ TM-Proteins mit der Anilinblau-gefärbten Callose 20 Stunden nach Inokulation mit Bgh hin.

(D) Eine Kolokalisation von freiem GFP innerhalb Anilinblau-gefärbter Callose konnte 20 hpi mit Bgh nicht beobachtet werden (siehe Pfeile). Ap, Appressorium. Maßstabsbalken $=10 \mu \mathrm{m}$.

Durch Analysen doppelt transgener PEN2-RFP- und PEN2-GFP- $\triangle$ TM-Linien konnte zusätzlich bestätigt werden, dass Unterschiede in der subzellulären Lokalisation der beiden Proteine nach Pathogenbehandlung bestehen. Die repräsentative Abbildung 3.20 zeigt ein sich 24 Stunden nach Inokulation mit Bgh entwickelndes Haustorium. Im Hellfeld der mikroskopischen Aufnahme sind die einzelnen Strukturen des haustoriellen Komplexes 
erkennbar. Der haustorielle Komplex besteht dabei aus einer extrahaustoriellen Membran (EHM), die durch den haustoriellen Kragen (HK) von der Plasmamembran des Wirts getrennt wird (Panstruga, 2003). Zwischen der EHM und der pilzlichen Zellwand (PZW) befindet sich die so genannte extrahaustorielle Matrix (EHMAT). Wie die fluoreszenzmikroskopischen Aufnahmen in Abbildung 3.20 zeigen, kommt es nur im Bereich des haustoriellen Kragens zur Überlappung des PEN2-GFP- $\triangle$ TM- und des PEN2-RFPSignals. Allerdings unterscheidet sich das Akkumulationsmuster des PEN2-RFP-Proteins dennoch von dem des Deletionsproteins, und ist daher mit diesem nicht deckungsgleich. Im Gegensatz zum gerade beschriebenen Bereich, konnte keine Kolokalisation der Signale am Membrankompartiment, an der EHM oder innerhalb der EHMAT festgestellt werden (siehe Pfeile in Abb. 3.20). Eine Lokalisation innerhalb der EHMAT konnte nur für das PEN2-GFP- $\triangle$ TM-Protein beobachtet werden, wohingegen das PEN2-RFP-Fusionsprotein Aggregate an der EHM ausbildet und in der Peripherie eines Membrankompartiments lokalisiert ist. Aufgrund der unterschiedlichen subzellulären Lokalisation der beiden Proteine ist davon auszugehen, dass keine Interaktion zwischen dem PEN2-RFP und PEN2-GFP- $\triangle$ TM-Protein stattfindet. Dies wird durch den Befund unterstützt, dass in SplitUbiquitin Experimenten keine Interaktion zwischen dem vollständigen PEN2-Protein und dem globulären Teil ohne C-terminale Extension festgestellt werden konnte (Christine Klapprodt, eigene Arbeitsgruppe, persönliche Kommunikation). Zusammengefasst legen die Ergebnisse also nahe, dass neben dem globulären Teil von PEN2 auch die subzelluläre Lokalisation des Proteins essentiell für die PEN2-PEN2-Interaktion ist. Zusätzlich konnte mit Hilfe von doppelt transgenen Linien gezeigt werden, dass die flächige Aggregation des PEN2-GFP- $\triangle$ TM-Fusionsproteins außerhalb des Cytoplasmas stattfindet. 


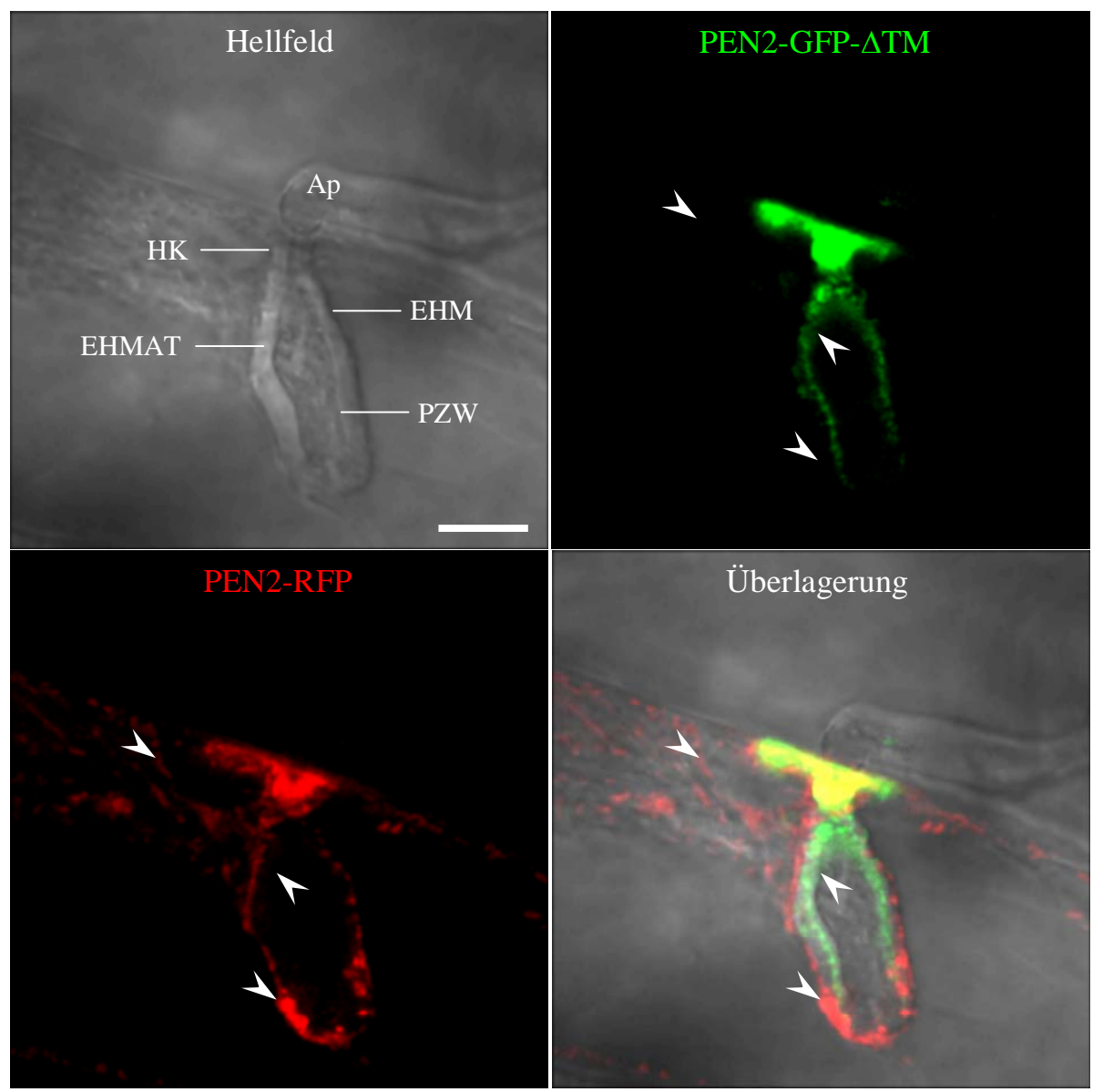

Abb. 3.20: PEN2-GFP- $\triangle T M$ und PEN2-RFP weisen unterschiedliche Lokalisationen am haustoriellen Komplex auf.

Abgebildet ist eine fluoreszenzmikroskopische Einzelaufnahme der doppelt transgenen Linie für PEN2-RFP und PEN2-GFP- $\triangle T$ TM (24 hpi Bgh). Die Pfeile weisen auf die fehlende Kolokalisation der beiden Proteine hin. Ap, Appressorium; EHM, extrahaustorielle Membran; EHMAT, extrahaustorielle Matrix; HK, haustorieller Kragen; $\mathrm{PZW}$, pilzlichen Zellwand. Maßstabsbalken $=10 \mu \mathrm{m}$.

\subsubsection{Fluoreszenzmikroskopische Untersuchungen zum Assoziationsverhalten von PEN2 mit Membrankompartimenten}

Wie bereits aus den vorherigen Ergebnissen hervor ging, ist die Lokalisation in der Peripherie des Membrankompartiments ausschlaggebend für die Funktionalität des PEN2Proteins. Um ermitteln zu können, mit welchem Membrankompartiment PEN2-assoziiert ist, wurden doppelt transgene Linien von PEN2-GFP mit unterschiedlen Organellmarkern generiert (Nelson et al., 2007).

In transienten Assays wurde bereits eine Assoziation von PEN2-GFP mit RFP-markierten Peroxisomen nachgewiesen (Lipka et al., 2005). Zur Markierung der Peroxisomen wurde das Konstrukt RFP-PTS1 („peroxisomal targeting sequence 1“) verwendet, das aufgrund seiner peroxisomalen Lokalisationssequenz zur Akkumulation des RFP-Proteins in der Matrix von Peroxisomen führt. Im Rahmen dieser Arbeit wurden fluoreszenzmikroskopische Analysen mit stabilen, doppelt transgenen Linien für PEN2-GFP und RFP-PTS1 
durchgeführt, die eine Assoziation von PEN2 mit Peroxisomen bestätigen konnten. Wie in Abbildung 3.21 zu erkennen ist, lokalisiert PEN2-GFP-Fusionsprotein in der Peripherie von Peroxisomen (siehe Pfeile in Abb. 3.21A). Allerdings ist das PEN2-GFP-Protein nicht ausschließlich mit Peroxisomen assoziiert, sondern auch in der Peripherie von nicht RFP. markierten Membrankompartimenten lokalisiert. Außerdem konnte keine PeroxisomenKolokalisation der PEN2-GFP-Aggregate an der direkten Interaktionsstelle mit dem Mehltaupilz festgestellt werden (Abb. 3.21A). Wie das Zeitverlaufsexperiment in Abbildung 3.21B zeigt, sind die Peroxisomen in der Zelle frei beweglich und nicht wie die PEN2-GFPAggregate an der Penetrationsstelle immobilisiert. Überdies konnte zu keinem Zeitpunkt eine Akkumulation von mehreren Peroxisomen zeitgleich an der Penetrationsstelle beobachtet werden (Abb. 3.21B). Zwar akkumulieren Peroxisomen im Zeitverlauf am Invasionsort, wie die Maximalprojektion des Zeitverlaufsexperiments erkennen lässt, doch ist diese Akkumulation nur transient und ist nicht deckungsgleich mit dem Ort der oben beschriebenen PEN2-GFP-Aggregation (Abb. 3.21C). Darüber hinaus konnte nie eine Assoziation von PEN2-GFP-Aggregaten mit maturen RFP-PTS1-markierten Peroxisomen belegt werden. Aus diesen Ergebnissen kann geschlossen werden, dass PEN2 durchaus in der Peripherie von Peroxisomen zu finden ist und dass letztere vorübergehend mit Orten der versuchten Pathogeninvasion assoziiert sind. Jedoch stellen Peroxisomen weder die subzellulären Kompartimente dar, welche stationär an Pathogen-Interaktionsstellen akkumulieren, noch findet in ihrer Peripherie die beschriebene pathogen-induzierte PEN2Aggregatbildung statt. 


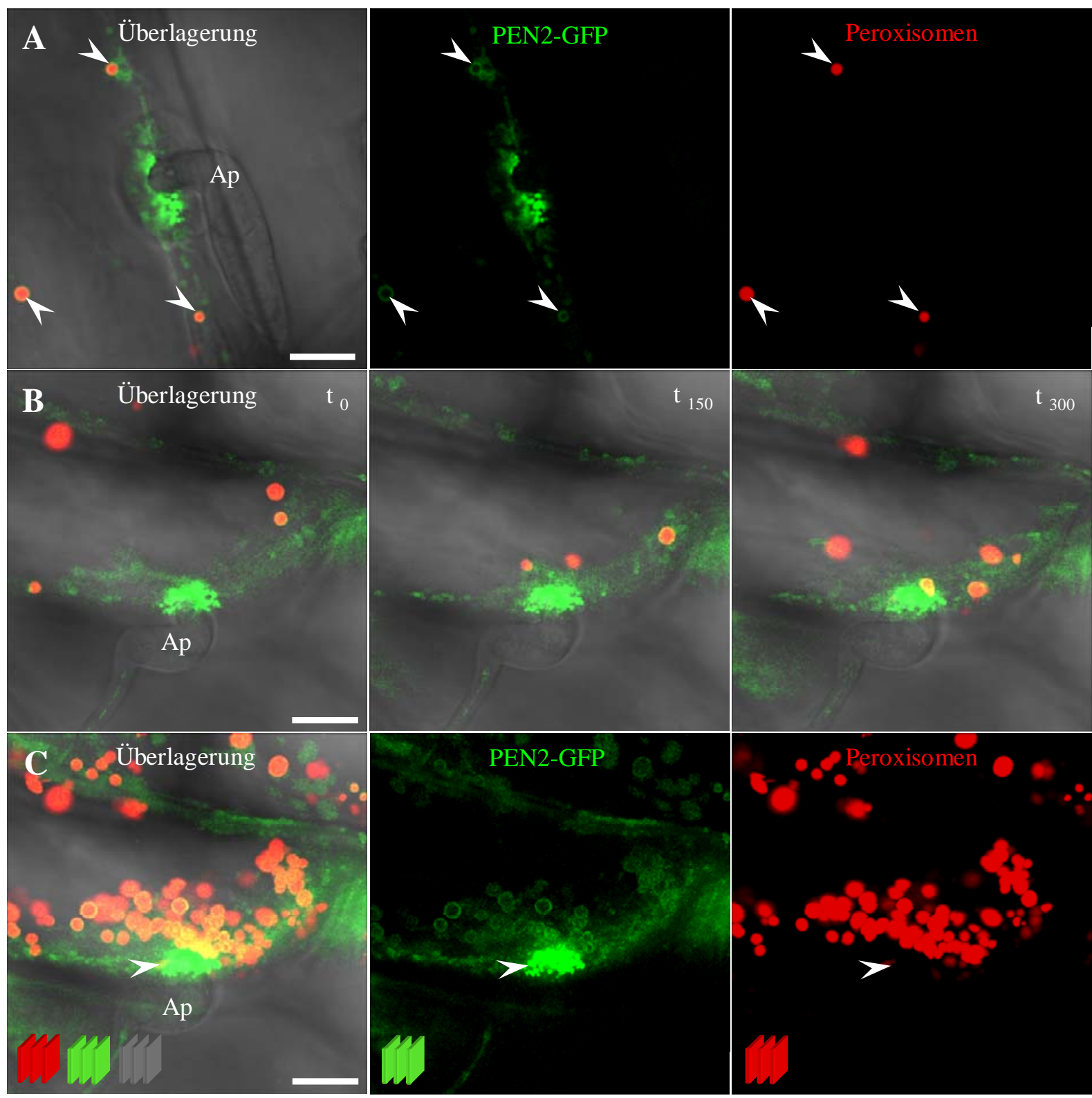

Abb. 3.21: Peroxisomen sind nicht an der fokalen Akkumulation der PEN2-GFP-Aggregate an der Invasionsstelle beteiligt.

Abgebildet sind fluoreszenzmikroskopische Einzelaufnahmen bzw. die Maximalprojektion einer Zeitreihe der doppelt transgenen Linie PEN2-GFP und RFP-PTS1. (A) Die Pfeile weisen auf die Lokalisation des PEN2-GFPFusionsproteins in der Peripherie von RFP-markierten Peroxisomen 20 Stunden nach Inokulation mit Bgh hin. (B) Die dargestellten mikroskopischen Aufnahmen sind Einzelaufnahmen in derselben konfokalen Ebene einer Zeitreihe von 5 Minuten (24 hpi Bgh). (C) Der Pfeil in der Maximalprojektion des Zeitverlaufexperiments (B) weist auf die fehlende Kolokalisation von Peroxsiomen und Aggregaten am Ort der versuchten Penetration hin. Ap, Appressorium; t, Zeit in Sekunden. Maßstabsbalken = $10 \mu \mathrm{m}$.

Im Rahmen dieser Arbeit konnte nun vielmehr gezeigt werden, dass PEN2-GFP neben der bereits demonstrierten Lokalisation in der Peroxisomenperipherie ebenfalls in der Peripherie von Mitochondrien lokalisiert ist (Abb. 3.22A). In den relevanten Experimenten wurde zur Markierung der mitochondrialen Matrix ein Fusionsprotein aus RFP und den ersten 29 Aminosäuren der Cytochrom c Oxidase IV (ScCOX4) von Saccharomyces cerevisiae verwendet (Nelson et al., 2007). Diese Peptidsequenz des ScCOX4-Proteins enthält ein 
spezifisches Importsignal für Mitochondrien (Köhler et al., 1997). Wie die fluoreszenzmikroskopischen Aufnahmen in Abbildung 3.22A erkennen lassen, akkumulieren mehrere Mitochondrien direkt an der Penetrationsstelle im Bereich der PEN2-GFPAggregation (Abb. 3.22A). Zusätzliche konnte in Detailaufnahmen gezeigt werden, dass auch die oben beschriebenen PEN2-GFP-Aggregate ausschließlich mit Mitochondrien assoziiert sind (siehe Pfeile in Abb. 3.22B).

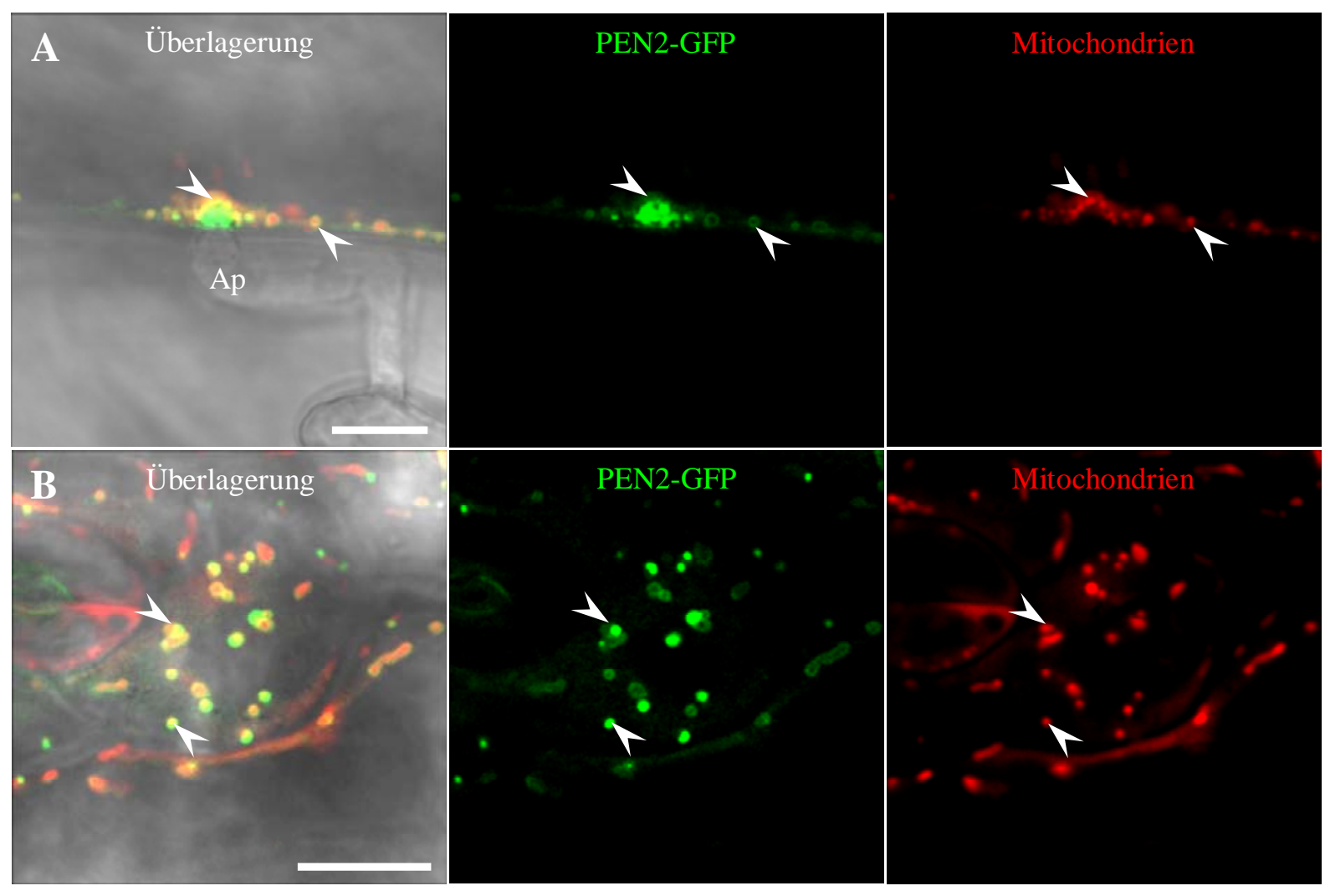

Abb. 3.22: PEN2-GFP-Aggregate sind mit Mitochondrien assoziiert.

Abgebildet sind fluoreszenzmikroskopische Einzelaufnahmen der doppelt transgenen Linie für PEN2-GFP und RFP-markierten Mitochondrien. (A) Die Pfeile weisen auf die Assoziation von PEN2-GFP mit der Peripherie von Mitochondrien und deren Akkumulation am Ort der versuchten Penetration hin (22 hpi Bgh). (B) Wie die Pfeile aufzeigen, sind die PEN2-GFP-Aggregate mit Mitochondrien assoziiert (22 hpi Bgh). Ap, Appressorium. Maßstabsbalken $=10 \mu \mathrm{m}$.

Darüber hinaus konnte eine Lokalisation von PEN2-GFP gleichermaßen in der äußeren Membran von epidermalen Plastiden festgestellt werden (Abb. 3.23). Zur Markierung der Plastiden wurde ein Fusionsprotein aus RFP und den ersten 79 Aminosäuren der kleinen Rubisco-Untereinheit von Tabak verwendet (Nelson et al., 2007). Diese Aminosäure beinhaltet ein spezifisches Signalpeptid für den Transport in das plastidäre Lumen (DabneySmith et al., 1999). Wie man in Abbildung 3.23 erkennen kann, ist das PEN2-GFPFluoreszenzsignal jedoch nur schwach in der Peripherie von RFP-markierten Plastiden sichtbar. Eine Assoziation von PEN2-GFP-Aggregaten mit Plastiden konnte allerdings zu keinem Zeitpunkt beobachtet werden. Zusätzlich konnte keine fokale Akkumulation von 
Plastiden an Orten der versuchten Pathogeninvasion nachgewiesen werden. Auch eine transiente Akkumulation über die Zeit, wie sie etwa bei Peroxisomen auftritt, konnte nicht belegt werden (Ergebnisse nicht gezeigt).

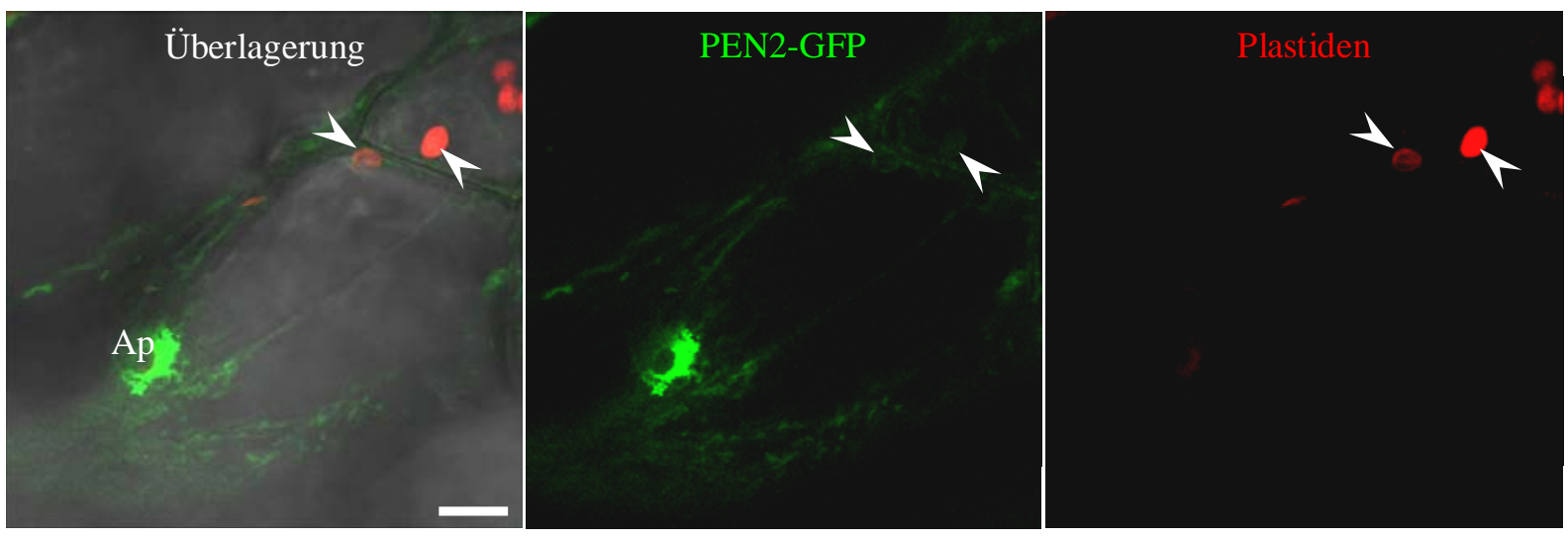

Abb. 3.23: PEN2-GFP ist in der Peripherie von Plastiden lokalisiert.

Abgebildet ist eine fluoreszenzmikroskopische Einzelaufnahme einer Epidermiszelle der doppelt transgenen Linie für PEN2-GFP und RFP-markierte Plastiden (21 hpi Bgh). Die Pfeile weisen auf das PEN2-GFPFluoreszenzsignal in der äußeren Membran von Plastiden hin. Ap, Appressorium. Maßstabsbalken $=10 \mu \mathrm{m}$.

Im Gegensatz zu Peroxisomen, Mitochondrien und Plastiden konnte keine Assoziation des PEN2-GFP-Proteins mit Golgi-Vesikeln oder dem ER festgestellt werden (Abb. 3.24). Zur Bestimmung der subzellulären Lokalisation von Golgi-Vesikeln, wurden die ersten 49 Aminosäuren des Sojabohnen Enzyms $\alpha$-1,2-Mannosidase (GmManl) mit dem RFP-Protein fusioniert (Nelson et al., 2007). Die GmManl-Aminosäuresequenz beinhaltet eine Transmembrandomäne, die zur spezifischen Integration des Fusionsproteins in die Membran von Golgi-Vesikeln führt (Saint-Jore-Dupas et al., 2006). Wie die Aufnahme der doppelt transgenen Linie von PEN2-GFP und RFP-markierten Golgi-Vesikeln zeigt, kann weder eine Kolokalisation, noch eine fokale Akkumulation von Golgi-Vesikeln am Ort der versuchten Invasion nachgewiesen werden (Abb. 3.24A). Ebenso fand keine Kolokalisation von PEN2-GFP mit RFP-markiertem ER statt (Abb. 3.24B). Die Markierung des ERs erfolgte durch die N-terminale Fusion des Signalpeptides der Kinase AtWAK2 („Arabidopsis thaliana wall-associated kinase 2") und der C-terminalen Fusion der Aminosäuresequenz HDEL an das RFP-Protein (Nelson et al., 2007). Aufgrund des AtWAK2-Signalpeptides wird das Reporterprotein in den sekretorischen Transportweg eingeschleust und durch das Retentionssignal HDEL im ER-Lumen zurückgehalten (He et al., 1999; Gomord et al., 1997). 


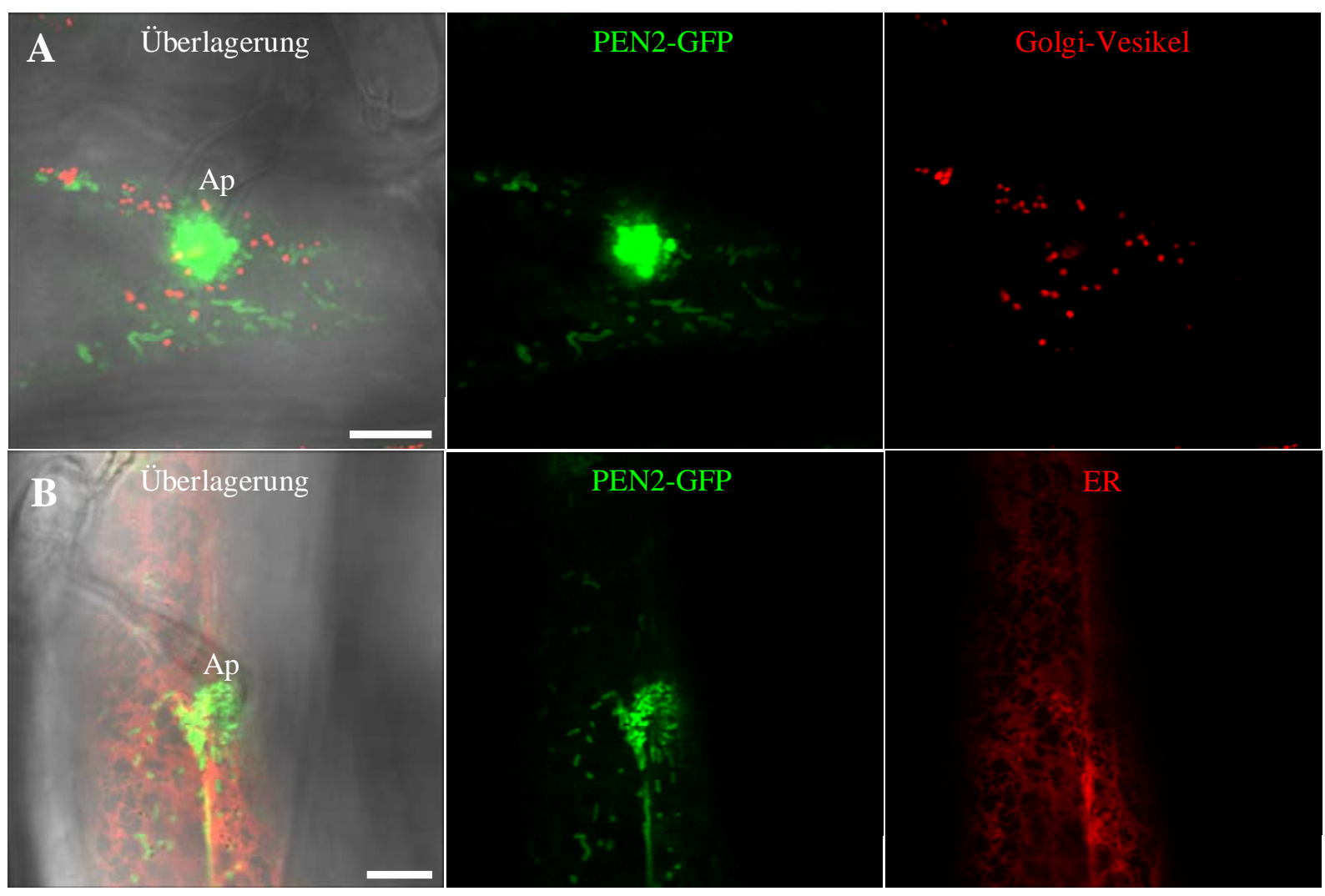

Abb. 3.24: PEN2-GFP zeigt keine Kolokalisation mit Golgi-Vesikeln oder ER.

Abgebildet ist eine fluoreszenzmikroskopische Einzelaufnahme der doppelt transgenen Linie von PEN2-GFP und RFP-markierten Golgi-Vesikeln (23 hpi Bgh), sowie die der PEN2-GFP und RFP-markierten ER-Linie (22 hpi Bgh). Ap, Appressorium. Maßstabsbalken $=10 \mu \mathrm{m}$.

Um zu untersuchen ob der globuläre Teil von PEN2 einen Einfluss auf die Assoziation von PEN2 zu einem bestimmten Organell hat, wurden doppelt transgene Linien von GFPPEN2cterm mit den zuvor beschriebenen Markerproteinen hergestellt. Wie die fluoreszenzmikroskopischen Aufnahmen in Abbildung 3.25 deutlich veranschaulichen, ist das Deletionsprotein nach wie vor in der Peripherie von Peroxisomen, Mitochondrien und Plastiden lokalisiert (Abb. 3.25). Im Vergleich zum PEN2-GFP-Fusionsprotein, zeigt das GFP-PEN2 ${ }_{\text {Cterm}}$-Protein somit keinen Unterschied in der subzellulären Lokalisation.

Diese Ergebnisse verdeutlichen noch einmal, dass die C-terminale Extension von PEN2 ausschlaggebend für die beobachteten subzellulären Lokalisationsmuster ist, und dass der globuläre Teil keinen Einfluss die Assoziation mit einem bestimmten Organell hat. 


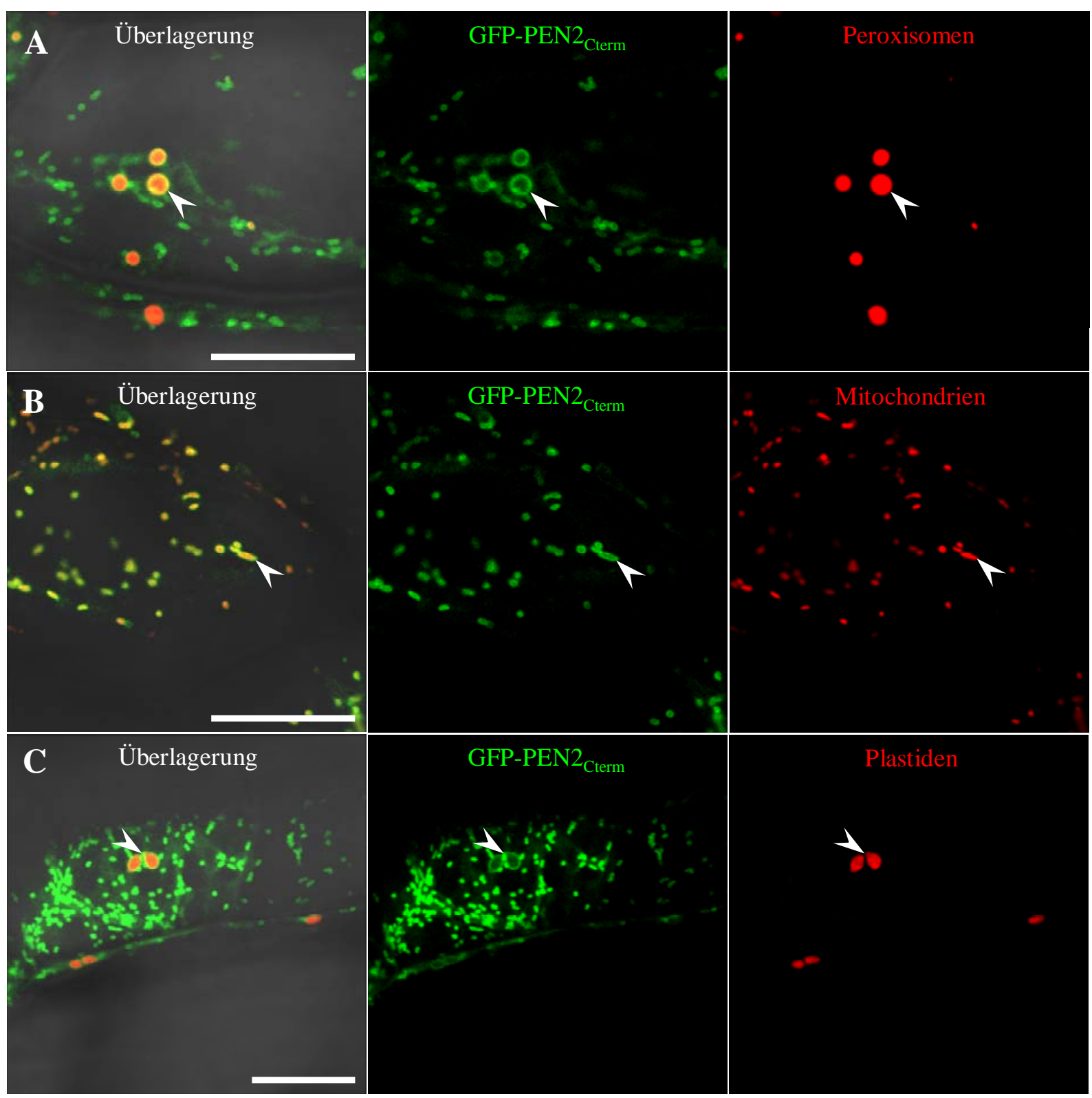

Abb. 3.25: GFP-PEN2 ${ }_{\text {Cterm }}$ ist ebenfalls mit Peroxisomen, Mitochondrien und Plastiden assoziiert.

Abgebildet sind fluoreszenzmikroskopische Einzelaufnahmen von doppelt transgenen Linien, die PEN2-GFP und ein entsprechendes RFP-Fusionsprotein zur Markierung von (A) Peroxisomen, (B) Mitochondrien bzw. (C) Plastiden exprimieren. Die Pfeile weisen auf die Lokalisation des PEN2-GFP-Fusionsproteins in der äußeren Membran des jeweiligen Organells hin. Maßstabsbalken $=25 \mu \mathrm{m}$.

Abschließend kann noch einmal zusammengefasst werden, dass das PEN2-GFP-Protein mit Peroxisomen, Mitochondrien und Plastiden assoziiert ist, allerdings nicht mit GolgiVesikeln oder dem ER (Abb. 3.21 bis 3.24). Eine Kolokalisation des Fusionsproteins mit RFP-markierter Plasmamembran konnte ebenfalls nicht nachgewiesen werden (Ergebnisse nicht gezeigt). Somit scheint die Lokalisation des Reporterproteins in der Peripherie von Peroxisomen, Mitochondrien und Plastiden spezifisch zu sein und nicht durch eine generelle Assoziation des PEN2-GFP-Proteins mit Membranstrukturen zustande zu kommen. Weiterhin konnte gezeigt werden, dass auschließlich der mitochondrien-assoziierte PEN2- 
GFP-Pool der pathogen-induzierten Zellpolarisation und fokalen Organellen-Immobilisierung unterliegt. Außerdem wurden die PEN2-GFP-Aggregate lediglich an Oberflächen von Mitochondrien, nicht jedoch an Oberflächen von Peroxisomen oder Plastiden beobachtet. Aufgrund dieser Ergebnisse kann davon ausgegangen werden, dass Mitochondrien in der PEN2-vermittelten Resistenz gegenüber nicht adaptierten Mehltaupilzen involviert sind. Welche Bedeutung die transiente Akkumulation von PEN2-GFP-assoziierten Peroxisomen an der versuchten Invasionsstelle für die Pathogenabwehr hat, muss allerdings noch im Detail geklärt werden.

\subsubsection{Biochemische Analyse der subzellulären PEN2-Lokalisation}

Um die Ergebnisse der fluoreszenzmikroskopischen Analysen der subzellulären Lokalisation des PEN2-GFP-Proteins durch weitere Experimente zu bekräftigen, wurde das Verhalten des PEN2-GFP-Fusionsproteins und des PEN2-Proteins im Dichtegradienten untersucht. Als Ausgangsmaterial wurde das gesamte Blattmaterial von ca. vier bis sechs Wochen alten, nicht pathogen-behandelten Pflanzen geerntet. Zur Auftrennung der Organellen in einem kontinuierlichen Dichtegradienten, wurde das von Lisenbee et al. (2003) publizierte Protokoll modifiziert. Anstelle des vorzentrifugierten Überstands des Pflanzenextrakts wurde ein Pellet, welches durch Ultrazentrifugation bei $100000 \mathrm{~g}$ gewonnen wurde, auf den kontinuierlichen Dichtegradienten (15 - $55 \%$ Sucrose) geladen. Dieser zusätzliche Zentrifugationsschritt sollte der Anreicherung von Organellen im Pellet dienen und gleichzeitig den Anteil des cytoplasmatischen PEN2-GFP-Pool reduzieren. Der Dichtegradient wurde für 16 bis 18 Stunden bei $100000 \mathrm{~g}$ zentrifugiert und anschließend fraktioniert. Wie anhand von Abbildung 3.26 zu erkennen ist, entstehen im Dichtegradient zwei Bereiche erhöhter PEN2-GFP-Abundanz. Der erste Bereich erstreckt sich über die Fraktionen 6 bis 9, was einer Sucrosekonzentration von 43 bis $37 \%$ entspricht, während der zweite Bereich sich über die Fraktionen 17 bis 24 mit einer Sucrosekonzentration von 19 bis $12 \%$ erstreckt. Neben der Bestimmung der PEN2-GFP-Lokalisation im Dichtegradient wurde auch die Lokalisation von Peroxisomen und Mitochondrien untersucht. Zur Detektion der beiden Organellen im Western-Blot wurden spezifische Antikörper der Firma Agrisera verwendet. Der Antikörper $\alpha$-PEX14 detektiert hierbei das peroxisomale Transmembranprotein PEX14 (,peroxin 14“), wobei der Antikörper $\alpha$-VDAC1 das ebenfalls membranständige mitochondriale Protein VDAC1 („Voltage-dependent anion-selective channel protein 1“) erkennt (Abb. 3.26B). Im Vergleich zum PEN2-GFP können PEX14 und VDAC1 nur im Bereich höherer Sucrosekonzentrationen nachgewiesen werden. Dieser Bereich erstreckt sich für das peroxisomale Protein von Fraktion 3 bis 14, bzw. von Fraktion 
4 bis 12 für das mitochondriale Protein, mit einer Sucrosekonzentration von 49 bis $27 \%$, bzw. 48 bis $31 \%$. Aufgrund dieser Ergebnisse ist davon auszugehen, dass das PEN2-GFPProtein in den Fraktionen 6 bis 9 wahrscheinlich mit Mitochondrien bzw. Peroxisomen assoziiert ist und bestätigt somit die mittels fluoreszenzmikroskopischer Analysen festgestellte Lokalisierung. Allerdings konnte infolge der unzureichenden Auftrennung der Organellen im Dichtegradienten nicht zwischen der mitochondrialen und peroxisomalen Lokalisation des Fusionsproteins unterschieden werden. Im Gegensatz zu den Fraktionen 6 bis 9 liegt definitiv keine Assoziation des Reporterproteins mit den beiden Organellen in den Fraktionen 17 bis 24 vor. Warum das Fusionsprotein eine deutlich höhere Konzentration in den Fraktionen 17 bis 24 aufweist, ist allerdings unklar. Es ist aber davon auszugehen, dass in diesem Bereich des Gradienten hauptsächlich gelöste Proteine zurückbleiben, die aufgrund ihrer Dichte nicht in den Gradienten sedimentieren. Wie eingangs schon erwähnt, sollte der cytoplasmatische PEN2-GFP-Pool mit Hilfe eines zusätzlichen Zentrifugationsschritts entfernt werden. Entweder wurde dieser Pool durch Pelletierung doch nicht ausreichend entfernt oder das PEN2-GFP-Protein wurde während der Resuspendierung des Pellets und bei der Beladung des Gradienten von der Mitochondrienbzw. Peroxisomenmembran ungewollt entfernt. Eine versehentliche Beschädigung der Organellen kann zwar nicht ausgeschlossen werden, ist aber aufgrund des fehlenden Signals der Markerproteine im Immunoblots in den Fraktion 17 bis 24 eher unwahrscheinlich. Man könnte daher spekulieren, dass die Assoziation des Reporterproteins mit der Organellenmembran weit geringer ist als die der Markerproteine PEX14 und VDAC1. Möglicherweise könnte auch das integrierte GFP-Protein einen destabilisierenden Effekt auf die Assoziation mit den Organellenmembranen haben.

Um diese Hypothese zu testen, wurde ebenfalls das Verhalten des nativen PEN2-Proteins im kontinuierlichen Dichtegradienten untersucht. 


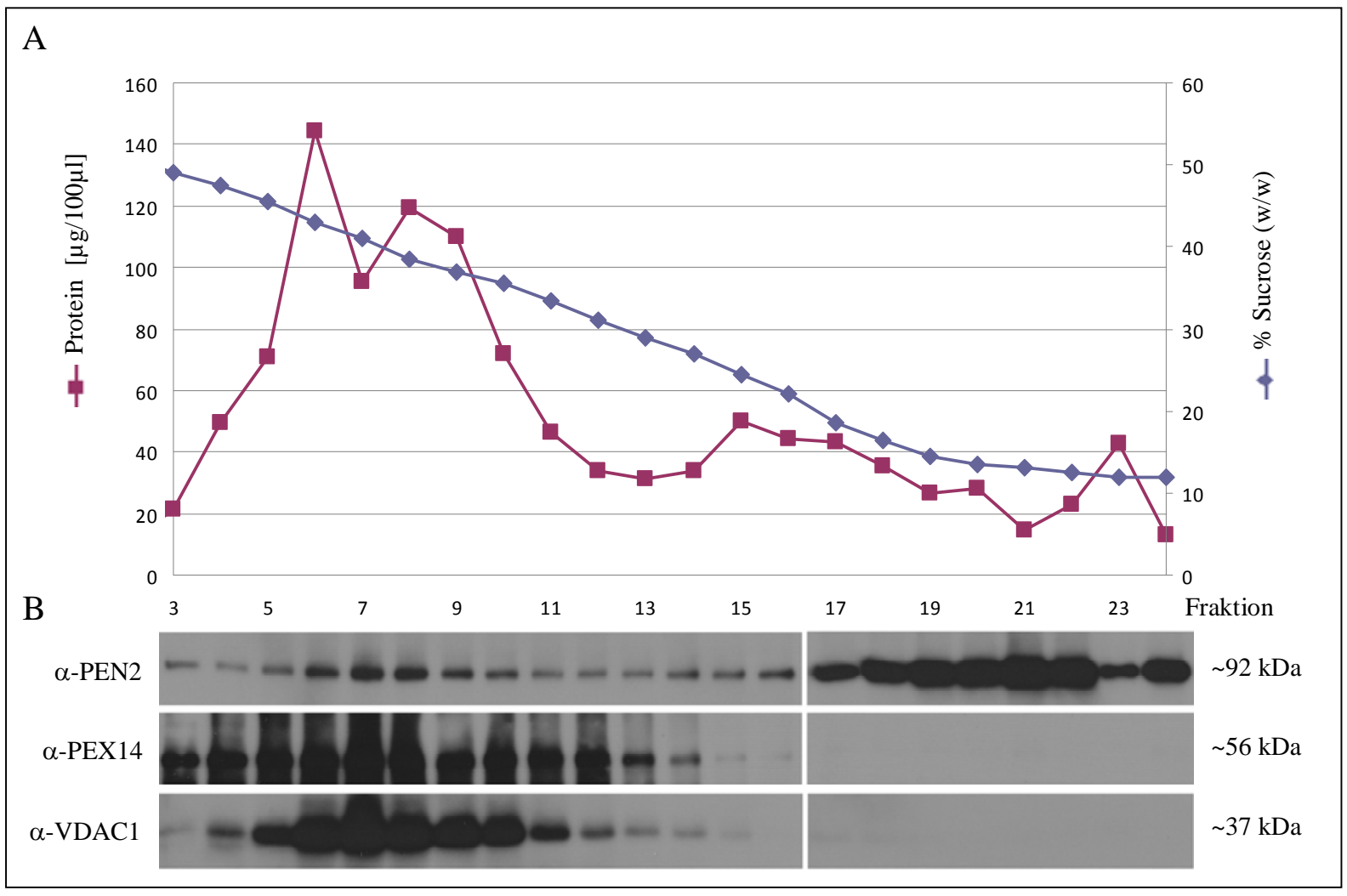

Abb. 3.26: PEN2-GFP kosedimentiert mit Mitochondrien und Peroxisomen im Dichtegradienten, ist aber hauptsächlich in den löslichen Fraktionen vorhanden.

(A) Abgebildet ist die Analyse der Protein- und Sucrosekonzentration in den unterschiedlichen Fraktionen des Dichtegradientens.

(B) Jeweils $30 \mu \mathrm{g}$ Proteinisolat wurden in zwei $10 \%$ igen SDS-Polyacryamidgelen aufgetrennt und mittels Elektroblot auf eine PVDF-Membran übertragen. Der immunologische Nachweis erfolgte mit Hilfe eines PEN2spezifischen Antikörpers (1:10000 verdünnt), PEX14-spezifischen Antikörpers (1:10000 verdünnt) und VDAC1spezifischen Antikörpers (1:5000 verdünnt). Die molekulare Masse der Proteine ist am rechten Rand angegeben.

Wie die Western-Blot-Analyse der Verteilung des PEN2-Proteins im Dichtegradient zeigt, konnte kein signifikanter Unterschied im Vergleich zur Verteilung des PEN2-GFPFusionsproteins festgestellt werden (Abb. 3.27). Das PEN2-Protein weist, wie die Markerproteine PEX14 und VDAC1 auch, eine erhöhte Konzentration in den Fraktionen 6 bis 10 auf (Sucrosekonzentration von 43 bis $35 \%$ ). Allerdings ist die PEN2-Abundanz in den Fraktionen 14 bis 24 (Sucrosekonzentration von 27 bis $16 \%$ ) wesentlich höher. Somit entspricht das PEN2-Verteilungsmuster im Dichtegradienten dem des PEN2-GFP-Proteins. Während der an Organellen gebundene Pool von PEN2 mit Mitochondrien und Peroxisomen im Dichtegradient kosedimentiert, bleibt der höhere Anteil in den löslichen Fraktionen zurück. Die Assoziation des PEN2-Proteins mit der Organellenmembran ist demnach genauso fragil, wie die des Fusionsproteins. Wie zuvor schon spekuliert wurde, könnte eine Ablösung des Proteins aus der Membran durch die präparativen Aufarbeitungsschritte hervorgerufen worden sein. Aufgrund der Ergebnisse kann allerdings davon ausgegangen werden, dass das integrierte GFP-Molekül im Fusionsprotein keinen Einfluss auf die 
subzelluläre Lokalisation des Reporterproteins bzw. die Interaktion mit der Organellenmembran von Mitochondrien oder Peroxisomen hat.

An dieser Stelle ist außerdem noch zu erwähnen, dass die zuvor beschrieben Experimente ebenfalls mit pathogen-behandeltem Pflanzenmaterial durchgeführt worden sind. Allerdings konnte kein signifikanter Einfluss auf das Sedimentationsverhalten von PEN2 und PEN2GFP nach Inokulation mit Bgh festgestellt werden (Ergebnisse nicht gezeigt). Vereinzelt konnte zwar eine geringe Erhöhung der Proteinabundanz der beiden Proteine in den Organellen-gebunden Fraktionen nach Bgh-Behandlung festgestellt werden, jedoch war dieses Ergebnis nicht ausreichend reproduzierbar.

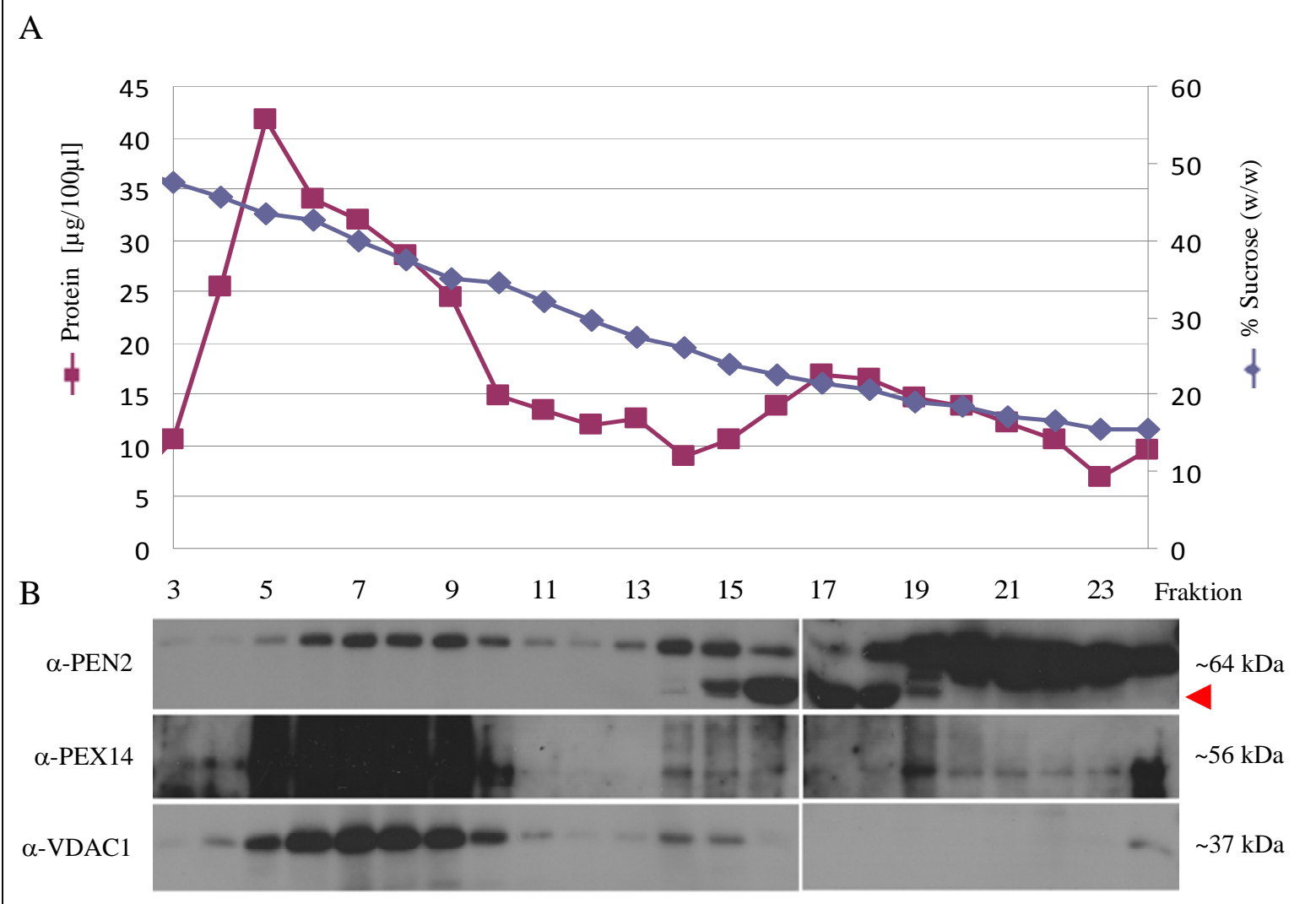

Abb. 3.27: Unmarkiertes PEN2 kosedimentiert mit Mitochondrien und Peroxisomen im Dichtegradienten, ist aber hauptsächlich in den löslichen Fraktionen vorhanden.

(A) Abgebildet ist die Analyse der Protein- und Sucrosekonzentration in den unterschiedlichen Fraktionen des Dichtegradientens.

(B) Jeweils $30 \mu \mathrm{g}$ Proteinisolat wurden in zwei 10 \%igen SDS-Polyacryamidgelen aufgetrennt und mittels Elektroblot auf eine PVDF-Membran übertragen. Der immunologische Nachweis erfolgte mit Hilfe eines PEN2spezifischen Antikörpers (1:10000 verdünnt), PEX14-spezifischen Antikörpers (1:10000 verdünnt) und VDAC1spezifischen Antikörpers (1:5000 verdünnt). Am rechten Rand ist die molekulare Masse der Proteine angegeben. Der rote Pfeil weist auf die Kreuzreaktion des PEN2-Antikörpers mit einem unbekannten Protein hin. Diese unspezifische Interaktion konnte auch in Western-Blot-Analysen von Dichtegradienten beobachtet werden, die mit Pflanzenextrakt von pen2-1-Mutanten beladen wurden (Daten nicht gezeigt). 
Aufgrund der unzureichenden Auftrennung der Organellen im verwendeten Dichtegradienten sollte mit Hilfe organellen-spezifischer Isolationsprotokolle die Assoziation des nativen PEN2-Proteins mit Peroxisomen bzw. Mitochondrien näher charakterisiert werden.

Die Anreicherung von Peroxisomen erfolgte dabei nach einer vereinfachten Version des von Reumann et al. (2007) publizierten Protokolls. Der verwendete Stufengradient bestand aus 3 $\mathrm{ml}$ einer 15 \%igen Percoll-Lösung, $9 \mathrm{ml}$ einer 38 \%iger Percoll-Lösung und $3 \mathrm{ml}$ einer 36 \%iger Sucrose-Lösung (Abb. 3.28A). Als Ausgangsmaterial dienten ca. $20 \mathrm{ml}$ Extrakt von unbehandelten Wildtyp- oder PEN2-GFP-exprimierenden Pflanzen. Mit Hilfe des PEX14spezifischen Antikörpers konnte im Immunoblot die Anreicherung von Peroxisomen im Pellet bestätigt werden (Abb. 3.28B). Im Gegensatz zum peroxisomalen Membranprotein konnte jedoch keine Anreicherung von PEN2 bzw. PEN2-GFP in der Pelletfraktion festgestellt werden. Während sowohl im Extrakt als auch im Überstand von Wildtyppflanzen, bzw. im Überstand der Pflanzen der Reporterlinie, ein deutliches Signal des PEN2-spezifischen Antikörpers im Western-Blot erkennbar war, wurde in der Pelletfraktion ein wesentlich schwächeres Signal nachgewiesen. Aufgrund dessen ist es nicht möglich, PEN2 durch die Isolation von Peroxisomen anzureichern.
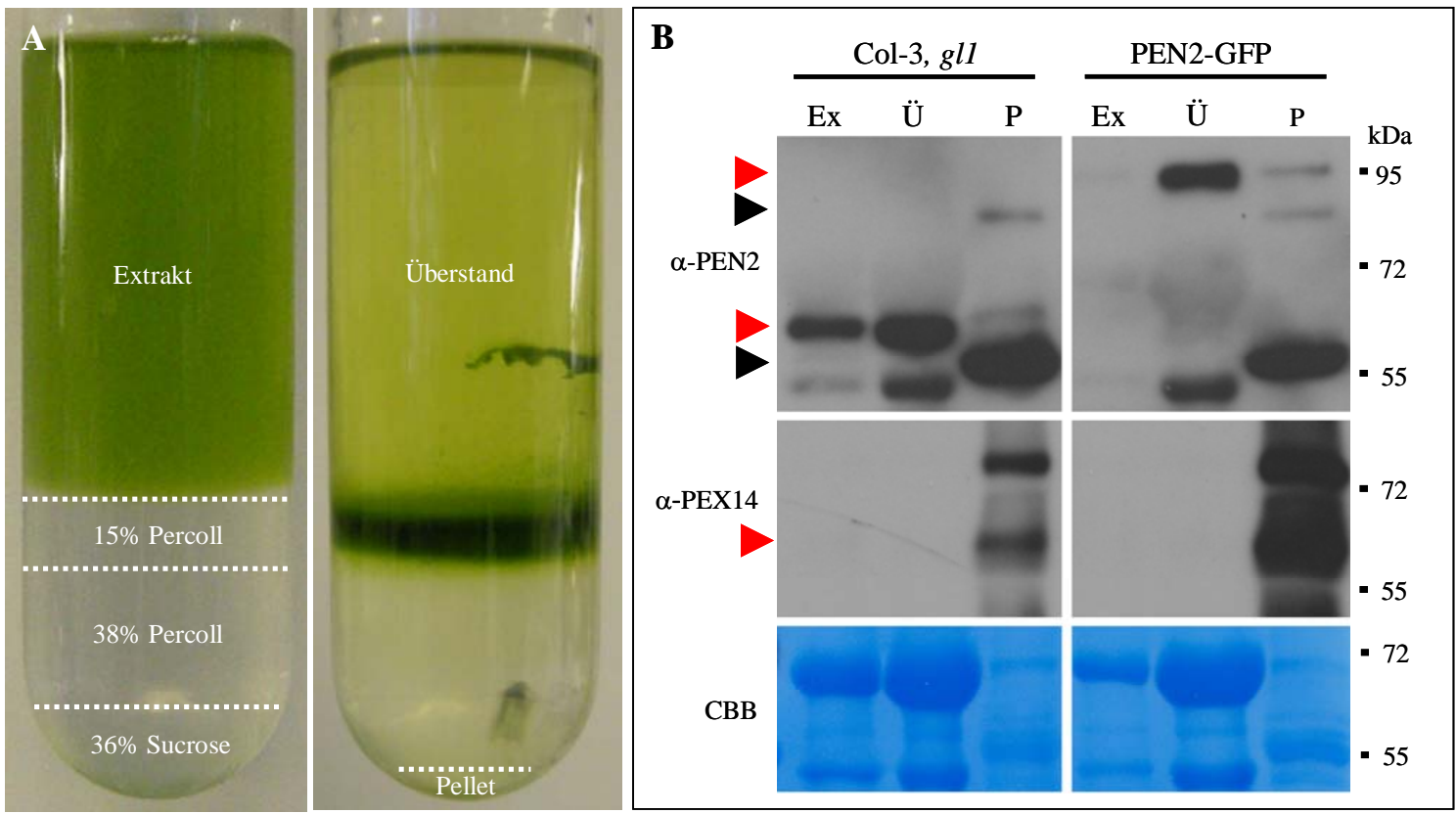

Abb. 3.28: PEN2 kann nicht mit Hilfe von Peroxisomen-Isolations-Protokollen angereichert werden.

(A) Abgebildet sind Aufnahmen des Stufengradienten vor und nach der Zentrifugation. Die unterschiedlichen Schichten bzw. verwendeten Fraktionen sind entsprechend beschriftet.

(B) Jeweils $30 \mu \mathrm{g}$ Proteinisolat wurden in einem $10 \%$ igen SDS-Polyacryamidgel aufgetrennt und mittels Elektroblot auf eine PVDF-Membran übertragen. Der immunologische Nachweis erfolgte mit Hilfe eines PEN2spezifischen Antikörpers (1:10000 verdünnt) und des PEX14-spezifischen Antikörpers (1:10000 verdünnt). Am rechten Rand ist die molekulare Masse der Markerproteine angegeben. Die roten Pfeile markieren das proteinspezifische Signal, die schwarzen Pfeile weisen auf die Kreuzreaktion des PEN2-Antikörpers mit unbekannten Proteinen hin. Im unteren Teil ist die Coomassiefärbung des Gesamtproteins dargestellt. Das Experiment wurde dreimal mit Wildtyppflanzen und zweimal mit PEN2-GFP-exprimierenden Pflanzen wiederholt. CBB, CoomassieBrilliant-Blau; Ex, Extrakt; P, Pellet; Ü, Überstand. 
Zur Isolierung von Mitochondrien wurde ein von Holger Eubel (Leibniz Universität Hannover, Institut für Pflanzengenetik) vorgeschlagenes Protokoll verwendet (persönliche Kommunikation). Als Ausgangsmaterial diente der Blattextrakt von Col-3, gl1-Pflanzen. Wie die Western-Blot-Analysen in Abbildung 3.29 zeigen, ist PEN2 nur im Gradientenpellet eindeutig nachweisbar. Ebenso konnte das mitochondriale Markerprotein VDAC1 mit dem entsprechenden Antikörper im Pellet nachgewiesen werden. Es ist jeweils eine deutliche Bande von PEN2 und VADC1 in der Pelletprobe erkennbar. Eine Kontamination der Pelletprobe mit Peroxisomen kann ausgeschlossen werden, da kein Signal des PEX14spezifischen Antikörpers im Immunoblot beobachtet werden konnte. Aufgrund der hohen BSA-Konzentration im Extraktionspuffer wurde die PEN2-Proteinmenge vermutlich verdünnt, weshalb das Protein im Extrakt nicht nachgewiesen werden konnte.

Eine einmalige Durchführung des Experiments mit Pflanzenextrakt von PEN2-GFPexprimierenden Pflanzen, führte ebenfalls zur spezifische Anreicherung des Fusionsproteins im Pellet (Ergebnis nicht gezeigt).

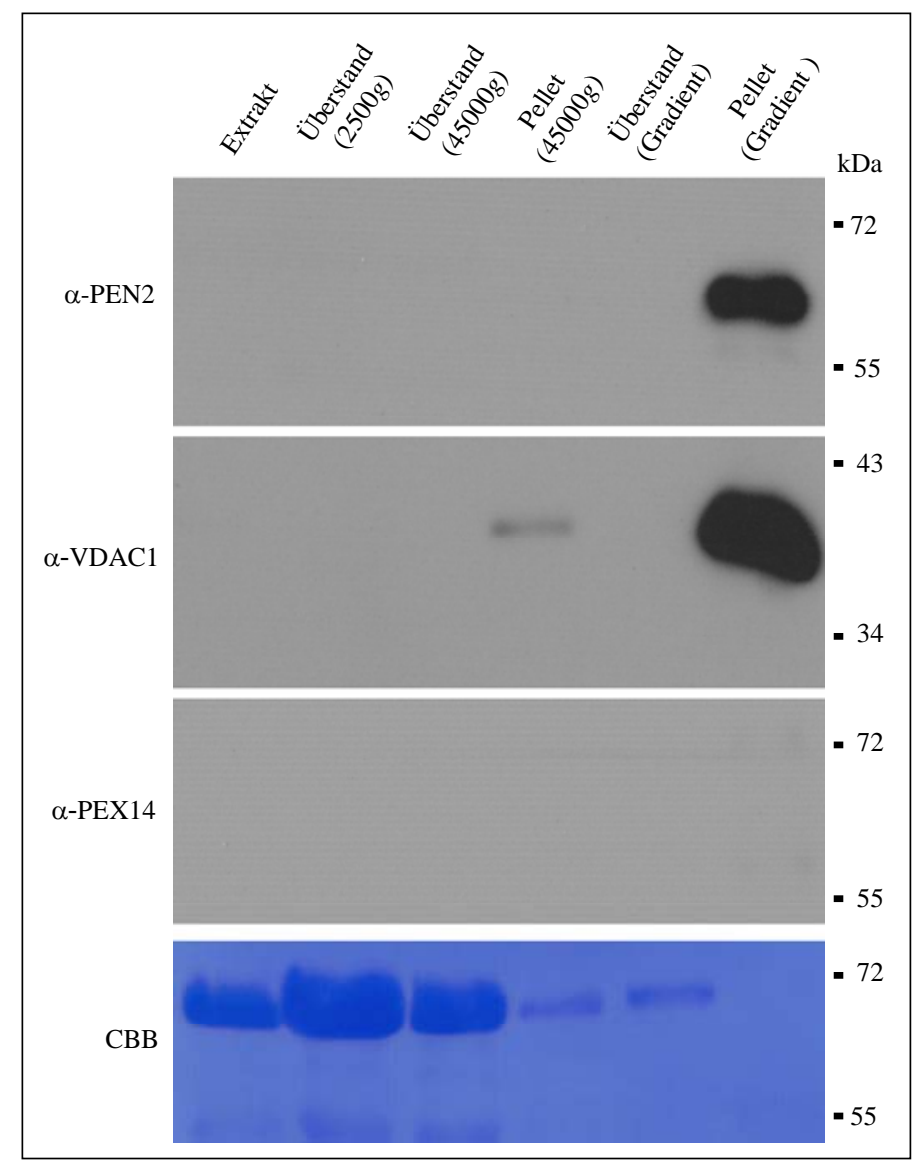

Abb. 3.29: PEN2 kann durch die Isolation von Mitochondrien angereichert werden.

Jeweils 30 mg Proteinisolat wurden in einem 10 \%igen SDS-Polyacryamidgel aufgetrennt und mittels Elektroblot auf eine PVDF-Membran übertragen. Der immunologische Nachweis erfolgte mit Hilfe eines PEN2-spezifischen Antikörpers (1:10000 verdünnt), VDAC1-spezifischen Antikörpers (1:5000 verdünnt) und PEX14-spezifischen Antikörpers (1:10000 verdünnt). Am rechten Rand ist die molekulare Masse der Markerproteine angegeben. Im unteren Teil ist die Coomassiefärbung des Gesamtproteins dargestellt. Das Experiment wurde dreimal durchgeführt. CBB, Coomassie-Brilliant-Blau. 
Abschließend kann zusammengefasst werden, dass PEN2 und PEN2-GFP das gleiche Sedimentationsverhalten im kontinuierlichen Dichtegradient aufweisen. Während ein Teil des PEN2- bzw. PEN2-GFP-Pools mit Mitochondrien und Peroxisomen kosedimentiert, bleibt der größere Anteil in den löslichen Fraktionen zurück. Inwieweit diese durch eine ungewollte Ablösung des Proteins durch präparative Schritte geschieht und/oder aufgrund einer nur schwachen Assoziation des PEN2-Proteins mit der entsprechenden Organellenmembran hervorgerufen wird, muss noch in weiteren Experimenten untersucht werden. Allerdings konnte nachgewiesen werden, dass PEN2 und PEN2-GFP mittels einer spezifischen Isolation von Mitochondrien angereichert werden konnten. Im Gegensatz dazu führte eine Isolierung von Peroxisomen nicht zur Anreicherung der beiden Proteine. Wie die fluoreszenzmikroskopischen Analysen von doppelt transgenen Linien hingegen gezeigt haben, ist das Fusionsprotein auch in der Peripherie von RFP-markierten Peroxisomen lokalisiert. Daher kann nicht vollständig ausgeschlossen werden, dass der peroxisomenassoziierte PEN2-GFP-Pool eine Funktion in der Nichtswirts-Resistenz besitzt.

\subsubsection{Lokalisationsbestimmung chimärer PEN2-GFP-Proteine}

Um die Bedeutung der Assoziation von PEN2 mit Peroxisomen oder Mitochondrien in der Pathogenabwehr zu testen, wurden chimäre Konstrukte von PEN2 und der C-terminalen Extension der Proteine APX3 und TOM20-4 generiert. Wie in der Einleitung bereits beschrieben gehören APX3 und TOM20-4 zur Gruppe der TA-Proteine, die sich durch eine C-terminale Transmembrandomäne auszeichnen (Arai et al., 2004), welche die Lokalisation des Proteins in der entsprechenden Organellenmembran konstituiert. In fluoreszenzmikroskopischen Analysen konnte gezeigt werden, dass GFP-APX3 mit RFPPTS1 markierten Peroxisomen assoziiert ist (Narendra et al., 2006), während TOM20-4 in der äußeren Mitochondrienmembran nachgewiesen werden konnte (Werhahn et al., 2001). Im Folgenden sollte durch die Substitution der C-terminalen Extension von PEN2 mit den organellen-spezifischen Transmembrandomänen von APX3 bzw. TOM20-4 eine exklusive Lokalisation von PEN2 mit nur einer der beiden Organellen erzwungen werden. Demnach sollte das chimäre PEN2-GFP-APX3 $3_{\text {cterm }}$ ausschließlich in der Peripherie von Peroxisomen und das PEN2-GFP-TOM20-4cterm ausschließlich in der Peripherie von Mitochondrien lokalisiert sein. In Abbildung 3.30 sind die C-terminalen Aminosäuresequenzen der beiden chimären Konstrukte im Vergleich zur Wildtyp-Sequenz aufgeführt. 
[PEN2][GFP]QEDDSSTSKKEEKKESYGKQLLHSVQDSQFVHSIKDSGALPAVLGSLFVVSATVGTSLFFKGANN PEN2-GFP

[PEN2][GFP]QEDDSSTSKKLSELGFNPNSSAGKAVADSTILAQSAFGVAVAAAVVAFGFYEIRKRMK

PEN2-GFP-APX3 $3_{\text {Cterm }}$

[PEN2][GFP]QEDDSSTSKKTSEFKYDVFGWVILASYVVAWISFANSQTPVSRQ

PEN2-GFP-TOM20

Abb. 3.30: Darstellung der C-terminalen Aminosäuresequenzen der chimären PEN2-GFP-Konstrukte. Abgebildet sind Aminosäuresequenzen der C-terminalen Extension von PEN2 und die der chimären Konstrukte (rote Schrift). Der unterstrichene Bereich entspricht der vorhergesagten Transmembrandomäne der Proteine (Arai et al., 2004).

Vor der eigentlichen Analyse der chimäre Konstrukte, wurde die subzelluläre Lokalisation der Proteine APX3 und TOM20-4 mittels fluoreszenzmikroskopischer Analysen nochmals überprüft. Hierfür wurden doppelt transgene Linien erzeugt, die ein Fusionsprotein FP-APX3 bzW. FP-TOM20-4 und einen entsprechenden Organellenmarker für Peroxisomen oder Mitochondrien beinhalten.

Wie in Abbildung 3.31 zu erkennen ist, führt die Expression des GFP-APX3-Proteins unter der Kontrolle des 35S-Promotors nicht nur zur Lokalisation des Fusionsproteins in der Peripherie von Peroxisomen, sondern auch von Mitochondrien (Abb. 3.31A und 3.31B). Daher scheint die C-terminale Extension des APX3-Proteins nicht geeignet zu sein, eine ausschließliche Peroxisomen-Lokalisation herbeizuführen. Interessanterweise konnte jedoch keine Assoziation von RFP-APX3 mit Mitochondrien festgestellt werden, wenn das Fusionsprotein unter der Kontrolle des nativen APX3-Promotors $\left(\mathrm{P}_{A P X 3}\right)$ exprimiert wurde. In Abbildung 3.31C ist eine deutliche Lokalisation des RFP-APX3-Proteins in der Peripherie von CFP-markierten Peroxisomen in Mesophyllzellen zu erkennen. Im Gegensatz dazu konnte keine Assoziation des Proteins mit der Peripherie von CFP-markierten Mitochondrien in Mesophyllzellen nachgewiesen werden (Abb. 3.31D). An dieser Stelle ist noch zu erwähnen, dass eine Expression des RFP-APX3-Fusionsproteins nur in Mesophyllzellen beobachtet werden konnte, jedoch nicht in Epidermiszellen. Daher ist anzunehmen, dass das native Promotorelement eine gewebespezifische Expression des Proteins ausweist. Ob die gewebespezifische Expression auch Einfluss auf die subzelluläre Lokalisation hat, ist eher fraglich. Es konnte jedenfalls kein Unterschied in der Assoziation von überexprimiertem GFP-APX3 mit Peroxisomen und Mitochondrien zwischen Epidermis- und Mesophyllzellen festgestellt werden (Ergebnisse nicht gezeigt). Beim Vergleich der beiden transgenen Linien konnte allerdings beobachtet werden, dass das Fluoreszenzsignal des GFP-APX3Fusionsproteins wesentlich stärker ist als das des RFP-APX3-Proteins, was auf eine deutlich höhere Proteinabundanz in der Zelle schließen lässt (Ergebnisse nicht gezeigt). Aufgrund dieser Ergebnisse ist anzunehmen, dass eine Fehllokalisation des Proteins mit Mitochondrien durch eine Überexpression des konstitutiven 35S-Promotor hervorgerufen worden sein könnte. 


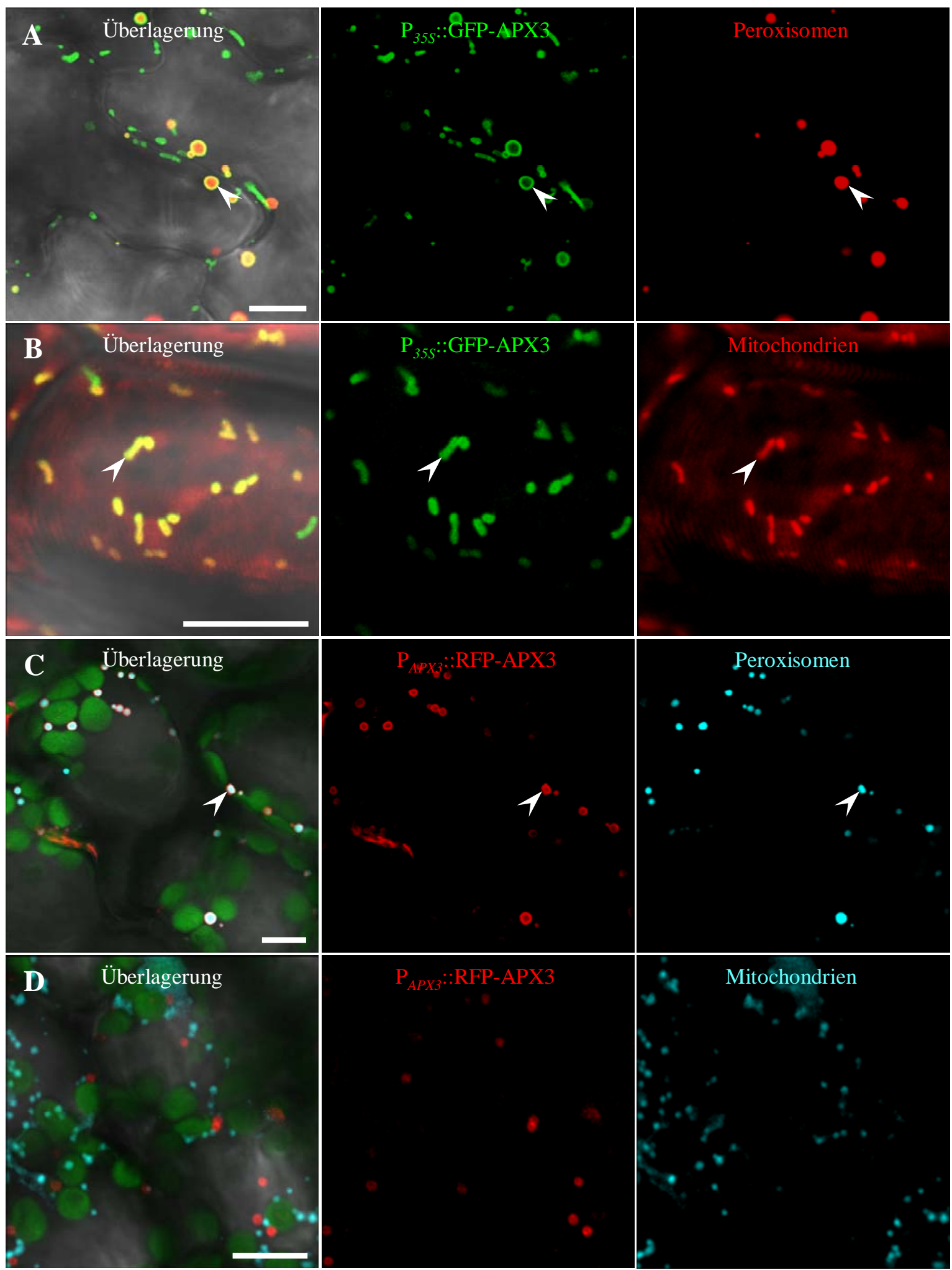

Abb. 3.31: Eine Überexpression des GFP-APX3-Proteins führt zur Assoziation mit Mitochondrien.

Abgebildet sind fluoreszenzmikroskopische Einzelaufnahmen von doppelt transgenen Linien für (A) GFP-APX3 und RFP-markierte Peroxisomen, (B) GFP-APX3 und CFP-markierte Mitochondrien (Falschfarbendarstellung), (C) RFP-APX3 und CFP-markierte Peroxisomen und (D) RFP-APX3 und CFP-markierte Mitochondrien. Der verwendete Promotor zur Expressionskontrolle der jeweiligen APX3-Fusionsproteine ist angegeben. Die Pfeile weisen beispielhaft auf die Lokalisation des FP-APX3-Proteins in der äußeren Membran des jeweiligen Organells hin. Die Autofluoreszenz der Chloroplasten im Mesophyll ist in grün dargestellt. Maßstabsbalken $=10 \mu \mathrm{m}$. 
Um eine Fehllokalisation des chimären PEN2-GFP-APX $3_{\text {Cterm }}$-Proteins durch Überexpression ausschließen zu können, wurde das Konstrukt unter der Kontrolle des nativen PEN2-Promotors im Mutantenhintergrund exprimiert. Wie in Abbildung 3.32A zu erkennen ist, bildet das Fusionsprotein rundliche Aggregate in der Peripherie eines Membrankompartiments aus, welches der pathogen-induzierten Zellpolarisation und fokaler Organellen-Immobilisierung unterliegt. In vorherigen Untersuchungen konnte bereits gezeigt werden, dass Peroxisomen nicht am Ort der versuchten Invasion immoblisiert werden, noch konnte eine Aggregatbildung an der peroxisomalen Membran beobachtet werden. Aufgrund dieser Ergebnisse ist anzunehmen, dass auch das chimäre PEN2-GFP-APX $3_{\text {cterm }}$-Protein nicht ausschließlich in der Peripherie von Peroxisomen lokalisiert ist. Im Unterschied zur PEN2-GFP-Referenzlinie, konnte allerdings eine erhöhte Fluoreszenzintensität in der Membran einiger Organellen festgestellt werden (siehe Pfeile in Abb. 3.32A). Ansonsten war keine Differenz in der subzellulären Lokalisation und der Aggregatbildung der beiden Proteine nachweisbar. Inwieweit das chimäre Fusionsprotein auch den pen2Penetrationsphänotyp komplementieren kann, wurde in vergleichenden Analysen der Invasions- und Zelltodraten Bgh-inokulierter PEN2-GFP-APX $3_{\text {Cterm }}$-Linien, pen2-Mutanten und Wildtyppflanzen untersucht. Das Ergebnis, dargestellt in Abbildung 3.32B, beweist eindeutig die Funktionalität des chimären Proteins. Dabei korreliert die Komplementationskapazität mit der Proteinabundanz des Fusionsproteins. Dies wird besonders deutlich beim Vergleich der Ergebnisse des Penetrationsassays mit den Ergebnissen der Western-Blot-Analyse, die mit Hilfe eines GFP-spezifischen Antikörpers durchgeführt wurde (Abb. 3.32B und 3.32C). Die PEN2-GFP-APX3 $3_{\text {Cterm }}$-Linie \#2-1 zeigt hierbei keinen Penetrationsphänotyp und besitzt eine ähnlich hohe Proteinkonzentrationen wie die Referenzlinie PEN2-GFP \#62-2, während die Linie \#3-3 deutlich geringere Proteinmengen des chimären Proteins aufweist und eine erhöhte Penetrationsrate erkennen lässt. Somit besitzt das PEN2-GFP-APX $3_{\text {Cterm }}$-Protein nicht nur eine nahezu identische subzelluläre Lokalisation wie das PEN2-GFP-Referenzprotein, sondern kann dieses auch funktional in der Pathogenabwehr ersetzen, sobald eine kritische Proteinkonzentration erreicht ist. 

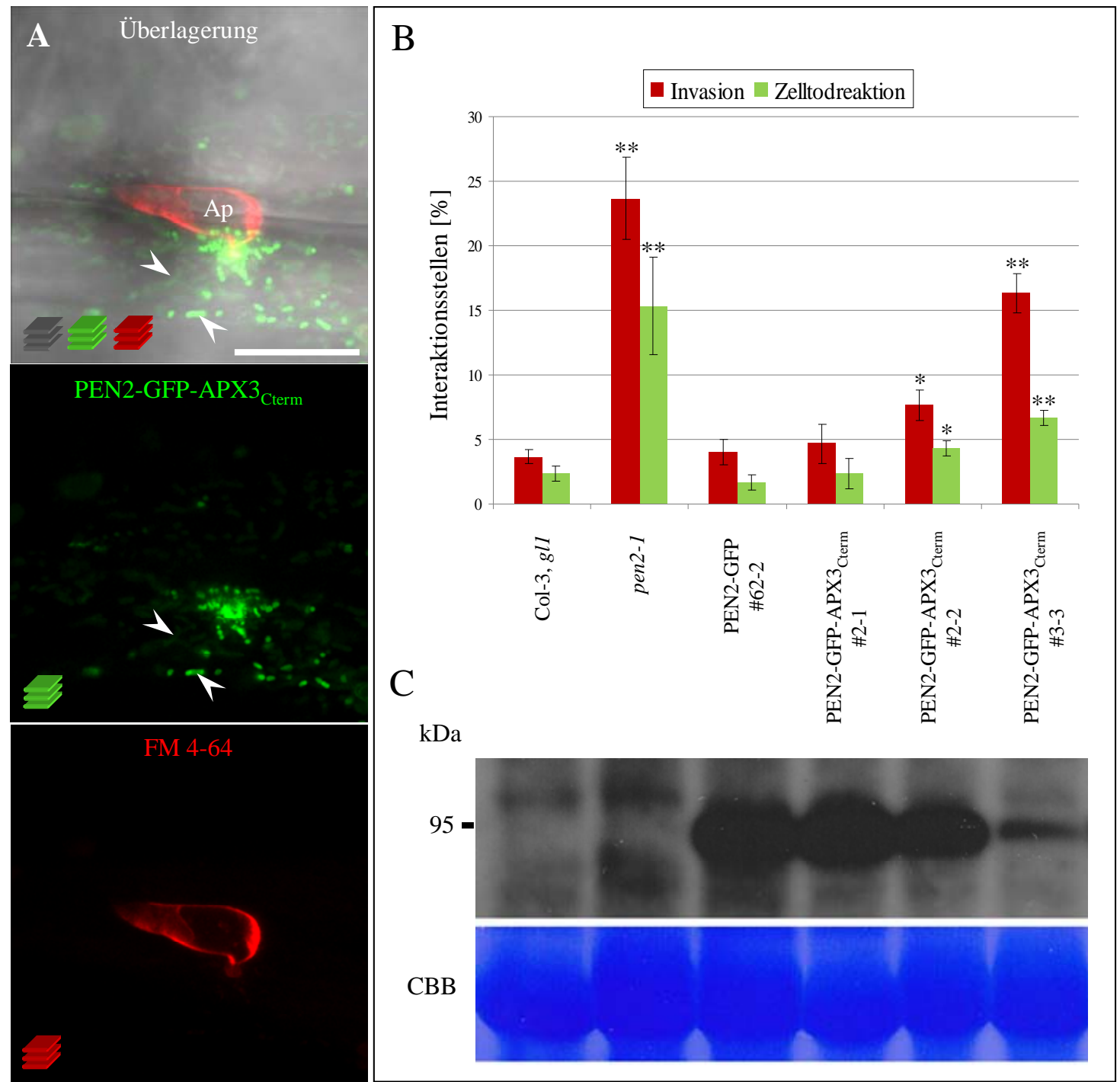

Abb. 3.32: Der C-Terminus von APX3 kann den von PEN2 funktional ersetzen.

(A) Die Abbildung zeigt die Maximalprojektion einer Z-Serie, welche 17 Stunden nach Inokulation mit Bgh aufgenommen wurde. Die Pfeile weisen auf die unterschiedliche Fluoreszenzintensität in der Membran einiger Organellen hin. Mit Hilfe des Farbstoffs FM 4-64 wurde die pilzliche Struktur angefärbt. Ap, Appressorium. Maßstabsbalken $=25 \mu \mathrm{m}$.

(B) Abgebildet ist die vergleichende Analyse der Invasions- und Zelltodraten Bgh-inokulierter Wildtyppflanzen,

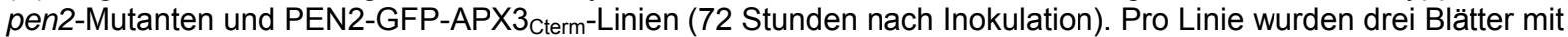
je 100 Interaktionsstellen ausgezählt und in drei unabhängigen Experimenten wiederholt. Die Sterne geben den signifikanten Unterschied der Invasions- und Zelltodraten zu Wildtyppflanzen an $\left({ }^{*} P \leq 0,05 ;{ }^{*} P \leq 0,005\right)$.

(C) Jeweils $30 \mu \mathrm{g}$ Proteinisolat wurden in einem 10 \%igen SDS-Polyacryamidgel aufgetrennt und mittels Elektroblot auf eine PVDF-Membran übertragen. Der immunologische Nachweis erfolgte mit Hilfe eines GFPspezifischen Antikörpers (1:5000 verdünnt). Am linken Rand ist die molekulare Masse des Markerproteins angegeben. Im unteren Teil ist die Coomassiefärbung des Gesamtproteins dargestellt. Das Experiment wurde dreimal wiederholt. CBB, Coomassie-Brilliant-Blau.

Inwiefern das Protein mit Peroxisomen oder auch mit Mitochondrien assoziiert ist, sollte in doppelt transgenen Linien näher untersucht werden. Hierzu wurde die transgene Linie pen2-1 ( $P_{P E N 2}::$ PEN2-GFP-APX3 $\left.3_{\text {Cterm }}\right)$ \#2-1 mit den zuvor im Detail beschriebenen Organellenmarkern für Peroxisomen bzw. Mitochondrien stabil transformiert (Nelson et al., 2007). Wie die fluoreszenzmikroskopischen Aufnahmen in Abbildung 3.33A belegen, ist das chimäre Protein nicht ausschließlich mit Peroxisomen assoziiert. Es kann zwar eine erhöhte 
Fluoreszenzintensität des PEN2-GFP-APX3 $3_{\text {Cterm }}$-Proteins in der Peripherie von Peroxisomen festgestellt werden, jedoch liegt ebenfalls eine deutliche Assoziation mit Mitochondrien vor (Abb. 3.33B). Die verstärkte Signalintensität in der Peripherie von Peroxisomen könnte auf eine höhere Affinität der C-terminalen Extension des APX3-Proteins zur peroxisomalen Membran hinweisen. Allerdings kann aufgrund dieses Ergebnisses kein Rückschluss für die Bedeutung der Assoziation des PEN2-Proteins mit der peroxisomalen Membran in der Pathogenabwehr gezogen werden. Demnach ist auch wahrscheinlich, dass die beobachteten Aggregate des chimären Proteins nicht an der Membran von Peroxisomen gebildet wurden, sondern an der von Mitochondrien. Weitere fluoreszenzmikroskopische Analysen der doppelt transgenen Linie müssen dies allerdings noch bestätigen.

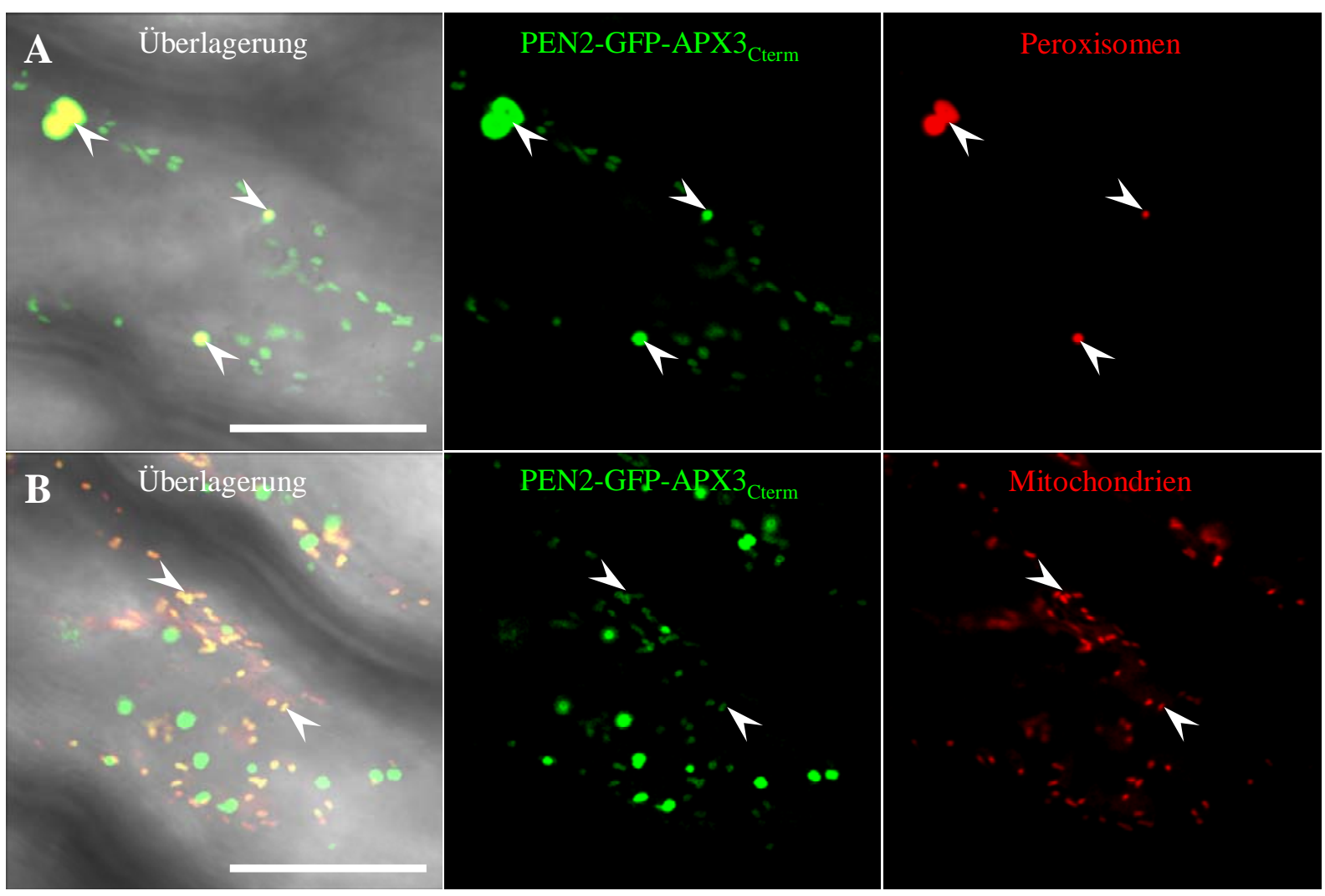

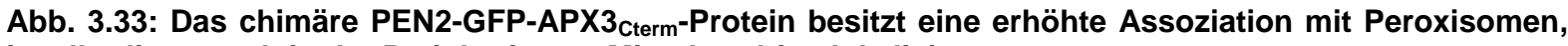
ist allerdings auch in der Peripherie von Mitochondrien lokalisiert.

Abgebildet sind fluoreszenzmikroskopische Einzelaufnahmen von Epidermiszellen doppelt transgener Linien. Die Pfeile weisen auf die Assoziation des chimären Proteins mit der jeweiligen Organellenmembran hin. Maßstabsbalken $=25 \mu \mathrm{m}$.

Im Gegensatz zum GFP-APX3, besitzt das RFP-TOM20-4-Fusionsprotein eine spezifische Assoziation mit nur einem Organell. Wie die fluoreszenzmikroskopischen Aufnahmen in Abbildung 3.34A zeigen, ist das Fusionsprotein mit GFP-markierten Mitochondrien assoziiert. Eine Lokalisation in der Peripherie von CFP-markierten Peroxisomen konnte nicht beobachtet werden (3.33B). Somit führt die Überexpression des RFP-TOM20-4- 
Fusionsproteins, im Unterschied zum GFP-APX3, nicht zur Fehllokalisation mit anderen Organellen. Aufgrund dessen scheint der C-Terminus von TOM20-4 geeignet zu sein, eine spezifische Assoziation mit der mitochondrialen Membran zu bewirken. Aus diesem Grund wurde die C-terminale Extension von TOM20-4 zur Herstellung des chimären PEN2-GFP-TOM20-4 ${ }_{\text {Cterm }}$-Konstrukts verwendet.

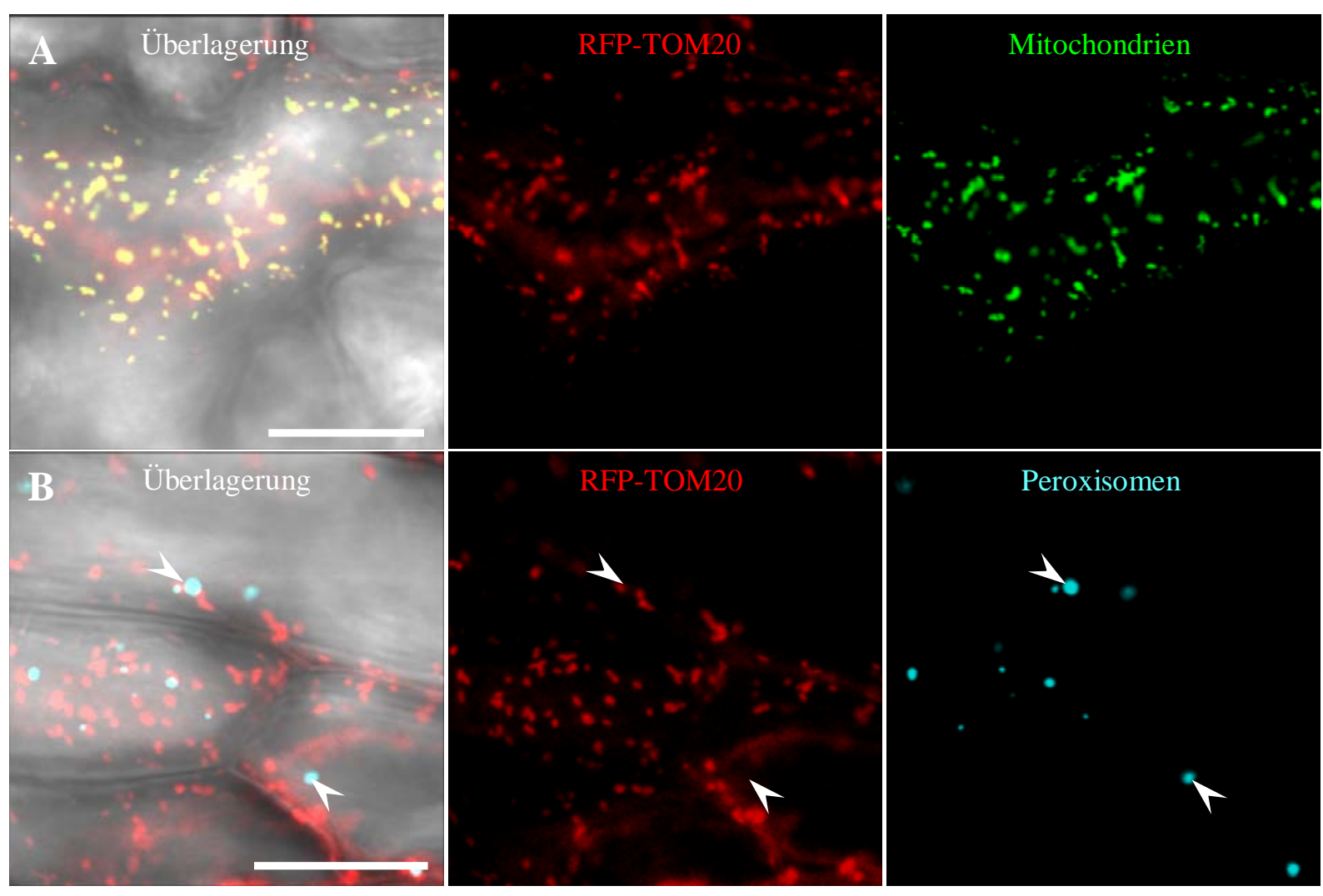

Abb. 3.34: Das Fusionsprotein RFP-TOM20-4 ist ausschließlich mit Mitochondrien assoziiert.

Abgebildet sind fluoreszenzmikroskopische Einzelaufnahmen von Epidermiszellen doppelt transgener Linien. Die Pfeile weisen auf die fehlende Assoziation des Fusionsproteins RFP-TOM20-4 mit CFP-markierten Peroxisomen hin. Maßstabsbalken $=25 \mu \mathrm{m}$.

Um allerdings ganz sicher zu gehen, dass der C-terminale Teil von TOM20-4 auch wirklich zur Mitochondrien-spezifischen Assoziation des chimären PEN2-GFP-TOM20-4 cterm- $^{-}$ Proteins führt, wurde zunächst die Lokalisation in transienten Expressionsexperimenten in Nicotiana benthamiana überprüft. Dabei konnte festgestellt werden, dass das Fusionsprotein ausschließlich in der Peripherie von Mitochondrien, jedoch nicht in der von Peroxisomen lokalisiert ist (Abb. 3.35). Im Gegensatz dazu zeigt das PEN2-GFP-Protein in der transienten Expression nach wie vor eine Interaktion mit Peroxisomen und Mitochondrien (Daten nicht gezeigt). Die Expression der beiden Konstrukte erfolgte jeweils unter der Kontrolle des nativen PEN2-Promotors. Aufgrund dieser Ergebnisse ist davon auszugehen, dass das chimäre PEN2-GFP-TOM20-4 $4_{\text {Cterm }}$-Protein für Untersuchungen der Assoziation von PEN2 mit Mitochondrien in der Pathogenabwehr geeignet ist. In weiter führenden Experimenten 
soll mit Hilfe von stabilen transgenen Linien für dieses Konstrukt die Komplementationsfähigkeit des pen2-Phänotyps in zukünftigen Analysen getestet werden.
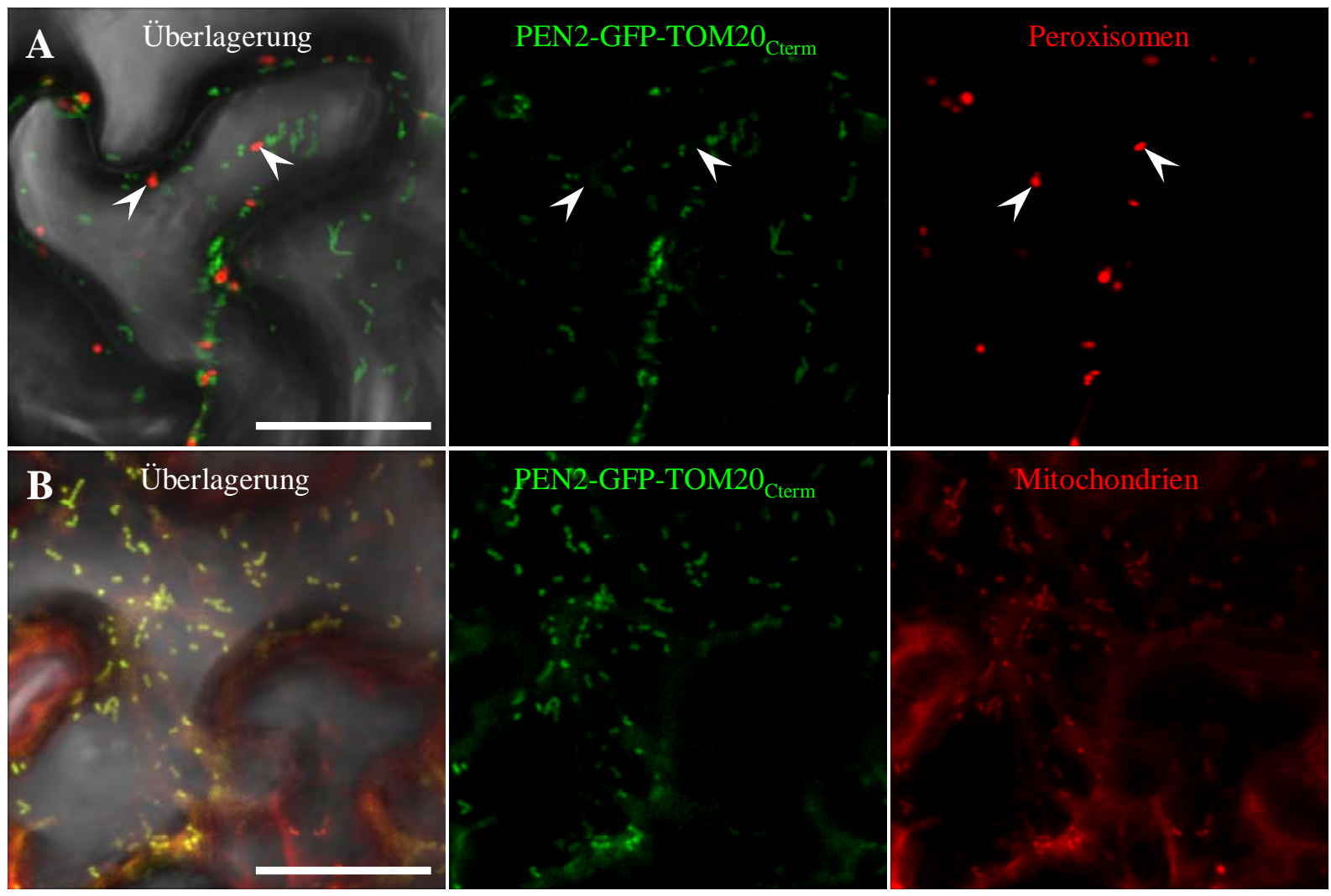

Abb. 3.35: Das chimäre PEN2-GFP-TOM20-4cterm-Protein ist ausschließlich mit Mitochondrien assoziiert. Abgebildet sind fluoreszenzmikroskopische Einzelaufnahmen von transient transformierten Nicotiana benthamina Epidermiszellen drei Tage nach Infiltration mit Agrobakterien. Die Pfeile weisen auf die fehlende Assoziation des PEN2-GFP-TOM20-4cterm-Fusionsproteins mit RFP-markierten Peroxisomen hin. Das Experiment wurde zweimal durchgeführt. Maßstabsbalken $=25 \mu \mathrm{m}$.

Aufgrund der spezifischen Assoziation des RFP-TOM20-4-Fusionsproteins mit Mitochondrien, ist dieses Fusionsprotein sehr gut geeignet, um die Lokalisation des PEN2-GFP-Proteins in der Peripherie von Mitochondrien nochmals zu bestätigt. Daher wurden stabile doppelt transgene Linien von PEN2-GFP und RFP-TOM20-4 im pen2-1Mutantenhintergrund generiert. Anhand der mikroskopischen Aufnahmen in Abbildung 3.36A ist eine deutliche Kolokalisation der beiden Fusionsproteine erkennbar. Dieses Ergebnis bestätigt noch einmal zusätzlich die Vermutung, dass PEN2 mit der Membran von Mitochondrien assoziiert ist. Wie in Abbildung 3.36B weiter zu erkennen ist, akkumulieren die RFP-TOM20-4-markierten Mitochondrien am Ort der versuchten Invasion. In diesem Bereich kann ebenfalls eine Akkumulation der PEN2-GFP-Aggregate beobachtet werden. Allerdings ist das RFP-TOM20-4-Protein nicht Bestandteil der PEN2-GFP-Aggregate (siehe Pfeile in Abb. 3.36B). 

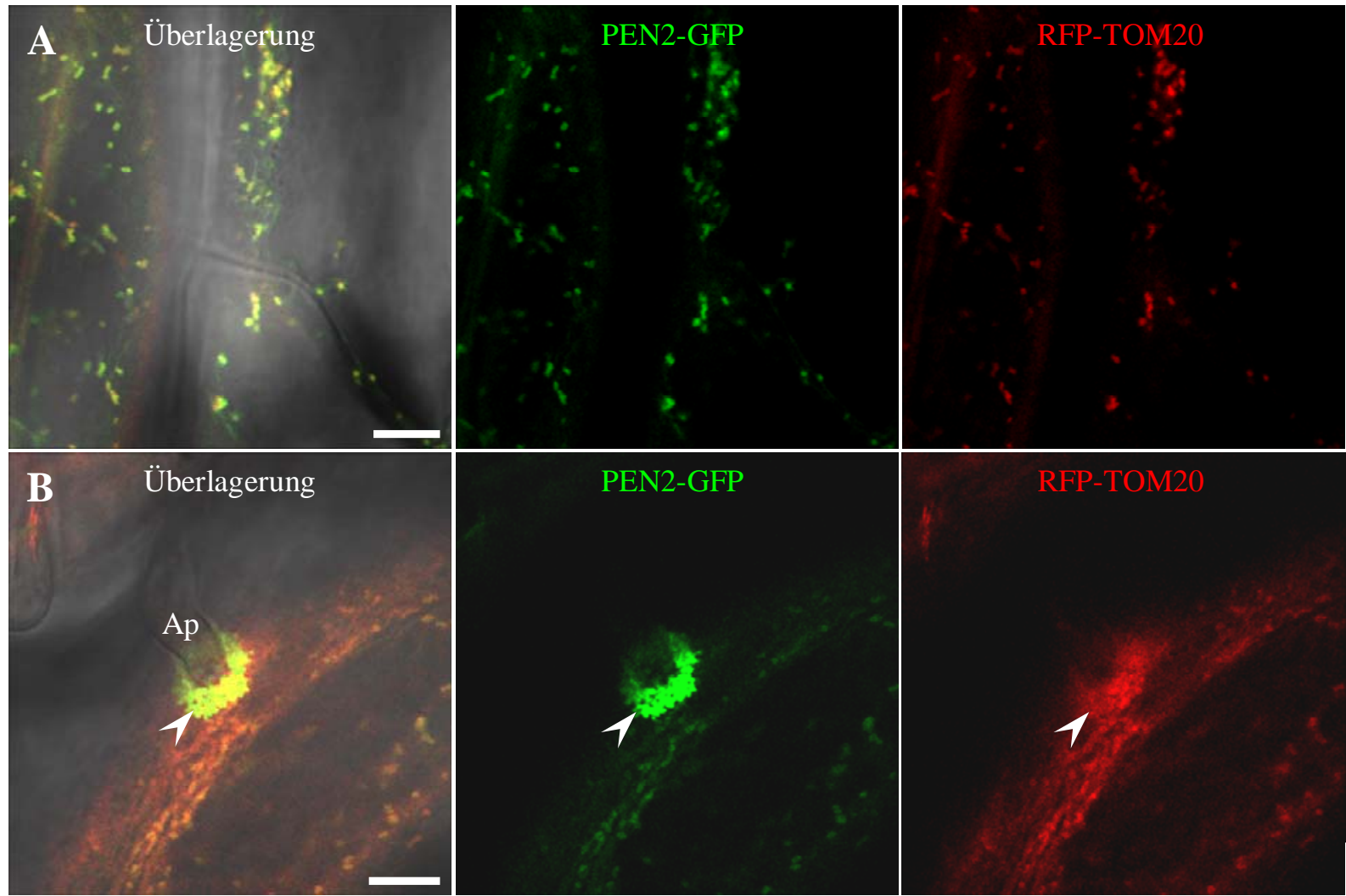

Abb. 3.36: PEN2-GFP und RFP-TOM20-4 kolokalisieren in der Peripherie von Mitochondrien.

Abgebildet sind fluoreszenzmikroskopische Einzelaufnahmen von (A) unbehandelten und (B) pathogenbehandelten Epidermiszellen doppelt transgener Linien 23 Stunden nach Inokulation mit Bgh. Die Pfeile weisen auf die Kolokalisation der PEN2-GFP-Aggregate mit den RFP-TOM20-4-assoziierten Mitochondrien hin. Ap, Appressorium. Maßstabsbalken $=10 \mu \mathrm{m}$.

Wie die Ergebnisse im vorherigen Abschnitt gezeigt haben, führt die C-terminale Extension des TA-Proteins APX3 nicht zu einer spezifischen Assoziation des PEN2-GFP-APX3 Cterm- $^{-}$ Proteins mit der peroxisomalen Membran. Trotz der Expression des chimären Konstrukts unter dem nativen PEN2-Promotor kommt es zur Fehllokalisation mit Mitochondrien. Daher ist es nicht möglich, mit Hilfe dieses Fusionsproteins die Funktion der Assoziation von PEN2 mit Peroxisomen in der Pathogenabwehr zu analysieren. Im Unterschied dazu kann die mitochondrien-spezifische Interaktion von PEN2 mit Hilfe des chimären Proteins PEN2-GFP-TOM20-4 $4_{\text {Cterm }}$ in zukünftigen Experimenten untersucht werden. 


\subsection{Untersuchungen zur pathogen-induzierten Akkumulation von Mitochondrien und Peroxisomen}

Wie bereits gezeigt wurde, akkumulieren Mitochondrien am Ort der versuchten Invasion (siehe Abb. 3.22A und 3.36B). Durch Zeitverlaufsexperimente mit RFP-markierten Mitochondrien sollte die Dynamik der pathogen-induzierten Mitochondrientranslokation genauer untersucht werden. Als Marker diente das schon beschriebene Matrix lokalisierte Fusionsprotein, welches aus den ersten 29 Aminosäuren des ScCOX4-Proteins und RFP zusammengesetzt ist (Nelson et al., 2007). Neben dem Akkumulationsverhalten von Mitochondrien in Wildtyppflanzen wurde auch das Verhalten in pen2-1-Mutanten analysiert, um eine mögliche PEN2-abhängige Mitochondrienakkumulation zu überprüfen. In Zeitverlaufsexperimenten konnte festgestellt werden, dass kein Unterschied im Akkumulationsverhalten von Mitochondrien in Wildtyppflanzen und pen2-1-Mutanten besteht (Abb. 3.37).

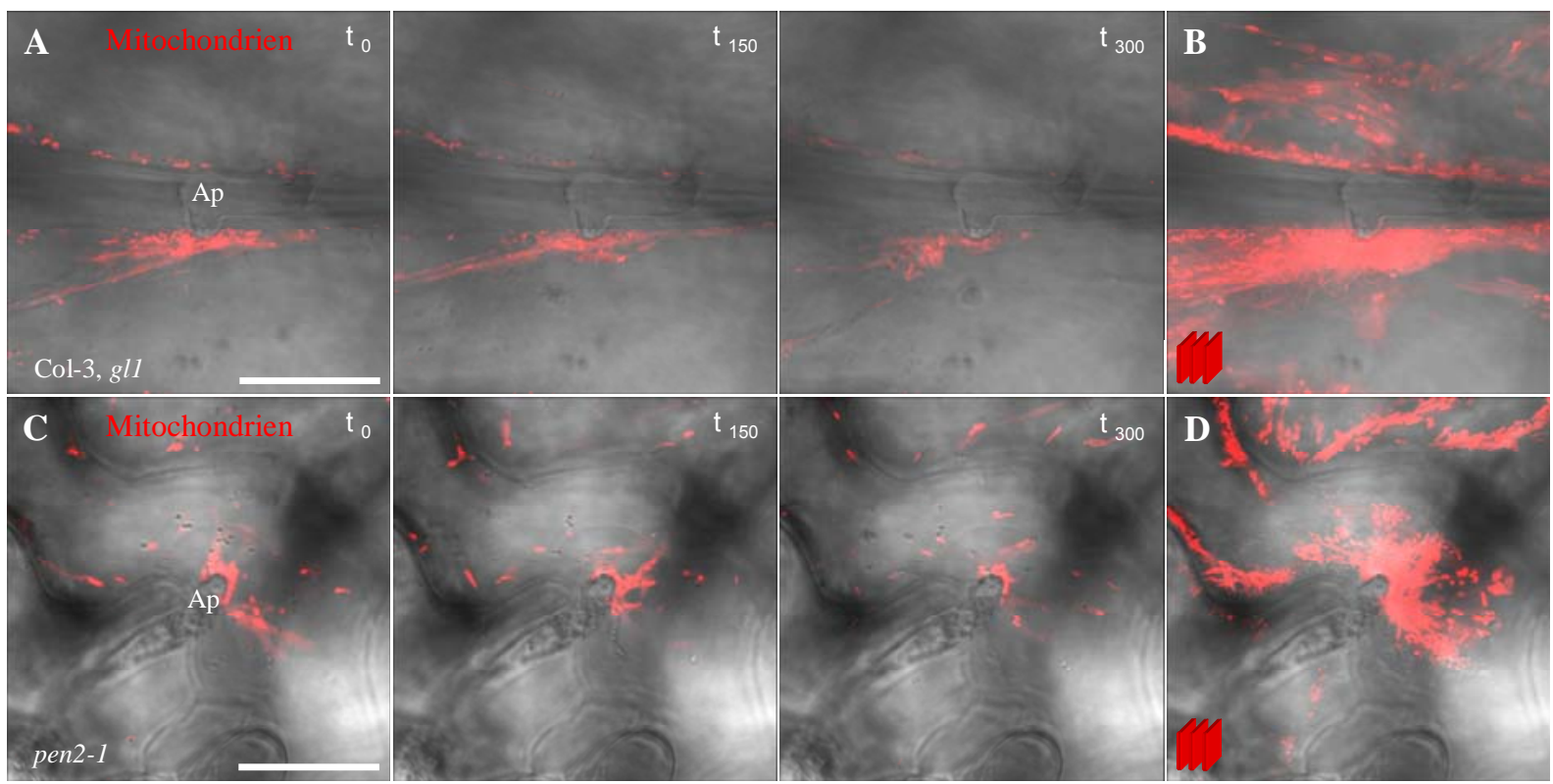

Abb. 3.37: PEN2 hat keinen Einfluss auf das Akkumulationsverhalten von Mitochondrien an der Penetrationsstelle.

Abgebildet sind repräsentative fluoreszenzmikroskopische Einzelaufnahmen $(A, C)$ bzw. die Maximalprojektion zweier Zeitreihe (B, D) transgener Wildtyppflanzen (A, B) und transgener pen2-1-Mutanten (C, D). Zur Markierung der mitochondrialen Matrix wurde das von Nelson et al. (2007) beschrieben RFP-Fusionsprotein verwendet. Die Aufnahmen wurden ca. 20 Stunden nach Inokulation mit Bgh aufgenommen. Das Experiment wurde dreimal durchgeführt. Ap, Appressorium; t, Zeit in Sekunden. Maßstabsbalken = $25 \mu \mathrm{m}$.

Demnach scheint die fokale Akkumulation von Mitochondrien an Orten der versuchten Penetration nicht abhängig vom PEN2-Protein zu sein. Eine deutliche Akkumulation von Mitochondrien über die Zeit wurde in beiden Linien beobachtet, was durch die Maximalprojektion der einzelnen Aufnahmen visualisiert werden konnte (Abb. 3.37B und 
3.37D). Außerdem konnte, neben der erhöhten Akkumulation von Mitochondrien über einen Zeitraum von fünf Minuten, zusätzlich eine ständige Akkumulation weniger Mitochondrien an der Penetrationsstelle in den einzelnen Aufnahmen nachgewiesen werden (Abb. 3.37A und 3.37C).

Im Gegensatz hierzu konnte keine ständige Akkumulation von Peroxisomen an Orten der versuchten Pathogeninvasion im Zeitverlauf beobachtet werden. Wie die fluoreszenzmikroskopischen Aufnahmen in Abbildung 3.38A zeigen, akkumulieren RFPPTS1-markierte Peroxisomen zu keinem Zeitpunkt an der Penetrationsstelle. Erst die Maximalprojektion der Zeitreihe offenbart eine zeitliche Akkumulation von Peroxisomen an der Invasionsstelle (Abb. 3.38B). Wie ein Vergleich von Wildtyppflanzen mit pen2-1Mutanten erkennen lässt, hat das PEN2-Protein auch auf das Akkumulationsverhalten von Peroxisomen keinen Einfluss (Abb. 3.38C und 3.38D).

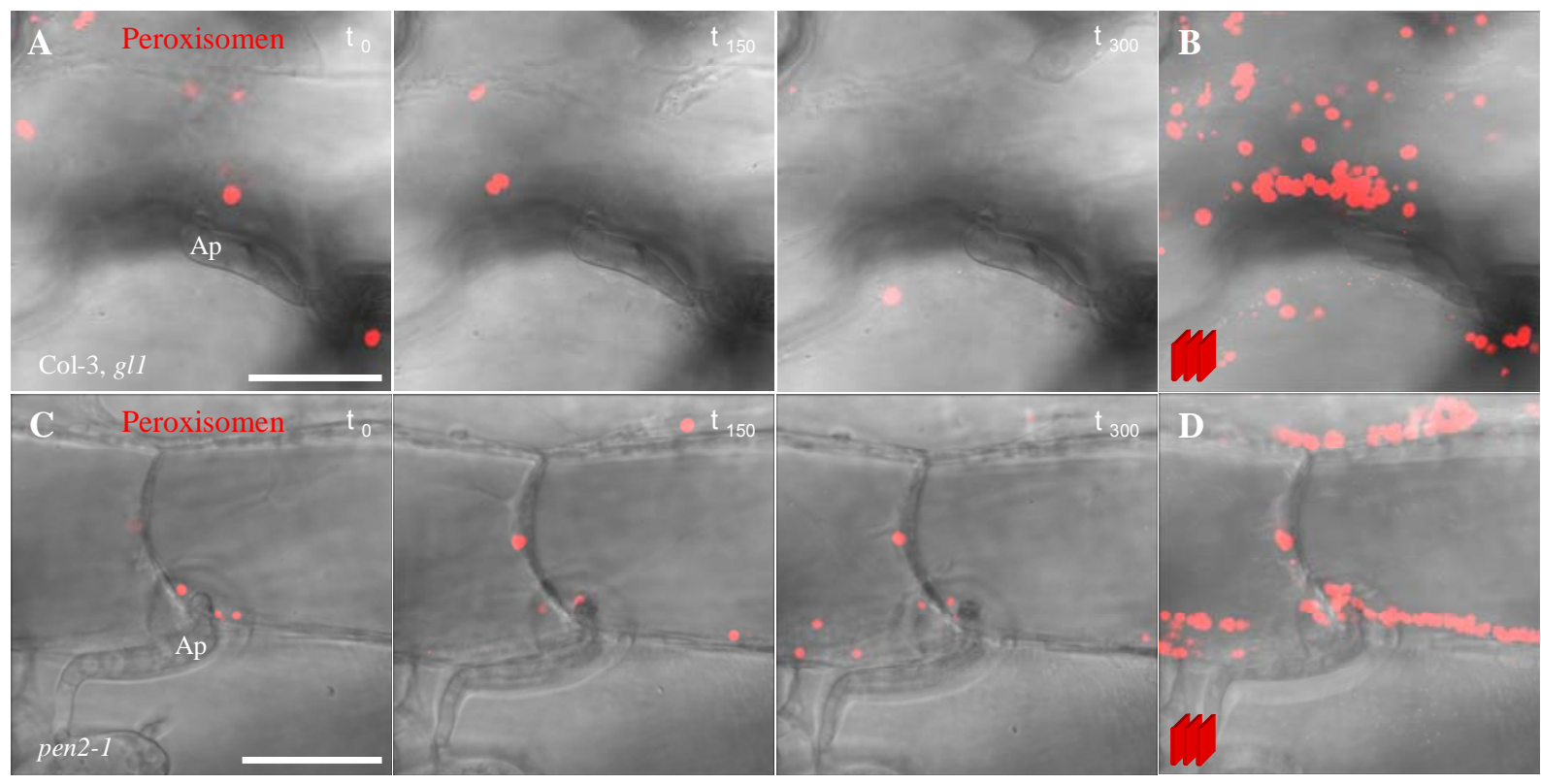

Abb. 3.38: Die zeitliche Akkumulation von Peroxisomen an der Invasionsstelle wird durch das PEN2Protein nicht beeinflusst.

Abgebildet sind repräsentative fluoreszenzmikroskopische Einzelaufnahmen $(A, C)$ bzw. die Maximalprojektion zweier Zeitreihe (B, D) transgener Wildtyppflanzen (A, B) und transgener pen2-1-Mutanten (C, D). Zur Markierung der peroxisomalen Matrix wurde das von Nelson et al. (2007) beschriebene RFP-Fusionsprotein verwendet. Die Aufnahmen wurden ca. 19 Stunden nach Inokulation mit Bgh aufgenommen. Das Experiment wurde dreimal durchgeführt. Ap, Appressorium; t, Zeit in Sekunden. Maßstabsbalken = $25 \mu \mathrm{m}$.

Elektronenmikroskopische Analysen von nicht-transgenen Wildtyppflanzen, die in Zusammenarbeit mit Gerd Hause (Halle) gemacht wurden, konnten wie auch die fluoreszenzmikroskopischen Analysen von transgenen Pflanzen wiederholt eine Akkumulation von Mitochondrien an Orten der versuchten Pathogeninvasion belegen. In den elektronenmikroskopischen Aufnahmen in Abbildung 3.39 ist die Papille unterhalb des pilzlichen Appressoriums im Querschnitt zu erkennen. Neben der Akkumulation von 
Mitochondrien können auch andere Zellorganellen, wie Golgi-Apparate, Golgi-Vesikel oder ER an der Penetrationsstelle beobachtet werden. Interessanterweise konnten in den EMAnalysen der untersuchten Gewebeschnitte keine Peroxisomen an den pilzlichen Invasionsorten nachgewiesen werden (Gerd Hause, Martin-Luther-Universität HalleWittenberg, persönliche Kommunikation).

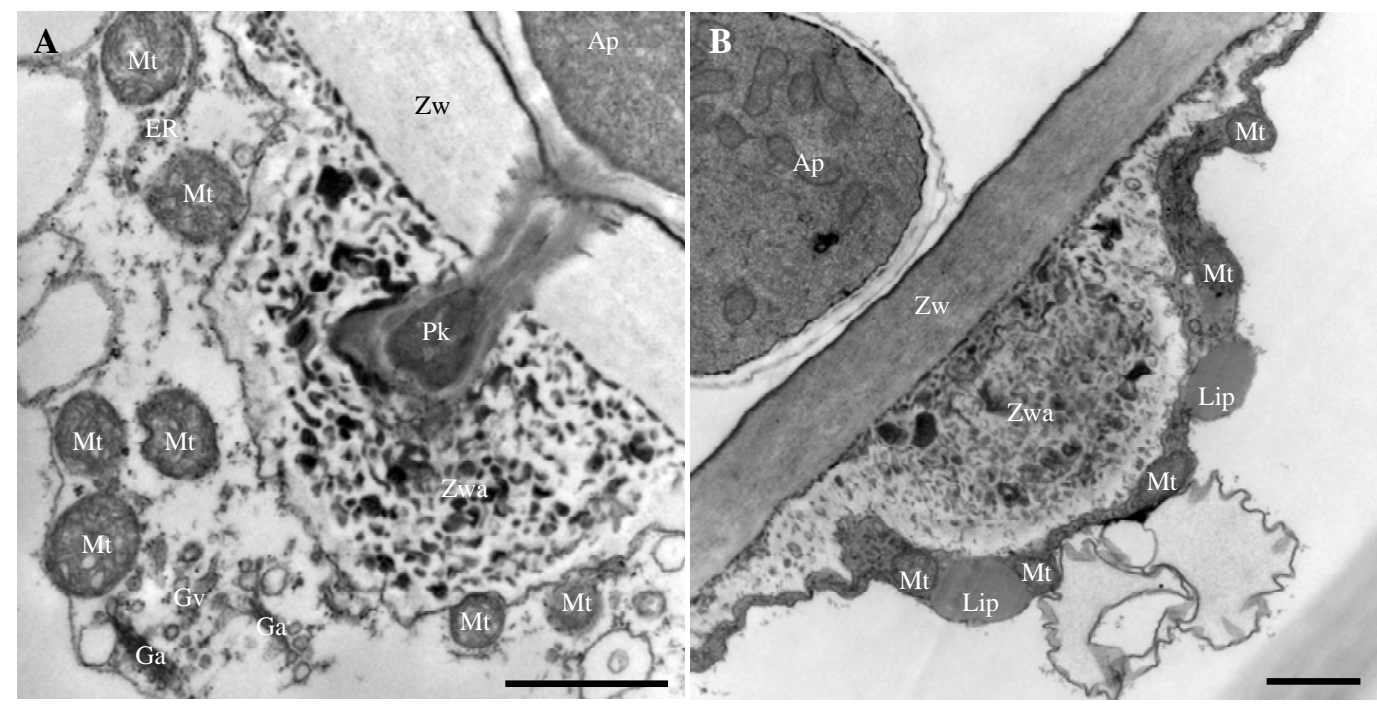

Abb. 3.39: Akkumulation von Mitochondrien an der Papille.

Abgebildet sind zwei elektronenmikroskopische Aufnahmen von Wildtyppflanzen ca. 19 Stunden nach Inokulation mit Bgh. Das Experiment wurde zweimal durchgeführt. Ap, Appressorium; ER, Endoplasmatisches Retikulum; Ga, Golgi-Apparate; Gv, Golgi-Vesikel; Lip, Lipidtropfen; Pk, Penetrationskeil; Zw, Zellwand; Zwa Zellwandapposition. Maßstabsbalken $=1 \mu \mathrm{m}$.

Wie die fluoreszenzmikroskopischen und elektronenmikroskopischen Untersuchungen gezeigt haben, weisen Mitochondrien im Gegensatz zu Peroxisomen eine stationäre Akkumulation an der versuchten Invasionsstelle auf. Allerdings konnte für beide Organellen eine transiente Akkumulation über die Zeit festgestellt werden. Somit entsprechen diese Ergebnisse den schon zuvor gemachten Beobachtungen, wonach Peroxisomen in doppelt transgenen PEN2-GFP- und RFP-PTS1-Linien ebenfalls nur kurzzeitig an der Penetrationsstelle lokalisiert sind. Im Unterschied dazu konnten PEN2-GFP-assoziierte RFP-markierte Mitochondrien immer an der Pathogen-Interaktionsstelle nachgewiesen werden. 


\subsection{Analysen zur subzellulären Lokalisation weiterer Komponenten des PEN2-vermittelten Abwehrmechanismus}

Wie in der Einleitung bereits beschrieben wurde, konnten bereits weitere Komponenten des präinvasiven PEN2-vermittelten Abwehrmechanismus identifiziert werden (Stein et al., 2006; Bednarek et al., 2009; Kian Hématy, persönliche Kommunikation). Im folgenden Abschnitt wird die subzelluläre Lokalisation der Komponenten PEN3, PEN4 und CYP81F2 näher untersucht und mit der Lokalisation von PEN2 verglichen. Dazu wurden doppelt transgene Linien von FP-PEN2 und den zuvor genannten Proteinen, entweder durch Kreuzung bereits vorhandener Linien oder durch erneute Transformation, generiert. Die fluoreszenzmikroskopischen Analysen der transgenen Linien erfolgten nach Pathogenbehandlung mit dem Gerstenmehltaupilz.

\subsubsection{Bestimmung der PEN2-Aggregation in Abhängigkeit von PEN3}

Der ABC-Transporter PEN3 unterliegt ebenfalls der pathogen-induzierten Zellpolarisation, ist jedoch im Unterschied zum PEN2-Protein plasmamembran-lokalisiert. Mit Hilfe von doppelt transgenen Linien sollte das Akkumulationsverhalten der beiden Proteine analysiert werden. In Abbildung 3.40A und 3.40B sind fluoreszenzmikroskopische Aufnahmen der doppelt transgenen PEN2-RFP- und PEN3-GFP-Linie nach Pathogenbehandlung dargestellt. Beim Vergleich der beiden Abbildungen fällt auf, dass die Akkumulation von PEN3-GFP in der Membran und die der PEN2-RFP-Aggregate an der Membran zeitlich nicht streng miteinander korrelieren. Während eine deutliche Fluoreszenzintensivierung von PEN3-GFP unterhalb des pilzlichen Appressoriums zu erkennen ist, akkumulieren nur wenige PEN2-RFP-Aggregate in diesem Bereich (Abb. 3.40A). Im Gegensatz dazu ist die PEN3-GFP-Proteinabundanz am haustoriellen Kragen in Abbildung 3.40B nicht signifikant erhöht, allerdings kann hier eine deutliche PEN2-RFP-Aggregation beobachtet werden (siehe Pfeile in Abb. 3.40A und 3.40B). Es müssen dennoch weitere Untersuchungen durchgeführt werden, um den zeitlichen Verlauf der Akkumulation der beiden Fusionsproteine an der Penetrationsstelle zu bestimmen. Diese Analysen könnten im Folgenden Aufschluss darüber geben, inwieweit die pathogen-induzierte Zellpolarisation von PEN3 und PEN2 an der Invasionsstelle miteinander korrelieren.

Durch Transformation der Doppelmutante pen3-1 pen2-3 mit dem PEN2-RFP-Konstrukt konnte gezeigt werden, dass die Anreicherung von PEN2-RFP-Aggregaten an Orten der versuchten Invasion nicht von PEN3 abhängig ist (Abb. 3.40C). Wie in den fluoreszenzmikroskopischen Aufnahmen in Abbildung 3.40C zu erkennen ist, akkumulieren 
die Aggregate direkt unterhalb des Appressoriums. Aufgrund dessen kann eine Beteiligung von PEN3 an der PEN2-vermittelten Aggregation ausgeschlossen werden.

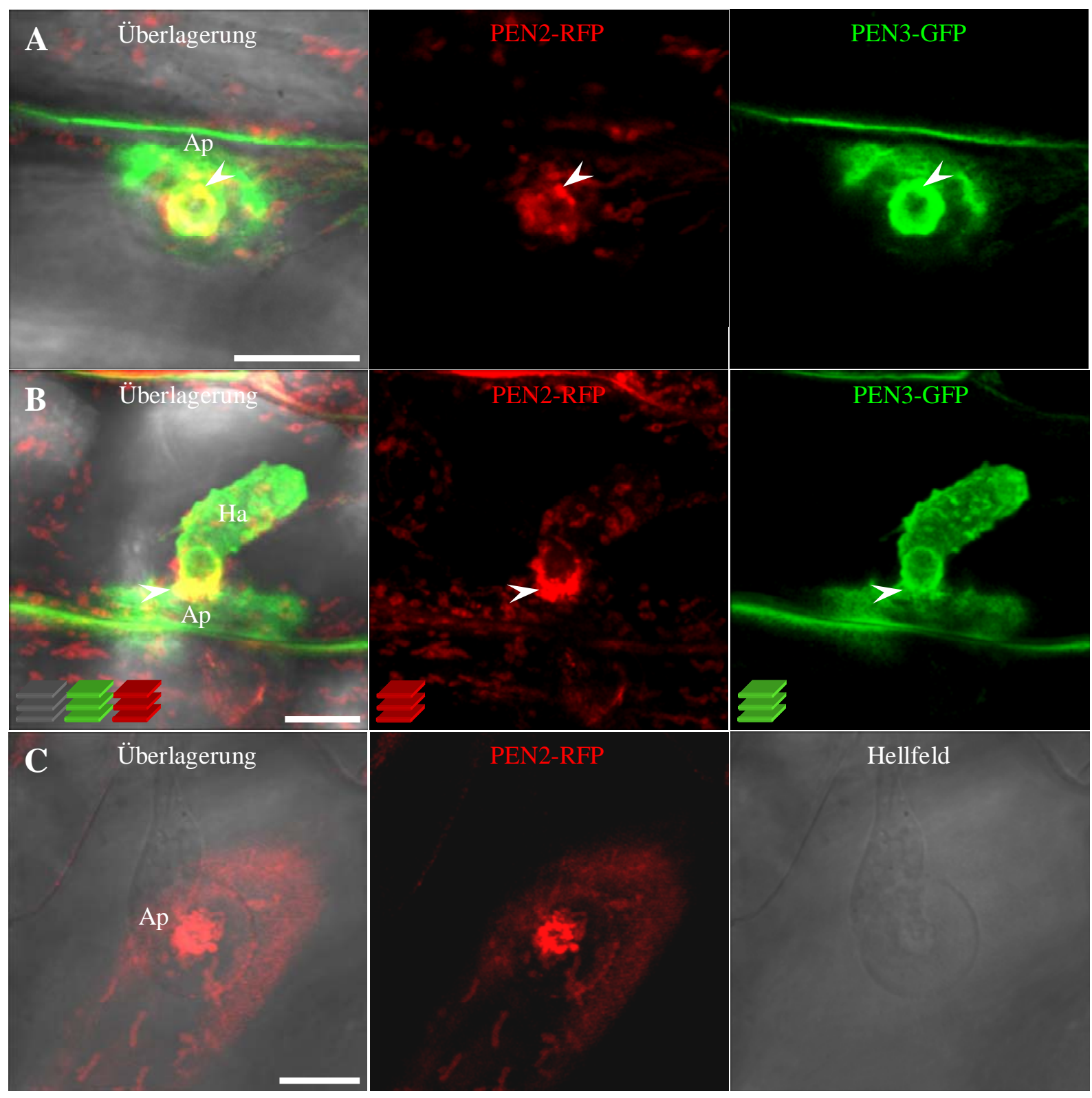

Abb. 3.40: PEN3 hat keinen Einfluss auf die Akkumulation der PEN2-RFP-Aggregate.

(A) Abgebildet ist eine fluoreszenzmikroskopische Einzelaufnahme, bzw. (B) die Maximalprojektion einer Z-Serie der doppelt transgenen Linie PEN2-RFP und PEN3-GFP (24 hpi Bgh). Die Pfeile weisen auf die Kolokalisation der beiden Fusionsproteine unterhalb des pilzlichen Appressoriums hin.

(C) Die Einzelaufnahme zeigt die Bildung von PEN2-RFP-Aggregaten in der Doppelmutante pen3-1 pen2-3 an der Penetrationsstelle 20 Stunden nach Inokulation mit Bgh. Ap, Appressorium; Ha, Haustorium. Maßstabsbalken $=10 \mu \mathrm{m}$. 


\subsubsection{Untersuchungen zur PEN4-Lokalisation nach Pathogenbehandlung}

Im Unterschied zum PEN3-Protein scheint eine Korrelation in der Fluoreszenzintensitätszunahme der Phytochelatin-Synthase PEN4 und PEN2 unterhalb des pilzlichen Appressoriums zu bestehen. Das RFP-PEN4-Fusionsprotein, welches unter der Kontrolle des 35S-Promotors exprimiert wurde, ist in unbehandelten Epidermiszellen ausschließlich im Cytoplasma lokalisiert und weist keine Assoziation mit PEN2-GFPmarkierten Organellen auf (Abb. 3.41A). Nach Inokulation kann allerdings eine Kolokalisation des RFP-PEN4-Proteins mit PEN2-GFP-Aggregaten festgestellt werden (Abb. 3.41B). In Abbildung 3.41B ist deutlich zu erkennen, dass die beiden Fusionsproteine nur in den rundlichen Aggregatstrukturen, jedoch nicht generell in der Membran von Mitochondrien bzw. Peroxisomen kolokalisieren (siehe Pfeile in Abb. 3.41C). Demnach handelt es sich bei den zuvor beschriebenen PEN2-GFP-Aggregaten vermutlich um Komplexe aus PEN4 und PEN2-Homooligomeren. Inwieweit PEN4 ebenfalls Homooligomere bildet, die zur Ausbildung der Aggregate beitragen, muss noch näher untersucht werden. Zusätzlich muss geklärt werden, ob die Phytochelatin-Synthase generell essentiell für die Aggregatbildung ist. Nach der Transformation der pen2-1-Mutante mit dem RFP-PEN4-Konstrukt konnte gezeigt werden, dass RFP-PEN4 noch immer Aggregate unterhalb des pilzlichen Appressoriums ausbildet. Somit ist die pathogen-induzierte Aggregation von PEN4 unabhängig von PEN2 (Abb. 3.41D). Diese Ergebnisse stimmen mit den Daten von Shauna Somervilles Arbeitsgruppe (University of California at Berkeley, Energy Biosciences Institute, USA) überein, wonach RFP-PEN4 in rundlichen Strukturen an der Penetrationsstelle in pen2-Mutanten akkumuliert, bzw. in doppelt transgenen Linien mit PEN2-GFP nach Pathogenbehandlung kolokalisiert (Kian Hématy, persönliche Kommunikation).

In weiteren Experimenten sollte zusätzlich geklärt werden, ob PEN2 und PEN4 direkt miteinander interagieren können, was jedoch mit Hilfe des Split-Ubiquitin-Systems nicht bestätigt werden konnte (Christine Klapprodt, eigene Arbeitsgruppe, persönliche Mitteilung). Aufgrund dieser Ergebnisse ist davon auszugehen, dass mindestens noch ein weiteres Protein Bestandteil bzw. Induktor der PEN2/PEN4-Aggregate an der Pathogeninvasionsstelle sein muss. Trotz intensiver Bemühungen konnte bisher keine weitere Komponente mittels Yeast Two-Hybrid-Screens und Koimmunopräzipitationsexperimenten indentifiziert werden, die möglicherweise mit PEN2 interagiert (Christine Klapprodt, persönliche Mitteilung; Daten nicht gezeigt). Allerdings konnte in den letzten Jahren die Cytochrom-P450-Monooxygenase CYP81F2 als eine weitere Komponente des PEN2-vermittelten Resistenzmechanismus identifiziert werden (Bednarek et al., 2009). 


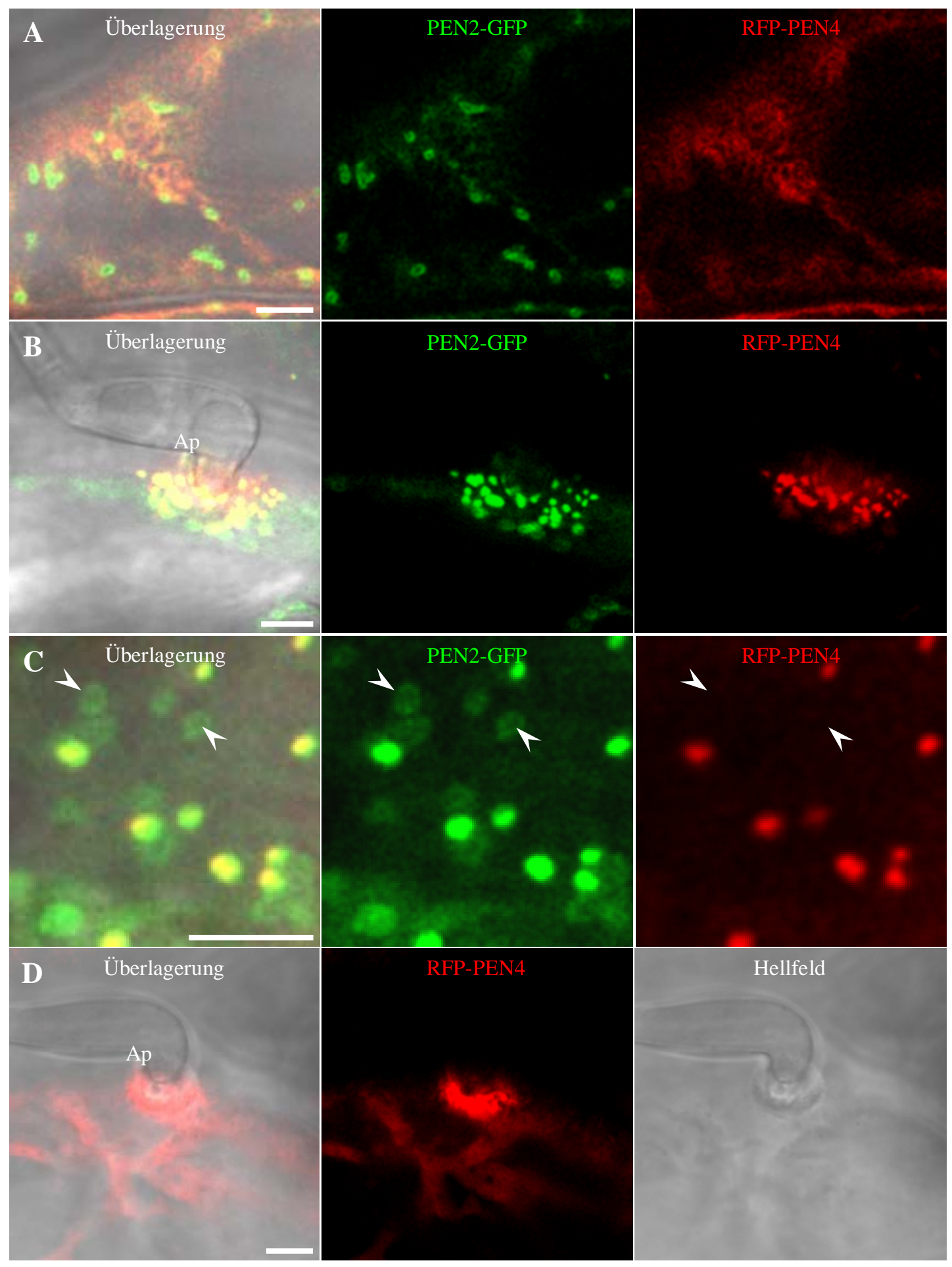

Abb. 3.41: RFP-PEN4 ist Bestandteil der PEN2-GFP-Aggregate.

Abgebildet sind fluoreszenzmikroskopische Einzelaufnahmen von $(A)$ unbehandelten und $(B, C)$ pathogenbehandelten Epidermiszellen doppelt transgener PEN2-GFP- und RFP-PEN4-Linien (20 hpi Bgh).

(D) Die Einzelaufnahme zeigt die Bildung von RFP-PEN4-Aggregaten in der pen2-1-Mutante an der Penetrationsstelle 20 Stunden nach Inokulation mit dem Gerstenmehltaupilz. Die Pfeile weisen auf das Fehlen des RFP-PEN4-Signals in der Peripherie von PEN2-GFP-assoziierten Membranen hin. Ap, Appressorium. Maßstabsbalken $=10 \mu \mathrm{m}$. 


\subsubsection{Mikroskopische und molekularbiologische Analysen von CYP81F2}

Um die Hypothese zu überprüfen, ob die Monooxygenase CYP81F2 ein weiterer Bestandteil der PEN2/PEN4-Aggregate ist und somit zur Ausbildung eines pathogen-induzierten Multienzymkomplexes beiträgt, der darüber hinaus einer pathogen-induzierten Zellpolarisation unterliegt, wurden weitere transgene Markerlinien erzeugt. So wurde zunächst die cyp81F2-2-Mutante mit dem Fusionskonstrukt CYP81F2-RFP unter der Kontrolle des endogenen CYP81F2-Promotors ( $P_{\text {CYP81F2 }}$ ) transformiert, um die subzelluläre Lokalisation der Monooxygenase zu untersuchen. Wie in Abbildung 3.42A zu erkennen ist, konnte zunächst in keiner der transgenen Linien ein Fluoreszenzsignal in Epidermiszellen detektiert werden. Erst nach Inokulation mit Bgh konnte eine zellautomone Expression des Fusionskonstrukts in den Epidermiszellen beobachtet werden, die einem Pathogeninvasionsversuch ausgesetzt waren (Abb. 3.42B). Aufgrund der netzwerkartigen Struktur des Fluoreszenzsignals wurde eine ER-Lokalisation des Enzyms vermutet. Diese konnte durch die stabile Transformation der CYP81F2-RFP-Linie mit einem ER-lokalisierten, CFP-markierten Fusionsprotein bestätigt werden (Nelson et al., 2007; Abb. 3.42C). Anhand von Abbildung $3.42 \mathrm{C}$ ist die Kolokalisation der beiden Fluoreszenzsignale deutlich erkennbar. Allerdings kann aufgrund des beschränkten Auflösungsvermögens des konfokalen Fluoreszenzmikroskops nicht genau bestimmt werden, ob das CYP81F2-RFPProtein im CFP-markierten ER-Lumen oder an der Membran lokalisiert ist. 


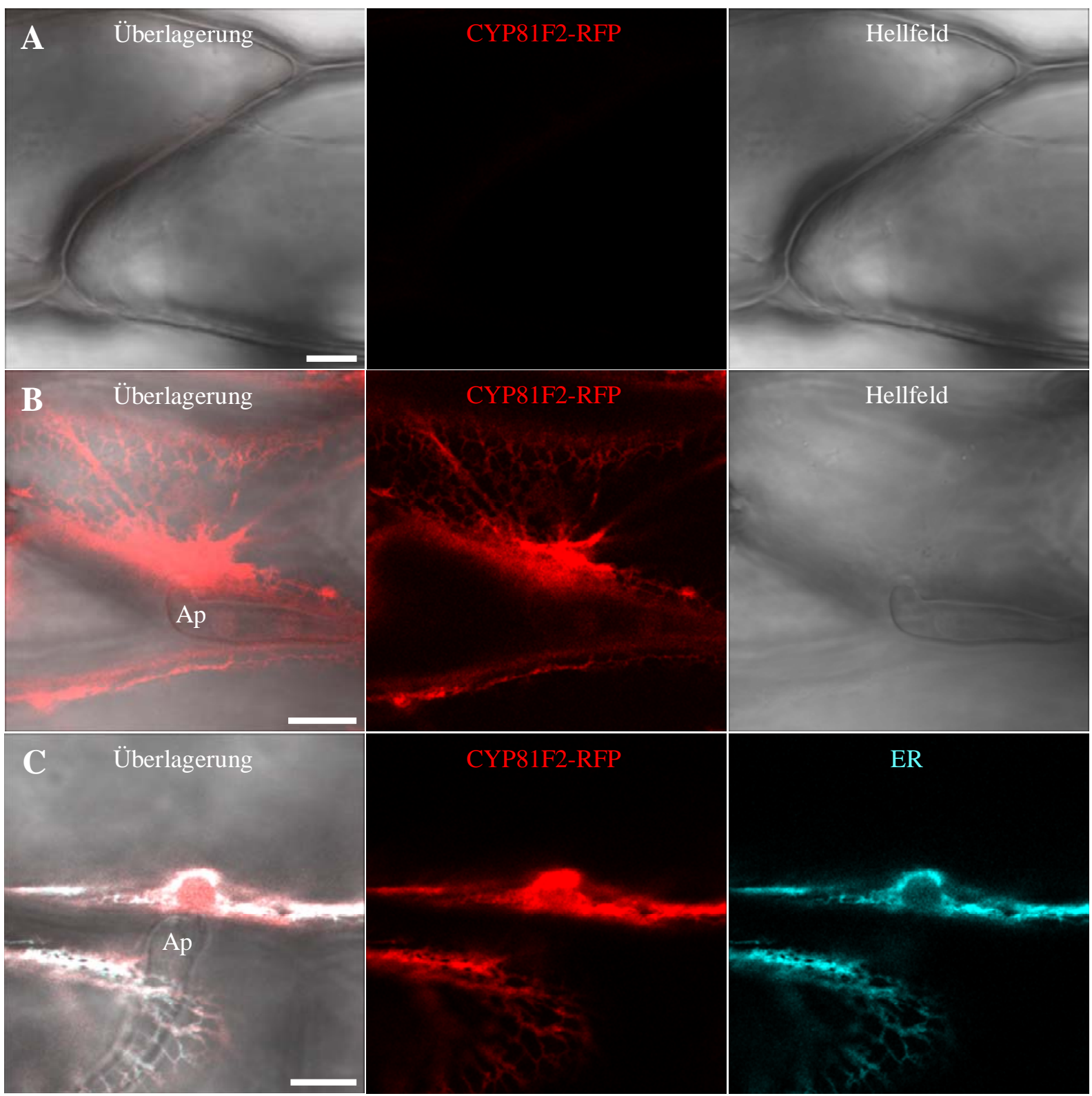

Abb. 3.42: Die CYP81F2-Monooxygenase ist ein ER-lokalisiertes Protein.

Abgebildet sind fluoreszenzmikroskopische Einzelaufnahmen von (A) unbehandelten und (B) pathogenbehandelten Epidermiszellen transgener CYP81F2-RFP-Pflanzen (18 hpi Bgh). (C) Die Einzelaufnahme zeigt die Kolokalisation des CYP81F2-RFP-Fluoreszenzsignals mit dem des CFP-markierten ER in einer doppelt transgenen Linien 18 Stunden nach Inokulation mit Bgh. Ap, Appressorium. Maßstabsbalken $=10 \mu \mathrm{m}$.

Dass das CYP81F2-RFP-Fusionsprotein definitiv nicht Bestandteil der PEN2/PEN4Aggregate ist, konnte durch Kreuzung der beiden Reporterlinien cyp81f2-2

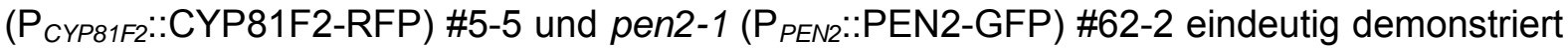
werden. Wie die fluoreszenzmikroskopischen Aufnahmen in Abbildung 3.43 zeigen, kann zwar eine Überlagerung der beiden Fluoreszenzsignale unterhalb des pilzlichen Appressoriums festgestellt werden, allerdings unterscheidet sich die Struktur der beiden Signale deutlich voneinander. Daher ist davon auszugehen, dass es sich nicht um eine wirkliche Kolokalisation der beiden Proteine handelt, sondern um eine Signalüberlagerung 
aufgrund der räumlichen Nähe der beiden Organellen in der konfokalen Aufnahme. Somit ist das Protein CYP81F2-RFP ausschließlich ER-lokalisiert.

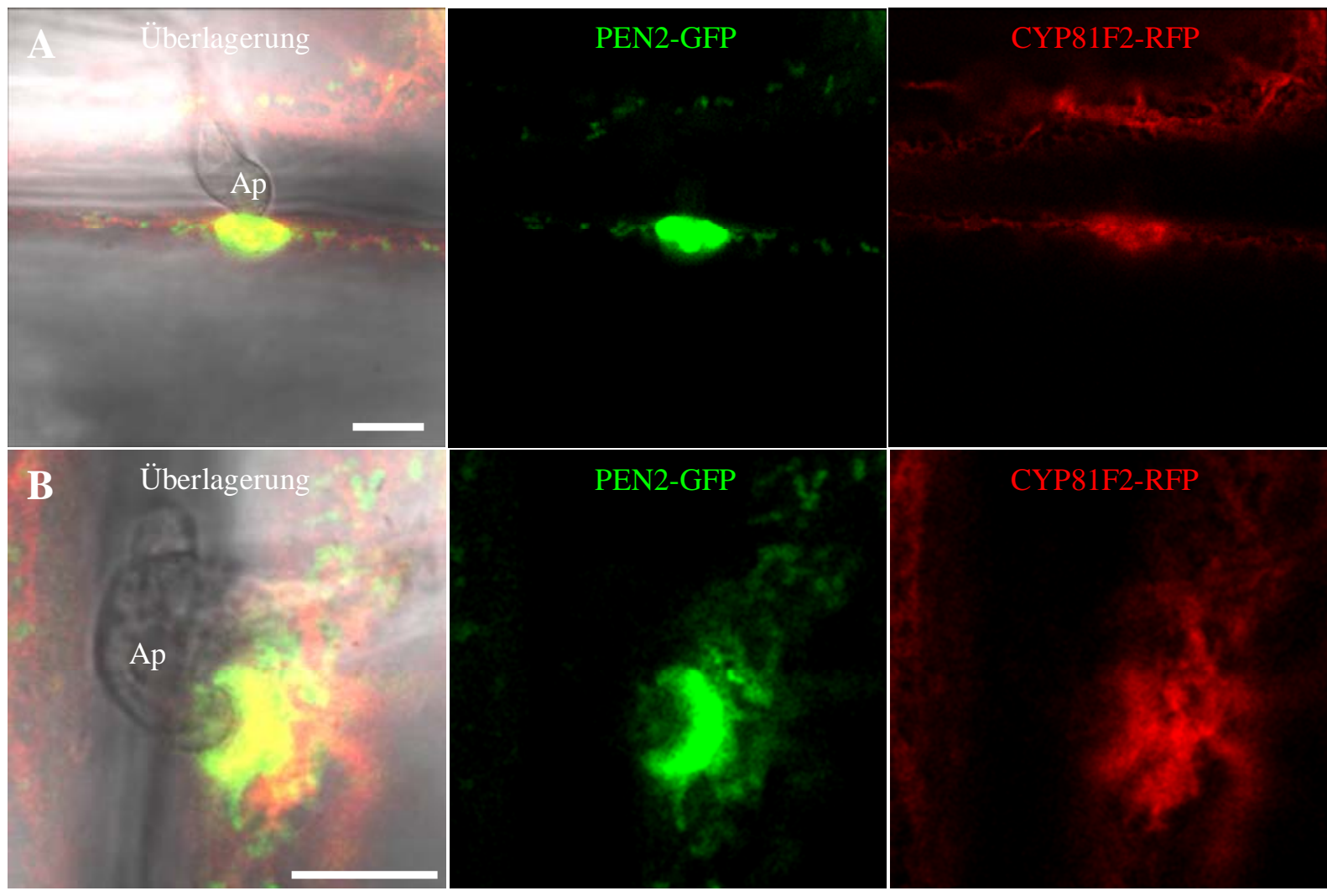

Abb. 3.43: CYP81F2-RFP ist nicht Bestandteil der PEN2-GFP-Aggregate.

Abgebildet sind fluoreszenzmikroskopische Einzelaufnahmen (A und $B$ ) der doppelt transgenen PEN2-GFP- und CYP81F2-RFP-Linie (23 hpi Bgh). Ap, Appressorium. Maßstabsbalken = $10 \mu \mathrm{m}$.

Inwiefern das Fusionsprotein den cyp81F2-Phänotyp komplementieren kann, wurde in vergleichenden Analysen der Invasions- und Zelltodraten nach Pathogenbehandlung untersucht. Dabei konnte festgestellt werden, dass die Penetrationsraten und Zelltodreaktionen der transgenen CYP81F2-RFP-Linien denen des Wildtyps entsprechen (Abb. 3.44). Im Gegensatz zu Wildtyppflanzen weisen die beiden Mutanten pen2-2 und cyp81F2-2 sowohl eine deutlich erhöhte Invasionshäufigkeit, als auch eine höhere Zelltodreaktion auf. Aufgrund der Komplementationseigenschaft des CYP81F2-RFPProteins ist daher anzunehmen, dass die zuvor beschriebene ER-Lokalisation der Monooxygenase dem des nativen Proteins entspricht. 


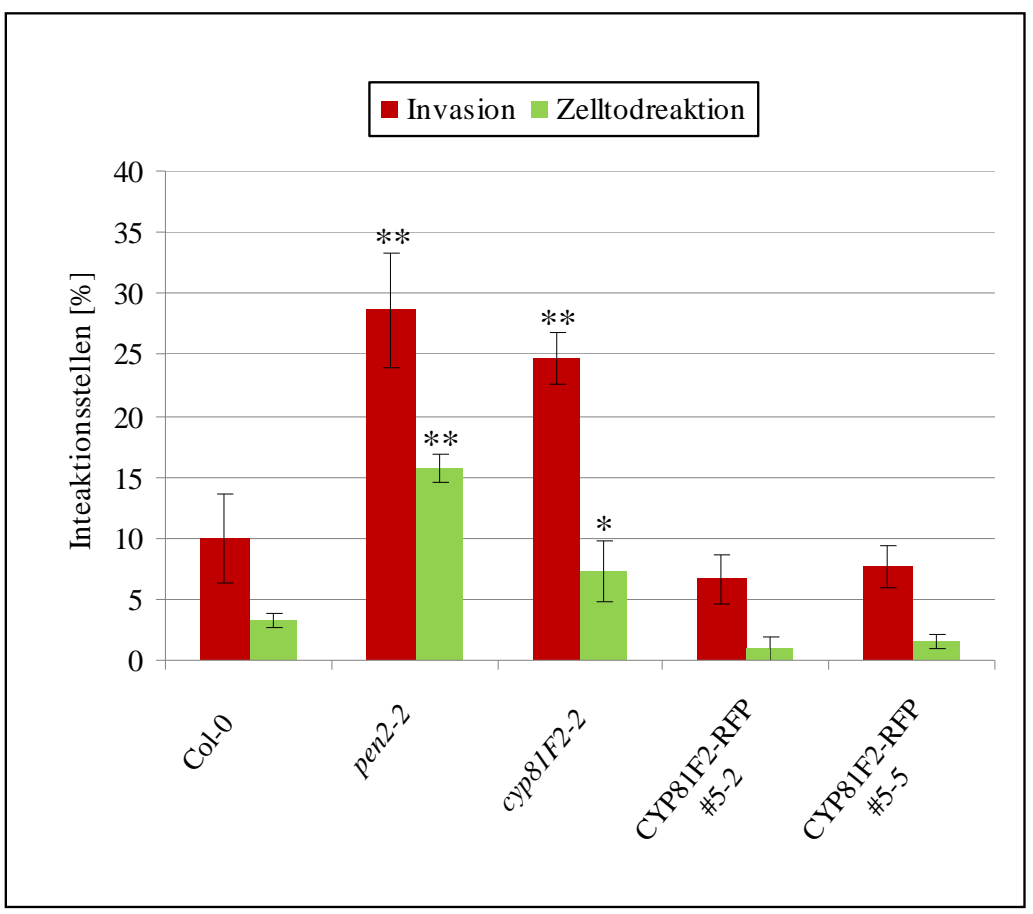

Abb. 3.44: Das CYP81F2-RFP-Fusionsprotein komplementiert den cyp81F2-Phänotyp.

Abgebildet ist die vergleichende Analyse der Invasions- und Zelltodraten Bgh-inokulierter Wildtyppflanzen, pen2bzw. cyp81F2-Mutanten und transgener CYP81F-RFP-Linien (72 Stunden nach Inokulation). Pro Linie wurden drei Blätter mit je 100 Interaktionsstellen ausgezählt und in zwei unabhängigen Experimenten wiederholt. Die Sterne geben den signifikanten Unterschied der Invasions- und Zelltodraten zu Wildtyppflanzen an $\left({ }^{*} P \leq 0,05\right.$; $\left.{ }^{* *} P \leq 0,005\right)$.

Durch die vorherigen fluoreszenzmikroskopischen Untersuchungen konnte nicht nur die Lokalisation des CYP81F2-Proteins bestimmt, sondern auch demonstriert werden, dass das Fusionsprotein erst 18 Stunden nach Inokulation mit Bgh ausreichend detektierbar war. Durch Bestimmung der Transkriptionslevel des CYP81F2-Gens und der Proteinabundanz des CYP81F2-RFP-Reporterproteins sollte geklärt werden, inwiefern die FluoreszenzIntensivierung möglicherweise auf eine transkriptionelle oder post-translationelle Regulation zurückzuführen ist. Mit Hilfe von semiquantitativen RT-PCR-Analysen wurde zunächst die Transkriptmenge in Wildtyppflanzen zu unterschiedlichen Zeitpunkten nach Pathogenbehandlung untersucht. Wie die Ergebnisse in Abbildung 3.45A zeigen, steigen die CYP81F2-Transkriptlevel im Laufe der Zeit an und sind 18 und 24 Stunden nach Inokulation deutlich erhöht. Analog dazu ist die Transkriptmenge für das PR1-Gen (,pathogenesisrelated gene 1"), welches als positive Kontrolle verwendet wurde, ebenfalls zu beiden Zeitpunkten signifikant erhöht. Im Gegensatz zum CYP81F2 bleibt die Transkription des PEN2-Gens 18 Stunden nach Behandlung konstant und nimmt erst zum 24Stundenzeitpunkt zu. Allerdings ist im Unterschied zur Monooxygenase ein deutliches PEN2-PCR-Produkt bereits in der unbehandelten Probe im Agarosegel sichtbar (Abb. 3.45A). Somit wird PEN2 auch in unbehandelten Pflanzen in ausreichenden Mengen transkribiert. Dass diese Unterschiede nicht auf eine ungleichmäßige Beladung des Gels 
zurückzuführen sind, konnte durch die gleich bleibende Bandenintensität des UBQ10-PCRProdukts („polyubiquitin 10“) belegt werden. Diese Ergebnisse implizieren, dass die Expression der Gene CYP81F2 und PEN2 pathogen-induziert ist. Aufgrund ihres abweichenden Transkriptionsverhaltens ist jedoch anzunehmen, dass sie sich in ihrer Regulation unterscheiden.

In Western-Blot-Analysen wurde im Folgenden die Pathogeninduktion der CYP81F2-RFP-

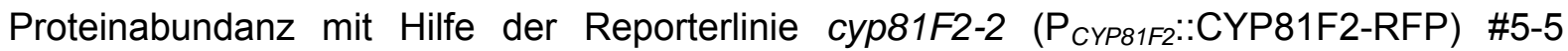
untersucht. Wie der Immunoblot in Abbildung 3.45B zeigt, ist die CYP81F2-RFPProteinkonzentration 18 Stunden nach Inokulation mit Bgh stark erhöht und fällt 48 Stunden später wieder auf die Ausgangsmenge zurück. Eine Änderung der Proteinkonzentration konnte in unbehandelten Pflanzen hingegen nicht beobachtet werden. Interessanterweise entspricht die zeitliche Zunahme der Fusionsproteinmenge in transgenen Pflanzen dem zeitlichen Anstieg der Transkription des CYP81F2-Gens in Wildtyppflanzen nach Pathogenbehandlung. Daher kann angenommen werden, dass die Transkription in der Reporterlinie ebenfalls in den ersten 24 Stunden der Abwehrreaktion induziert ist, was wiederum zu einer Erhöhung der CYP81F2-RFP-Proteinabundanz geführt hat. Im Vergleich zur Proteinmenge der Monooxygenase in der Reporterlinie konnte keine signifikante Änderung in der Proteinkonzentration von PEN2, 18 oder 24 Stunden nach Inokulation mit $B g h$ festgestellt werden. Dieses Ergebnis entspricht damit den zuvor gewonnenen Daten, wonach keine Änderung der PEN2-Konzentration im Laufe der Pathogenabwehr in Wildtypoder transgenen PEN2-GFP-Pflanzen beobachtet werden konnte (siehe Abb. 3.45B und Abb. 3.8). Ein Anstieg der Transkriptmenge, wie sie 24 Stunden nach Inokulation mit Bgh in den PCR-Analysen für PEN2 festgestellt werden konnte, führt somit nicht zwangsläufig zu einer Zunahme der Proteinabundanz. Aufgrund der Ergebnisse der semiquantitativen RT-PCR und Western-Blot-Analysen ist daher anzunehmen, dass die CYP81F2Proteinmenge scheinbar transkriptionell reguliert wird, während die PEN2-Konzentration möglicherweise durch post-translationelle Mechanismen nach Pathogenbehandlung konstant gehalten wird. Allerdings muss diese Hypothese durch vertiefende Untersuchungen mittels RT-PCR und Western-Blot-Analysen derselben Proben bestätigt werden. 


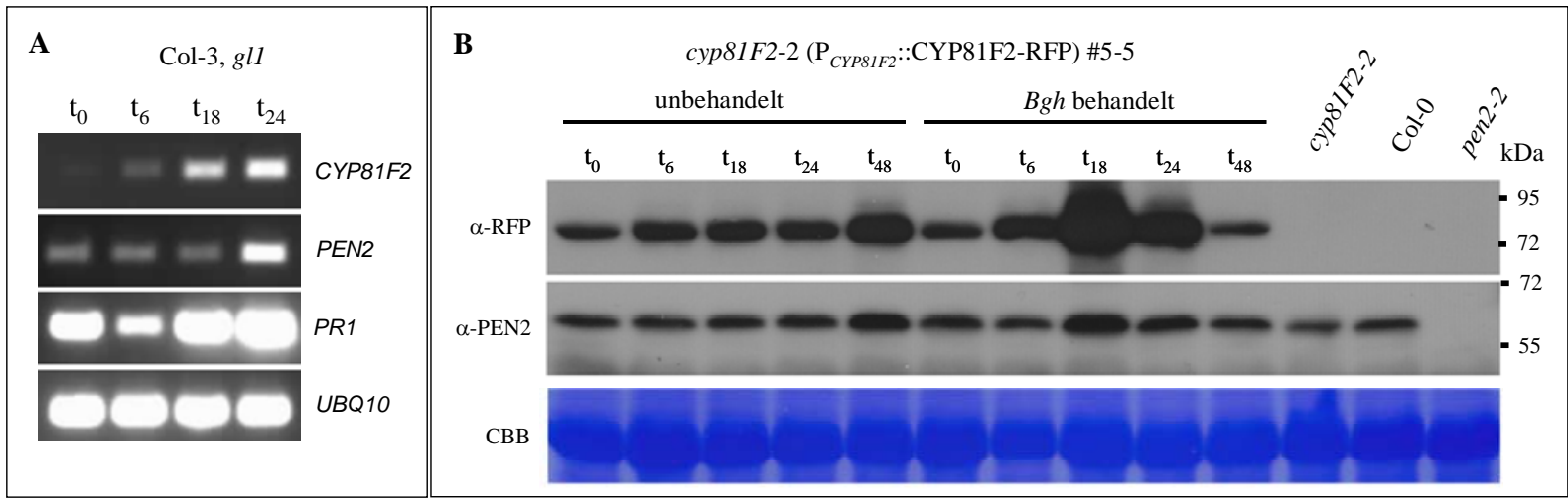

Abb. 3.45: Die Transkriptlevel von CYP81F2 in Wildtyppflanzen und die CYP81F2-RFPProteinkonzentration in transgenen Pflanzen sind 18 und 24 Stunden nach Pathogenbehandlung deutlich erhöht.

(A) Abgebildet ist ein $1 \%$ iges Agarosegel, in dem jeweils $10 \mu \mathrm{l}$ der verschieden semiquantitativen RT-PCRReaktionsansätze analysiert wurden.

(B) Jeweils $30 \mu \mathrm{g}$ Proteinisolat wurden in einem $10 \%$ igen SDS-Polyacryamidgel aufgetrennt und mittels Elektroblot auf eine PVDF-Membran übertragen. Der immunologische Nachweis erfolgte mit Hilfe eines RFPspezifischen Antikörpers (1:10000 verdünnt) und PEN2-spezifischen Antikörpers (1:10000 verdünnt). Am rechten Rand sind die molekularen Massen der Markerproteine angegeben. Im unteren Teil ist die Coomassiefärbung des Gesamtproteins dargestellt. Das Experiment wurde dreimal wiederholt. CBB, Coomassie-Brilliant-Blau. $t$, Zeit in Stunden.

Abschießend kann festgehalten werden, dass mit Hilfe des CYP81F2-RFP-Proteins die subzelluläre Lokalisation der Monooxygenase als ER-lokalisiertes Protein identifiziert werden konnte. Zudem wurde durch die vergleichende Analyse der Invasions- und Zelltodraten gezeigt, dass die Reporterlinien den cyp81F2-Phänotyp komplementieren können und damit die Funktionalität des Fusionsproteins unterstreichen. Außerdem konnte gezeigt werden, dass die Proteinabundanz des Substrat produzierenden Enzyms CYP81F2 nach Pathogenbehandlung vermutlich transkriptionell erhöht wird, während die Konzentration des spaltenden Enzyms PEN2 posttranslationell konstant gehalten wird. Somit kann eine unterschiedliche Regulation der beiden Proteine in der Pathogenabwehr angenommen werden. 


\section{Diskussion}

\subsection{Akkumulation von PEN2 an der Pathogen-Interaktionsstelle}

Die atypische Myrosinase PEN2 ist eine molekulare Komponente der Nichtwirtsresistenz von Arabidopsis gegenüber nicht-adaptierten Pathogenen. Durch die Expression funktionaler PEN2-GFP-Fusionsproteine konnten Lipka et al. (2005) eine fokale Akkumulation von PEN2-GFP-assoziierten Membrankompartimenten an der versuchten Invasionsstelle des Gerstenmehltaupilzes Blumeria graminis f. sp. hordei (Bgh) nachweisen. Neben den inkompatiblen Mehltaupilzisolaten Bgh und E. pisi konnte in der vorliegenden Arbeit ebenfalls eine Anreicherung der Kompartimente an der Penetrationsstelle von virulenten Mehltaupilzen wie Erysiphe cruciferarum, Golovinomyces cichoracearum und Golovinomyces orontii beobachtet werden (Abb. 3.1; Daten teilweise nicht gezeigt). Somit kann kein Unterschied zwischen kompatiblen und inkompatiblen Mehltaupilzen bezüglich der Relokalisation des PEN2-assoziierten Membrankompartiments in der präinvasiven Resistenz festgestellt werden. Daher ist die Zellpolarisation des PEN2-Proteins als Teil der PAMP-induzierten Immunisierung (PTI) in kompatiblen Interaktionen offensichtlich nicht von der effektor-induzierten Suszeptibilität (ETS) betroffen. Inwieweit pathogene Effektoren möglicherweise die Aktivität der Myrosinase beeinflussen oder das freigesetzte Aglycon detoxifizieren, ist bislang nicht geklärt. Wie die Arbeiten von Lipka et al. (2005) und Stein et al. (2006) allerdings gezeigt haben, scheint die potentielle Suppression durch pilzliche Effektoren nicht zu einer vollständigen Inhibierung des Abwehrmechanismus zu führen, da PEN2 als Teil der Basalen Resistenz der Pflanze gegenüber kompatiblen Mehltaupilzen identifiziert werden konnte.

In weiteren fluoreszenzmikroskopischen Analysen konnte zudem gezeigt werden, dass PEN2-GFP ebenfalls an der Interaktionstelle nach Behandlung mit weiteren phytopathogen Pilzen akkumuliert. So wurde nachgewiesen, dass die Abundanz des Fusionsproteins unterhalb des Appressoriums des hemibiotrophen Pilzes Colletotrichum higginsianum ebenfalls signifikant erhöht war (Abb. 3.1). Zusätzlich konnten Hiruma et al. (2010) eine Akkumulation an der versuchten Invasionsstelle des nicht-adaptieren Pilzes Colletotrichum gloeosporioides demonstrieren und eine Funktion des PEN2-Proteins in der Nichtwirtsresistenz gegenüber inkompatiblen Colletotrichum Spezies feststellen. Außerdem wurde in der vorliegenden Arbeit dokumentiert, dass es zur Anreicherung der PEN2-GFPassoziierten Kompartimente in der Interaktion mit dem nekrotrophen Pilz Botrytis cinerea 
kommt (Abb. 3.1). Für einen weiteren nekrotrophen Pilz, Plectosphaerella cucumerina, konnten Lipka et al. (2005) die Bedeutung von PEN2 für die Abwehr des Nekrotrophs bereits zeigen.

Interessanterweise scheint dieses Phänomen der zielgerichteten Akkumulation des Fusionsproteins nicht nur auf die Abwehrreaktion von Pilzen beschränkt zu sein, sondern kann auch in der pflanzlichen Abwehr des Oomyceten Phytophthora capsici beobachtet werden (Abb. 3.1). Eine Beteiligung von PEN2 an der Nichtwirtsresistenz gegenüber den Oomyceten Phytophthora infestans und Phytophthora brassicae konnte zudem bereits demonstriert werden (Lipka et al., 2005; Schlaeppi et al., 2010).

Aufgrund der Ergebnisse der fluoreszenzmikroskopischen Analysen kann davon ausgegangen werden, dass die fokale Akkumulation der PEN2-GFP-assoziierten Membrankompartimente einen universellen Mechanismus der präinvasinen Resistenz gegenüber einer Vielzahl unterschiedlicher Pathogene darstellt. Diese Hypothese wird zusätzlich durch die Arbeiten anderer Arbeitsgruppen bestärkt, in denen eine Funktion von PEN2 für die Resistenz gegenüber adaptierten und nicht-adaptierten Pathogenen nachgewiesen werden konnte (Lipka et al., 2005; Stein et al., 2006; Hiruma et al., 2010; Schlaeppi et al., 2010). Welche Faktoren für die zielgerichtete Reorganisation der PEN2Kompartimente verantwortlich sind, ist nicht bekannt. Wie bereits in der Einleitung erwähnt, konnten Gus-Mayer et al. (1998) und Hardham et al. (2008) nachweisen, dass allein durch mechanische Stimulation eine Zellpolarisation ausgelöst werden kann. Ob dieser Stimulus ebenfalls ausreichend für die Polarisation von PEN2 ist oder möglicherweise zusätzlich von der Perzeption von PAMPs abhängt, muss noch durch fluoreszenzmikroskopische Analysen der PEN2-GFP-Reporterlinie nach mechanischer Stimulation mit und ohne PAMPApplikation untersucht werden. Außerdem gilt es zu klären, inwieweit das pflanzliche Cytoskelett am Transport der PEN2-GFP-assoziierten Kompartimente involviert ist. In vorläufigen Experimenten konnte allerdings kein signifikanter Einfluss auf die fokale Akkumulation des Fusionsproteins an Pathogen-Interaktionsstellen nach Behandlung mit Cytochalasin E festgestellt werden. Nach unveröffentlichten Ergebnissen von W. Underwood und S.C. Somerville beeinflusst der Actin-Polymerisations-Inhibitor Cytochalasin E die fokale Akkumulation von PEN1 ebenfalls nicht, jedoch die von PEN3. Somit scheint die pathogeninduzierte Translokation von PEN1 und PEN2 sich vom Actin-abhängigen Transport von PEN3 deutlich zu unterscheiden. Diese Hypothese wird zusätzlich durch die fluoreszenzmikroskopischen Analysen von doppelt transgenen PEN3-GFP und PEN2-RFP Pflanzen gestützt, in denen keine zeitlich streng miteinander korrelierende Akkumulation des ABC-Transporters in der Membran und der Myrosinase an der Membran beobachtet werden konnte (Abb. 3.40A und 3.40B). Inwiefern nun Mikrotubuli verantwortlich für die Reorganisation nach Pathogenbehandlung von PEN1 und PEN2 sind, bedarf weiterer 
mikroskopischer Untersuchungen von PEN1- und PEN2-Reporterlinien nach pharmakologischer Behandlung mit Inhibitoren, welche spezifisch die Polymerisation bzw. Depolymerisation der Mikrotubuli-Untereinheiten verhindern.

Neben der von Lipka et al. (2005) beschriebenen fokalen Akkumulation der PEN2-GFPassoziierten Membrankompartimente konnte in Zeitverlaufsexperimenten im Rahmen dieser Arbeit eine deutliche Intensitätszunahme des Fluoreszenzsignals an der versuchten Invasionsstelle beobachtet werden, die nicht auf eine vermehrte Ansammlung der Kompartimente zurückzuführen war. Mit Hilfe von Detailaufnahmen konnte gezeigt werden, dass diese Fluoreszenzintensivierung durch Bildung von rundlichen Strukturen von 0,6 bis 1,2 $\mu \mathrm{m}$ Größe hervorgerufen wurde, die sich in ihrer Intensität von der des Membrankompartiments deutlich unterschieden (Abb. 3.2 und 3.3). Diese als PEN2-GFPAggregate bezeichneten Strukturen entstehen in der Peripherie des myrosinase-assoziierten Kompartiments und nehmen im Laufe der Pathogenabwehr nicht nur in ihrer Größe, sondern auch in ihrer Anzahl zu. Außerdem konnte mit Hilfe von transgenen pen2 pen3Doppelmutanten gezeigt werden, dass die Aggregatbildung des Fusionsproteins dabei unabhängig vom ABC-Transporter PEN3 verläuft (Abb. 3.40C). Des Weiteren sind diese Aggregate in der Regel ausschließlich an der Pathogen-Interaktionsstelle lokalisiert und nicht weiter mobil. Der Grund für die Immobilisierung ist nicht näher bekannt, allerdings weisen Plasmolyse-Experimente auf eine stabile Interaktion der PEN2-GFP-Aggregate oder des PEN2-GFP-assoziierten Kompartiments mit der Plasmamembran hin (Abb. 3.5). So konnte durch die Verwendung einer doppelt transgenen Linie, die neben PEN2-GFP zusätzlich ein RFP-markiertes Plasmamembranprotein exprimiert, gezeigt werden, dass die Aggregate zusammen mit Teilen der Plasmamembran unterhalb des pilzlichen Appressoriums zurückblieben, während sich der Protoplast weiter zusammen gezogen hat. Das Zusammenziehen des Protoplasten müsste, wenn nicht eine stabile Interaktion der Aggregate oder des Kompartiments mit der Membran vorliegen würde, zur Ablösung dieser Strukturen von der Plasmamembran führen. Aufgrund der unzureichenden Detailschärfe der mikroskopischen Aufnahmen konnte bisher nicht genau geklärt werden, ob die PEN2-GFPAggregate direkt mit der Plasmamembran interagieren und somit selbst für die Anhaftung verantwortlich sind, oder eine Interaktion zwischen den Membrankompartimenten und der Plasmamembran besteht.

Zusätzlich zur Lokalisation der Aggregate an der versuchten Invasionsstelle konnten diese Strukturen auch nach einer erfolgreichen Penetration am haustoriellen Kragen bzw. Komplex beobachtet werden (Abb. 3.4). Inwiefern die PEN2-GFP-Aggregate in der postinvasiven Abwehr ebenfalls am haustoriellen Komplex gebildet werden oder ob sie bereits vor der eigentlichen Penetration vorhanden waren, und erst durch die Entwicklung des Haustoriums ins Zelleninnere verschoben wurden, muss noch in weiteren 
Zeitverlaufsexperimenten geklärt werden. Allerdings scheint das beschriebene duale Verteilungsmuster der Aggregate (die Lokalisation am Kragen und an der Spitze des Haustoriums) unter Berücksichtigung einer stabilen Interaktion mit der Plasmamembran eher für ein Vorhandensein der Aggregate vor der eigentlichen Entwicklung des haustoriellen Komplexes zu sprechen.

Neben der Akkumulation dieser Strukturen unterhalb des pilzlichen Appressoriums oder Haustoriums konnte wiederholt eine Aggregatbildung am primären Keimschlauch des Gerstenmehltaupilzes festgestellt werden (Abb. 3.7). Inwieweit diese pilzliche Struktur einen mechanischen Stimulus auslöst und/oder PAMPs bzw. DAMPs frei setzt, was dann zur Bildung der Aggregatstrukturen am primären Keimschlauch führen würde, ist bisher nicht bekannt. Wie zuvor beschrieben kann durch rein mechanische Stimulation der Zelloberfläche eine Zellpolarisation ausgelöst werden, die unter anderem eine Reorganisation des Cytoskeletts und Aggregation des Cytoplasmas bewirkt (Gus-Mayer et al., 1998; Hardham et al., 2008). Darüber hinaus wurde eine fokale Akkumulation von PEN3-GFP nach Applikation der PAMPs Flg22 und Chitin auch ohne mechanischen Reiz beobachtet (W. Underwood, persönliche Kommunikation). Inwiefern eine mechanische Stimulation bzw. die alleinige Perzeption von PAMPs ausreichend für die fokale Akkumulation der PEN2-GFP-Aggregate ist, oder ob hierfür eine Kombination beider Stimuli benötigt wird, ist wie bereits erwähnt nicht genau bekannt und muss durch die oben vorgeschlagen Experimente untersucht werden. In vorläufigen Experimenten konnte jedoch nachgewiesen werden, dass eine Infiltration von Chitin oder Flg22 nicht zur Aggregation des Fusionsproteins führt (Daten nicht gezeigt). Auch ein alleiniger direkter, mechanischer Reiz scheint ebenfalls nicht verantwortlich für die Aggregatbildung zu sein, da wiederholt eine Aggregation von PEN2-GFP in benachbarten Zellen beobachtet werden konnte, die nicht dem mechanischen Druck des Appressoriums ausgesetzt waren. In diesen Nachbarzellen wurde zusätzlich eine zielgerichtete Ansammlung von PEN2-GFP-Aggregaten zur attackierten Zelle hin festgestellt (Abb. 3.6). Diese zellübergreifende Polarisation ist kein unbekanntes Phänomen, da sie bereits bei der Papillenbildung und der fokalen Akkumulation von PEN1 und PEN3 nachgewiesen werden konnte (Assaad et al., 2004; Underwood und Somerville, 2008; Kwon et al., 2008b). So wurde eine Ringstrukturbildung von GFP-PEN1 bzw. PEN3-GFP an der versuchten Invasionstelle beobachtet, die je nach Position die Zellgrenze der attackierten Zelle überschritt, ohne ihre kreisförmige Struktur dabei zu unterbrechen. Die molekularen Mechanismen für dieses Phänomen sind bislang nicht identifiziert worden. Es wird jedoch vermutet, dass durch die Perzeption des Pathogens eine Signaltransduktion ausgelöst wird, die zur Entstehung einer neuen Domäne in der Plasmamembran führt, welche wiederum in ihrer Funktionsweise der der Immunologischen Synapse von T-Zellen in Vertebraten entspricht (zusammengefasst in Kwon et al., 2008b). 
Als Immunologische Synapse wird die Kontaktstelle zwischen einer T-Zelle und einer antigen-präsentierenden Zelle bezeichnet, an der es unter anderem zu vermehrten Exocytoseprozessen und zur Reorganisation des Cytoskeletts kommt. Weiterhin kennzeichnend für die Interaktionstelle der beiden Zellen ist die Ausbildung einer ringförmigen Struktur, welche auch als Bullauge (,bulls-eye“) bekannt ist (zusammengefasst in Kwon et al., 2008b). Wie von Kwon et al. (2008b) diskutiert, ähnelt die Bullaugen-Struktur der der PEN1- und PEN3-Ringstruktur. Darüber hinaus finden an der pflanzlichen PathogenInteraktionsstelle ebenfalls Exocytoseprozesse und eine Reorganisation des Cytoskeletts statt, woraufhin Kwon und Kollegen (2008b) einen Vergleich zwischen der Immunolgischen Synapse und der Pflanze-Pathogen-Kontaktstelle gezogen haben. Inwieweit die Ausbildung einer zellübergreifenden Bullaugen-Struktur in der Plasmamembran Einfluss auf die PEN2-GFP-Aggregation in attackierten und benachbarten Zellen besitzt, ist bisher nicht bekannt. Allerdings steht fest, dass die Perzeption von PAMPs zwar ausreichend für die Formation der Bullaugen-Struktur ist, welche zur beschriebenen ringförmigen Akkumulation von PEN3-GFP in der Membran führt, jedoch nicht hinreichend genug für die PEN2Aggregation ist (W. Underwood, persönliche Kommunikation; Daten nicht gezeigt). Daher kann angenommen werden, dass neben der Ausbildung der Immunolgischen Synapse in Pflanzen ein anderer oder zusätzlicher Mechanismus zur Aggregatbildung der Myrosinase beträgt und dass dieser nicht durch die alleinige Perzeption von Chitin oder Flg22 induziert wird. Dieser noch unbekannte Mechanismus wird erst nach Perzeption eines Pathogens ausgelöst und führt möglicherweise zur Freisetzung eines diffusiblen Signals, welches über Plasmodesmata in angrenzende Zellen gelangt und dort ebenfalls die PEN2-GFPAggregation induziert. Dieses diffusible Signal würde auch die zuvor beschriebene zeitgleiche Bildung von PEN2-GFP-Aggregaten an zwei unterschiedlichen Stellen erklären. Ein weiteres diffusibles Signal könnte der Grund für die beobachtete synchrone Dissoziation der Aggregate in zwei benachbarten Zellen sein. Die zeitgleiche Auflösung der Strukturen an zwei unterschiedlichen Stellen konnte zwar bisher nur einmal beobachtet werden, hingegen wurde eine Dissoziation der PEN2-GFP-Aggregate an der Penetrationsstelle innerhalb mehrerer Minuten bis zu einer Stunde wiederholt festgestellt (Daten nicht gezeigt). Aufgrund dessen ist anzunehmen, dass die Auflösung dieser Strukturen ein aktiver Prozess der Pflanzenzelle ist, welcher möglicherweise dann ausgelöst wird, wenn das Pathogen erfolgreich gestoppt worden ist und eine PEN2-vermittelte präinvasive Abwehr nicht länger benötigt wird. Im Falle einer erfolgreichen Penetration hingegen bleiben die PEN2-GFPAggregate so lange am haustoriellen Komplex erhalten, bis auch hier die weitere Entwicklung des Pathogens vollständig gestoppt wird.

Mit Hilfe von Western-Blot-Analysen konnte gezeigt werden, dass die Aggregatbildung oder deren Dissoziation nicht durch eine Neusynthese bzw. Degradation des Fusionsproteins 
bedingt ist. Sowohl die Proteinmenge des nativen PEN2-Proteins als auch die des Fusionsproteins, die im Übrigen gleich stark konzentriert waren, blieben im Lauf der Pathogenabwehr im gesamten Blattmaterial konstant (Abb. 3.8). Diese Ergebnisse demonstrieren zum Einen, dass die PEN2-GFP-Reporterlinie das Verhalten der nativen Myrosinase widerspiegelt und zum Anderen, dass keine pathogen-induzierte Zunahme der PEN2-Proteinabundanz vorliegt. Wie schon im Ergebnisteil angedeutet, könnte demnach eine Relokalisation des Fusionsproteins aus dem cytoplasmatischen Pool hin zum Membrankompartiment gebundenen Pool der Grund für die Entstehung der Aggregatstrukturen sein. Welcher Mechanismus für die Verschiebung des PEN2-Pools verantwortlich ist, ist bisher nicht geklärt. Durchaus vorstellbar wäre eine post-translationelle Modifikation der Myrosinase, welche eine erhöhte Assoziation mit der Membran des Zielkompartiments bewirkt. Alternativ dazu könnte ein molekulares Chaperon für die Translokation von PEN2 verantwortlich sein. Für einige wenige Mitglieder der Gruppe der C-terminal verankerten Membranproteine (TA-Proteine) konnte inzwischen gezeigt werden, dass diese durch molekulare Chaperone zu ihrem Zielort dirigiert und in die entsprechende Membran integriert werden (zusammengefasst in Abell und Mullen, 2011). Wie bereits in der Einleitung beschrieben wird vermutet, dass PEN2 aufgrund seiner putativen Transmembrandomäne am C-Terminus ebenfalls zur Gruppe der TA-Proteine gehört, was erstmals durch die Ergebnisse der vorliegenden Arbeit belegt werden konnte. Aufgrund dessen kann spekuliert werden, dass ein pathogen-induziertes Chaperon den Transport und die Integration von PEN2 reguliert, was folglich wiederum zur Bildung der Aggregate führt.

\subsection{Pathogen-induzierte Oligomerisation von PEN2}

Mit Hilfe von Immunopräzipitationsexperimenten und anschließenden Western-BlotAnalysen konnte demonstriert werden, dass die Myrosinase PEN2 in unbehandelten Zellen Homodimere und in pathogen-behandelten Homooligomere bildet, die vermutlich zur Ausbildung der zuvor beschriebenen PEN2-Aggregate beitragen.

Wie im Ergebnisteil beschrieben, wurde eine Dimerisierung der beiden Fusionsproteine PEN2-GFP und PEN2-RFP in Koimmunopräzipitationsexperimenten in vivo eindeutig nachgewiesen (Abb. 3.10A). Zusätzlich konnte in fluoreszenzmikroskopischen Analysen bestätigt werden, dass das funktionale PEN2-RFP-Protein die gleiche subzelluläre Lokalisation wie PEN2-GFP aufweist und ebenfalls Aggregate ausbildet (Abb. 3.10B und 3.10C). Aufgrund der beobachteten PEN2-RFP-Aggregation ist daher anzunehmen, dass die Aggregation von PEN2-GFP nicht auf eine mögliche Dimerisierung des GFP-Proteins zurückzuführen ist, sondern wahrscheinlich auf einer PEN2-PEN2-Inteaktion beruht. Diese 
Hypothese konnte durch die Arbeiten von Christine Klapprodt zusätzlich bestätigt werden, in denen eine Dimerisierung des nativen PEN2-Proteins in Split-Ubiquitin-Experimenten nachgewiesen werden konnte (persönliche Kommunikation). Somit kann die Myrosinase PEN2 sowohl im heterologen als auch im homologen System Homodimere ausbilden. Wie in der Einleitung bereits erwähnt, konnte eine Dimerisierung von Glycosidhydrolasen schon in anderen Pflanzenspezies beobachtet werden. So wurde beispielsweise eine Bildung von Dimeren für die Glycosidhydrolase CBG1 („cyanogenic $\beta$-glucosidase 1“), welche zur Familie1-Glycosidhydrolasen (F1GH) in Trifolium repens (Weiß-Klee) gehört, und für eine Myrosinase aus Sinapis alba (Weißer Senf) nachgewiesen (Barrett et al., 1995; Burmeister et al., 1997). Die Funktion der Dimerisierung ist nicht genau bekannt, allerdings wird angenommen, dass sie möglicherweise zur Stabilisierung des Proteins beträgt und der Regulation der Enzymaktivität dient bzw. Einfluss auf die Substratspezifität hat (zusammengefasst in Kwak et al., 2009).

Neben der Dimerisierung von PEN2 wurde zusätzlich eine pathogen-induzierte Homomerisierung des PEN2-GFP-Fusionsproteins festgestellt, die vermutlich zum molekularen Aufbau der Aggregate beiträgt (Abb. 3.11 und 3.12B). Ob noch weitere Enzyme für die PEN2-Aggreagtion benötigt werden oder ob dieser Prozess möglicherweise autokatalytisch abläuft, muss noch näher untersucht werden. In der Literatur finden sich sowohl Beispiele für Glycosidasen, die zur Selbstaggregation befähigt sind, als auch für Glycosidasen, die erst mit weiteren Proteinen hochmolekulare Komplexe ausbilden (Fieldes und Gerhardt, 1994; Eriksson et al., 2002; Nagano et al., 2008; Kwak et al., 2009). Die Glycosidase AsGlu1 aus Hafer (Avena sativa) bildet homomultimere Strukturen ohne die Beteiligung weiterer Enzyme aus (Kwak et al., 2009). Im Kontrast dazu entsteht ein Glycosidhydrolase-Komplex in Raps (Brassica napus) erst nach Interaktion einer Myrosinase mit so genannten myrosinase-bindenden Proteinen (MBP; Eriksson et al., 2002). Diese Interaktion, welche zur Bildung von hochmolekularen Komplexen führt (250 bis 1000 $\mathrm{kDa}$ ), kommt erst nach Verwundung der Pflanze zustande, wodurch die Kompartimentierung der Zellen zerstört wird (Eriksson et al., 2002). Dabei tritt die Myrosinase aus spezifischen Zellen, die auch als Idioblasten bezeichnet werden, aus. Das Enzym reagiert daraufhin mit MBPs, die konstitutiv in den meisten Zellen vorliegen, allerdings nicht in den Idioblasten selbst (Eriksson et al., 2002). Ein weiteres Beispiel für eine Glycosidase, die ebenfalls nach Verwundung mit weiteren Proteinen Multienzymkomplexe formiert, ist die in der Einleitung vorgestellte Myrosinase PYK10 aus Arabidopsis. Diese bildet zusammen mit weiteren Glycosidhyrolasen und mehreren JAL-Proteinen (,jacalin-related lectins“) hochmolekulare Komplexe nach der Zerstörung der Membranstrukturen innerhalb der Zelle aus (Nagano et al., 2008). Inwieweit die PEN2-Aggregation in der Peripherie des Membrankompartiments ebenfalls durch MBPs reguliert wird, ist bisher nicht bekannt. Falls eine solche Regulation 
existiert, würde sich daraus die Frage ergeben, wie diese beiden Proteine voneinander getrennt, bzw. in der Pathogenabwehr zusammen gebracht werden könnten, da im Unterschied zur Komplexformation von PYK10 keine Aufhebung der Zellkompartimentierung in der Pathogenabwehr von biotrophen Pilzen stattfindet. Möglichweise könnte eine räumliche Trennung von PEN2 und einem potentiellen MBP als Interaktor durch eine pathogen-induzierte Translokation eines myrosinase-bindenden Proteins aus einem subzellulären Kompartiment aufgehoben werden. Da die PEN2-Aggregation ausschließlich in der Peripherie eines Membrankompartiments und nicht im Cytoplasma stattfindet, kann vermutet werden, dass das MBP ebenfalls mit dem Kompartiment assoziiert ist. Demnach könnte das PEN2-bindende Protein im Lumen des Membrankompartiments vorliegen und würde erst nach Pathogenbehandlung aus dem Lumen in die Membran transportiert werden, wodurch es zur Aufhebung der räumlichen Trennung und zur Interaktion mit dem PEN2Protein käme. Gegen diese Hypothese sprechen allerdings vorläufige Ergebnisse aus Verwundungsexperimenten, in denen keine Aggregation des PEN2-GFP-Fusionsproteins nach Aufhebung der subzellulären Kompartimentierung festgestellt werden konnte (Daten nicht gezeigt). Alternativ dazu wäre eine pathogen-induzierte Expression des mit PEN2 interagierenden MBPs durchaus vorstellbar, wodurch zwar keine räumliche, aber eine zeitliche Trennung der beiden Proteine bis zur Pathogenabwehr gewährleistet wäre. Weiterführende Analysen müssen diese Hypothese allerdings noch bestätigen oder widerlegen.

\subsection{Abhängigkeit der subzellulären PEN2-Lokalisation von der C-terminalen Extension}

Wie im Abschnitt zuvor erwähnt, findet die PEN2-GFP-Aggregation erst nach Pathogenbehandlung in der Peripherie eines Membrankompartiments statt, und ist nicht auf eine artifizielle Eigenschaft des GFP-Proteins zurückzuführen. Dies konnte unter anderem durch die Expression des Deletionskonstrukts GFP-PEN2 ${ }_{\text {Cterm }}$ demonstriert werden, in dem der globuläre Teil von PEN2 entfernt wurde (Abb. 3.13 und 3.14). Dieses Deletionsprotein zeigt die gleiche subzelluläre Lokalisation wie koexprimiertes PEN2-RFP, bildet aber im Gegensatz zum vollständigen RFP-Fusionsprotein keine Aggregate mehr aus (Abb. 3.15). Somit konnte nicht nur gezeigt werden, dass die Aggregation vom globulären Teil abhängig ist, sondern auch, dass die subzelluläre Lokalisation durch die C-terminale Extension bestimmt wird. Neben PEN2 konnte bereits für weitere C-terminal verankerte Proteine (TAProteine) demonstriert werden, dass der C-Terminus ausschlaggebend für die Assoziation mit Membrankompartimenten ist. So haben beispielsweise Mullen und Trelease (2000) 
nachgewiesen, dass die letzten 36 Aminosäuren der peroxisomalen Ascorbat-Peroxidase von Gossypium hirsutum ausreichend für die Bestimmung der subzellulären Lokalisation des Proteins sind. Des Weiteren konnten sie demonstrieren, dass eine Deletion der Transmembrandomäne (TMD) oder eine Verkürzung bzw. Veränderung der Aminosäuresequenz am Ende des C-Terminus Einfluss auf die Lokalisation des Proteins hat. Wie die Ergebnisse der vorliegenden Arbeit gezeigt haben, ist die putative TMD von PEN2 ebenfalls essentiell für die Bestimmung der subzellulären Lokalisation (Abb. 3.17D). Darüber hinaus konnte nachgewiesen werden, dass eine Verkürzung der Aminosäurenanzahl am C-terminalen Ende ebenfalls zur Lokalisation im Cytoplasma führen kann (Abb. 3.17A bis 3.17C). Während die Deletion der letzten drei Aminosäuren am CTerminus von PEN2 keinen Einfluss auf die Lokalisation hat, reduzierte die Deletion der vierten Aminosäure die Assoziation des Fusionsproteins mit den Membrankompartimenten. Die Deletion einer weiteren Aminosäure $\left(\mathrm{K}^{556}\right)$ hingegen führte zum Verlust der Assoziation mit dem Membrankompartiment und zur vollständigen Lokalisation im Cytoplasma. Aufgrund dieser Ergebnisse kann angenommen werden, dass eine Verkürzung des C-Terminus möglicherweise Einfluss auf die stabile Integration der Myrosinase in der Zielmembran hat. Interessanterweise wurde durch die Substitution der C-terminalen Aminosäure Lysin $\left(\mathrm{K}^{556}\right)$ durch Glycin ebenfalls die Assoziation des Fusionsproteins mit der Peripherie des rundlichen Membrankompartiments aufgehoben. Im Kontrast $\mathrm{zu}$ den zuvor beschriebenen Deletionsproteinen ist das Substitutionsprotein PEN2-GFP ${ }^{\mathrm{K} 556 \mathrm{G}}$ allerdings nicht im Cytoplasma lokalisiert, sondern möglicherweise ER-assoziiert (Abb. 3.17F). Ein ähnliches Phänomen konnten bereits Kuroda et al. (1998) für das mitochondriale Membranprotein Cytochrom b5 in menschlichen Zellen beobachten. Durch die Substitution einer positiv geladenen Aminosäure im Bereich der C-terminalen Endregion durch eine ungeladene, wurde eine Verschiebung des mitochondrialen Proteins zum ER hin festgestellt. Eine Änderung der Lokalisation der oben beschriebenen peroxisomalen Ascorbat-Peroxidase wurde ebenfalls nach dem Austausch von positiv geladenen Aminosäuren durch ungeladene nachgewiesen (Mullen und Trelease, 2000). Somit scheint die Ladung am Ende des C-Terminus von TA-Proteinen für die subzelluläre Lokalisation mit entscheidend zu sein. Inwiefern die veränderte Lokalisation des PEN2-Proteins Einfluss auf die Funktion in der Pathogenabwehr hat, wurde in vergleichenden Analysen der Invasionsrate von Bgh auf Wildtyppflanzen, transgenen Linien und Mutanten untersucht. Dabei konnte festgestellt werden, dass das ER-lokalisierte Substitutionsprotein zwar Aggregate ausbildet, diese aber im Gegensatz zu den Aggregaten, welche in der Peripherie von rundlichen Membrankompartimenten lokalisiert sind, den pen2-Phänotyp nicht komplementieren können (Abb. 3.18A). Warum die ER-assoziierten Aggregate nicht funktional sind, ist nicht bekannt. Es kann allerdings spekuliert werden, dass durch die veränderte Lokalisation der 
Myrosinase möglicherweise das Substrat nicht mehr in ausreichenden Mengen zur Verfügung steht. Alternativ dazu könnten auch Proteine in den ER-lokalisierten Aggregaten fehlen, die für die Funktionalität eines möglichen Multienzymkomplexes aus PEN2 und weiteren Enzymen notwendig sind und nur in der Membran des rundlichen Membrankompartiments vorhanden sind.

Wie das Substitutionsprotein komplementieren auch die Deletionsproteine PEN2-GFP- $\triangle \mathrm{C} 5$ und PEN2-GFP- $\triangle T M$ den pen2-Phänotyp nicht (Abb. 3.18A). Im Kontrast zum PEN2-GFP ${ }^{\mathrm{K} 556 \mathrm{G}}$-Protein bilden die Deletionsproteine keine Aggregate mehr aus. Erstaunlicherweise akkumulieren diese Proteine dennoch an der versuchten Invasionsstelle (Abb. 3.17C bis 3.17E). Dass diese Akkumulation dabei völlig unabhängig von der C-terminalen Extension abläuft, konnte durch das PEN2-GFP- $\Delta$ Cterm-Protein eindeutig demonstriert werden, in dem die C-terminale Extension vollständig deletiert wurde. Weiterhin konnte durch fluoreszenzmikroskopische Analysen von doppelt transgenen Pflanzen gezeigt werden, dass die flächige Akkumulation der Deletionsproteine nicht auf eine bloße Ansammlung des Cytoplasmas, wie sie im Lauf der Zellpolarisation beobachtet werden kann, sondern vermutlich auf die Eigenschaft der Myrosinase selbst zurückgeführt werden muss. Im Unterschied zum Deletionsprotein wurde keine Fluoreszenzintensivierung des RFP-markierten Cytoplasmas unterhalb des pilzlichen Appressoriums beobachtet (Abb. 3.19B). Mit Hilfe von Anilinblau-gefärbter Callose konnte zusätzlich demonstriert werden, dass die Anreicherung des PEN2-GFP- $\triangle$ TM-Proteins außerhalb des Symplasten und vermutlich innerhalb der Papillen stattgefunden hat (3.19C). Dieser Befund ist insofern interessant, da er einen Transport des Deletionsproteins aus dem Cytoplasma in den Apoplasten impliziert. Dass diese Translokation des Fusionsproteins nicht zufällig geschieht, sondern selektiv abläuft, wurde durch die Analyse von RFP bzw. GFP exprimierenden Pflanzen eindeutig nachgewiesen. Freies GFP oder RFP sind wie das Deletionsprotein ebenfalls im Cytoplasma lokalisiert, werden aber im Gegensatz zum PEN2-GFP- $\triangle T$ TMProtein nicht in den Apoplasten transportiert (Abb. 3.19B und 3.19D). Ein ähnliches Phänomen konnten bereits Meyer et al. (2009) für das plasmamembran-ständige PEN1Protein beobachten. Auch im Fall des Fusionsproteins GFP-PEN1 wurde eine Integration in die Matrix von Papillen festgestellt. Meyer et al. (2009) haben daraufhin geschlossen, dass möglicherweise Exosomen für den extrazellulären Transport verantwortlich sind. Exosomen sind 30 bis $100 \mathrm{~nm}$ große Vesikel, die durch Endocytoseprozesse an der Zellmembran entstehen und mit dem Endosom fusionieren. Durch anschließende Einstülpung der Endosomenmembran kommt es zur Bildung von so genannten multivesikulären Körpern („multivesicular bodies“), die dann wiederum mit der Zellmembran fusionieren und die intraluminalen Vesikel in den extrazellulären Raum freisetzen können (zusammengefasst in van Niel et al., 2006). Inwiefern die gleichen Mechanismen an der Translokation des PEN2- 
Deletionsproteins beteiligt sind, ist bisher nicht bekannt. Möglicherweise könnte das Deletionsprotein aufgrund seiner Akkumulation an der Penetrationsstelle ebenso durch Exosomen transportiert werden. Allerdings wäre dafür eine Interaktion des PEN2-GFP- $\triangle T$ TMProteins mit der Plasmamembran notwendig. Wie zuvor beschrieben wurde, zeigen die PEN2-GFP-Aggregate eine deutliche Affinität zur Plasmamembran an der PathogenInteraktionsstelle. Aufgrund dessen wäre es durchaus vorstellbar, dass PEN2 möglicherweise mit einem membranständigen Protein interagiert, was wiederum der Grund für die Anhaftung der Aggregate an der Plasmamembran ist. Diese hypothetische Interaktion zwischen der Myrosinase und einem Plasmamembranprotein könnte auch der Grund für die Akkumulation des Deletionsproteins an der Invasionsstelle und die Assoziation mit Exosomen sein.

Interessanterweise wird das vollständige PEN2-GFP-Reporterprotein im Unterschied zu den cytoplasmatischen Deletionsproteinen nicht in die Matrix von Papillen integriert. Möglicherweise verhindert die Assoziation des Reporterproteins mit dem Membrankompartiment die Translokation aus dem Symplasten. Warum allerdings der cytoplasmatische PEN2-GFP-Pool nicht in den Apoplasten unterhalb des pilzlichen Appressoriums transportiert wird, bleibt unklar. Möglicherweise werden die molekularen Eigenschaften der Myrosinase durch die Deletion über die Änderung der subzellulären Lokalisation hinaus modifiziert, was zu der ungewöhnlichen Integration der Deletionsproteine in die Matrix von Papillen führt. Darüber hinaus konnte in doppelt transgenen PEN2-RFP und PEN2-GFP- $\triangle T$ TM Linien keine Interaktion der beiden Proteine miteinander festgestellt werden. Wie die fluoreszenzmikroskopischen Analysen der doppelt transgenen Linie gezeigt haben, unterscheidet sich die subzelluläre Lokalisation der beiden Proteine deutlich von einander (Abb. 3.20). Während das Deletionsprotein teilweise in der extrahaustoriellen Matrix lokalisiert ist, was möglicherweise auf den Transport durch Exosomen zurückgeführt werden kann, bildet das PEN2-RFP-Protein Aggregate außerhalb des haustoriellen Komplexes aus. Diese Aggregatstrukturen werden dabei ohne die Beteiligung des PEN2-GFP- $\triangle T M$ gebildet, was darauf schließen lässt, dass das Deletionsprotein nicht mehr in der Lage ist, mit dem vollständigen Reporterprotein zu interagieren. Inwiefern der Verlust der Aggregation des mutierten Proteins von der fehlenden Assoziation mit dem Membrankompartiment abhängig ist, muss noch durch fluoreszenzmikroskopische Analysen weiterer Deletions- bzw. Substitutionsproteine von PEN2 näher untersucht werden. Es ist allerdings durchaus vorstellbar, dass die Lokalisation in der Peripherie eines Membrankompartiments essentiell für die Aggregatbildung ist, da zu keinem Zeitpunkt eine Aggregation des PEN2-GFP/RFP-Proteins im Cytoplasma beobachtet werden konnte. Abschließend kann daher festgehalten werden, dass die Assoziation mit einem bestimmten Membrankompartiment für die PEN2-Aggregation notwendig ist, und 
dass diese Aggregatstrukturen vermutlich essentiell für die Komplementierung des pen2Phänotyps sind.

\subsection{Assoziation der PEN2-Aggregate mit Mitochondrien}

In fluoreszenzmikroskopischen Analysen von unterschiedlichen stabilen doppelt transgenen Linien, konnte die Identität des rundlichen Membrankompartiments geklärt werden, welches der Ausgangspunkt der PEN2-Aggregation ist. Dabei handelt es sich nicht wie die transienten Expressionsassays von Lipka et al. (2005) vermuten ließen um Peroxisomen, sondern um Mitochondrien (Abb. 3.21 und 3.22). Das PEN2-GFP-Protein ist zwar ebenfalls in der Peripherie von RFP-markierten Peroxisomen lokalisiert, bildet aber im Gegensatz zur Interaktion mit Mitochondrien keine Aggregate an diesem Organell aus. Neben der Assoziation des Fusionsproteins mit Mitochondrien und Peroxisomen konnte darüber hinaus eine Lokalisation zu Plastiden in Epidermiszellen beobachtet werden (Abb. 3.23). Aufgrund des deutlich schwächeren Fluoreszenzsignals des PEN2-GFP-Proteins in der Peripherie von Plastiden im Kontrast zur Signalstärke in der Membran von Mitochondrien und Peroxisomen, kann eine deutlich geringere Affinität der Myrosinase zu diesem Organell angenommen werden. Eine Bildung der Aggregate des Fusionsproteins konnte ebenfalls nicht an Plastiden festgestellt werden. Somit ist nicht nur die Assoziation mit einem Membrankompartiment entscheidend für die PEN2-Aggregation, sondern auch die Spezifität der Organellenmembran selbst. Im Unterschied zu den drei genannten Organellen wurde keine Kolokalisation des Fusionsproteins mit RFP-markierten Golgi-Vesikeln, markiertem ER oder markierter Plasmamembran nachgewiesen (Abb. 3.24 und 3.5B). Aufgrund dessen ist anzunehmen, dass die Lokalisation des Reporterproteins in der Peripherie von Mitochondrien, Peroxisomen und Plastiden spezifisch, und damit nicht auf eine generelle Assoziation des PEN2-GFP-Proteins mit Membranstrukturen zurückzuführen ist. Mit Hilfe des schon vorgestellten Deletionsproteins GFP-PEN2 cterm konnte zudem gezeigt werden, dass der C-Terminus von PEN2 die subzelluläre Lokalisation zu allen drei Organellen unabhängig vom globulären Teil bestimmt (Abb. 3.25).

Neben den fluoreszenzmikroskopischen Analysen der PEN2-GFP-Reporterlinie wurden zusätzlich Immunogoldmarkierungsexperimente durchgeführt, welche die Lokalisation des nativen PEN2-Proteins in Wildtyppflanzen untersuchen und die gewonnenen Ergebnisse der Fluoreszenzmikroskopie bestätigen sollten. Allerdings konnte in den elektronenmikroskopischen Aufnahmen keine spezifische Markierung eines Organells festgestellt werden (Gerd Hause, Martin-Luther-Universität Halle-Wittenberg, persönliche Kommunikation). Ein möglicher Grund für die fehlende Immunogoldmarkierung könnte der 
verwendete PEN2-Anitkörper sein, da das Epitop in der C-terminalen Extension der Myrosinase liegt und wahrscheinlich durch den globulären Enzymteil blockiert wird, was wiederum eine Bindung des Antikörpers verhinderen würde.

Wie bereits erwähnt, wurden die PEN2-GFP-Aggregate lediglich an Oberflächen von Mitochondrien, nicht jedoch an Oberflächen von Peroxisomen oder Plastiden festgestellt. Neben dem unterschiedlichen Aggregationsverhalten von PEN2 in Abhängigkeit vom Membrankompartiment konnte darüber hinaus ein Unterschied im Verhalten der drei Organellen an der versuchten Penetrationsstelle nachgewiesen werden. Während die wenigen in der Epidermiszelle vorhandenen Plastiden offensichtlich nicht einer pathogeninduzierten Zellpolarisation unterliegen (Daten nicht gezeigt), konnte eine Akkumulation von Mitochondrien und Peroxisomen an der Pathogen-Interaktionsstelle detektiert werden (Abb. 3.22A und 3.21C). Eine Akkumulation der beiden Organellen wurde schon von Koh und Kollegen an der Penetrationsstelle des kompatiblen Mehltaupilzes G. cichoracearum beobachtet (Koh et al., 2005). Durch die Maximalprojektion einer Zeitreihe haben Koh et al. (2005) nachweisen können, dass Peroxisomen im Laufe der Zeit an der Invasionsstelle akkumulieren. Die fokale Anreicherung von Mitochondrien wurde hingegen durch die Maximalprojektion einer Z-Serie demonstriert. Wie die Analysen der vorliegenden Arbeit gezeigt haben, besteht allerdings ein signifikanter Unterschied im Akkumulationsverhalten der beiden Organellen. Beide Organellen weisen eine zeitliche Akkumulation unterhalb des Appressoriums auf, die im Fall der Peroxisomen allerdings nur transient ist, d. h. die Peroxisomen werden zielgerichtet zur Interaktionsstelle hin transportiert, aber verweilen dort nicht für längere Zeit (Abb. 3.38A). Im Kontrast dazu unterliegt eine Subpopulation von Mitochondrien einer dauerhaften fokalen Organellen-Immobilisierung an der Penetrationsstelle (Abb. 3.37A). Dass die Immobilisierung der Mitochondrien dabei unabhängig von der PEN2-Aggregation verläuft, wurde in Zeitverlaufsexperimenten von RFP-markierten Mitochondrien in pen2-1-Mutanten nach Pathogenbehandlung eindeutig demonstriert (Abb. 3.37B). Neben den fluoreszenzmikroskopischen Analysen von transgenen Pflanzen haben auch elektronenmikroskopische Aufnahmen von Wildtyppflanzen wiederholt eine Präsenz von mehreren Mitochondrien an der Papille belegen können, während Peroxisomen jedoch nicht vorhanden waren (Abb. 3.39).

Welche Funktion Mitochondrien neben ihrer Beteiligung am Transport und der Aggregation von PEN2 in der Nichtwirtsresistenz besitzen, ist bisher nicht bekannt. Allerdings haben Untersuchungen an Mitochondrien von Säugetieren gezeigt, dass das Organell eine wichtige Rolle in der Immunabwehr spielt. So sind Mitochondrien unter anderem in der Signaltransduktion nach Perzeption viraler PAMPs involviert. Außerdem sind sie an der Produktion von reaktiven Sauerstoffspezies und an der Kontrolle des programmierten Zelltods nach Infektion beteiligt (zusammen gefasst in West et al., 2011; Ohta und 
Nishiyama, 2011). Eine Beteiligung an der Bildung von reaktiven Sauerstoffspezies und an der Zelltodreaktion während der Pathogenabwehr wird auch bei pflanzlichen Mitochondrien vermutet (zusammengefasst in Kusano et al., 2009). Zusätzlich könnte die Akkumulation der Mitochondrien an der Pathogen-Interaktionsstelle auch einer beschleunigten Bereitstellung von ATP dienen, da eine Vielzahl unterschiedlicher Abwehrmechanismen, wie beispielsweise die Translokation von Indolderivaten durch den ABC-Transporter PEN3, ATP-abhängig sind (Stein et al., 2006).

Welche Funktion die transiente Akkumulation von Peroxisomen an Orten der versuchten Invasion hat, ist ebenfalls nicht ausreichend geklärt. Wie in der Einleitung bereits beschrieben, sind Peroxisomen unter anderem an Signaltransduktions-Prozessen und an der Redox-Regulation in attackierten Zellen beteiligt (del Rio et al., 2002; Mittler et al., 2004; Apel und Hirt, 2004; Torres und Dangl, 2005). Daher ist es durchaus vorstellbar, dass die transiente Akkumulation von Peroxisomen der Detoxifikation von reaktiven Saustoffspezies unterhalb des pilzlichen Appressoriums dient. Alternativ dazu könnte die zeitliche Anreichung des Organells auch zur Freisetzung von $\mathrm{H}_{2} \mathrm{O}_{2}$ führen, dass entweder als Signalmolekül fungiert und damit die Immunantwort der Pflanze zusätzlich induziert, oder zur Verstärkung der Zellwand bzw. als toxische Komponente dient. Darüber hinaus wäre auch eine Freisetzung weiterer Substanzen an der Pathogen-Interaktionsstelle möglich, da Peroxisomen an der Synthese unterschiedlicher Substanzen wie Jasmonsäure und dem Indolderivat Auxin beteiligt sind (zusammengefasst in Palma et al., 2009). Inwiefern Peroxisomen möglicherweise auch zur Synthese des PEN2-Substrats 4-Methoxyindol-3ylmethylglucosinolat (4MI3G), was ebenfalls ein Indolderivat darstellt, beitragen, ist nicht bekannt. Eine Metabolom-Analyse von isolierten Peroxisomen aus pathogen-infizierten Pflanzen könnte dies unter Umständen klären.

Weshalb die Myrosinase PEN2 nun eine Affinität zu drei unterschiedlichen Membrankompartimenten besitzt, ist noch unbekannt. Aufgrund der geringen Assoziation mit Plastiden und der fehlenden fokalen Akkumulation dieses Organells an Orten der versuchten Invasion, besitzt die PEN2-Plastid-Interaktion vermutlich keine Relevanz für die Nichtwirtsresistenz. Inwieweit die duale Assoziation der Myrosinase mit Mitochondrien und Peroxisomen essentiell für die Pathogenabwehr ist, oder ob es sich bei der Lokalisation mit Peroxisomen um eine mögliche Fehllokalisation handelt, ist bislang nicht ausreichend geklärt. In der Literatur finden sich jedenfalls Beispiele für C-terminal verankerte Proteine, deren duale Assoziation mit zwei unterschiedlichen Organellen sowohl spezifisch als auch unspezifisch sein kann. So konnten Zhang und Hu (2009) zeigen, dass die TA-Proteine FIS1A (,fission 1A“) und FIS1B eine duale Lokalisation zu Mitochondrien und Peroxisomen besitzen. FIS1A und FIS1B sind beide an der Teilung von Mitochondrien und Peroxisomen beteiligt (Zhang und $\mathrm{Hu}, 2008$ ), weshalb die duale Lokalisation spezifisch und für die 
Funktionalität der beiden Proteine notwendig ist. Im Unterschied dazu weist das Protein Cytochrom b5-6 nur dann eine Assoziation mit Mitochondrien auf, wenn keine Chloroplasten in der Zelle vorhanden sind (Maggio et al., 2007). Maggio et al. (2007) haben daraus geschlossen, dass die Isoform von Cytochrom b5 zwar eine höhere Affinität zu Chloroplasten besitzt, aber beide Organellen im Endeffekt um das TA-Protein konkurrieren. Mit Hilfe eines chimären Konstrukts aus dem globulären Teil von PEN2 und der Cterminalen Extension der peroxisomalen Ascorbat-Peroxidase 3 sollte in der vorliegenden Arbeit nun geklärt werden, ob die Assoziation von PEN2 mit Peroxisomen für die Pathogenabwehr essentiell ist, oder ob es sich bei der Interaktion um eine Fehllokalisation wie im Fall des Cytochrom b5-6-Proteins handelt. Wie die Ergebnisse allerdings gezeigt haben, führt die C-terminale Extension des TA-Proteins APX3 nicht zu einer spezifischen

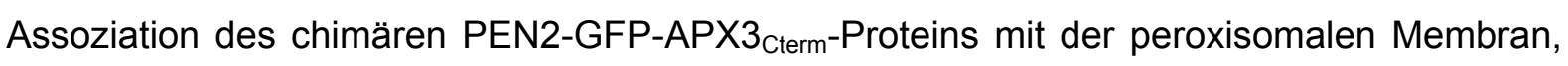
sondern auch mit der von Mitochondrien (Abb. 3.33). Zwar konnte eine erhöhte Fluoreszenzintensität in der Peripherie von Peroxisomen im Vergleich zu Mitochondrien festgestellt werden, die auf eine verstärkte Affinität des chimären Proteins mit der peroxisomalen Membran hinweist, allerdings war die Assoziation mit der äußeren mitochondrialen Membran dennoch deutlich erkennbar. Ebenso deutlich nachweisbar war die Bildung von Aggregaten an der Pathogen-Interaktionsstelle, die auf den mit

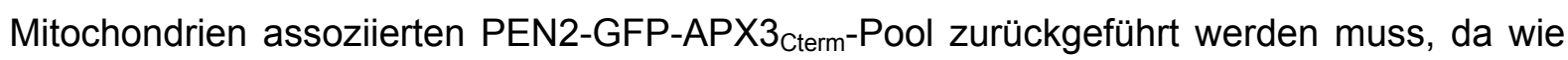
schon beschrieben zu keinem Zeitpunkt eine Aggregation in der Peripherie von Peroxisomen beobachtet werden konnte (Abb. 3.32A). Die Aggregation in der Peripherie von Mitochondrien wird vermutlich auch der Grund für die Komplementation des pen2Phänotyps durch das chimäre Protein sein. Somit konnte durch die Analysen des PEN2-GFP-APX3 $3_{\text {Cterm }}$-Proteins nicht auf eine mögliche Funktion der PEN2-PeroxisomenInteraktion für die Nichtwirtsresistenz geschlossen werden. Aus welchem Grund das chimäre Protein nun mit Mitochondrien assoziiert war, muss noch näher untersucht werden. Wie die Untersuchungen zum Lokalisationsverhalten des GFP-APX3- bzW. RFP-APX3-Proteins jedoch vermuten lassen, ist die Fehllokalisation zu Mitochondrien wahrscheinlich von der Proteinabundanz abhängig. So konnte eindeutig demonstriert werden, dass die Überexpression des GFP-APX3-Fusionsproteins neben der beschriebenen Lokalisation zu Peroxisomen ebenfalls zur Assoziation mit Mitochondrien führte, wohingegen die Expression des RFP-APX3-Proteins unter dem nativen Promotor ausschließlich eine Lokalisation in der Peripherie von Peroxisomen aufwies (Abb. 3.31). Aufgrund dieser Ergebnisse kann gemutmaßt werden, dass Mitochondrien und Peroxisomen mit großer Wahrscheinlichkeit um die Ascorbat-Peroxidase konkurrieren, jedoch das TA-Protein APX3 eine höhere Affinität zu Peroxisomen besitzt. Außerdem kann spekuliert werden, dass die Expressionslevel des

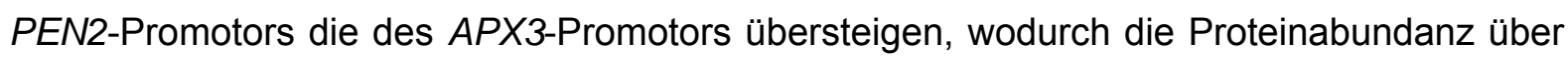


den endogen Wert der C-terminalen Extension von APX3 hinaus erhöht wurde, was wiederum zur Fehllokalisation des chimären Proteins geführt haben könnte. Daher wird für zukünftige Experimente, die die Bedeutung der PEN2-Peroxisomen-Interaktion klären sollen, eine C-terminale Extension eines TA-Proteins benötigt, die trotz Überexpression ihre spezifische Assoziation mit Peroxisomen beibehält, und dadurch zur spezifischen peroxisomalen Lokalisation des chimären PEN2-Proteins führen würde. Alternativ dazu könnte durch eine ausschließliche Assoziation eines chimären PEN2-Konstrukts mit der mitochondrialen Membran demonstriert werden, dass eine Assoziation mit Peroxisomen nicht essentiell für die PEN2-vermittelte Nichtwirtsresistenz ist. Wie die Ergebnisse der vorliegenden Arbeit weiterhin gezeigt haben, ist die C-terminale Extension des TA-Proteins TOM20-4 geeignet, dieses Kriterium zu erfüllen. Weder das chimäre Protein PEN2-GFP-TOM20-4 unter der Kontrolle des PEN2-Promotors, noch die Überexpression des Fusionsproteins RFP-TOM20-4 führten zu einer Fehllokalisation mit der peroxisomalen Membran (Abb. 3.35 und 3.34). Somit scheint der C-Terminus von TOM20-4 ideal dafür geeignet zu sein, um die Bedeutung der Affinität von PEN2 mit Mitochondrien in vergleichenden Penetrationsanalysen zu demonstrieren und eine Funktion der Assoziation der Myrosinase mit Peroxisomen vollständig auszuschließen.

Neben der fehlenden PEN2-Aggregation in der Peripherie von Peroxisomen sprechen die Ergebnisse der Organellen-Isolation möglicherweise zusätzlich gegen eine Bedeutung der PEN2-Peroxisomen-Interaktion in der Pathogenabwehr. Wie OrganellenIsolationsexperimente gezeigt haben, konnte das native PEN2-Protein durch die spezifische Isolation von Mitochondrien angereichert werden, wohingegen keine Anreicherung im peroxisomalen Pellet festgestellt wurde (Abb. 3.29 und 3.28B). Da die fluoreszenzmikroskopischen Analysen allerdings eine Assoziation mit beiden Organellen aufgezeigt haben, stellt sich die Frage, warum die Isolation von Peroxisomen nicht zur Anreicherung der Myrosinase geführt, und damit die mikroskopischen Untersuchungen bestätigt hat. Ein möglicher Grund für diese Diskrepanz könnte ein unterschiedliches Verhalten in der subzellulären Lokalisation des nativen Proteins zum PEN2-GFPFusionsprotein sein. Allerdings sprechen gegen diese Hypothese sowohl die Ergebnisse der Isolierungsexperimente der Organellen, als auch die der Dichtegradientenanalyse. So wurde kein Unterschied in der Anreicherung zwischen PEN2 und PEN2-GFP nach der Isolierung von Peroxisomen aus Wildtyppflanzen bzw. transgenen Pflanzen festgestellt (Abb. 3.28B). Darüber hinaus wiesen beide Proteine ein identisches Sedimentationsverhalten im Dichtegradient auf (Abb. 3.26 und 3.27). Alternativ zur vorherigen Hypothese könnte der Grund für die fehlende Assoziation der Myrosinase mit Peroxisomen auch auf eine verglichen mit Mitochondrien geringere Affinität des PEN2 bzw. PEN2-GFP-Proteins zu dem Organell zurückzuführen sein. Diese geringere Affinität der Myrosinase zu der 
peroxisomalen Membran würde bei der Isolierung von Organellen möglicherweise eher zur Ablösung des Proteins aus der Membran von Peroxisomen als aus der von Mitochondrien führen. Dass das PEN2-Protein scheinbar relativ leicht von der Organellenmembran abgelöst werden kann, haben die Western-Blot-Analysen der unterschiedlichen Fraktionen der Dichtegradientenzentrifugation gezeigt. Während nur ein vergleichsweise geringer Anteil der Myrosinase mit den Organellen kosedimentierte, blieb der größere Anteil in den löslichen Fraktionen zurück (Abb. 3.26 und 3.27). Wie im Ergebnisteil schon erwähnt, wurde der cytoplasmatische PEN2-GFP-Pool mit Hilfe eines zusätzlichen Zentrifugationsschritts vor der eigentlichen Dichtegradientenzentrifugation entfernt, und kann somit nicht für den PEN2Pool in den löslichen Fraktionen verantwortlich sein. Auch wenn es keinen direkten Beweis für die zuletzt genannte Hypothese gibt, liefert sie zumindest eine Erklärung für die beschriebene Diskrepanz zwischen den mikroskopischen Analysen und denen der Organellen-Isolierung, ohne dabei im Widerspruch mit vorhandenen Ergebnissen zu stehen. Allerdings werden noch die zuvor beschriebenen Experimente mit weiteren chimären PEN2Konstrukts benötigt, um eine Funktion der PEN2-Assoziation mit Peroxisomen in der Pathogenabwehr vollkommen ausschließen zu können. Wie die Ergebnisse in der vorliegenden Arbeit jedoch eindeutig gezeigt haben, scheint die Lokalisation zu Mitochondrien aufgrund der PEN2-Aggregation in der Peripherie des an der Invasionsstelle immobilisierten Organells essentiell für die pflanzliche Abwehr von nicht adaptierten Pathogenen zu sein. Somit konnte erstmalig eine Beteiligung von Mitochondrien an der Nichtwirtsresistenz von Arabidopsis beschrieben werden.

\subsection{Beteiligung von PEN4 an PEN2-Aggregaten}

Dass die Myrosinase PEN2 scheinbar nicht das einzige Enzym ist, welches Aggregate in der Peripherie von Mitochondrien ausbildet, konnte durch die fluoreszenzmikroskopischen Untersuchungen der Phytochelatin-Synthase 1 (PCS1) demonstriert werden. PCS1 oder auch PEN4 genannt, ist neben der Stresstoleranz gegenüber Schwermetallen ebenfalls in der Nichtwirtsresistenz von Arabidopsis involviert (Clay et al., 2009; Blum et al., 2010; Melisa Lim, Kian Hématy und Shauna Somerville persönliche Kommunikation). So lassen die Analysen von Clay et al. (2009) beispielsweise auf eine Beteiligung des Enzyms an der Spaltung des PEN2-Substrats schließen. Des Weiteren konnten Melisa Lim und Kian Hématy in vergleichenden Analysen der Penetrationsraten nach Inokulation mit Bgh nachweisen, dass PEN4 und PEN2 vermutlich im gleichen Abwehrmechanismus zusammenarbeiten (Melisa Lim, Kian Hématy und Shauna Somerville, persönliche Kommunikation). Zusätzlich konnten sie mit Hilfe fluoreszenzmikroskopischer 
Untersuchungen zeigen, dass das Fusionsprotein GFP-PEN4 in unbehandelten Epidermiszellen im Cytoplasma lokalisiert ist, während eine Relokalisation des Reporterproteins nach Pathogenbehandlung zur versuchten Invasionsstelle hin beobachtet werden konnte. Dieses Ergebnis konnte durch die vorliegenden Analysen bestätigt und darüber hinaus noch weiter charakterisiert werden. So wurde anhand von Detailaufnahmen eindeutig festgestellt, dass das RFP-PEN4-Protein an der Penetrationsstelle ausschließlich mit den PEN2-GFP-Aggregaten kolokalisiert, und nicht generell mit der Membran von Mitochondrien assoziiert ist (Abb. 3.41C). Somit ist scheinbar keine Assoziation der Phytochelatin-Synthase mit der Membran des Organells, wie sie bei der Myrosinase PEN2 beobachtet wurde, für die Integration in die Aggregate notwendig. Dies wiederum lässt auf eine direkte Translokation des PEN4-Proteins aus dem Cytoplasma in die Aggregatstruktur schließen. Weiterhin konnte anhand von fluoreszenzmikroskopischen Aufnahmen von transgenen pen2-1-Mutantenpflanzen aufgezeigt werden, dass das RFP-PEN4Fusionsprotein dabei unabhängig von PEN2 Aggregatstrukturen ausbildet (Abb. 3.41D). Somit scheint die Translokation und Aggregation von PEN4 nicht auf eine direkte Interaktion der beiden Proteine zurückgeführt werden können, was durch Split-Ubiquitin-Experimente ebenfalls bestätigt wurde (Christine Klapprodt, persönliche Kommunikation). Inwiefern PEN4 ebenfalls Homooligomere ausbildet, die zur Formation der Aggregate führen, oder ob noch weitere Enzyme daran beteiligt sind, ist nicht bekannt. Jedenfalls konnten Grill und Kollegen zeigen, dass eine Phytochelatin-Synthase aus Silene cucubalus (Leimkraut) Dimere ausbildet, welche die aktive Form des Enzyms darstellen (Grill et al., 1989). Daher ist es durchaus vorstellbar, dass die zuvor beschriebenen PEN2-GFP-Aggregate aus PEN2Homoligomeren und PEN4-Dimeren zusammengesetzt sind. Außerdem kann angenommen werden, dass noch weitere Enzyme an der Komplexbildung beteiligt sind, wie es bereits diskutiert und im Fall der Myrosinase PYK10 schon beschrieben worden ist (Nagano et al., 2008).

\subsection{ER-Lokalisierung des pathogen-induzierten CYP81F2-Genprodukts}

Wie die fluoreszenzmikroskopischen Analysen von RFP-CYP81F2 und PEN2-GFP exprimierenden Pflanzen demonstrieren konnten, ist die an der PEN2-Substrat-Synthese beteiligte Cytochrom-P450-Monooxygenase keine Komponente des PEN2/PEN4Komplexes, sondern ein ER-lokalisiertes Protein (Abb. 3.43 und 3.42C). Dass die ERAssoziation des CYP81F2-Proteins funktional ist und somit vermutlich der Lokalisation des nativen Proteins entspricht, konnte durch die vergleichende Analyse der Invasions- und Zelltodraten von transgenen Linien und Kontrollpflanzen nach Inokulation mit Bgh eindeutig 
gezeigt werden (Abb. 3.44). Bereits Reintanz et al. (2001) haben eine Assoziation der beiden Monooxygenasen CYP79F1 und CYP79F2, die an der Synthese von aliphatischen Glucosinolaten beteiligt sind, mit dem Endoplasmatischen Retikulum nachgewiesen, was zusätzlich für eine potentielle ER-Lokalisation des CYP81F2-Proteins spricht. Inwiefern CYP81F2 ebenfalls Teil eines an der cytoplasmatischen Seite des ERs lokalisierten Multienzymkomplexes ist, wie er für CYP79F1/CYP79F2 und weitere Enzyme von Grubb und Abel (2006) vorgeschlagen wurde, muss noch durch fluoreszenzmikroskopische Analysen weiterer Reporterlinien von Enzymen der PEN2-Substrat-Synthese oder durch Koimmunopräzipitationsexperimente näher untersucht werden. Allerdings würde dies eine Synthese des PEN2-Substrats 4MI3G im Cytoplasma bedeuten und möglicherweise zu einer ungewollten Spaltung des Glucosinolats durch den cytoplasmatischen PEN2-Pool führen. Da offensichtlich keine räumliche Trennung von PEN2 und Substrat-Synthese in unterschiedlichen Zellen vorliegt, wie sie beispielsweise bei den zuvor beschriebenen Idioblasten der Fall ist, muss die Pflanzenzelle weitere Mechanismen entwickelt haben, die einer vorzeitigen Hydrolyse des Glucosinolats entgegen wirken. Als mögliche Mechanismen kämen unter anderem eine schnelle Zwischenspeicherung des Substrats in anderen Zellorganellen oder eine Regulation der Enzyme in Frage, die eine vorzeitige SubstratSynthese verhindert. So könnte beispielsweise das fertige Glucosinolat nach der Synthese im Cytoplasma in der Vakuole zwischen gespeichert werden und wäre somit nicht länger frei für die Myrosinase zugänglich. Eine Speicherung des Braunen Senf (Brassica juncea)Glucosinolats Sinigrin in Vakuolen konnten Kelly und Kollegen bereits belegen (Kelly et al., 1998). Alternativ oder zusätzlich dazu könnte eine transkriptionelle oder posttranslationelle Regulation der Monooxygenase selbst vorliegen, wodurch die Synthese des Glucosinolats nicht konstitutiv, sondern erst nach Induktion erfolgt. Aufgrund der Ergebnisse der vorliegenden Arbeit und der Daten von Humphry et al. (2010) kann darauf geschlossen werden, dass die Synthese von 4MI3G möglicherweise abhängig von der transkriptionellen Regulation des CYP81F2-Gens ist. Wie die hier präsentierten Ergebnisse der semiquantitativen RT-PCR-Analyse gezeigt haben, stieg die CYP81F2-Transkriptmenge 18 und 24 Stunden nach Behandlung mit dem Gerstenmehltaupilz deutlich an (Abb. 3.45A). Humphry und Kollegen konnten zudem eine signifikante Zunahme des Glucosinolats 16 Stunden nach Inokulation mit Bgh nachweisen (Humphry et al., 2010). Somit scheint eine potentielle Korrelation zwischen der Expression von CYP81F2 und der Produktion von 4MI3G zu bestehen. Einen Zusammenhang zwischen der erhöhten Expression von Enzymen des Glucosinolat-Biosynthesewegs und der Konzentration von Glucosinolaten wurde bereits durch die Untersuchungen zu HIG1 („high indolic glucosinolate 1“), auch als MYB51 bezeichnet, demonstriert (Gigolashvili et al., 2007). Der Transkriptionsfaktor MYB51 aktiviert neben Genen der Tryptophan-Biosynthese ebenfalls die Expression der 
Monooxygenasen CYP79B2, CYP79B3 und CYP83B1, die an der Synthese des Indol-3ylmethylglucosinolats (I3G) beteiligt sind, einem Intermediärprodukt der 4MI3G-Synthese (Gigolashvili et al., 2007; Bednarek et al., 2009). Durch die Arbeiten von Humphry et al. (2010) wurde weiterhin nachgewiesen, dass myb51-Mutanten reduzierte Konzentrationen von I3G und 4MI3G aufweisen, was zu einer erhöhten Invasionsrate des nicht adaptierten Mehltaupilzes geführt hat.

Dass eine Erhöhung der Transkriptmenge von CYP81F2 auch definitiv zu einer Zunahme der Proteinabundanz der Monooxygenase und somit zu einer gesteigerten Synthese des PEN2-Substrats führt, wurde durch die Ergebnisse der Western-Blot-Analysen der vorliegen Arbeit zusätzlich bestärkt. So konnte in Western-Blot-Analysen von transgenen Pflanzen, die das funktionale Konstrukt CYP81F2-RFP unter der Kontrolle des nativen Promotors exprimieren, gezeigt werden, dass die Proteinabundanz des Fusionsproteins im Lauf der Pathogenabwehr signifikant zunimmt (Abb. 3.45B). Somit kann ein direkter Zusammenhang zwischen Gen-Transkription, Proteinabundanz und Substratmenge angenommen werden. Allerdings muss dies noch durch eine Analyse der 4MI3G-Konzentration, der CYP81F2-RFP-Proteinabundanz und der Transkriptmenge in der Reporterlinie im Verlauf der Pathogenabwehr bestätigt werden.

Im Kontrast zur Monooxygenase scheint die Regulation von PEN2 in der Pathogenabwehr nicht transkriptionell, sondern möglicherweise posttranslationell zu erfolgen. So konnte in semiquantitativen RT-PCR-Analysen zwar eine Zunahme der PEN2-Transkriptmenge 24 Stunden nach Pathogenbehandlung beobachtet werden, allerdings wurde zu keinem Zeitpunkt eine Veränderung der Proteinkonzentration in Western-Blot-Analysen nachgewiesen (Abb. 3.45 und 3.8). Welcher molekulare Mechanismus für die Konstanthaltung der Proteinmenge innerhalb der Epidermiszellen verantwortlich ist, ist bislang nicht bekannt. Ebenfalls ist nicht bekannt, inwiefern PEN2 einer möglichen posttranslationellen Modifikation unterliegt, welche die Enzymaktivität reguliert und eine ungewollte Hydrolyse des Substrats verhindert. Alternativ dazu wäre auch eine Regulation der PEN2-Aktivität durch eine Interaktion mit weiteren Proteinen denkbar. So konnten beispielsweise Nagano und Kollegen nachweisen, dass die Myrosinase PYK10, die zur gleichen Unterfamilie der F1GH wie PEN2 gehört, erst in hochmolekularen Komplexen aktiv ist, und dass das PYK10-bindende Protein PBP1 („PYK10-binding protein 1“) Einfluss auf die Aktivität der Myrosinase hat (Nagano et al., 2005 und 2008). Da PEN2 nach Pathogenbehandlung ebenfalls Bestandteil von molekularen Komplexen ist, könnte die enzymatische Aktivität durch die pathogen-induzierte Aggregation reguliert sein, an der neben PEN4 möglicherweise auch weitere Proteine wie MBPs beteiligt sind. Die Aggregatbildung könnte unter Umständen zu einer erhöhten Affinität der Myrosinase zum 
Substrat führen und dadurch eine vorzeitige Hydrolyse des 4MI3G im Cytoplasma verhindern.

Anhand dieser Überlegungen und der vorgestellten Ergebnisse kann folgendes Model für das Zusammenspiel der beiden Protein CYP81F2 und PEN2 in der Nichtwirtsresistenz vorgeschlagen werden: Während die Monooxygenase nach Perzeption des Pathogens transkriptionell reguliert wird, was zu einer Zunahme der Proteinkonzentration des Enzyms und dadurch zu einer erhöhten Substrat-Synthese führt, wird die Enzymaktivität der Myrosinase dagegen nicht durch die Proteinabundanz kontrolliert, sondern möglicherweise durch die Interaktion mit weiteren Proteinen reguliert, welche zur pathogen-induzierten Aggregatbildung beitragen. Erst die Aggregation von PEN2 an der PathogenInteraktionsstelle induziert die vollständige Enzymaktivität und bewirkt eine Hydrolyse des am ER produzierten Glucosinolats. In zukünftigen Experimenten muss die Erhöhung der enzymatischen Aktivität von PEN2 nach Aggregation allerdings noch bestätigt oder widerlegt werden. Ebenso müssen noch die Faktoren identifiziert werden, die zur Aggregatbildung beitragen. Darüber hinaus sollte noch geklärt werden, ob das Substrat zum Ort der versuchten Invasion durch Diffusion im Cytoplasma gelangt, oder ob es in der Vakuole zwischen gespeichert wird und anschließend fokal unterhalb des Appressoriums freigesetzt wird. 


\section{Zusammenfassung}

Die atypische Myrosinase PEN2 ist Teil der präinvasiven Nichtwirtsresistenz von Arabidopsis thaliana. Mit Hilfe eines funktionalen GFP-Fusionsproteins, bei dem das Fluoreszenzprotein zwischen den globulären Teil und der C-terminalen Extension von PEN2 integriert wurde, konnte die Lokalisation in der Peripherie von mobilen Membrankompartimenten nachgewiesen werden, die nach Inokulation mit dem nichtadaptierten, biotrophen Mehltaupilz Blumeria graminis f. sp. hordei (Bgh) an Interaktionsstellen akkumulieren (Lipka et al., 2005). Wie die vorliegenden Untersuchungen demonstriert haben, tritt die pathogen-induzierte Fluoreszenzakkumulation des PEN2-GFPProteins nicht nur in der Interaktion mit Bgh, sondern ebenfalls mit kompatiblen biotrophen, hemibiotrophen und nekrotrophen Pilzen, sowie in Interaktion mit dem Oomycet Phytophthora capsici auf. Neben der Akkumulation der fluoreszenz-markierten Kompartimente wurde in der vorliegenden Arbeit darüber hinaus eine deutliche zeitverlaufsabhängige Intensitätszunahme des Fluoreszenzsignals an der versuchten Invasionsstelle beobachtet, die durch Aggregation des PEN2-GFP-Proteins in der Peripherie der Membrankompartimente entsteht. Die ca. 0,6 bis 1,2 $\mu \mathrm{m}$ großen Aggregate sind vornehmlich an Orten der versuchten Penetration lokalisiert, nehmen in Anzahl und Größe im Verlauf der Pathogenabwehr zu und sind in der Regel nicht mobil.

Der molekulare Aufbau der PEN2-GFP-Aggregate ist bisher nicht genau bekannt. Allerdings kann angenommen werden, dass diese aus PEN2-GFP-Homooligomeren zusammengesetzt sind. So konnte durch Immunopräzipitationsexperimente gezeigt werden, dass das Fusionsprotein in pathogen-behandelten Zellen detergenz-resistente Oligomere ausbildet. Wie die Analysen von PEN2-GFP-Deletionsproteinen eindeutig belegen, ist die Oligomerisierung des PEN2-GFP-Fusionproteins dabei nicht auf eine unspezifische GFPGFP-Interaktion zurückzuführen, sondern abhängig vom globulären Teil der Myrosinase. Durch die Analyse weiterer Deletionsproteine konnte zusätzlich demonstriert werden, dass die C-terminale Extension für die subzelluläre Lokalisation der Myrosinase essenziell ist, was wiederum PEN2 als C-terminal verankertes Membranprotein bestätigt. Außerdem konnte bewiesen werden, dass die Assoziation zum Membrankompartiment ausschlaggebend für die PEN2-Aggregation bzw. die Komplementation des pen2-Phänotyps ist.

Mit Hilfe von doppelt transgenen Linien, die neben PEN2-GFP ebenfalls ein organellenspezifisches, RFP-markiertes Reporterprotein exprimieren, wurden neben Peroxisomen auch Mitochondrien und Plastiden als PEN2-GFP-assoziierte Kompartimente fluoreszenzmikroskopisch identifiziert. Allerdings unterliegt ausschließlich der mitochondrienassoziierte PEN2-GFP-Pool der pathogen-induzierten Aggregation und fokalen Organellen- 
Immobilisierung. Die Assoziation des Fusionsproteins und des nativen PEN2-Proteins mit Mitochondrien wurde ergänzend zu den mikroskopischen Untersuchungen durch spezifische Isolierung von Organellen nachgewiesen, wohingegen keine Anreicherung der Myrosinase durch die Isolierung von Peroxisomen festgestellt werden konnte. Somit konnte erstmalig eine Beteiligung von Mitochondrien an der Nichtwirtsresistenz von Arabidopsis beschrieben werden.

Neben der Lokalisation von PEN2 wurde die subzelluläre Lokalisation weiterer Komponenten der PEN2-vermittelten Nichtwirtsresistenz untersucht. Dabei wurde unter anderem festgestellt, dass die Akkumulation des ABC-Transporters PEN3 in der Plasmamembran und die der PEN2-Aggregate an der Membran zeitlich nicht streng miteinander korrelieren. Darüber hinaus konnte durch Transformation der pen3-1 pen2-3Doppelmutante mit einem PEN2-RFP-Konstrukt gezeigt werden, dass die Anreicherung von PEN2-RFP-Aggregaten an Orten der versuchten Invasion nicht abhängig von PEN3 ist.

Des Weiteren wurde die Phytochelatin-Synthase PEN4 als zusätzliche Komponente der PEN2-GFP-Aggregate identifiziert. Das im Cytoplasma lokalisierte Protein PEN4 weist in unbehandelten Epidermiszellen keine Assoziation mit PEN2-GFP-markierten Organellen auf. Erst nach Pathogenbehandlung kolokalisieren PEN2 und PEN4 in den PEN2-GFPAggregaten an der Pathogen-Interaktionsstelle. Demnach handelt es sich bei den zuvor beschriebenen Aggregat-Strukturen vermutlich um Komplexe aus PEN4 und PEN2Homooligomeren.

Mittels eines funktionalen RFP-Fusionsproteins konnte in der vorliegenden Arbeit erstmals die an der PEN2-Substratsynthese beteiligte Monoxygenase CYP81F2 als ER-lokalisiertes Protein identifiziert werden. Außerdem wurde nachgewiesen, dass die Proteinabundanz der Monooxygenase nach Pathogenbehandlung vermutlich transkriptionell erhöht, während die Konzentration der Myrosinase posttranslationell konstant gehalten wird. Somit können für die beiden Proteine unterschiedliche Regulationmechanismen innerhalb der Pathogenabwehr angenommen werden.

Abschließend kann zusammengefasst werden, dass für die PEN2-vermittelte Nichtwirtsresistenz neben dem plasmamembran-ständigen Transporterprotein PEN3 ein Zusammenspiel des ER-lokalisierten substrat-produzierenden CYP81F2-Proteins und der in der Peripherie von Mitochondrien lokalisierten PEN2/PEN4-Aggregate notwendig ist. 


\section{Literaturangaben}

Abell, B.M. und Mullen, R.T. (2011) Tail-anchored membrane proteins: exploring the complex diversity of tail-anchored-protein targeting in plant cells. Plant Cell Reports 30: 137151

Apel, K. und Hirt, H. (2004) Reactive oxygen species: metabolism, oxidative stress and signal transduction. Annual Review of Plant Biology 55: 373-399

Arai, M., Mitsuke, H., Ikeda, M., Xia, J.-X., Kikuchi, T., Satake, M. und Shimizu, T. (2004) ConPred II: a consensus prediction method for obtaining transmembrane topology models with high reliability. Nucleic Acids Research 32: 390-393

Asai, T., Tena, G., Plotnikova, J., William, M.R., Chiu, W.L., Gomez-Gomez, L. Boller, T., Ausubel, F.M. und Sheen, J. (2002) MAP kinase signalling cascade in Arabidopsis innate immunity. Nature 415: 977-983

Aspinall, G.O. und Kessler, G. (1957) The structure of callose from the grape vine. Chemistry and Industry 39: 1296

Assaad, F.F., Qiu, J.L., Youngs, H., Ehrhardt, D., Zimmerli, L., Kalde, M., Wanner, G., Peck, S.C., Edwards, H., Ramonell, K., Somerville, C.R. und Thordal-Christensen, H. (2004) The PEN1 syntaxin defines a novel cellular compartment upon fungal attack and is required for the timely assembly of papillae. Molecular Biology of the Cell 15: 5118-1129

Baluska, F., Bacigalova, K., Oud, J.L., Hauskrecht, M. und Kubica, S. (1995) Rapid reorganization of microtubular cytoskeleton accompanies early changes in nuclear ploidy and chromatin structure in postmitotic cells of barley leaves infected with powdery mildew. Protoplasma 185: 140-151

Barrett, T., Suresh, C.G., Tolley, S.P., Dodson, E.J. und Hughes, M.A. (1995) The crystal structure of a cyanogenic beta-glucosidase from white clover, a family 1 glycosyl hydrolase. Structure 15: 951-960

Bartel, B., LeClere, S., Magidin, M. und Zolman, B.K. (2001) Inputs to the active indole-3acetic acid pool: de novo synthesis, conjugate hydrolysis, and indole-3-butyric acid $\beta$ oxidation. Journal of Plant Growth Regulation 20: 198-216

Bednarek, P., Pislewska-Bednarek, M., Svatos, A., Schneider, B., Doubsky, J., Mansurova, M., Humphry, M., Consonni, C., Panstruga, R., Sanchez-Vallet, A., Molina, A. und Schulze-Lefert, P. (2009) A glucosinolate metabolism pathway in living plant cells mediates broad-spectrum antifungal defense. Science 323:101-106

Bestwick, C.S., Brown, I.R., Bennett, M.H.R. und Mansfield, J.W. (1997) Localization of hydrogen peroxide accumulation during the hypersensitive reaction of lettuce cells to Pseudomonas syringae pv phaseolicola. Plant Cell 9: 209-221

Blum, R., Meyer, K.C., Wünschmann, J., Lendzian, K.J. und Grill, E. (2010) Cytosolic action of phytochelatin synthase. Plant Physiology 153: 159-169 
Boller, T. und Felix, G. (2009) A renaissance of elicitors: perception of microbe-associated molecular patterns and danger signals by pattern-recognition receptors. Annual Reviews of Plant Biology 60: 379-406

Bolwell, G.P. (1993) Dynamic aspects of the plant extracellular matrix. International Review of Cytology 146: 261-323

Borgese, N., Gazzoni, I., Barberi, M., Colombo, S. und Pedrazzini, E. (2001) Targeting of a tail-anchored protein to endoplasmic reticulum and mitochondrial outer membrane by independent but competing pathways. Molecular Biology of the Cell 12: 2482-2496

Borgese, N., Colombo, S. und Pedrazzini, E. (2003) The tale of tail-anchored proteins: coming from the cytosol and looking for a membrane. Journal of Cell Science 161: 10131019

Borgese, N., Brambillasca, S. und Colombo, S. (2007) How tails guide tail-anchored proteins to their destinations. Current Opinion in Cell Biology 19: 368-375

Both, M., Csukai, M., Stumpf, M.P. und Spanu, P.D. (2005) Gene expression profiles of Blumeria graminis indicate dynamic changes to primary metabolism during development of an obligate biotrophic pathogen. Plant Cell 17: 2107-2122

Bradford, M. M. (1976) A rapid and sensitive method for the quantitation of microgram quantities of protein utilizing the principle of protein-dye binding. Analytical Biochemistry 72: 248-254

Burmeister, W.P., Cottaz, S., Driguez, H., lori, R., Palmieri, S. und Henrissat, B. (1997) The crystal structures of Sinapis alba myrosinase and a covalent glycosyl-enzyme intermediate provide insights into the substrate recognition and active-site machinery of an S-glycosidase. Structure 5: 663-675

Chisholm S.T., Coaker, G., Day, B. und Staskawicz, B.J. (2006) Host-microbe interactions: shaping the evolution of the plant immune response. Cell 124: 803-814

Clay, N.K., Adio, A.M., Denoux, C., Jander, G. und Ausubel, F.M. (2009) Glucosinolate metabolites required for an Arabidopsis innate immune response. Science 323: 95-101

Clemens, S., Kim, E.J., Neumann, D. und Schroeder, J.I. (1999) Tolerance to toxic metals by a gene family of phytochelatin synthases from plants and yeast. European Molecular Biology Organization Journal 18: 3325-3333

Clough, S.J. und Bent, A.F. (1998) Floral dip: a simplified method for Agrobacteriummediated transformation of Arabidopsis thaliana. Plant Journal 16: 735-743

Collins, N.C., Thordal-Christensen, H., Lipka, V., Bau, S., Kombrink, E., Qiu, J.-L., Hückelhoven, R., Stein, M., Freialdenhoven, A., Somerville, S.C. und Schulze-Lefert, P. (2003) SNARE protein mediated disease resistance at the plant cell wall. Nature 425: 973977

Consonni, C., Humphry, M.E., Hartmann, H.A., Livaja, M., Durner, J., Westphal, L., Vogel, J., Lipka, V., Kemmerling, B., Schulze-Lefert, P., Somerville, S.C. und Panstruga, R. (2006) Conserved requirement for a plant host cell protein in powdery mildew pathogenesis. Nature Genetics 38: 716-720 
del Río, L.A., Corpas, F.J., Sandalio, L.M., Palma, J.M., Gómez, M. und Barroso, J.B. (2002) Reactive oxygen species, antioxidant systems and nitric oxide in peroxisome. Journal of Experimental Botany 53: 1255-1272

Eriksson, S., Andréasson, E., Ekbom, B., Granér, G., Pontoppidan, B., Taipalensuu, J., Zhang, J., Rask, L. und Meijer, J. (2002) Complex formation of myrosinase isoenzymes in oilseed rape seeds are dependent on the presence of myrosinase-binding proteins.

Plant Physiology 129: 1592-1599

Esen, A. und Blanchard, D.J. (2000) A specific beta-glucosidase-aggregating factor is responsible for the beta-glucosidase null phenotype in maize. Plant Physiology 122: 563-572

Felix, G., Duran, J.D., Volko, S. und Boller, T. (1999) Plants have a sensitive perception system fort he most conserved domain of bacterial flagellin. Plant Journal 18: 265-276

Feussner, I. und Wasternack, C. (2002) The lipoxygenase pathway. Annual Review of Plant Biology 53: 275-297

Fieldes, M.A. und Gerhardt, K.E. (1994) An examination of the $\beta$-glucosidase (linamarase) banding pattern in flax seedlings using Ferguson plots and sodium dodecyl sulphatepolyacrylamide gel electrophoresis. Electrophoresis 15: 654-661

Foyer, C.H. und Noctor, G. (2005) Redox homeostasis and antioxidant signalling: a metabolic interface between stress perception and physiological responses. Plant Cell 17: 1866-1875

Gigolashvili, T., Berger, B., Mock, H.P., Müller, C., Weisshaar, B. und Flügge, U.I. (2007) The transcription factor HIG1/MYB51 regulates indolic glucosinolate biosynthesis in Arabidopsis thaliana. Plant Journal 50: 886-901

Glawischnig, E., Hansen, B.G., Olsen, C.E. und Halkier, B.A. (2004) Camalexin is synthesized from indole-3-acetaldoxime, a key branching point between primary and secondary metabolism in Arabidopsis. Proceedings of the National Academy of Sciences 101: $8245-8250$

Goepfert, C., Vidoudez, E., Rezzonico, J., Hiltunen, K. und Poirier, Y. (2005) Molecular Identification and Characterization of the Arabidopsis \{Delta\}3,5,\{Delta\}2,4-DienoylCoenzyme A Isomerase, a Peroxisomal Enzyme Participating in the \{beta\}-Oxidation Cycle of Unsaturated Fatty Acids. Plant Physiology 138: 1947-1956

Gómez-Gómez, L. und Boller, T. (2000) FLS2: an LRR receptor-like kinase involved in the perception of the bacterial elicitor flagellin in Arabidopsis. Molecular Cell 5: 1003-1011

Grill, E., Löffler, S., Winnacker, E.L. und Zenk, M.H. (1989) Phytochelatins, the heavymetal-binding peptides of plants, are synthesized from glutathione by a specific gammaglutamylcysteine dipeptidyl transpeptidase (phytochelatin synthase). Proceedings of the National Academy of Sciences 86: 6838-6842

Grubb, C.D. und Abel, S. (2006) Glucosinolate metabolism and its control. Trends in Plant Science 11: 89-100

Gus-Mayer, S., Naton, B., Hahlbrock, K., Schmelzer, E. (1998) Local mechanical stimulation induces components of the pathogen defense response in parsley. Proceedings of the National Academy of Sciences 95: 8389-8403 
Hamdane, D., Zhang, H. und Hollenberg, P. (2008) Oxygen activation by cytochrome P450 monooxygenase. Photosynthesis Research 98: 657-666

Hammond-Kosack, K.E. und Parker, J. (2003) Deciphering plant-pathogen communication: fresh perspectives for molecular resistance breeding. Current Opinion in Biotechnology 14: 177-193

Hara-Nishimura, I. und Matsushima, R. (2003) A wound-inducible organelle derived from endoplasmic reticulum: a plant strategy against environmental stresses? Current Opinion in Plant Biology 6: 583-588

Hardham, A.R., Takemoto, D. und White, R.G. (2008) Rapid and dynamic subcellular reorganization following mechanical stimulation of Arabidopsis epidermal cells mimics responses to fungal and oomycete attack. BMC Plant Biology 8: 63

Hayashi, Y., Yamada, K., Shimada, T., Matsushima, R., Nishizawa, N.K., Nishimura, M. und Hara-Nishimura, I. (2001) A proteinase-storing body that prepares for cell death or stresses in the epidermal cells of Arabidopsis. Plant Cell Physiology 42: 894-899

Hazen, B.E. und Bushnell, W.R. (1983) Inhibition of the hypersensitive reaction in barley to powdery mildew by heat shock and cytochalasin B. Physiological Plant Pathology 23: 421438

Heath, M.C. und Skalamera, D. (1997) Cellular interactions between plants and biotrophic fungal parasites. Advances in Botanical Research 24: 195-225

Heath, M.C. (2000) Nonhost resistance and nonspecific plant defenses. Current Opinion in Plant Biology, 3, 315-319

Heath, M.C. (2002) Cellular interactions between biotrophic fungal pathogens and host or nonhost plants. Canadian Journal of Plant Pathology 24: 259-264

Heese, M., Gansel, X., Sticher, L., Wick, P., Grebe, M., Granier, F. und Jürgens, G. (2001) Functional characterization of the KNOLLE-interacting t-SNARE AtSNAP33 and its role in plant cytokinesis. Journal of Cell Biology 155: 239-249

Hiruma, K., Onozawa-Komori, M., Takahashi, F., Asakura, M., Bednarek, P., Okuno, T., Schulze-Lefert, P. und Takano, Y. (2010) Entry mode-dependent function of an indole glucosinolate pathway in Arabidopsis for nonhost resistance against anthracnose pathogens. Plant Cell 22: 2429-2443

Hull, A.K., Vij, R. und Celenza, J.L. (2000) Arabidopsis cytochrome P450s that catalyze the first step of tryptophan-dependent indole-3-acetic acid biosynthesis. Proceedings of the National Academy of Sciences 97: 2379-2384

Humphry, M., Bednarek, P., Kemmerling, B., Koh, S., Stein, M., Göbel, U., Stüber, K., Pislewska-Bednarek, M., Loraine, A., Schulze-Lefert, P., Somerville, S. und Panstruga, R. (2010) A regulon conserved in monocot and dicot plants defines a functional module in antifungal plant immunity. Proceedings of the National Academy of Sciences 107: 2189621901

Jacobs, A.K., Lipka, V., Burton, R.A., Panstruga, R., Strizhov, N., Schulze-Lefert P. und Fincher G.B. (2003) An Arabidopsis Callosesynthase, GSL5, Is Required for Wound and Papillary Callose Formation. Plant Cell 15: 2503-2513 
Jarosch, B., Collins, N.C., Zellerhoff, N. und Schaffrath, U. (2005) RAR1, ROR1, and the actin cytoskeleton contribute to basal resistance to Magnaporthe grisea in barley. Molecular Plant-Microbe Interactions 18: 397-404

Jones, J.D.G. und Dangl, J.L. (2006) The plant immune system. Nature 444: 323-329

Kelly, P.J., Bones, A. und Rossiter, J.T. (1998) Sub-cellular immunolocalization of the glucosinolate sinigrin in seedlings of Brassica juncea. Planta 206: 370-377

Kim, D.Y., Bovet, L., Maeshima, M., Martinoia, E. und Lee, Y. (2007) The ABC transporter AtPDR8 is a cadmium extrusion pump conferring heavy metal resistance. Plant Journal 50: 207-218

Kim, Y.W., Kang, K.S., Kim, S.Y. und Kim, I.S. (2000) Formation of fibrillar multimers of oat $\beta$-glucosidase isoenzymes is mediated by the As-Glu1 monomer. Journal of Molecular Biology 303: 831-842

Kittur, F.S., Lalgondar, M., Yu, H.Y., Bevan, D.R. und Esen, A. (2007) Maize betaglucosidase-aggregating factor is a polyspecific jacalin-related chimeric lectin, and its lectin domain is responsible for beta-glucosidase aggregation. Journal of Biological Chemistry 282: 7299-7311

Kobayashi, Y., Kobayashi, I., Funaki, Y., Fujimoto, S., Takemoto, T. und Kunoh, H. (1997) Dynamic re-organization of microfilaments and microtubules is necessary for the expression of nonhost resistance in barley coleoptile cells. Plant Journal 11: 525-537

Koh, S., André, A., Edwards, H., Ehrhardt, D. und Somerville, S.C. (2005) Arabidopsis thaliana subcellular responses to compatible Erysiphe cichoracearum infections. Plant Journal 44: 516-529

Kriechbaumer, V., Shaw, R., Mukherjee, J., Bowsher, C.G., Harrison, A.M. und Abell, B.M. (2009) Subcellular distribution of tail-anchored proteins in Arabidopsis. Traffic 10: 17531764

Kuroda, R., Ikenoue, T., Honsho, M., Tsujimoto, S., Mitoma, J.Y. und Ito, A. (1998) Charged amino acids at the carboxyl-terminal portions determine the intracellular locations of two isoforms of cytochrome b5. Journal of Biological Chemistry 273: 31097-31102

Kusano, T., Tateda, C., Berberich, T. und Takahashi, Y. (2009) Voltage-dependent anion channels: their roles in plant defense and cell death. Plant Cell Reports 28: 1301-1308

Kutay, U., Hartmann, E. und Rapoport, T.A. (1993) A class of membrane proteins with a C-terminal anchor. Trends in Cell Biology 3: 72-75

Kwak, S.N., Kim, S.Y., Choi, S.R. und Kim, I.S. (2009) Assembly and function of AsGlu2 fibrillar multimer of oat beta-glucosidase. Biochimica et Biophysica Acta 1794: 526-531

Kwon, C., Neu, C., Pajonk, S., Yun, H.S., Lipka, U., Humphry, M., Bau, S., Straus, M., Kwaaitaal, M., Rampelt, H., El, Kasmi, F., Jürgens, G., Parker, J., Panstruga, R., Lipka V. und Schulze-Lefert, P. (2008a) Co-option of a default secretory pathway for plant immune responses. Nature 451: 835-840

Kwon, C., Panstruga, R. und Schulze-Lefert, P. (2008b) Les liaisons dangereuses: immunological synapse formation in animals and plants. Trends in Immunology 29: 159-166 
Leckie, C.P., Callow, J.A. und Green, J.R. (1995) Re-organization of the endoplasmic reticulum in pea leaf epidermal cells infected by the powdery mildew fungus Erysiphe pisi. New Phytologist 131: 211-221

Levine, A., Tenhaken, R., Dixon, R. und Lamb C. (1994) $\mathrm{H}_{2} \mathrm{O}_{2}$ from the oxidative burst orchestrates the plant hypersensitive disease resistance response. Cell 79: 583-593

Liepman, A.H. und Olsen, L.J. (2001) Peroxisomal alanine: glyoxylate aminotransferase (AGT1) is a photorespiratory enzyme with multiple substrates in Arabidopsis thaliana. Plant Journal 25: 487-498

Liepman, A.H. und Olsen, L.J. (2003) Alanine aminotransferase homologs catalyze the glutamate: glyoxylate aminotransferase (GGT) reaction in peroxisomes of Arabidopsis thaliana. Plant Physiology 131: 215-227

Lipka, V., Dittgen, J., Bednarek, P., Bhat, R.A., Stein, M., Landtag, J., Brandt, W., Scheel, D., Llorente, F., Molina, A., Wiermer, M., Parker, J., Somerville, S.C. und Schulze-Lefert, P. (2005) Pre- and post-invasion defenses both contribute to non-host resistance in Arabidopsis. Science 310: 1180-1183

Lipka, V., Kwon, C. und Panstruga, R. (2007) SNARE-ware: the role of SNARE-domain proteins in plant biology. Annual Review of Cell and Developmental Biology 23: 147-174

Lipka, U., Fuchs, R., Kuhns, C., Petutschnig, E. und Lipka, V. (2010) Live and let die Arabidopsis nonhost resistance to powdery mildews. European Journal of Cell Biology 89: 194-199

Lisenbee, C.S., Heinze, M. und Trelease, R.N. (2003) Peroxisomal Ascorbate Peroxidase Resides within a Subdomain of Rough Endoplasmic Reticulum in Wild-Type Arabidopsis Cells. Plant Physiology 132: 870-882

Lopez-Huertas, E., Charlton, W.L., Johnson, B., Graham, I.A. und Baker, A. (2000) Stress induces peroxisome biogenesis genes. European Molecular Biology Organization Journal 19: 6770-6777

Lowry, O.H., Rosebrough, N. J., Farr, A. L. und Randall, R. J. (1951) Protein measurement with the Folin phenol reagent. Journal of Biological Chemistry 19: 265-275

Maggio, C., Barbante, A., Ferro, F., Frigerio, L. und Pedrazzini, E. (2007) Intracellular sorting of the tail-anchored protein cytochrome b5 in plants: a comparative study using different isoforms from rabbit and Arabidopsis. Journal of Experimental Botany 58: 13651379

Maleck, K., Levine, A., Eulgem, T., Morgan, A., Schmid, J., Lawton, K.A., Dangl, J.L. und Dietrich, R.A. (2000) The transcriptome of Arabidopsis thaliana during systemic acquired resistance. Nature Genetics 26: 403-410

Martinoia, E., Klein, M., Geisler, M., Bovet, L., Forestier, C., Kolukisaoglu, U., MullerRober, B. und Schulz, B. (2002) Multifunctionality of plant ABC transporters - More than just detoxifiers. Planta 214: 345-355

Matsushima, R., Hayashi, Y., Kondo, M., Shimada, T., Nishimura, M. und HaraNishimura, I. (2002) An endoplasmic reticulum-derived structure that is induced under stress conditions in Arabidopsis. Plant Physiology 130: 1807-1814 
Matsushima, R., Kondo, M., Nishimura, M. und Hara-Nishimura, I. (2003) A novel ERderived compartment, the ER body, selectively accumulates a $\beta$-glucosidase with an ER retention signal in Arabidopsis. Plant Journal 33: 493-502

Mellersh, D.G., Foulds, I.V., Higgins, V.J. und Heath, M.C. (2002) $\mathrm{H}_{2} \mathrm{O}_{2}$ plays different roles in determining penetration failure in three diverse plant-fungal interactions. Plant Journal 29: 257-268

Meyer, D., Pajonk, S., Micali, C., O'Connell, R. und Schulze-Lefert, P. (2009) Extracellular transport and integration of plant secretory proteins into pathogen-induced cell wall compartments. Plant Journal 57: 986-999

Mittler, R., Vanderauwera, S., Gollery, M. und Van Breusegem, F. (2004) Reactive oxygen gene network of plants. Trends in Plant Science 9: 490-498

Mullen, R.T. und Trelease, R.N. (2000) The sorting signals for peroxisomal membranebound ascorbate peroxidase are within its C-terminal tail. Journal of Biological Chemistry 275: $16337-16344$

Narendra, S., Venkataramani, S., Shen, G., Wang, J., Pasapula, V., Lin, Y., Kornyeyev, D., Holaday, A.S. und Zhang, H. (2006) The Arabidopsis ascorbate peroxidase 3 is a peroxisomal membrane-bound antioxidant enzyme and is dispensable for Arabidopsis growth and development. Journal of Experimental Botany 57: 3033-3042

Nagano, A.J., Matsushima, R. und Hara-Nishimura, I. (2005) Activation of an ER-bodylocalized beta-glucosidase via a cytosolic binding partner in damaged tissues of Arabidopsis thaliana. Plant Cell Physiology 46: 1140-1148

Nagano, A.J., Fukao, Y., Fujiwara, M., Nishimura, M. und Hara-Nishimura, I. (2008) Antagonistic jacalin-related lectins regulate the size of ER body-type beta-glucosidase complexes in Arabidopsis thaliana. Plant Cell Physiology 49: 969-980

Nelson, B.K., Cai, X. und Nebenführ, A. (2007) A multicolored set of in vivo organelle markers for co-localization studies in Arabidopsis and other plants. Plant Journal 51: 11261136

van Niel, G., Porto-Carreiro, I., Simoes, S. und Raposo, G. (2006) Exosomes: a common pathway for a specialized function. Journal of Biochemistry 140: 13-21

Nisius, A. (1988) The stromacentre in Avena plastids: an aggregation of $\beta$-glucosidase responsible for the activation of oat-leaf saponins. Planta 173: 474-481

Nürnberger, T. und Lipka, V. (2005) Non-host resistance in plants: new insights into an old phenomenon. Molecular Plant Pathology 6: 335-345

Ohta, A. und Nishiyama, Y. (2011) Mitochondria and viruses. Mitochondrion 11: 1-12

Padmanabhan, M.S. und Dinesh-Kumar, S.P. (2010) All hands on deck - the role of chloroplasts, endoplasmic reticulum, and the nucleus in driving plant innate immunity. Molecular Plant-Microbe Interactions 23: 1368-1380

Palma, J.M., Corpas, F.J. und del Río, L.A. (2009) Proteome of plant peroxisomes: new perspectives on the role of these organelles in cell biology. Proteomics 9: 2301-2312

Panstruga, R. (2003) Establishing compatibility between plants and obligate biotrophic pathogens. Current Opinion Plant Biology 6: 320-326 
Pedrazzini, E. (2009) Tail-Anchored Proteins in Plants. Journal of Plant Biology 52: 88-101

Petutschnig, E.K., Jones, A.M., Serazetdinova, L., Lipka, U. und Lipka, V. (2010) The lysin motif receptor-like kinase (LysM-RLK) CERK1 is a major chitin-binding protein in Arabidopsis thaliana and subject to chitin-induced phosphorylation. Journal of Biological Chemistry 285: 28902-28911

Pfalz, M., Mikkelsen, M.D., Bednarek, P., Olsen, C.E., Halkier, B.A. und Kroymann, J. (2011) Metabolic engineering in Nicotiana benthamiana reveals key enzyme functions in Arabidopsis indole glucosinolate modification. Plant Cell 23: 716-729

Qbadou, S., Tien, R., Soll, J. und Schleiff, E. (2003) Membrane insertion of the chloroplast outer envelope protein, Toc34: constrains for insertion and topology. Journal of Cell Science 116: $837-846$

Reintanz, B., Lehnen, M., Reichelt, M., Gershenzon, J., Kowalczyk, M., Sandberg, G., Godde, M., Uhl, R., und Palme, K. (2001) bus, a Bushy Arabidopsis CYP79F1 Knockout Mutant with Abolished Synthesis of Short-Chain Aliphatic Glucosinolates. Plant Cell 13: 351367

Reumann, S., Babujee, L., Ma, C., Wienkoop, S., Siemsen, T., Antonicelli, G.E., Rasche, N., Lüder, F., Weckwerth, W. und Jahn, O. (2007) Proteome Analysis of Arabidopsis Leaf Peroxisomes Reveals Novel Targeting Peptides, Metabolic Pathways, and Defense Mechanisms. Plant Cell 19: 3170-3193

Rosso, M.G., Li, Y., Strizhov, N., Reiss, B., Dekker, K. und Weisshaar, B. (2003) An Arabidopsis thaliana T-DNA mutagenized population (GABI-Kat) for flanking sequence tagbased reverse genetics. Plant Molecular Biology 53: 247-259

Schlaeppi, K., Abou-Mansour, E., Buchala, A. und Mauch, F. (2010) Disease resistance of Arabidopsis to Phytophthora brassicae is established by the sequential action of indole glucosinolates and camalexin. Plant Journal 62: 840-851

Schleiff, E., Tien, R., Salomon, M. und Soll, J. (2001) Lipid composition of outer leaflet of chloroplast outer envelope determines topology of OEP7. Molecular Biology of the Cell 12: 4090-4102

Schneider, K., Kienow, L., Schmelzer, E., Colby, T., Bartsch, M., Miersch, O., Wasternack, C., Kombrink, E. und Stuible, H.-P. (2005) A new type of peroxisomal acylcoenzyme A synthetase from Arabidopsis thaliana has the catalytic capacity of activate biosynthetic precursors of jasmonic acid . Journal of Biological Chemistry 280: 13962-13972

Sherameti, I., Venus, Y., Drzewiecki, C., Tripathi, S., Dan, V.M., Nitz, I., Varma, A., Grundler, F.M. und Oelmüller, R. (2008) PYK10, a beta-glucosidase located in the endoplasmatic reticulum, is crucial for the beneficial interaction between Arabidopsis thaliana and the endophytic fungus Piriformospora indica. Plant Journal 54: 428-439

Smart, M.G., Aist, J.R., und Israel, H.W. (1986) Structure and function of wall appositions. 1. General histochemistry of papillae in barley (Hordeum vulgare) coleoptiles attacked by Erysiphe graminis f. sp. hordei. Canadian Journal of Botany 64: 793-801

Stein, M., Dittgen, J., Sanchez-Rodriguez, C., Hou, B.-H., Molina, A., Schulze-Lefert, P., Lipka, V. und Somerville, S.C. (2006) Arabidopsis PEN3/PDR8, an ATP binding cassette transporter, contributes to nonhost resistance to inappropriate pathogens that enter by direct penetration. Plant Cell 18: 731-746 
Stone, B.A., Evans, N.A., Bonig, I. und Clarke, A.E. (1984) The application of Sirofluor, a chemically defined fluorochrome from aniline blue for the histochemical detection of callose. Protoplasma 122: 191-195

Strader, L.C. und Bartel, B. (2009) The Arabidopsis PLEIOTROPIC DRUG RESISTANCE8/ ABCG36 ATP binding cassette transporter modulates sensitivity to the auxin precursor indole-3-butyric acid. Plant Cell 21: 1992-2007

Takemoto, D., Jones, D.A. und Hardham, A.R. (2003) GFP-tagging of cell components reveals the dynamics of subcellular re-organization in response to infection of Arabidopsis by oomycete pathogens. Plant Journal 33: 775-792

Tao, Y., Xie, Z., Chen, W., Glazebrook, J., Chang, H.-S., Han, B., Zhu, T., Zou, G., und Katagiri, F. (2003) Quantitative nature of Arabidopsis responses during compatible and incompatible interactions with the bacterial pathogen Pseudomonas syringae. Plant Cell 15: 317-330

Thordal-Christensen, H., Zhang, Z., Wei, Y., und Collinge, D.B. (1997) Subcellular localization of $\mathrm{H}_{2} \mathrm{O}_{2}$ in plants: $\mathrm{H}_{2} \mathrm{O}_{2}$ accumulation in papillae and hypersensitive response during the barley-powdery mildew interaction. Plant Journal 11: 1187-1194

Thordal-Christensen, H. (2003) Fresh insights into processes of nonhost resistance. Current Opinion in Plant Biology 6: 351-357

Tomiyama, K., Sato, K. und Doke, N. (1982) Effect of cytochalasin B and colchicine on hypersensitive death of potato cells infected by incompatible race of Phytophthora infestans. Annals of the Phytopathologicial Society of Japan 48: 228-230

Torres, M.A. und Dangl, J.L. (2005) Functions of the respiratory burst oxidase in biotic interactions, abiotic stress and development. Current Opinion in Plant Biology 8: 1-7

Underwood, W. und Somerville, S.C. (2008) Focal accumulation of defences at sites of fungal pathogen attack. Journal of Experimental Botany 59: 3501-3508

Werhahn, W., Niemeyer, A., Jänsch, L., Kruft, V., Schmitz, U.K. und Braun, H. (2001) Purification and Characterization of the Preprotein Translocase of the Outer Mitochondrial Membrane from Arabidopsis. Identification of Multiple Forms of TOM20. Plant Physiology 125: $943-954$

West, A.P., Shadel, G.S. und Ghosh, S. (2011) Mitochondria in innate immune responses. Nature Reviews Immunology 11: 389-402

Wiermer, M., Feys, B.J. und Parker, J.E. (2005) Plant immunity: the EDS1 regulatory node. Current Opinion in Plant Biology 8: 383-389

Xu, Z., Escamilla-Trevino, L.L., Zeng, L., Lalgondar, M., Bevan, D.R., Winkel, B.S.J., Mohamed, A., Cheng, C., Shih, M., Poulton, J.E. und Esen, A. (2004) Functional genomic analysis of Arabidopsis thaliana glycoside hydrolase family 1. Plant Molecular Biology 55: 343-367

Yun, B.W., Atkinson, H.A., Gaborit, C., Greenland, A., Read, N.D., Pallas, J.A. und Loake, G.J. (2003) Loss of actin cytoskeletal function and EDS1 activity, in combination, severely compromises non-host resistance in Arabidopsis against wheat powdery mildew. Plant Journal 34: 768-777 
Zhang, X. und Hu, J. (2008) FISSION1A and FISSION1B proteins mediate the fission of peroxisomes and mitochondria in Arabidopsis. Molecular Plant 1: 1036-1047

Zhang, X. und Hu, J. (2009) Two small protein families, DYNAMIN-RELATED PROTEIN3 and FISSION1, are required for peroxisome fission in Arabidopsis. Plant Journal 57: 146-159

Zolman B.K., Monroe-Augustus, M., Thompson, B., Hawes, J.W., Krukenberg, K.A., Matsuda, S.P.T. und Bartel, B. (2001) chy1, an Arabidopsis mutant with impaired ßoxidation, is defective in a peroxisomal ß-hydroxyisobutyryl-CoA hydrolase. Journal of Biological Chemistry 276: 31037-31046 


\section{Anhang}

7.1 Abkürzungs- und Symbolverzeichnis

\begin{tabular}{|c|c|}
\hline${ }^{\circ} \mathrm{C}$ & Grad Celsius \\
\hline$\%(v / v)$ & Volumenprozent \\
\hline$\%(w / v)$ & Gewichtsprozent \\
\hline$\Delta$ & delta (Deletion) \\
\hline \# & Nummer \\
\hline $4 \mathrm{MI} 3 \mathrm{G}$ & 4-Methoxyindol-3-ylmethylglucosinolat \\
\hline Abb. & Abbildung \\
\hline$A B C$ & „ATP binding cassette“ \\
\hline AKR2A & „ankyrin repeat protein $2 \mathrm{~A}^{\prime}$ \\
\hline Ap & Appressorium \\
\hline APS & Ammoniumpersulfat \\
\hline APX3 & „ascorbate peroxidase 3“ \\
\hline Aqua dest. & Entionisiertes Wasser \\
\hline ATP & Adenosintriphosphat \\
\hline$B g h$ & Blumeria graminis f. sp. hordei \\
\hline $\mathrm{bp}$ & Basenpaare \\
\hline BSA & „bovine serum albumin“ \\
\hline C-Terminus/ Cterm & Carboxy-Terminus \\
\hline Carb & Carbenicillin \\
\hline CBB & Coomassie-Brilliant-Blau \\
\hline cDNA & „copy DNA“ \\
\hline CFP & „cyan fluorescent protein“ \\
\hline $\mathrm{cm}$ & Zentimeter \\
\hline CYP & „cytochrome P450“ \\
\hline DAMPs & „damage-associated molecular patterns“ \\
\hline DMSO & Dimethylsulfoxid \\
\hline DNA & Desoxyribonukleinsäure \\
\hline DNase & Desoxyribonuklease \\
\hline DTT & 1,4-Dithiothreitol \\
\hline dYT & „double yeast tryptone“ \\
\hline E. coli & Escherichia coli \\
\hline E. pisi & Erysiphe pisi \\
\hline EDS1 & „enhanced disease susceptibility 1“ \\
\hline EDTA & Ethylendiamintetraessigsäure \\
\hline ER & Endoplasmatisches Retikulum \\
\hline et al. & et alii (und andere) \\
\hline ETI & „effector-triggered immunity“ \\
\hline ETS & „effector-triggered susceptibility“ \\
\hline f. sp. & forma specialis \\
\hline $\mathrm{F} 1 \mathrm{GH}$ & Familie1-Glycosidhydrolasen \\
\hline Flg22 & Flagellin 22 \\
\hline FP & Fluoreszenzprotein \\
\hline$g$ & Gramm \\
\hline$g$ & Beschleunigung \\
\hline G. orontii & Golovinomyces orontii \\
\hline GFP & „green fluorescent protein“ \\
\hline $\mathrm{Ha}$ & Haustorium \\
\hline
\end{tabular}




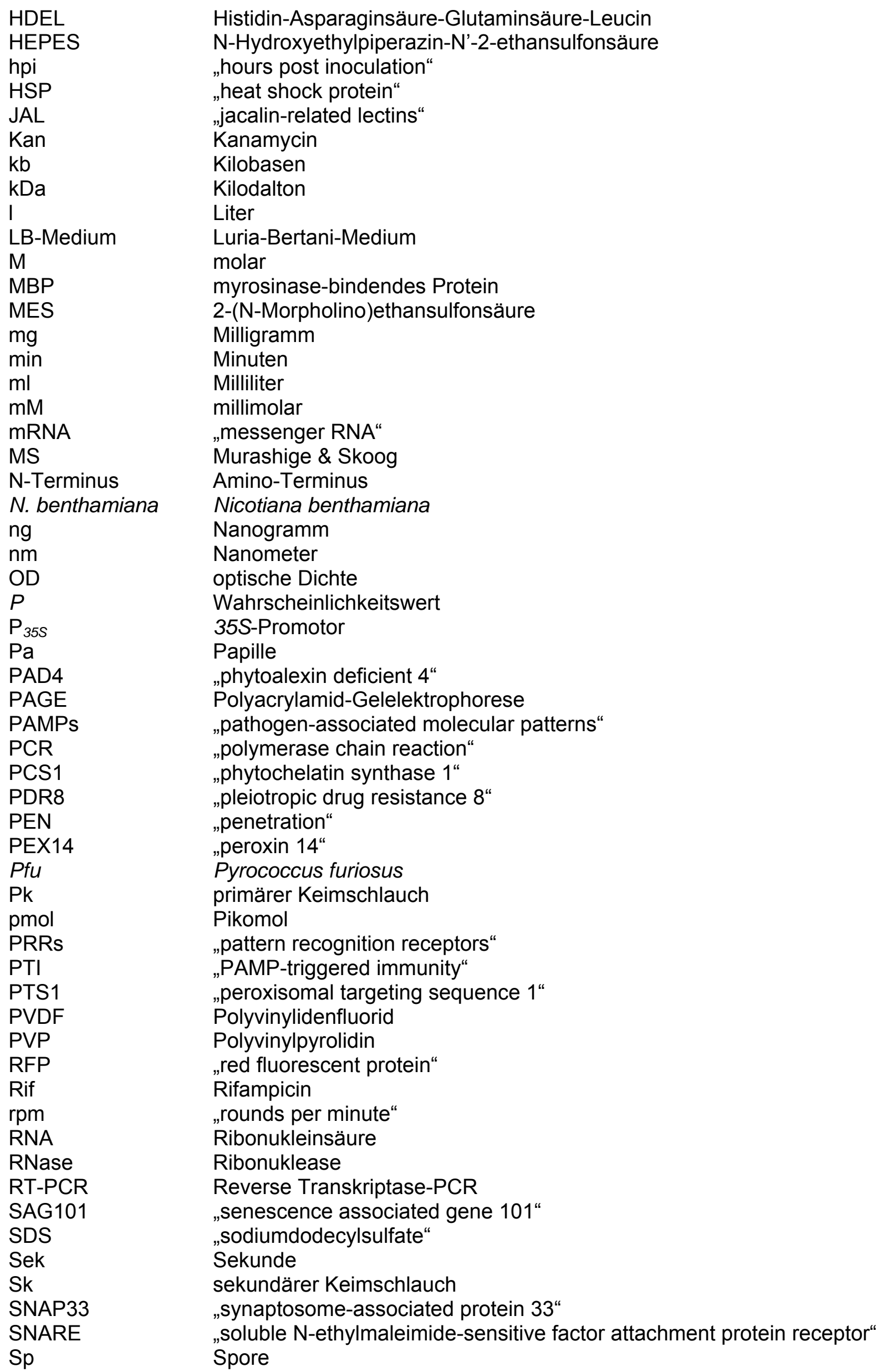




$\begin{array}{ll}\text { SYP121 } & \text { "syntaxin of plants 121“" } \\ \text { t } & \text { "time“ } \\ \text { TA } & \text { "tail-anchored“ } \\ \text { Tab. } & \text { Tabelle } \\ \text { Taq } & \text { Thermus aquaticus } \\ \text { TBS } & \text { "tris buffered saline“ } \\ \text { TCA } & \text { Trichloressigsäure } \\ \text { TE } & \text { Tris-EDTA } \\ \text { TEMED } & \text { N, N, N', N'-Tetramethyl-Ethylendiamin } \\ \text { TES } & \text { N-[Tris(hydroxymethyl)-methyl]-2-aminoethansulfonsäure } \\ \text { TMD/ TM } & \text { Transmembrandomäne } \\ \text { TOM20-4 } & \text { "translocase of outer membrane 20-4“ } \\ \text { Tris } & \text { Tris-(Hydroxymethyl)-aminoethan } \\ \text { UV } & \text { Ultraviolett } \\ \text { V } & \text { Volt } \\ \text { VAMP722 } & \text { "vesicle-associated membrane protein 722“ } \\ \text { VDAC1 } & \text { "Voltage-dependent anion-selective channel protein 1“ } \\ \text { Zw } & \text { Zellwand } \\ \mu & \text { Mikro } \\ \mu g & \text { Mikrogramm } \\ \mu l & \text { Mikroliter } \\ \mu m & \text { Mikrometer } \\ \mu M & \text { mikromolar }\end{array}$

7.2 Verzeichnis der Abbildungen

Seite

Abb. 1.1 Entwicklungszyklus von Blumeria graminis f. sp. hordei (Bgh) auf Gerste (aus Both et al., 2005).

Abb. 1.2 Prä- und postinvasive Abwehreaktionen tragen zur NichtwirtsResistenz von Arabidopsis gegenüber inkompatiblen Mehltaupilzen bei.

Abb. 1.3 PEN-Gen Produkte unterliegen der pathogen-induzierten Zellpolarisation.

Abb. 1.4 Das PEN2-Substrat 4-Methoxyindol-3-ylmethylglucosinolat (4MI3G).

Abb. 1.6 Übersicht über den post-translationellen Transport von TA- 17 Proteinen.

Abb. 1.7 ER-Körper in der Wurzelepidermis von transgenen ArabidopsisPflanzen.

Abb. 2.1 Schematische Darstellung einer Z-Serie und der daraus gebildeten Maximalprojektion. 
Abb. 3.1 Pathogen-induzierte PEN2-GFP-Fluoreszenzintensivierung an Orten der versuchten Penetration.

Abb. 3.2 Zeitliche Zunahme der PEN2-GFP-Fluoreszenzintensität am Ort der versuchten Penetration.

Abb. 3.3 Die PEN2-GFP-Aggregation beginnt in der Peripherie eines subzellulären Membrankompartiments.

Abb. 3.4 Die PEN2-GFP-Aggregate akkumulieren unterhalb von Appressorien und an sich entwickelnden Haustorien.

Abb. 3.5 Die PEN2-GFP-Aggregate weisen eine stabile Interaktion mit der Plasmamembran an Orten der versuchten Pathogeninvasion auf.

Abb. 3.6 Induzierte PEN2-GFP-Aggregation in angrenzenden Zellen zur Penetrationsstelle.

Abb. 3.7 Synchroner Auf- und Abbau der PEN2-GFP-Aggregate in zwei unterschiedlichen Zellen im Laufe der pflanzlichen Abwehrreaktion.

Abb. 3.8 Die PEN2- und PEN2-GFP-Proteinmenge bleibt im Laufe der Pathogenabwehr konstant.

Abb. 3.9 Das PEN2-RFP-Fusionsprotein komplementiert den pen2Phänotyp.

Abb. 3.10 PEN2-PEN2-Interaktion in vivo.

Abb. 3.11 Eine pathogen-induzierte Oliogomerisation von PEN2 und PEN2-GFP ist im nativen Gel nur unzureichend nachweisbar.

Abb. 3.12 Es entstehen detergenz-resistente PEN2-GFP-Oligomere nach Pathogenbehandlung.

Abb. 3.13 Darstellung des PEN2-GFP-und des GFP-PEN2 ${ }_{\text {Cterm }}$-Konstrukts (nach Lipka et al., 2005).

Abb. 3.14 Der C-Terminus von PEN2 bestimmt die subzelluläre Lokalisation.

Abb. 3.15 GFP-PEN2 ${ }_{\text {Cterm }}$ und PEN2-RFP kolokalisieren im gleichen Kompartiment, allerdings ist das Deletionskonstrukt nicht Teil der Aggregate.

Abb. 3.16 Auflistung der generierten C-terminalen Deletionskonstrukte von PEN2-GFP.

Abb. 3.17 PEN2-GFP-Deletionsproteine zeigen unterschiedliche subzelluläre Lokalisationen.

Abb. 3.18 Die Deletionsproteine PEN2-GFP- $\Delta$ C5I- $\left.\Delta T M\right|^{\text {K556G }}$ und GFPPEN2 ${ }_{\text {Cterm }}$ komplementieren den pen2-Phänotyp nicht.

Abb. 3.19 Das Deletionsprotein PEN2-GFP- $\triangle$ TM kolokalisiert mit Anilinblaugefärbter Callose am Ort der versuchten Pathogeninvasion. 
Abb. 3.20 PEN2-GFP- $\triangle T M$ und PEN2-RFP weisen unterschiedliche Lokalisationen am haustoriellen Komplex auf.

Abb. 3.21 Peroxisomen sind nicht an der fokalen Akkumulation der PEN2-GFP-Aggregate an der Invasionsstelle beteiligt.

Abb. 3.22 PEN2-GFP-Aggregate sind mit Mitochondrien assoziiert.

Abb. 3.23 PEN2-GFP ist in der Peripherie von Plastiden lokalisiert.

Abb. 3.24 PEN2-GFP zeigt keine Kolokalisation mit Golgi-Vesikeln oder ER.

Abb. 3.25 GFP-PEN2 2 Cterm ist ebenfalls mit Peroxisomen, Mitochondrien und Plastiden assoziiert.

Abb. 3.26 PEN2-GFP kosedimentiert mit Mitochondrien und Peroxisomen im

Dichtegradienten, ist aber hauptsächlich in den löslichen Fraktionen vorhanden.

Abb. 3.27 Unmarkiertes PEN2 kosedimentiert mit Mitochondrien und Peroxisomen im Dichtegradienten, ist aber hauptsächlich in den löslichen Fraktionen vorhanden.

Abb. 3.28 PEN2 kann nicht mit Hilfe von Peroxisomen-Isolations-Protokollen angereichert werden.

Abb. 3.29 PEN2 kann durch die Isolation von Mitochondrien angereichert werden.

Abb. 3.30 Darstellung der C-terminalen Aminosäuresequenzen der chimären PEN2-GFP-Konstrukte.

Abb. 3.31 Eine Überexpression des GFP-APX3-Proteins führt zur Assoziation mit Mitochondrien.

Abb. 3.32 Der C-Terminus von APX3 kann den von PEN2 funktional ersetzen.

Abb. 3.33 Das chimäre PEN2-GFP-APX3 ${ }_{\text {cterm }}$-Protein besitzt eine erhöhte

Assoziation mit Peroxisomen, ist allerdings auch in der Peripherie von Mitochondrien lokalisiert.

Abb. 3.34 Das Fusionsprotein RFP-TOM20-4 ist ausschließlich mit Mitochondrien assoziiert.

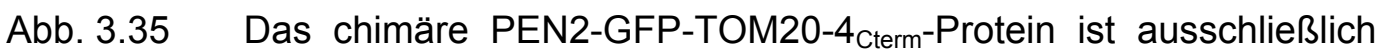
mit Mitochondrien assoziiert.

Abb. 3.36 PEN2-GFP und RFP-TOM20-4 kolokalisieren in der Peripherie von Mitochondrien.

Abb. 3.37 PEN2 hat keinen Einfluss auf das Akkumulationsverhalten von Mitochondrien an der Penetrationsstelle.

Abb. 3.38 Die zeitliche Akkumulation von Peroxisomen an der Invasionsstelle wird durch das PEN2-Protein nicht beeinflusst. 
$\begin{array}{lll}\text { Abb. 3.39 Akkumulation von Mitochondrien an der Papille. } & 97\end{array}$

Abb. 3.40 PEN3 hat keinen Einfluss auf die Akkumulation der PEN2-RFP- 99 Aggregate.

$\begin{array}{lll}\text { Abb. } 3.41 & \text { RFP-PEN4 ist Bestandteil der PEN2-GFP-Aggregate. } & 101\end{array}$

Abb. 3.42 Die CYP81F2-Monooxygenase ist ein ER-lokalisiertes Protein. 103

Abb. 3.43 CYP81F2-RFP ist nicht Bestandteil der PEN2-GFP-Aggregate. $\quad 104$

Abb. 3.44 Das CYP81F2-RFP-Fusionsprotein komplementiert den cyp81F2- 105 Phänotyp.

Abb. 3.45 Die Transkriptlevel von CYP81F2 in Wildtyppflanzen und die CYP81F2-RFP-Proteinkonzentration in transgenen Pflanzen sind 18 und 24 Stunden nach Pathogenbehandlung deutlich erhöht.

\subsection{Verzeichnis der Tabellen}

Tab. 2.1 Auflistung der verwendeten Geräte

Seite

Tab. 2.2 Auflistung der verwendeten Antikörper

Tab. 2.2 Auflistung der verwendeten Antikörper

Tab. 2.3 Liste der verwendeten Oligonukleotide

Tab. 2.4 Auflistung der hergestellten binären Vektoren

Tab. 2.5 Zusammenstellung der verwendeten Puffer und Lösungen

Tab. 2.6 Verwendete Einfach- bzw. Doppelmutanten 29

Tab. 2.7 Verwendete einfach transgene Fluoreszenzmarkerlinien 30

Tab. 2.8 Verwendete doppeltransgene Fluoreszenzmarkerlinien 30

Tab. 2.9 Verwendete Kreuzungen unterschiedlicher Linien 31

$\begin{array}{lll}\text { Tab. } 2.10 \quad \text { Konditionen der PCR } & 34\end{array}$

Tab. 2.11 Parameter zur Detektion unterschiedlicher Fluorophore 45

Tab. 3.1 Zusammenfassung der Ergebnisse der subzellulären Lokalisation, $\quad 69$ der Aggregatstruktur und des Penetrationsphänotyps der PEN2-GFP-Deletionsproteine 


\section{Danksagung}

An dieser Stelle möchte ich mich bei den Menschen bedanken, die mich in den letzten Jahren unterstützt und somit zum Gelingen dieser Arbeit beigetragen haben.

Mein ganz besonderer Dank gilt Herrn Prof. Dr. Volker Lipka, der mir das interessante Thema zur Verfügung gestellt und mir die Freiheit gegeben hat, das Projekt nach eigenen Vorstellungen mitzugestalten. Darüber hinaus möchte ich mich bei inm für die freundschaftliche Atmosphäre, seine ständige Diskussionsbereitschaft und konstruktive Kritik bedanken, die zum Gelingen der vorliegenden Arbeit, sowie vieler Vorträge beigetragen hat.

Bei Frau Prof. Dr. Christiane Gatz möchte ich mich ebenfalls für ihre Diskussionsbereitschaft und ganz herzlich für die Übernahme des Koreferates dieser Arbeit bedanken.

Zusätzlich möchte ich mich bei den weiteren Mietgliedern meiner Prüfungskommission, nämlich bei Prof. Dr. Andrea Polle, PD Dr. Thomas Teichmann, Prof. Dr. Jan Schirawski und Prof. Dr. Stefan Jakobs bedanken.

Ein ganz besonderer Dank geht an dieser Stelle an Christine Klapprodt, Gaby Schauermann und Melanie Klenke, die durch ihre immense Hilfsbereitschaft sehr zum Gelingen dieser Arbeit beigetragen haben. Außerdem möchte ich mich bei allen weiteren Mitgliedern und ehemaligen Mitgliedern der Abteilung für die überaus gute Arbeitsatmosphäre und Zusammenarbeit bedanken. Vielen Dank Anja, Charlotte, Christian, Elena, Magdalena, Marcel, Marnie, Michael, Sabine, Stefan, Thomas und Volker!

Ebenso möchte ich mich bei meinen ehemaligen Freunden und Kollegen am Sainsbury Lab für ihre Hilfsbereitschaft und schöne Stunden im Pub bedanken. Vielen Dank Alexi, Ben, Cecile, Charles, Cyril, Dave, Edgar, Freddy, Jagger, Joe, Jorunn, Jose, Kee, Martine, Tatiana, Thomas, Valerie, Vardis, Vlad und Yvan! 
Desweiteren möchte ich mich bei Holger Eubel für die Hilfe bei der Isolierung von Mitochondrien und Gerd Hause für die schönen elektronenmikroskopischen Aufnahmen bedanken. Ebenfalls danke ich Matthew Smoker für die Transformation so vieler Konstrukte. Darüber hinaus bin ich Alex Jones für die massenspektrometrische Analyse von unterschiedlichen Proteinproben und Roy Bongaerts für die FAOS-Experimente zu Dank verpflichtet, auch wenn die Ergebnisse leider nicht in dieser Arbeit präsentiert worden sind.

Nochmals möchte ich mich bei Prof. Dr. Volker Lipka und PD Dr. Thomas Teichmann, sowie Juliane Horlacher für das Korrekturlesen der vorliegenden Arbeit bedanken.

Zu großem Dank bin ich meinen Eltern und Großeltern verpflichtet, die mir zwar fachlich nicht helfen konnten, aber mich sonst in jeglicher Hinsicht unterstützt haben und somit ebenfalls zum Gelingen dieser Arbeit beigetragen haben.

Last but not least bedanke ich mich von ganzem Herzen bei meiner Lebensgefährtin Juliane Horlacher, die mir in jeder Hinsicht eine große Hilfe war und sehr zum Gelingen dieser Arbeit beigetragen hat. Vielen lieben Dank für das mehrmalige Lesen der Arbeit, deine moralische Unterstüzung und aufmunterende Art, und für unendlich viel mehr... 